\title{
Encuesta internacional de lectura IFLA para las bibliotecas de América Latina y el Caribe
}

Elsa M. Ramírez Leyva

(COORDINADORA)

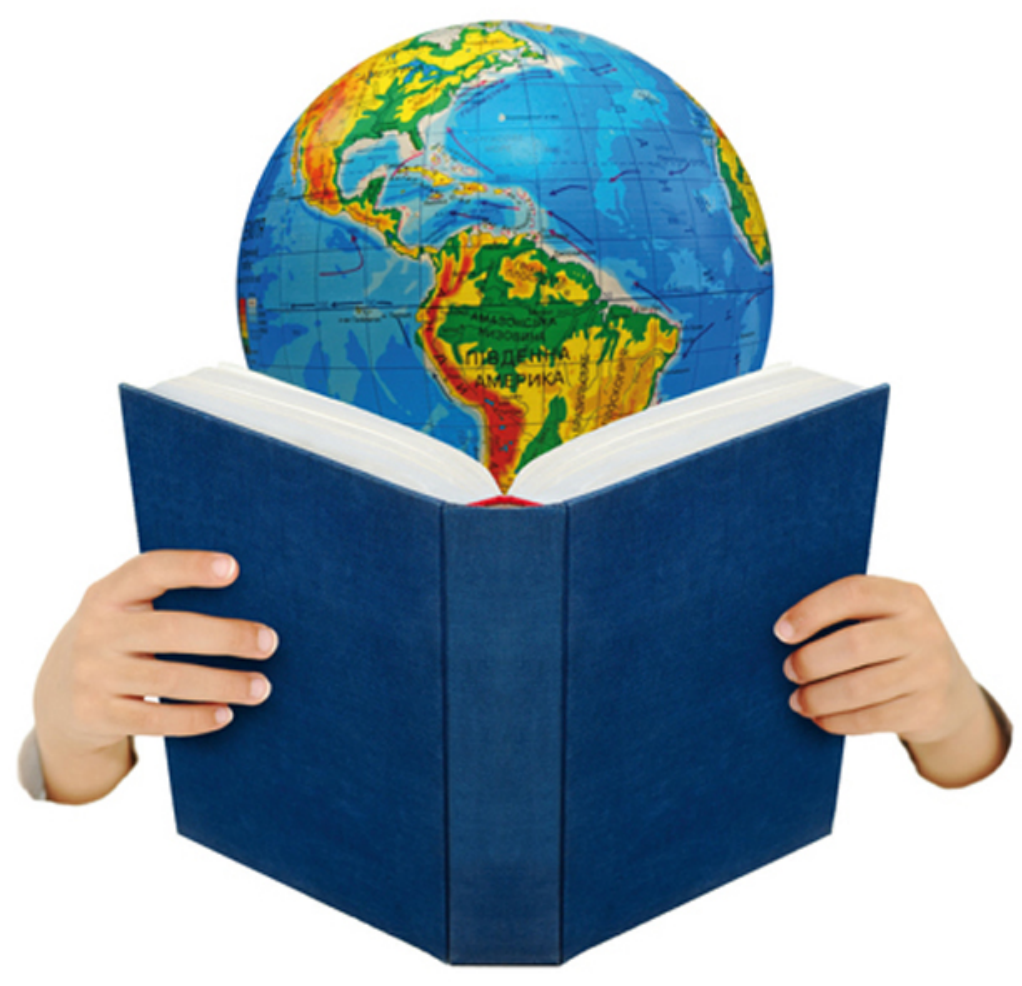




\section{La presente obra está bajo una licencia de:}

\section{http://creativecommons.org/licenses/by-nc-sa/3.0/deed.es MX}

\section{Atribución-No Comercial-Licenciamiento Reciproco 3.0 Unported}

Eres libre de:

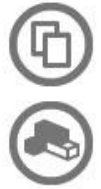

copiar, distribuir y comunicar públicamente la obra

hacer obras derivadas

Bajo las condiciones siguientes:

Atribución - Debes reconocer la autoría de la obra en los términos

especificados por el propio autor o licenciante.

No comercial - No puedes utilizar esta obra para fines comerciales.

Licenciamiento Recíproco - Si alteras, transformas o creas una obra a

partir de esta obra, solo podrás distribuir la obra resultante bajo una licencia

igual a ésta.

\section{Esto es un resumen fácilmente legible del: texto legal (de la licencia completa)}

En los casos que sea usada la presente obra, deben respetarse los términos especificados en esta licencia.
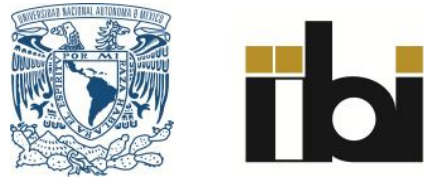
Encuesta Internacional de Lectura IFLA para las bibliotecas de América Latina y el Caribe 
LECTURA: PASADO, PRESENTE Y FUTURO

Instituto de Investigaciones Bibliotecológicas y de la Información 


\title{
Encuesta Internacional de Lectura IFLA para las bibliotecas de América Latina y el Caribe
}

\author{
Coordinadora \\ Elsa M. Ramírez Leyva
}

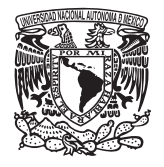

Universidad Nacional Autónoma de México 2013 


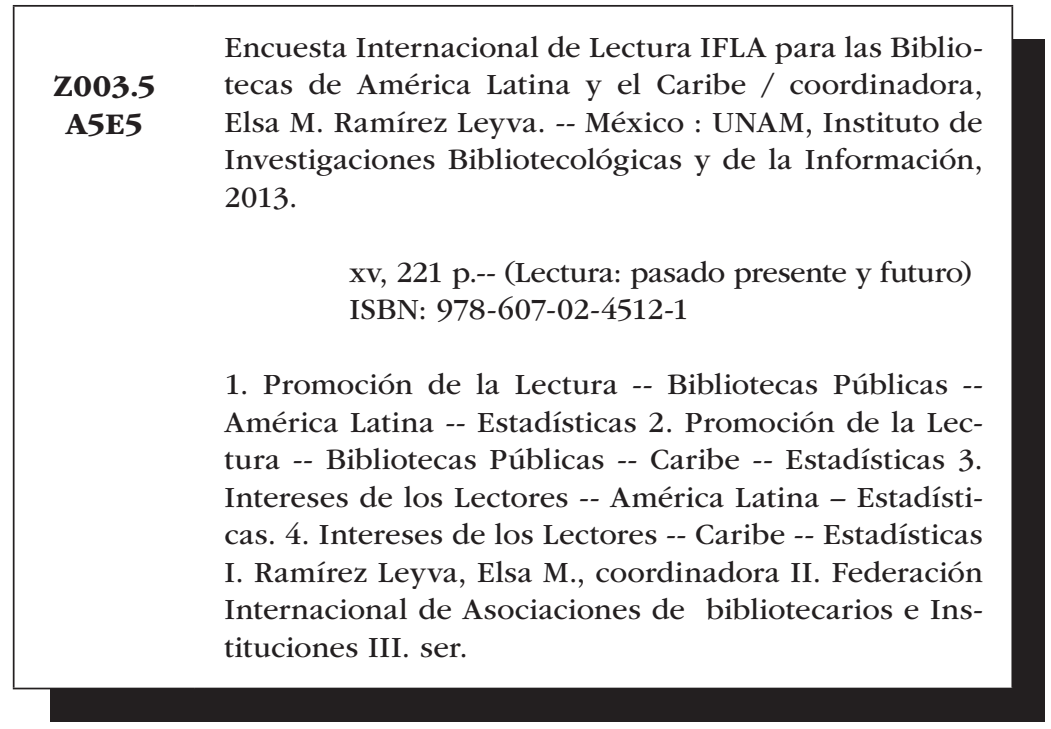

Diseño de portada: Arte Gráfico y Sonoro

Primera edición, 2013

D.R. (C) Universidad Nacional Autónoma de MéXico

Ciudad Universitaria, 04510, México D.F.

Impreso y hecho en México

ISBN: 978-607-02-4512-1 


\section{Contenido}

AGRADECIMIENTOS ...........................................................................................

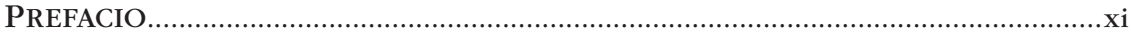

PRESENTACIÓN Y ANÁLISIS DE LA ENCUESTA........................................................ 1

Elsa M. Ramírez Leyva

ARGENTINA. PARTICIPACIÓN CULTURAL, FORMACIÓN CIUDADANA

Y ACCESO A LA INFORMACIÓN. UN ACERCAMIENTO A MODALIDADES

DE PROMOCIÓN DE LA LECTURA EN LAS BIBLIOTECAS POPULARES

Sebastián Ricardi

BIBLIOTECA PÚBLICA Y LECTURA EN BOLIVIA 81

Doris Samanez Alzamora

BIBLIOTECAS SIN MUROS. ACERCANDO LA LECTURA

A LAS FAMILIAS DE CHILE

Gonzalo Oyarzún

LA PROMOCIÓN DE LA LECTURA

EN LA BIBLIOTECA PÚBLICA DE COLOMBIA

Didier Álvarez Zapata y Yicel Nayrobis Giraldo Giraldo

PROMOCIÓN DE LA LECTURA EN LAS BIBLIOTECAS

PÚBLICAS COSTARRICENSES: GRANDES ESFUERZOS,

RESULTADOS INSUFICIENTES

Saray Córdoba González

LA PROMOCIÓN DE LA LECTURA

EN LAS BIBLIOTECAS PÚBLICAS CUBANAS 139

Emilio Setién Quesada

SINAB: DE BIBLIOTECAS COMUNITARIAS A COMPROMISO

ESTATAL. EL CASO DEL ECUADOR.

Julio César de la Roche Martínez 
LA BIBLIOTECA PÚBLICA VIAJERA EN LA FORMACIÓN

DE LECTORES A DISTANCIA EN EL SALVADOR 163 Olinda Estela Gómez Morán

La Red Nacional de Bibliotecas Públicas de México.

LA LECTURA Y LOS SERVICIOS BIBLIOTECARIOS 175

Lourdes López López

LOS AVANCES DE LAS BIBLIOTECAS PÚBLICAS

Y LA LECTURA EN PANAMÁ. 187

Octavio Castillo Sánchez

BIBLIOTECA PÚBLICA Y LECTURA:

SITUACIÓN PANORÁMICA DEL PERÚ

César Augusto Castro Aliaga

ANÁLISIS GLOBAL DE LOS RESULTADOS Y CONCLUSIONES 209

Elsa M. Ramírez Leyva

ANEXO 


\section{Agradecimientos}

la Sección de Alfabetización y Lectura de la Federación In-
ternacional de Asociaciones de Bibliotecarios e Institucio-
nes (IFLA):

Gwynneth Evans, Presidenta en turno de la Sección por la confianza depositada para emprender el proyecto en América latina y el Caribe.

Sección de América Latina y el Caribe (IFLA/LAC) por las gestiones ante el Programa Fundamental de Acción para el Desarrollo a través de Bibliotecas de la IFLA (IFLA/ALP), en la obtención de apoyo y respaldo para la realización de la Encuesta Internacional de Lectura para América Latina y el Caribe:

- María Isabel Cabral da Franca, Presidenta en turno de la Sección de América Latina de la IFLA.

- Elizabeth Ramos de Carvalho, Secretaria de la Oficina Regional de la IFLA de América Latina y del Caribe.

- Gunilla Natvige, Responsable del Programa Fundamental de Acción para el Desarrollo a través de Bibliotecas de la IFLA. 
Al Centro Universitario de Investigaciones Bibliotecológicas de la UNAM por auspiciar y respaldar la realización de la Encuesta:

- Filiberto Felipe Martínez Arellano, Director en turno del CUIB y Presidente de la Sección de América Latina y el Caribe de IFLA.

- Salvador Gorbea Portal, Investigador del Centro Universitario de Investigaciones Bibliotecológicas (UNAM).

- Agradecimiento especial a Martha Ibáñez Marmolejo, Técnico Académico del Centro Universitario de Investigaciones Bibliotecológicas (UNAM) por el apoyo invaluable en la sistematización de datos y en la coordinación de la Encuesta.

A los coordinadores e instituciones nacionales por sus invaluables trabajos, esfuerzos y compromisos que permitieron que la Encuesta Internacional de Lectura en las Bibliotecas Públicas de América Latina y el Caribe sea una realidad:

Argentina

- Sebastián Ricardi, Comisión Nacional Protectora de Bibliotecas Populares, Secretaría de Cultura de la República Argentina

Bolivia

- Doris Ivon Samanez Alzamora, Red de Estaciones del Conocimiento, Municipalidad de Santiago de Surco, Perú

Chile

- Virginia González, Subdirección de Bibliotecas Públicas, Dirección de Bibliotecas, Archivos y Museos (Dibam)

Colombia

- Didier Álvarez Zapata, Escuela Interamericana de Bibliotecología, Universidad de Antioquia, Colombia

Costa Rica

- Saray Córdoba González, Coordinación de Investigación, Sede de Occidente, Universidad de Costa Rica

Cuba

- Emilio Setién Quesada, Departamento de Bibliotecología y Ciencias de la Información, Universidad de La Habana, Cuba 
Ecuador

- Julio César de la Roche Martínez, Sistema Nacional de Bibliotecas, Ministerio de Educación y Cultura del Ecuador

El Salvador

- Olinda E. Gómez Morán, Biblioteca "Dr. José Gustavo Guerrero", Ministerio de Relaciones Exteriores, República de El Salvador

México

- Rocío del Pilar Correa, Dirección General de Bibliotecas, Conaculta

- Federico Hernández Pacheco, Dirección General de Bibliotecas, Conaculta

- Lourdes López López, Dirección General de Bibliotecas, Conaculta

- Verónica H. Sánchez Zarco, Dirección General de Bibliotecas, Conaculta

Panamá

- Octavio Castillo Sánchez, Sistema de Bibliotecas, Universidad de Panamá

Perú

- Cesar Augusto Castro Aliaga, Asesor en Servicios Bibliotecarios para Comunidades Indígenas de IFLA/LAC

West Indies

- Adele Merrit-Bernard, Presidenta electa de la Library and Information Association of Jamaica (LIAJA)

También nuestro agradecimiento a las siguientes personas por su colaboración en los primeros piloteos de la EIL/IFLA/LAC:

- Lusiola Castillo, Public Services Librarian, National Library Service, Belize

- Guadalupe Xiuyen Falcón Robles, Red Estatal de Bibliotecas Públicas de Chiapas, México

- Porfirio Díaz Pérez, Red Estatal de Bibliotecas Públicas de Tabasco, México 
- Luis Solís Vázquez, Biblioteca Pública Central Estatal "General Manuel Cepeda Peraza”, de Quintana Roo, México

- Ariel Gutiérrez Valencia, Universidad Juárez Autónoma de Tabasco, México

- Rosa María Matos, Biblioteca de la Universidad de Puerto Rico

Agradecemos a Enrique Ramírez Leyva su apoyo en la graficación de los resultados.

Al Instituto de Investigaciones Bibliotecológicas y de la Información (IIBI, antes CUIB, Centro Universitario de Investigaciones Bibliotecológicas) por la publicación de esta obra, que permitirá difundir los resultados de la Encuesta Internacional de Lectura con el deseo de contribuir a la reflexión y al desarrollo de estrategias que fortalezcan la participación de las Bibliotecas Públicas de América Latina y el Caribe en la construcción de una sociedad lectora e informada, de manera que el acceso y disfrute de la cultura escrita sean una realidad para todos por igual.

Elsa M. Ramírez Leyva 


\section{Prefacio}

T a biblioteca pública surge con la finalidad de conformar sociedades lectoras, más aún, podemos afirmar que esta función es parte constitutiva de su misión desde su nacimiento en el contexto de la sociedad industrial y la Ilustración hasta la actual sociedad de la información y el conocimiento del siglo XXI. Y no sólo por el hecho de ofrecer materiales y espacios para realizar dicha actividad, sino que paulatinamente se fueron incorporando programas de promoción y animación de la lectura. Recordemos que hacia finales del siglo XVIII la lectura empieza a extenderse más allá del ámbito académico y religioso y a integrase en los espacios públicos. En el siguiente siglo la biblioteca pública se consolida como espacio público y gratuito para el encuentro entre lectores y libros, fundamentalmente con fines instructivos, pero también tenía cabida la lectura recreativa.

En la actualidad la biblioteca pública tiene una función estratégica y con ello nuevos desafíos en el campo de la lectura ante los cambios propiciados por el modelo cultural y el proyecto de sociedad, que se sustentan en la información documentada, en la valorización de la multiculturalidad y en el marco de una economía y política globales que orientan las políticas sociales y culturales locales, así como también los cambios que han generado los usos de la tecnología electrónica. 
En este escenario, la lectura y el acceso a la información cobran mayor relevancia, hasta el punto de considerarlas condiciones indispensables para llevar a cabo la reordenación estructural que reduciría las desigualdades sociales de todo el orbe para alcanzar una equilibrio equitativo en la medida en que se abran las posibilidades para acceder y usar la información y el conocimiento. En este contexto, los países de América Latina y el Caribe representan un potencial en cuanto a su población infantil y juvenil, así como una diversidad multicultural que contribuiría al enriquecimiento de la cultura global. Sin embargo, para garantizar las oportunidades de inserción en el concierto mundial en condiciones de igualdad es indispensable tener una educación que fortalezca la calidad de la formación de los ciudadanos, por un lado, y por el otro que el Estado asegure la infraestructura para acceder, disponer y usar los recursos materiales y culturales.

Sin duda, en la actualidad la posición social de la biblioteca pública resulta privilegiada puesto que su misión es consolidar, extender y profundizar el lazo social entre los ciudadanos y la información. De ahí el compromiso de esa institución en el desarrollo de los ciudadanos del siglo XXI, como se puede observar claramente en los planes y programas nacionales e internacionales de lectura y el libro, con el objetivo de formar generaciones de niños, jóvenes y adultos que cuenten con las competencias lectoras y las habilidades informativas indispensables para desarrollar y articular las facultades intelectuales y espirituales -especialmente éstas últimas-, pues sólo así los ciudadanos del mundo tendrán la posibilidad de formar sociedades que construyan formas de vida dignas para todos los seres humanos que pueblan nuestro planeta.

En estas circunstancias nuestra región debe remontar situaciones de desigualdad histórica en la preparación de la población y el acceso a la cultura escrita y a la información en general, para lo cual será indispensable fortalecer las condiciones de las bibliotecas públicas de América Latina y el Caribe a fin de constituirlas en palanca de transformación social. Con este propósito los integrantes del Comité Permanente de la Sección de América Latina y el Caribe de la Federación Internacional de Asociaciones de Bibliotecarios y Bibliotecas (IFLA-LAC) consideraron importante reunir información 
-como se ha recomendado ampliamente- para elaborar diagnósticos y estudios comparados que permitan identificar los retos que deben emprenderse; entre ellos, las necesidades de formar y actualizar a los bibliotecarios con el fin de ofrecerles conocimientos, aptitudes y habilidades para emprender las innovaciones necesarias que fortalezcan el posicionamiento social y cultural de la biblioteca. También habremos de cumplir con la encomienda de alentar la difusión de experiencias, entre ellas los programas relacionados con el fomento y la promoción de la lectura así como la formación de nuevos lectores y programas de extensión de la lectura, en especial en comunidades que tienen dificultades para acceder a la misma, los recursos bibliográficos, la información y los servicios bibliotecarios.

Con esa finalidad, dicha Sección consideró oportuno que se aplicara la Encuesta Internacional de Lectura (EIL) en la región de América Latina y el Caribe. La iniciativa fue sometida a evaluación en 2006 con el fin de obtener apoyo del Programa Fundamental de Acción para el Desarrollo ALP/IFLA. La EIL forma parte de los proyectos emprendidos por la Sección de Lectura de la IFLA.

El proyecto incluyó la celebración del seminario La biblioteca pública en la formación de lectores, el cual se realizó en 2008, cuyo objetivo fue intercambiar y analizar sus resultados y discutir las áreas temáticas abordadas por las preguntas del cuestionario, conforme al modelo propuesto por Briony Birdi ${ }^{1}$ para estudiar el papel de las bibliotecas británicas en la formación de lectores. ${ }^{2}$

Con el fin de propiciar el debate, las conferencias del seminario fueron agrupadas en mesas temáticas de acuerdo con las áreas de la EIL que se enuncian más adelante. En cada una de ellas participaron tres ponentes responsables de analizar el documento básico

1 Investigadora del Departamento de Estudios de la Información de la Universidad de Sheffield, Inglaterra y miembro del Comité Permanente de la Sección de Lectura de la IFLA.

2 Reading Section. International Reading Survey: presentation of findings, Briony Train, Member, IFLA Reading Section Standing Committee, julio de 2002, en /www.ifla.org/node/1311 
a fin de dar lugar al coloquio y al debate. Al final se formularon conclusiones respecto a los cambios que la institución bibliotecaria requiere para incrementar su eficacia y ampliar sus alcances en lo tocante a la formación de lectores, de manera que se conviertan en elementos de orientación para la transformación de la vida de los habitantes de América Latina y el Caribe.

Las cuatro áreas fundamentales de la EIL son las siguientes:

I. Política de lectura

- Funcionamiento real de la política en la práctica.

- Nivel de eficacia alcanzado por ella.

- Papel que ha desempeñado en la formación de asociaciones entre diversas agencias y organismos.

II. Asociaciones para promover la lectura

- Razones para desarrollar estas asociaciones.

- Detalles del compromiso financiero.

- Beneficios de las asociaciones.

III. Actividades relacionadas con la lectura

- Detalles de las tareas relacionadas con la lectura y organizadas para lectores y no lectores adultos.

- Evaluación de los efectos de las actividades relacionadas con la lectura.

IV. Destrezas y capacitación del personal

- Fundamentación de las habilidades indispensables del promotor de la lectura para trabajar, tanto con lectores como con no lectores.

- Descripción de los cursos y programas de capacitación.

Los resultados del seminario fueron publicados en coedición por el Centro Universitario de Investigaciones Bibliotecológicas (CUIB) de la UNAM $^{3}$ y la Dirección General de Bibliotecas de Conaculta.

3 En abril de 2012, con base en lo acordado por el Consejo Universitario en su sesión extraordinaria del 30 de mayo del mismo año, el CUIB cambió su denominación a IIBI (Instituto de Investigaciones Bibliotecológicas y de la Información). 
Este volumen presenta el resultado de la EIL, que consta de dos partes: en la primera se muestran las características del proyecto, un panorama sobre la lectura y las bibliotecas en la región de América Latina y el Caribe y se analizan los resultados de la Encuesta. La segunda sección la integran los resultados sobre las encuestas de los países participantes y finalmente se incluyen las conclusiones generales. 


\title{
Presentación y análisis de la Encuesta
}

\author{
ElSA M. RAMÍREZ LEYVA \\ Centro Universitario de Investigaciones \\ Bibliotecológicas, UNAM, México
}

\section{LA ENCUESTA INTERNACIONAL DE LECTURA, IFLA}

$\tau$ a Encuesta Internacional de Lectura (EIL) de IFLA aplicada en las bibliotecas públicas de la región de América Latina y el Cada por Brioney Train, ${ }^{1}$ quien coordinó un equipo de bibliotecarios para aplicarla con el objetivo de "proporcionar una visión representativa del alcance del servicio provisto por las bibliotecas públicas británicas enfocado al lector", además de documentar las experiencias de los servicios bibliotecarios. La información obtenida formó parte de la Estrategia Nacional de Alfabetización del Gobierno Británico, al mismo tiempo que estaba en concordancia con las iniciativas correspondientes al Año Nacional de la Lectura y con la Campaña Nacional de Lectura. La actividad enfocada al lector o "desarrollo del lector" -concepto utilizado en el Reino Unido- se ha convertido en una preocupación fundamental del gobierno británico en los últimos años, al grado que asignó dos años de captación de fondos

1 Docente e investigadora del Centre for Information Research (CIRT) de la Facultad de Computación en la University of Central England (UCE) en Birmingham (briony.train@uce.ac.uk) y responsable de comunicación de la Sección de Lectura de IFLA. 
específicamente para este rubro. Esta actividad estuvo destinada a formular programas de entrenamiento para el personal de las bibliotecas públicas, no solamente con el propósito de que adquirieran las habilidades necesarias para promover la lectura como una actividad de tiempo libre entre los lectores actuales, sino también para alentar a los no usuarios y no lectores a disfrutar de los libros y la lectura.

Durante la conferencia de IFLA del 2001 en Boston, en la sesión abierta de la Sección de Lectura, se presentó un documento sobre las tendencias actuales en la investigación de la lectura en el Reino Unido, el cual se concentró en dos áreas en particular: la alfabetización y el desarrollo del lector, temas que suscitaron gran interés. Dada su importancia, la Sección de Lectura de la IFLA lo consideró un proyecto oportuno, porque complementaría dos de las áreas prioritarias relacionadas con el trabajo de esta sección: una, conocer la participación del personal de bibliotecas en la promoción de la lectura y el desarrollo de los lineamientos de alfabetización; y otra, documentar los antecedentes realizados por la IFLA y las instituciones bibliotecarias de los diferentes países. Se convino así en promover el proyecto entre los miembros de la IFLA, con la finalidad de conocer las diversas actividades de las bibliotecas de los diferentes países por lo que toca a los alcances de su participación en el desarrollo del lector. También se buscó dejar constancia de las experiencias exitosas, de utilidad para los análisis futuros de la IFLA y de las instituciones bibliotecarias de otros países.

Por tales razones el proyecto se integró al plan estratégico de la Sección de Lectura de IFLA y se formó un grupo de trabajo para llevar a cabo la investigación: Thomas Quigley de Canadá, Gertrude Hayaga Mullindwa de Uganda y Shirley Fitzgibbon de los Estados Unidos. ${ }^{2}$ La encuesta también fue promovida en la página de la Sección de Lectura del sitio web de IFLA. ${ }^{3}$

En la reunión de la Conferencia de la IFLA celebrada en Oslo, Noruega (2005) se invitó a otros países a realizar la EIL en sus bibliotecas

2 Véase Briony Train, "Reading: an international focus. The IFLA reading survey".

$3 \quad C f$. http://www.IFLA.org/VII/s33/project/irs.htm 
públicas. En mi calidad de miembro representante de México para la Sección de América Latina y el Caribe de la IFLA, consideré oportuno proponer al Comité Permanente de la citada Sección la aplicación de la Encuesta Internacional de Lectura a fin de sumar información sobre las acciones, alcances y experiencias de fomento a la lectura. Se consideró que la EIL resultaba pertinente dado que en varios países latinoamericanos y del Caribe las bibliotecas públicas impulsaban planes y acciones nacionales orientados a mejorar la calidad de las competencias, a elevar las prácticas de lectura y escritura, así como a mejorar y garantizar el acceso a la cultura escrita, a la información impresa, y ahora, a la digital. Además, en la última década se han impulsado programas de fomento a la lectura, el libro y la formación de lectores en el ámbito nacional, estatal y local en las bibliotecas públicas, que han derivado en acciones y desarrollo de experiencias significativas.

Al mismo tiempo, la EIL concuerda con algunas de las recomendaciones presentadas en las Políticas Iberoamericanas de Lectura, respecto a la necesidad de reunir información para formular indicadores y elaborar estudios comparados y diagnósticos. De igual manera el interés de la IFLA es compartir experiencias que permitan formular proyectos de promoción de la lectura, programas de extensión de la lectura y la formación de nuevos lectores, en especial en comunidades que han tenido pocas o nulas posibilidades de acceder a la lectura, a los libros y la biblioteca. De forma paralela, la IFLA está vinculada con uno de los temas que tienen particular importancia en los planes de la Sección de América Latina y el Caribe sobre la formación y actualización de los bibliotecarios de la región, la cual impulsa y apoya proyectos de actualización y entrenamiento.

El proyecto fue aceptado por el Comité Permanente de la Sección LAC en junio de 2006 y aprobado en el plan de financiamiento del Programa Fundamental de Acción para el Desarrollo, a través de Bibliotecas de la IFLA (IFLA/ALP) porque respondía al plan de trabajo de la sección, específicamente en su misión de fortalecer a las bibliotecas y a los bibliotecarios para lograr una participación más contundente en el desarrollo social de las regiones que enfrentan problemas de desigualdad. El financiamiento recibido se aplicó en la 
realización del seminario La formación de lectores en las bibliotecas públicas de América Latina y el Caribe, en el que se analizaron los temas de la EIL.

Misión de la EIL/LAC

La misión de la encuesta se centró en conocer y documentar la contribución de las bibliotecas públicas de América Latina y el Caribe en lo relativo al desarrollo del lector y la promoción de la lectura, a fin de formular programas de perfeccionamiento y actualización del personal bibliotecario, pero también buscaba fundamentar las acciones de la IFLA para fortalecer los programas en las escuelas de bibliotecología, las asociaciones bibliotecarias y las bibliotecas para solucionar los problemas de lectura y alfabetización de los ciudadanos.

\section{Objetivos}

Objetivo principal:

La Encuesta Internacional de Lectura se propone reunir información representativa sobre la región de América Latina y el Caribe en relación con el alcance que ésta tiene en las comunidades y en el personal de las bibliotecas públicas que está enfocado al desarrollo del lector y la promoción de la lectura, con el fin de identificar las necesidades y documentar los proyectos relacionados con actividades de fomento a la lectura y desarrollo del lector.

Objetivos particulares:

1. Realizar una investigación encuestando a las autoridades de las bibliotecas públicas sobre las actividades que se llevan a cabo con relación a la alfabetización, promoción de la lectura y el desarrollo del lector.

2. Identificar las percepciones que tiene el personal respecto al efecto del trabajo concentrado en el lector y su repercusión en el ánimo del personal bibliotecario. 
3. Utilizar la información recabada con el fin de conocer las percepciones del personal con relación al trabajo y compartir los ejemplos.

4. Divulgar la información vía Internet.

Justificación

La Encuesta se corresponde con los valores de la IFLA:

- Creemos que las comunidades e instituciones necesitan acceder sin trabas a la información, ideas y productos de la imaginación, para conseguir un bienestar físico, mental, democrático y económico.

- Creemos que la prestación de servicios bibliotecarios y de información de gran calidad ayudan a garantizar este acceso.

- Nos comprometemos a hacer todo lo posible para que las asociaciones de bibliotecarios y bibliotecas de todo el mundo y su personal participen en el trabajo de la Federación, sin importar su procedencia geográfica.

- Apoyamos y promovemos los principios de libertad y de acceso a la información, a las ideas y a los productos de la imaginación manifestados en el Artículo 19 de la Declaración Universal de los Derechos Humanos.

- Reconocemos los derechos de todos los socios a participar y beneficiarse de nuestras actividades sin importar su ciudadanía, origen étnico, género, lengua, ideología política, raza o religión. ${ }^{4}$

Estos principios dan fundamento a los tres pilares de la IFLA.

\section{Sociedad}

La lectura es un tema importante para la sociedad actual, que promueve el uso eficiente de la información para transformarla en conocimiento; una modalidad diferente de información que conduzca no sólo a una

4 Véase http://www.diputados.gob.mx/cedia/sia/spe/SPE-CI-A-20-08.pdf 
alfabetización permanente, sino al aprendizaje para toda la vida; un dominio cada vez más perfeccionado de destrezas en la lectura y la escritura; las mismas oportunidades de acceso a la lectura y a la información para todos lo ciudadanos y a que la lectura, la información y la educación no sean factores de desigualdad y exclusión.

\section{Profesión}

Los planes y acciones dirigidos a fomentar el gusto por la lectura y el libro, así como la alfabetización, colocan a la institución bibliotecaria como corresponsable en estas tareas, por lo que es oportuno que las asociaciones nacionales, regionales e internacionales de bibliotecarios, las escuelas de bibliotecología y los centros de investigación contribuyan a que sus políticas se transformen en programas y acciones. Al mismo tiempo habrá que fortalecer la preparación del personal bibliotecario, para garantizar una participación contundente que se refleje en el liderazgo de este sector, en el desarrollo de la construcción de la Sociedad del Conocimiento.

\section{Miembros}

La IFLA ofrece servicios a sus miembros y busca la inscripción y renovación de su membresía, y también ofrece diferentes oportunidades de actualización, mediante conferencias y publicaciones, talleres, seminarios, etcétera. Estas acciones y el trabajo conjunto fortalecen a la IFLA para poder aportarles mayores beneficios a sus miembros en todo el mundo.

Beneficiarios de los resultados de la EIL/IFLA/ALP/LAC

La información que se desprenda de la encuesta podrá ser de utilidad para los siguientes sectores: las bibliotecas públicas; las asociaciones y colegios de bibliotecología; la IFLA, específicamente las secciones de América Latina y el Caribe, de la Lectura, de las Bibliotecas Públicas y de la Educación y el Entrenamiento, así como a la sociedad latinoamericana y caribeña en general. 


\section{Apoyo de autoridades y organizaciones}

El proyecto Encuesta Internacional de Lectura para la región de América Latina y el Caribe contó con el apoyo del Centro Universitario de Investigaciones Bibliotecológicas (CUIB/UNAM) y las instituciones que asumieron las coordinaciones nacionales.

\section{Coordinadores}

El proyecto está integrado por la doctora Elsa M. Ramírez Leyva, investigadora del Centro Universitario de Investigaciones Bibliotecológicas (CUIB/UNAM), con el apoyo la maestra Martha Ibáñez Marmolejo, técnico académico del CUIB/UNAM y estudiante del posgrado de Bibliotecología y Estudios de la Información de la Facultad de Filosofía y Letras.

\section{Coordinadores nacionales}

\begin{tabular}{|l|l|}
\hline Argentina & Bolivia \\
$\begin{array}{l}\text { Ma. del Carmen Bianchi } \\
\text { Presidenta de la Comisión Nacional Protec- } \\
\text { tora de Bibliotecas Populares, Secretaría de } \\
\text { Cultura de la Nación } \\
\text { 1vega@conabip.gov.ar }\end{array}$ & $\begin{array}{l}\text { Doris Samanez Alzamora } \\
\text { Biblioteca Pública y Estación del Conoci- } \\
\text { miento } \\
\text { samanezalzamora@hotmail.com } \\
\text { dsamanez@pucp.edu.pe }\end{array}$ \\
$\begin{array}{l}\text { Sebastián Ricardi } \\
\text { Coordinador del Área de Planificación, } \\
\text { Monitoreo y Evaluación de Políticas, Planes y } \\
\begin{array}{l}\text { Programas de la Comisión Nacional Protec- } \\
\text { tora de Bibliotecas Populares, Secretaría de } \\
\text { Cultura de la Nación, Argentina }\end{array}\end{array}$ \\
\hline $\begin{array}{l}\text { Chile } \\
\text { Gladys Calderón Navarrete }\end{array}$ \\
$\begin{array}{l}\text { Enzo Abbagliati Boïls } \\
\text { Subdirector de Bibliotecas Públicas de Chile } \\
\text { Alameda 651 Piso 2 Santiago, Chile } \\
\text { eabbagliati@SBP.cl }\end{array}$ & $\begin{array}{l}\text { Colombia } \\
\text { Didier Álvarez Zapata } \\
\text { Docente de la Escuela Interamericana de } \\
\text { Universidad de Antioquia } \\
\text { Colombia. } \\
\text { dialnucleo@gmail.com }\end{array}$ \\
\hline
\end{tabular}


Encuesta Internacional...

\begin{tabular}{|c|c|}
\hline $\begin{array}{l}\text { Costa Rica } \\
\text { Saray Córdoba González } \\
\text { Coordinadora de Investigación } \\
\text { Sede de Occidente, Universidad de Costa } \\
\text { Rica } \\
\text { Apdo. 111-4250 } \\
\text { Ciudad Universitaria Carlos Monge Alfaro. } \\
\text { scordoba@cariari.ucr.ac.cr }\end{array}$ & $\begin{array}{l}\text { Cuba } \\
\text { Emilio Setién } \\
\text { Universidad de La Habana, Departamento } \\
\text { de Bibliotecología y Ciencia de la Informa- } \\
\text { ción } \\
\text { Facultad de Comunicación, Calle G \# 506e } \\
23 \text { y 21, Vedado, Cuba } \\
\text { esetien@infomed.sld.cu }\end{array}$ \\
\hline $\begin{array}{l}\text { Ecuador } \\
\text { Julio César de la Roche Martínez } \\
\text { Asesor de Dirección Ejecutiva } \\
\text { Sistema Nacional de Bibliotecas } \\
\text { Ministerio de Educación del Ecuador } \\
\text { Av. Amazonas } 353 \text { y Robles 4to. piso } \\
\text { jc_buzon@yahoo.es }\end{array}$ & $\begin{array}{l}\text { El Salvador } \\
\text { Olinda E. Gómez Morán } \\
\text { Biblioteca "Dr. José Gustavo Guerrero" } \\
\text { Ministerio de Relaciones Exteriores } \\
\text { Final 17 Av. Norte, Edificio No. 4, 1a. planta, } \\
\text { Centro de Gobierno } \\
\text { ogomez@rree.gob.sv }\end{array}$ \\
\hline $\begin{array}{l}\text { México } \\
\text { Lourdes López López } \\
\text { Dirección General de Bibliotecas, Conaculta } \\
\text { lulucnca@yahoo.com.mx } \\
\text { Verónica Sánchez } \\
\text { Dirección General de Bibliotecas, } \\
\text { Conaculta }\end{array}$ & $\begin{array}{l}\text { Panamá } \\
\text { Octavio Castillo Sánchez } \\
\text { Edificio Principal del Campus Universitario } \\
\text { "Octavio Méndez Pereira", el Cangrejo, } \\
\text { Panamá } \\
\text { Universidad de Panamá. } \\
\text { biblis2@ancon.up.ac.pa }\end{array}$ \\
\hline $\begin{array}{l}\text { Perú } \\
\text { César Augusto Castro Aliaga } \\
\text { BARATZ } \\
\text { Av. San Borja Norte 379-Depto. } 201 \\
\text { San Borja, Lima } 21 \\
\text { http://www.baratz.es } \\
\text { castroaliaga@hotmail.com }\end{array}$ & $\begin{array}{l}\text { West Indies } \\
\text { Adele Merrit-Bernard } \\
\text { Presidenta electa de Jamaica Library Asso- } \\
\text { ciation } \\
\text { ambernard@cokcu.com }\end{array}$ \\
\hline
\end{tabular}

\section{Metodología}

La metodología utilizada en la EIL/LAC fue la propuesta por el Comité Permanente de la Sección de Lectura de IFLA, para aplicarse en diferentes bibliotecas públicas de la región. Se envió una invitación para coordinar la encuesta a asociaciones de bibliotecarios, direcciones o coordinaciones de redes de bibliotecas públicas y académicos de países de América Latina y el Caribe; finalmente tuvimos respuesta de doce países que son los siguientes: 


\begin{tabular}{|l|c|}
\hline \multicolumn{1}{|c|}{ País } & Número de bibliotecas \\
\hline Argentina & 2026 \\
\hline Bolivia & 60 \\
\hline Chile & 415 \\
\hline Colombia & 1209 \\
\hline Costa Rica & 54 \\
\hline Cuba & 413 \\
\hline Ecuador & 15 \\
\hline El Salvador & - \\
\hline México & 7210 \\
\hline Panamá & 59 \\
\hline Perú & 876 \\
\hline West Indies & - \\
\hline
\end{tabular}

Etapas y fases de la EIL/IFLA/LAC

\section{El cuestionario}

El cuestionario aceptado por la Sección de Lectura de IFLA está integrado por cuatro áreas, a cada una de las cuales les corresponden preguntas cerradas, de opción sí o no, y otras abiertas.

Las preguntas tienen el propósito de conocer aspectos tales como:

- Concepciones acerca de la "promoción de la lectura".

- Destreza del personal requerido para promover la lectura como una actividad de tiempo libre y para alentar a los no usuarios y no lectores.

- Naturaleza de las actividades promocionales en bibliotecas e impacto percibido por los usuarios.

- Promoción de la lectura como una prioridad del personal, el servicio y el Gobierno.

Las cuatro áreas fundamentales son: 
1. Política de lectura

- ¿Cómo ha funcionado la política en la práctica?

- ¿Cuán eficaz ha sido?

- ¿Hasta qué punto ha facilitado el desarrollo de sociedades con otras agencias/organizaciones?

2. Sociedades para promover la lectura

- Razones para desarrollar tales sociedades.

- Contribuciones.

- Beneficios de las sociedades.

3. Sus actividades relacionadas con la lectura

- Actividades relacionadas con la lectura, organizadas para lectores y no lectores adultos.

- ¿Cómo ha sido o podría ser utilizada la evidencia del valor y del impacto de las actividades relacionadas con la lectura?

4. Destrezas del personal y necesidad de capacitación

- Sugerencias sobre las destrezas necesarias para promover la lectura en lectores y no lectores.

- Propuestas de cursos o programas de capacitación.

Las fases de la metodología

\section{Primera etapa}

Integración del grupo de investigación de diferentes países de la región de América Latina y el Caribe con la finalidad de establecer los acuerdos de colaboración y agenda de trabajo. Al final se conformó un grupo de coordinadores responsables de aplicar la encuesta en los siguientes países: Argentina, Bolivia, Chile, Colombia, Costa Rica, Cuba, Ecuador, El Salvador, México, Panamá, Perú y West Indies.

Traducción al español (Elsa M. Ramírez Leyva) y al portugués (Marcia Rosseto, Presidenta de la Federación Brasileña de Asociaciones de Bibliotecarios). Se diseñó una muestra para determinar las cuotas que le corresponderían a cada país, según el número de bibliotecas públicas; sin embargo, como se verá en el cuadro 
más adelante, la proporción propuesta no se logró debido a las circunstancias en las cuales se realizó la encuesta. Destacan las situaciones de Argentina y México, donde se aprovecharon actividades nacionales, por lo mismo la respuesta superó el porcentaje establecido, y se tomó la decisión de no excluir a ninguna. En otros países se redujo la muestra dada la dificultad de abarcar todo el territorio, pero la diferencia no fue significativa.

Previo a la aplicación definitiva de la EIL/IFLA/LAC se realizaron pruebas del instrumento, para lo cual se contó con la cooperación de los siguientes colegas:

- Belice:

Mtra. Lusiola Castillo

Directora de Bibliotecas Públicas.

- México:

Mtro. Ariel Gutiérrez Valencia

Profesor de la Universidad Autónoma de Tabasco

Asesor del Plan de Lectura del Estado de Tabasco del Instituto Estatal de Lectura.

Estudiante del Posgrado de Bibliotecología y Estudios de la Información de la UNAM.

Lic. Guadalupe Xiuyen Falcón Robles

Coordinadora de la Red Estatal de Bibliotecas Públicas de Chiapas, México.

- Puerto Rico:

Lic. Rosa Matos

Biblioteca Pública "José Emilio González".

\section{Segunda etapa}

La EIL/IFLA/LAC se aplicó durante 16 meses, las encuestas recabadas sumaron un total de 523, distribuidas por país de la siguiente manera: 
Encuesta Internacional...

\begin{tabular}{|l|c|}
\hline Argentina & 188 \\
\hline Bolivia & 20 \\
\hline Chile & 20 \\
\hline Colombia & 36 \\
\hline Costa Rica & 15 \\
\hline Cuba & 30 \\
\hline Ecuador & 24 \\
\hline El Salvador & 11 \\
\hline México & 150 \\
\hline Panamá & 10 \\
\hline Perú & 10 \\
\hline West Indies & 9 \\
\hline Total & 523 \\
\hline
\end{tabular}

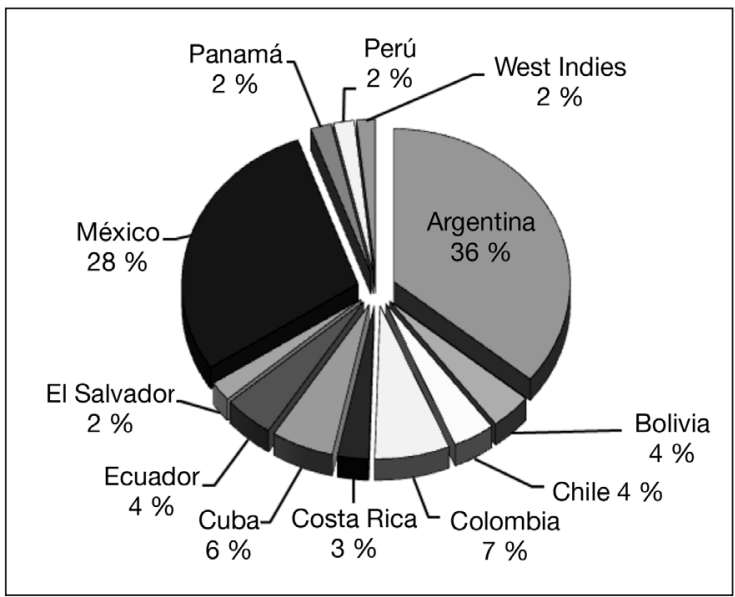

\section{Tercera etapa}

Se seleccionaron casos de estudio de la muestra en bibliotecas públicas identificadas con programas exitosos y originales para obtener información más amplia acerca de esos programas.

Se celebró el seminario La biblioteca pública y la formación de lectores en la sociedad de la información, con especialistas y el grupo de los encuestadores nacionales que analizaron la información de los resultados. Con los trabajos a los que dio lugar el seminario se publicó la Memoria del Seminario La biblioteca pública en la formación de lectores en coedición con el Centro Universitario de Investigaciones Bibliotecológicas de la UNAM y la Dirección General de Bibliotecas de Conaculta.

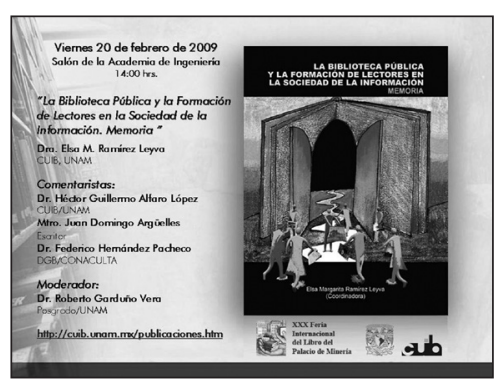


EL CONTEXTO DE LA LECTURA Y LAS BIBLIOTECAS PÚBLICAS EN AMÉRICA LATINA Y EL CARIBE

Entre las acciones que los países de América Latina y el Caribe deben afrontar en la naciente sociedad del conocimiento, se encuentran las destinadas a solucionar las causas que han impedido alcanzar la equidad en nuestras sociedades, entre ellas la desigualdad educativa, que ha provocado deficiencias en cuanto al uso de la lectura y la escritura. De igual manera está presente una desigual distribución del acceso a los libros y a la información en general, y ahora también en las tecnologías de información y comunicación. Por tales motivos la Unesco propone como objetivo central "la promoción de la educación como derecho fundamental y el mejoramiento de la calidad y el fomento de la innovación y la generación de conocimientos". 5 Sin duda, en los últimos años los países que integran América Latina y el Caribe han efectuado acciones para avanzar en el área educativa, al ampliarse la duración de la educación obligatoria, aumentar la cobertura del sistema educativo y mejorar la dotación de materiales e infraestructura de las bibliotecas, entre otros aspectos; sin embargo aún no se logra un desarrollo homogéneo en la región.

Los gobiernos, así como diversas organizaciones internacionales, también se encuentran trabajando en conjunto para aplicar acuerdos y planes educacionales que ofrezcan soluciones para erradicar el analfabetismo en la sociedad, ya que el porcentaje de éste se sitúa alrededor de los 34 millones de individuos, lo que representa $10 \%$ de la población total de América Latina y el Caribe. Sin embargo se prevé que el número de analfabetos seguirá disminuyendo y que para 2015 esta población sumará 31.2 millones (Tabla 1). Esto significa que por cada 100 latinoamericanos jóvenes y adultos, 10 no saben ni leer ni escribir, además se suman

5 Unesco, Los aprendizajes de los estudiantes de América Latina y el Caribe, p. 11. 


\section{aquéllos que no pudieron completar sus estudios de educación primaria, que ascienden a 24 millones de personas. ${ }^{6}$}

Tabla 1. Datos de América Latina y el Caribe

\begin{tabular}{|c|c|}
\hline Analfabetismo & $\begin{array}{l}10 \% \text { (35 millones) de la población de América Latina declara no } \\
\text { saber leer ni escribir. } \\
\text { En la población de } 15 \text { años y más, } 11 \text { de } 24 \text { países registra una } \\
\text { tasa de analfabetismo de } 10-20 \% \text {, entre hombres y mujeres, } \\
\text { ellas en mayor porcentaje. }\end{array}$ \\
\hline Nivel de educación & $\begin{array}{l}25 \text { \% de jóvenes no concluye la educación básica (no logran los } \\
\text { seis años de educación básica). } \\
64 \text { \% de niños no concluye la educación básica en cuatro países } \\
\text { de Centroamérica. } \\
40 \% \text { de la población latinoamericana no llega al nivel de secun- } \\
\text { daria (tres años posteriores a la educación básica de seis años). }\end{array}$ \\
\hline $\begin{array}{l}\text { Núm. de bibliotecas } \\
\text { públicas en América } \\
\text { Latina }\end{array}$ & $\begin{array}{l}14616 \text { bibliotecas públicas para una población de } 551764000 \\
\text { de habitantes. } \\
\text { El número de escuelas de nivel básico que tienen biblioteca no } \\
\text { llega a } 1 \% \text {, por tanto las bibliotecas públicas cubren las funcio- } \\
\text { nes escolares. }\end{array}$ \\
\hline
\end{tabular}

\begin{tabular}{|l|c|c|}
\hline \multicolumn{1}{|c|}{ País } & Analfabetas & Población analfabeta \\
\hline Argentina & 2.4 & 751000 \\
\hline Bolivia & 9.4 & 613000 \\
\hline Brasil & 9.6 & 13751000 \\
\hline Colombia & 5.9 & 2067000 \\
\hline Costa Rica & 3.2 & 110000 \\
\hline Chile & 2.9 & 367000 \\
\hline Cuba & 2.1 & 197000 \\
\hline Ecuador & 5.8 & 610000 \\
\hline El Salvador & 18 & 682738 \\
\hline Guatemala & 25.2 & 2220000 \\
\hline Honduras & 19.4 & 982000 \\
\hline México & 6.2 & 5026000 \\
\hline Nicaragua & 30.3 & 1216 \\
\hline
\end{tabular}

6 Véase Unesco, "Panorama regional: América Latina y el Caribe", [en línea].

7 Los datos sobre analfabetismo y educación están basados en la información que proporcionan las Naciones Unidas. 


\begin{tabular}{|l|c|c|}
\hline Panamá & 6 & 143000 \\
\hline Paraguay & 4.7 & 211000 \\
\hline Perú & 7 & 1487 \\
\hline R. Dominicana & 12.9 & 872000 \\
\hline Uruguay & 1.7 & 46000 \\
\hline Venezuela & 4.8 & 981000 \\
\hline
\end{tabular}

Fuente: Unesco, Estadísticas de población de 15 años y más.

\begin{tabular}{|l|c|c|}
\hline \multicolumn{1}{|c|}{ País } & Analfabetas & Población analfabeta \\
\hline Argentina & 1.1 & 75000 \\
\hline Bolivia & 2 & 41000 \\
\hline Brasil & 3.1 & 1029000 \\
\hline Colombia & 1.7 & 150000 \\
\hline Costa rica & 1 & 9000 \\
\hline Chile & 0.6 & 16000 \\
\hline Cuba & 0.2 & 3000 \\
\hline Ecuador & 1.5 & 43000 \\
\hline El Salvador & 6 & 70098 \\
\hline Guatemala & 16 & 488000 \\
\hline Honduras & 10.8 & 182000 \\
\hline México & 1.7 & 358000 \\
\hline Nicaragua & 25.2 & 336000 \\
\hline Panamá & 2.1 & 12000 \\
\hline Paraguay & 1.9 & 27000 \\
\hline Perú & 1.7 & 96000 \\
\hline R. Dominicana & 6.3 & 113000 \\
\hline Uruguay & 0.6 & 3000 \\
\hline Venezuela & 0.9 & 50000 \\
\hline
\end{tabular}

Fuente: Unesco, Estadísticas de población de 15 a 24 años.

Si comparamos el analfabetismo adulto (población de 15 años y más) y el joven (población de 15 a 24 años), observamos una tasa menor en el último grupo. En Guatemala, República Dominicana, Panamá y Venezuela el índice de analfabetismo de la población de 15 años y más (el $25.2 \%$, el $12.9 \%$, el $6 \%$ y el $4.8 \%$, respectivamente), representa casi el doble cuando se compara con la población de 15 a 24 años (el $16 \%$, el $6.3 \%$, el $2.1 \%$ y el $0.9 \%$, respectivamente). 
El programa "Educación para Todos" (EPT) tiene contemplado como uno de sus objetivos erradicar los niveles de analfabetismo de los adultos en $50 \%$ para el año 2015, por lo cual se está creando un entorno alfabetizado para fomentar la disponibilidad y utilización de materiales escritos plurilingües y de las nuevas tecnologías de la información y comunicación, con la finalidad de incitar a los individuos a través de diversas acciones, como adquirir el hábito de leer, mejorar la retención de las competencias que han obtenido en la lectura, escritura y cálculo, y facilitar así su acceso a la información. ${ }^{8}$

De acuerdo con el programa META 2021 en su capítulo dos, se destaca la democratización del acceso a la educación escolar y su impacto sobre la disminución de la tasa de analfabetismo joven, en donde se comenta que 91.3 \% de las personas de 15 a 19 años concluyó la educación primaria en la región. La mayoría de los países latinoamericanos garantizan la gratuidad de la enseñanza primaria; sin embargo todavía existen en América Latina y el Caribe 4.5 millones de personas entre 15 y 19 años que no completaron la educación primaria, de las cuales 42.9 \% son jóvenes de Brasil y México -los dos países más poblados de la región-. También llama la atención un grupo de países que están más alejados de poder garantizar la conclusión de la educación primaria: El Salvador, Nicaragua, Honduras y Guatemala. Además, con excepción de Panamá, Surinam, Guatemala y Honduras, todos los demás países consideran la secundaria como obligatoria en sus legislaciones. Sin embargo, considerando a la región como un todo, el $71.1 \%$ de la población entre 20 y 24 años no concluyó este nivel de escolaridad, lo que equivale a $\mathbf{1 4 . 2}$ millones de personas en ese grupo de edad.

La educación primaria en los países de América Latina en los últimos años ha tenido una tasa de matrícula por encima de $100 \%$ en Cuba y México. En Uruguay, Costa Rica, Brasil, Perú, Panamá, Argentina y Venezuela se encuentran alrededor de 60 y $80 \%$. El acceso a la educación básica se ha extendido a la mayoría de los países; se menciona que un primer grupo presenta valores superiores al

Idem. 
$97 \%$ en tasas netas (Argentina, Panamá, México, Ecuador y Cuba). En la educación secundaria las disparidades en la tasa escolar son muy fuertes, porque mientras que Cuba cuenta con $87.2 \%$ en el otro extremo de la tasa está Guatemala, que sólo alcanza $33.7 \%$. En la educación terciaria (media superior), la proporción de la población de 25 años y más graduada en el nivel superior muestra una enorme brecha, porque mientras que Perú, Chile, Argentina y Colombia tienen entre 10 y $15 \%$ de su población graduada en esos niveles, para Honduras, Paraguay y Nicaragua estos valores apenas alcanza 1.7 y $4.3 \%$ ?

En relación con el panorama educativo y la cultura de la región de América Latina y el Caribe, los analistas aseguran que el analfabetismo y la falta de posibilidades para ingresar al proceso educativo se encuentran relacionados con la distribución del poder y sobre todo con las oportunidades para educarse que existen en la sociedad, lo que genera una exclusión, por lo que es necesario darle seguimiento a las políticas educacionales de jóvenes y adultos con la finalidad de cerrar brechas y erradicar desigualdades sociales. Esta situación es grave porque se reducen las posibilidades de los ciudadanos de acceder y apropiarse de la información para construir un capital de conocimientos que les permita crear posibilidades de transformación, independencia y mejoría en su calidad de vida. Por ello se asume un compromiso a nivel latinoamericano a través del programa "Educación para Todos" de la Unesco, una de cuyas metas es contar con una sociedad libre de analfabetismo para el año 2015 y facilitarles a los adultos un acceso equitativo a la educación básica y permanente, como se ve reflejado en los diversos objetivos y estrategias que se plantean en el programa META 2021.

Otro de los factores que afectan la estabilidad del sistema educativo en América Latina es la deserción escolar, la que de acuerdo con el estudio realizado por la CEPAL demuestra que:

9 Véase OEI, META 2021, ¿De dónde partimos? [en línea] 
- Hacia el año 2000 cerca de 15 millones de jóvenes de entre 15 y 19 años de edad, de un total de 49.4 millones, habían abandonado la escuela antes de completar 12 años de estudio.

- Alrededor del $70 \%$ de ellos (10.5 millones) lo habían hecho tempranamente, antes de completar la educación primaria o una vez terminada ésta.

- Al no concluir siquiera su ciclo básico de formación escolar, esta población joven no logra reunir el capital educacional mínimo que le permita tener mayores opciones de insertarse en el mercado laboral, de manera que pudieran superar la línea de pobreza.

La deserción escolar y la repetición de cursos son altas y siguen generando problemas importantes, porque se comenta que en 2006 el porcentaje medio de los alumnos de primaria que repetían curso representaba $4.1 \%$ para América Latina y el Caribe en su conjunto y se desglosa así: $2.9 \%$ en el Caribe y $6.4 \%$ en América Latina. El caso del abandono de la escuela está representado por el $37 \%$ de los adolescentes (de 15 a 19 años) quienes dejan la escuela antes de completar el ciclo escolar secundario, y es mucho más frecuente en las zonas rurales que en las urbanas. La tasa de deserción escolar sigue siendo muy alta, pese a la elevada cobertura de la educación básica (casi de $90 \%$ ), al incrementarse la matrícula de educación secundaria (alrededor de $70 \%$ ).

Son varias las razones que motivan la deserción escolar de las personas jóvenes. Ocho de estos países dieron diversas respuestas sobre las causas que alejaron a los jóvenes del sistema educativo. En primer lugar destacan las razones económicas, pero también se mencionan la falta o la no accesibilidad de un establecimiento educativo pertinente así como los problemas familiares (más frecuentemente aludidos por las jóvenes), la falta de interés (personal y/o familiar), los problemas de rendimiento escolar y finalmente "otras razones", entre las que se cuentan discapacidad, enfermedad, servicio militar, etcétera. 


\section{Bibliotecas y lectura}

De acuerdo con el panorama anterior, cabe destacar la relevancia de impulsar la formación de lectores y el fortalecimiento del sistema bibliotecario, con la finalidad de brindar a esta población un mayor acceso a la información. Esto es lo que se ha intentado en las últimas décadas, al realizarse iniciativas por parte de las autoridades educativas de América Latina para promover la lectura, así como la creación de bibliotecas públicas y escolares, con la intención de multiplicar las acciones orientadas al desarrollo de la región, que permitan consolidar la cultura escrita de los egresados de la educación básica.

El programa "Educación para Todos" de la Unesco contempla en uno de sus objetivos generales, con proyección para el año 2015, mejorar todos los aspectos cualitativos de la educación y garantizar parámetros más elevados para conseguir resultados de aprendizaje reconocidos y mensurables, especialmente en lectura, escritura, aritmética y competencias prácticas esenciales.

La Organización de Estados Iberoamericanos (OEI) señala que el porcentaje promedio para los países de la Región es de $51.1 \%$ de escuelas con bibliotecas. Con más de $60 \%$ de escuelas con bibliotecas se destacan Guatemala, Argentina, Uruguay, Chile y Cuba $(82.1 \%$, mientras que en las peores situaciones, con porcentajes menores al 40 \%, están República Dominicana, Panamá, Paraguay, Ecuador, Costa Rica y Nicaragua (23 \%). La cantidad de libros promedio por biblioteca (850 es la media para los países de la región) es en general mayor a medida que aumenta la proporción de escuelas con biblioteca (a excepción de Guatemala). Con 1300 o más libros promedio por biblioteca están Cuba, Colombia, Chile, Argentina y Brasil; mientras que con menos de 500 libros por biblioteca se encuentran Nicaragua, Ecuador, Paraguay y Guatemala. ${ }^{10}$

En el caso de El Salvador se desarrolló un Plan de Educación 2021 por parte del Ministerio de Educación, el cual incluye un programa

Idem. 
denominado "Comprendo", cuya principal característica es mejorar las capacidades de razonamiento matemático, así como las competencias de comprensión y expresión del lenguaje en los niños del primer ciclo de educación básica, a través de la comprensión lectora. Para la enseñanza del lenguaje se apoyaron en el enfoque comunicativo funcional, una de cuyas acciones es seleccionar textos para que puedan realizar aprendizajes de lectura, escritura, habla y escucha. También consideraron los procesos pedagógicos, los cuales se sustentarán a través de programas de estudio y de seguimiento a las acciones a corto y largo plazo, como el programa "Te presto a mi abuelo" (que busca el desarrollo del gusto por la lectura a través de la vinculación de personas de la tercera edad en los procesos educativos de los niños en la escuela), "Mi mamá me cuenta cuentos, leo, comprendo y aprendo" (el propósito es mejorar el uso de las bibliotecas escolares en las comunidades educativas). ${ }^{11}$

También El Salvador ha sido receptor de "bibliotecas recreativas", las cuales son financiadas con el Programa de Canje de Deuda con España. La primera fase consiste en dotar de bibliotecas a 388 centros escolares asociados a 59 redes escolares de 53 municipios. La segunda fase consiste en dotar de bibliotecas a 382 centros escolares para completar el $100 \%$ que conforma el Programa de Redes Escolares. Las bibliotecas están integradas por libros recreativos, como categoría única, que abarcan diversos géneros literarios, y se tiene contemplado impartir talleres sobre bibliotecas recreativas a docentes en cada centro escolar beneficiado. En total se invertirán 10 millones de dólares para infraestructura, mobiliario, bibliotecas escolares y capacitación.

Argentina presentó un informe llamado "El desarrollo de la educación", y de acuerdo con las diversas modalidades que conforman el sistema educativo y con base en su informe, se menciona que la modalidad "Educación en contextos de privación de libertad" está destinada a garantizar el derecho a la educación a

11 Programa Comprendo [en línea], http://www.mined.gob.sv/2021/comprendo /descargas/comprendo.pdf 
todas las personas privadas de libertad, para promover su formación integral y desarrollo pleno, y contempla como una de sus acciones el proporcionar libros y materiales didácticos, la redefinición del rol del bibliotecario como promotor de lectura y una actualización tecnológica y bibliográfica.

En el informe se puede identificar un rubro específico relacionado con la promoción de la lectura, considerado tanto una práctica cultural como una de las prioridades del Ministerio de Educación de Argentina. Aquí el Plan Nacional de Lectura ha permitido fortalecer los planes de lectura en todas las jurisdicciones del país, así como el desarrollo de acciones para capacitar a docentes, bibliotecarios y diversos actores sociales para el desempeño de tareas relacionadas con la promoción de la lectura, destinada a los alumnos y a la comunidad en general. Otras acciones que destacan son la compra de libros para completar las bibliotecas de las escuelas en los diferentes niveles educativos y la entrega de 9000 bibliotecas de 100 libros cada una para escuelas secundarias, y 55000 bibliotecas con 42 libros de literatura infantil y juvenil de autores argentinos para las denominadas "Escritores en las escuelas".

También están trabajando en la creación de Centros de Promoción de la Lectura en cada jurisdicción, como espacios de referencia dirigidos a los docentes y a otros interesados en general.

En el caso de Guatemala, se colabora con la Academia de Español PROBIGUA (Proyecto Bibliotecas Guatemala es una organización de utilidad pública), que promueve como solución a los problemas educativos la creación de bibliotecas en áreas rurales. Recientemente ha logrado crear 23 bibliotecas de las cuales 13 son públicas y 10 escolares con programas de lectura infantil.

En Nicaragua y de acuerdo con la Dirección de Formación Docente y Educación Continua del MINED se propusieron cinco objetivos generales, uno de ellos destaca lo siguiente: "modernizar las bibliotecas de las escuelas normales". El proyecto Excelencia, que cuenta con el apoyo técnico y financiero de la Agencia de los Estados Unidos para el Desarrollo Internacional (USAID) tiene la finalidad de "expandir centros de excelencia en Nicaragua con énfasis en el método Aprendo, Practico y Aplico", por lo cual su interés se ve 
reflejado en impulsar la ambientación física y pedagógica de las escuelas, así como en asegurar la disposición de bibliotecas escolares.

Existe un proyecto literario bajo el nombre de "Rota cajas de lectura", el cual es impulsado por la Organización de Estados Iberoamericanos (OEI) y cuenta con el apoyo del Ministerio de Educación de España. Se propone llevar en cajas de plástico alrededor de 50 títulos de libros de literatura infantil, guías de actividades y material didáctico para promover la lectura dirigida a los niños en edad escolar. Las actividades se iniciaron en los albergues de El Salvador y continuaron con Honduras y Nicaragua.

En Nicaragua se organizó durante la Semana Mundial de Acción por la Educación, una campaña bajo el nombre "La gran lectura".

En su informe titulado "El desarrollo de la educación. Informe nacional de Brasil" se comenta que en 2007 el Ministerio de Educación lanzó el Plan de Desarrollo de la Educación (PDE) como una política de integración de sus acciones fundamentales, dirigidas a la manutención y desarrollo de la enseñanza en todos los niveles. Este plan está compuesto por 40 programas relacionados directamente con la pobreza, la exclusión social y la marginación cultural, mismos que se describen a continuación:

- Programa Nacional Biblioteca Escolar para la Educación Secundaria, que establece el suministro de acervos de libros para 17049 instituciones de enseñanza.

- Programa Nacional del Libro Didáctico de la Educación Secundaria. Realizó la distribución de 774 computadoras portátiles con la primera colección de libros digitales en audio y en sistema Braille.

- Programa Nacional de Biblioteca Escolar. Destinó su presupuesto para beneficiar a 21 millones de alumnos de la educación infantil y primaria con la compra de 5.1 millones de libros.

- Programa Nacional de Biblioteca Escolar. Realiza la distribución de libros complementarios para escuelas de educación primaria y en sistema Braille. En 2008 ampliaron su acción al adquirir libros para completar acervos de orientación 
pedagógica para profesores y libros para alumnos que van desde educación infantil hasta secundaria.

- Programa Proinfancia. Destinado a suplir la carencia de guarderías y escuelas de educación infantil con la finalidad de prestar asistencia financiera para la construcción y adquisición de equipo y mobiliario para dichas instituciones públicas; se tiene contemplado establecer contacto con áreas como bibliotecas o salas de informática con el objetivo de permitirle el acceso universal a la población estudiantil a una edad temprana.

Otro punto a destacar es el Programa Técnico 2009 elaborado por CERLALC, el cual contiene una serie de actividades que trabajarán para consolidar un espacio regional que ayude con los diferentes tipos de lectura y escritura, vinculando a los agentes que tienen un papel en esos temas, particularmente a la biblioteca.

Se destaca "Lectura y Escritura", cuyo objetivo estratégico es contribuir al desarrollo integral de la región, apoyando el diseño, la formulación y la gestión de políticas públicas en sus planes y programas de lectura y escritura. Los proyectos en esta área son:

- Red regional de responsables de políticas y planes nacionales de lectura (Redplanes). Es una red con soporte virtual que comparte un interés común y se apoya en la búsqueda de estrategias para dinamizar la formulación de políticas y acciones concretas.

- Red regional de conocimiento en lectura y escritura. Busca convertirse en una red de aprendizaje y construcción social del conocimiento, enfocada a la acción y transformación de políticas y programas de lectura y escritura de la región; quiere convertirse en un punto de convergencia entre la investigación y la práctica alrededor de la lectura y la escritura.

- Lectoescritura y desarrollo en la sociedad de la información. Se propone adelantar una investigación-acción que permita hacer visibles las prácticas de lectura y escritura que contribuyan al desarrollo social y cultural de las comunidades. 
Apunta a insertar las políticas y proyectos de lectura y escritura en un horizonte más amplio, además de hacer un seguimiento de las experiencias que desborden la lectura y la escritura y la liguen con la autoestima, la inclusión social y la creatividad, la conexión y la participación ciudadana.

- Situación de la formación docente en la pedagogía de la lengua escrita en América Latina. Se propone producir un análisis de un especialista en lectura y escritura acerca de la situación actual de la formación docente, sus horizontes y las recomendaciones que deben tener en cuenta los gobiernos de los países miembros.

- Comicteca: el cómic como soporte para promover la lectura en los jóvenes. Pretende disminuir la carencia de iniciativas de fomento a la lectura dirigidas a la población juvenil mediante la creación de comictecas, que buscan instaurar en el corazón de la biblioteca pública un espacio consagrado al lector joven.

Otro rubro que pretende desarrollar CERLALC es "Biblioteca", cuyo objetivo estratégico es contribuir a la creación y fortalecimiento de los sistemas nacionales de bibliotecas públicas, escolares y otras en Iberoamérica, que promuevan la democratización del acceso a la información y el conocimiento a través de los siguientes proyectos:

- Programa Iberoamericano de Cooperación en materia de Bibliotecas Públicas (PICBIP). Su interés es profundizar en las acciones de cooperación en las diversas líneas aprobadas por los países miembros del CERLALC fortaleciendo las líneas de formación y capacitación, de normatividad en materia de bibliotecas y de divulgación a través de la plataforma del Firbip.

- Campaña Iberoamérica de apoyo de las bibliotecas al Año Internacional de la Alfabetización. Se propone generar conciencia sobre el valor social de la alfabetización como una de las principales competencias para el aprendizaje a lo largo de la vida, y lograr alianzas estratégicas entre bibliotecas, instituciones 
educativas y otros, con el fin de poner a disposición de las personas en riesgo de exclusión una oferta amplia de alfabetización.

- Observatorio Iberoamericano de Bibliotecas. Se creará un observatorio sobre la lectura y las bibliotecas a cargo del CERLALC, que permita ofrecer a los países información relevante para la toma de decisiones.

- Lineamientos para las bibliotecas indígenas de Latinoamérica. Con el apoyo de un grupo indígena, se construirá una metodología participativa para la definición de directrices sobre bibliotecas indígenas, que reconozca la pluralidad y diversidad de las culturas existentes en la comunidad.

- Desarrollo de una política de bibliotecas digitales para Iberoamérica.

\section{Planes y programas de lectura}

Se cuenta con la existencia a nivel estado de los planes de promoción de lectura que en ocasiones se convierten en políticas nacionales para el fomento de la lectura.

\begin{tabular}{|c|c|c|c|}
\hline País & & Plan de Lectura & Entidad \\
\hline Argentina & $\begin{array}{l}\text { Plan Nacional de Lectura } \\
\text { en las Bibliotecas Populares } \\
\text { 'Argontina crece leyondo" }\end{array}$ & $\begin{array}{l}\text { Plan Nacional de Lec- } \\
\text { tura en las Bibliotecas } \\
\text { Populares "Argentina } \\
\text { crece Leyendo" } \\
\text { Plan Lectura. Programa } \\
\text { Educativo Nacional para } \\
\text { el Mejoramiento de la } \\
\text { Lectura }\end{array}$ & Ministerio de Educación \\
\hline Brasil & Plano Nacional & $\begin{array}{l}\text { Plano Nacional do Livro } \\
\text { e Leitura-PNLL }\end{array}$ & $\begin{array}{l}\text { Ministerio de Educación } \\
\text { y Ministerio de Cultura }\end{array}$ \\
\hline Chile & & $\begin{array}{l}\text { Plan Nacional de } \\
\text { Fomento a la Lectura }\end{array}$ & CONLL \\
\hline Colombia & $\underbrace{N}_{\text {LER LBERA }}$ & $\begin{array}{l}\text { Plan Nacional de } \\
\text { Lectura y Bibliotecas } \\
\text { "Leer libera" }\end{array}$ & Ministerio de Cultura \\
\hline
\end{tabular}


Encuesta Internacional...

\begin{tabular}{|c|c|c|c|}
\hline Cuba & $\begin{array}{l}\text { Gy } \\
\text { hrograma. } \\
\text { pacioutura }\end{array}$ & $\begin{array}{l}\text { Programa Nacional por } \\
\text { la Lectura }\end{array}$ & Ministerio de Cultura \\
\hline Ecuador & & $\begin{array}{l}\text { Campaña de Lectura } \\
\text { "Eugenio Espejo" }\end{array}$ & $\begin{array}{l}\text { Ministerio de Educación } \\
\text { y Cultura }\end{array}$ \\
\hline El Salvador & & $\begin{array}{l}\text { Plan Nacional de } \\
\text { Fomento de la Lectura }\end{array}$ & Ministerio de Educación \\
\hline Guatemala & & $\begin{array}{l}\text { Políticas públicas del } \\
\text { Libro, la Lectura, la } \\
\text { Escritura y las } \\
\text { Bibliotecas (PPLLEB) }\end{array}$ & Conalibro \\
\hline México & $\begin{array}{l}\text { México } \\
\text { Lee } \\
\begin{array}{l}\text { Programa de fomento } \\
\text { parael lubro vilatertura }\end{array}\end{array}$ & $\begin{array}{l}\text { "México Lee" Plan Na- } \\
\text { cional de Fomento para } \\
\text { el Libro y la Lectura }\end{array}$ & Conaculta \\
\hline Nicaragua & & $\begin{array}{l}\text { Plan Estratégico Nacio- } \\
\text { nal del Libro y la Lectura }\end{array}$ & Ministerio de Educación \\
\hline Panamá & & $\begin{array}{l}\text { Plan Nacional de Lectu- } \\
\text { ra "Para Leer Panamá" }\end{array}$ & $\begin{array}{l}\text { Ministerio de Cultura y } \\
\text { Educación }\end{array}$ \\
\hline Paraguay & 作 & $\begin{array}{l}\text { Plan Nacional de } \\
\text { Lectura "Todos leemos } \\
\text { en Paraguay" }\end{array}$ & $\begin{array}{l}\text { Ministerio de Educación } \\
\text { y Cultura }\end{array}$ \\
\hline Perú & 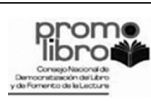 & $\begin{array}{l}\text { Plan Nacional del Libro } \\
\text { y la Lectura }\end{array}$ & Ministerio de Educación \\
\hline $\begin{array}{l}\text { República } \\
\text { Dominicana }\end{array}$ & & $\begin{array}{l}\text { Plan Quinquenal del } \\
\text { Libro y la Lectura ¡Hacia } \\
\text { un país de lectores! }\end{array}$ & $\begin{array}{l}\text { Secretaría del Estado } \\
\text { de Cultura y DGLL }\end{array}$ \\
\hline Uruguay & & $\begin{array}{l}\text { Plan Nacional de Lectu- } \\
\text { ra "Leer: un derecho" }\end{array}$ & $\begin{array}{l}\text { Ministerio de Educación } \\
\text { y Cultura }\end{array}$ \\
\hline País & & $\begin{array}{l}\text { Plan de Lectura } \\
\text { (En preparación) }\end{array}$ & Notas \\
\hline Bolivia & & $\begin{array}{l}\text { Plan Nacional de } \\
\text { Fomento de la Lectura }\end{array}$ & $\begin{array}{l}\text { Fue anunciado ante } \\
\text { los medios en el mes } \\
\text { de abril de } 2009 \text { por } \\
\text { parte del gobierno de } \\
\text { Bolivia. }\end{array}$ \\
\hline
\end{tabular}




\begin{tabular}{|l|l|l|}
\hline Venezuela & $\begin{array}{l}\text { Plan Nacional } \\
\text { Revolucionario de la } \\
\text { Lectura }\end{array}$ & $\begin{array}{l}\text { Mlnisterio del poder } \\
\text { Popular de la Lectura, } \\
\text { anunciado en el mes de } \\
\text { abril de 2009. }\end{array}$ \\
\hline
\end{tabular}

La institución bibliotecaria es parte importante de las políticas y programas de lectura nacionales y regionales en los que se aprecia la configuración de un modelo bibliotecario "humano", que junto con la escuela y la familia, están involucradas en la construcción de sociedades donde las condiciones favorezcan el desarrollo de sus facultades para emprender formas de transformación personal y de su entorno que los conduzcan hacia una mejor calidad de vida. Identificamos los siguientes propósitos que consideramos como cuestiones de investigación, con el fin de orientar el análisis global de los resultados de las encuestas:

- Crear, transformar, mejorar y acrecentar prácticas de lectura conforme a las características e identidades de las comunidades.

- Formar lectores que sean capaces de ejercer su derecho a leer y escribir y utilizar esto para la transformación personal y social.

- Fortalecer destrezas de lectura y escritura diversas para interactuar con la "biblioesfera".

- Reconocer el papel fundamental que tiene la biblioteca en el desarrollo de la lectura y la escritura.

- Crear, fortalecer y cualificar programas de formación inicial y continua para que docentes, bibliotecarios, padres de familia y otros actores se tornen en mediadores eficientes de la lectura.

- Apoyar, desde la biblioteca, otros espacios de lectura: hospitales, cárceles, medios masivos de transporte, asilos, hospicios, albergues, entre otros.

- Incrementar programas de promoción de lectura dirigidos a la primera infancia y a la familia.

- Contribuir a preservar la cultura y la tradición oral así como a fijarlas en lengua escrita.

- Contribuir a resolver problemas de lectura, escritura y habilidades informativas de los diferentes sectores de la sociedad, 
en especial grupos marginados cultural, económica y territorialmente.

- Instaurar cambios en las concepciones que limitan la formación de lectores, como una actividad que incluya a los diferentes sectores de la sociedad y la organice a favor de la lectura y la escritura en el ámbito de la "biblioesfera".

- Crear experiencias significativas de lectura y escritura que promuevan el uso de diversos materiales de calidad, en diferentes géneros y formatos.

- Fortalecer los vínculos de las bibliotecas con otras entidades que también promuevan las diferentes manifestaciones culturales.

- Crear y actualizar las bibliotecas escolares y otros espacios de lectura en las escuelas públicas, y considerarlos como instrumentos indispensables en la formación de alumnos y maestros así como de lectores y productores de texto.

- Formar a los docentes y a los bibliotecarios como auténticos lectores y escritores, de tal modo que puedan ser mediadores efectivos de la lectura y la escritura.

- Ampliar los alcances de los programas de educación intercultural bilingüe.

- Hacer valer también el derecho a la lectura y la escritura de niños, niñas y jóvenes afectados por algún tipo de discapacidad.

- Atender las recomendaciones del Manifiesto de la Unesco que hacen énfasis en la necesidad de implementar políticas para que la biblioteca escolar se convierta en un espacio de formación de lectores y escritores.

- Crear y fortalecer programas de formación de alumnos y docentes, como lectores y escritores.

- Formular proyectos de promoción de la lectura en el ámbito escolar.

- Promover investigaciones sobre las problemáticas de la lectura y la escritura en las universidades y otros centros de estudio.

- Sistematizar las experiencias valiosas que realizan otros actores en diversos países de la región y aprovechar los mecanismos de cooperación internacional existentes. 
- Impulsar el intercambio de experiencias en el interior de cada país.

- Crear, fortalecer y cualificar programas de formación inicial y continua, para que docentes, bibliotecarios y otros actores se conviertan en mediadores de lectura y escritura.

- Desarrollar experiencias de formación y actualización, a través de las cuales los mediadores continúen su proceso de formación y se reconozcan como lectores y productores de textos.

- Incorporar la formación de la lectura en los programas de formación profesional y posgrado.

- Diseñar e implementar, desde las bibliotecas, programas permanentes de formación de lectores, lectura y escritura dirigidos a distintos grupos de la comunidad.

Asimismo, cabe resaltar los estudios que abordan aspectos educativos, pero que evalúan el proceso de enseñanza y aprendizaje del alumno tomando en cuenta las áreas de lenguaje, lectura, matemáticas y ciencias. Un ejemplo son los estudios de PISA que evalúan el grado de adquisición con base en tres competencias básicas (lectura, matemáticas y científica), y SERCE que valora los conocimientos del currículo relativos a matemáticas y lenguaje.

Las metas propuestas para el 2021 son "disminuir entre un 10 y un $20 \%$ en los dos niveles bajos de rendimiento en las pruebas de LLECE [...] o en los estudios PISA o de la IEA en los que participen los diferentes países, y aumentar en la misma proporción los alumnos en los dos niveles altos en dichas pruebas". ${ }^{12}$

En el tema de la lectura se identifican:

- Meta General 5. Ofrecer un currículo significativo que asegure la adquisición de las competencias básicas para el desarrollo personal y el ejercicio de la ciudadanía democrática.

12 PISA [en línea], http://www.oecd.org/document/25/0,3343,en_32252351_32 235731_39733465_1_1_1_1,00.html 
- Meta específica 15. Ofrecer un currículo que incorpore la lectura y el uso de la computadora en los procesos de enseñanza y de aprendizaje, donde la educación artística tenga un papel relevante y estimule el interés por la ciencia entre alumnas y alumnos.

En los indicadores y nivel de logro se han propuesto los siguientes indicadores:

- Indicador 18. Tiempo semanal de lectura en las distintas etapas, en cuanto a nivel de logro; dedicar al menos 3 horas de lectura obligatoria en educación primaria y 2 en secundaria básica.

- Indicador 13. Proporción de alumnos por computadora. Nivel de logro: conseguir que la proporción entre computadora y alumno se encuentre entre $1 / 1$ y $1 / 10$.

- Indicador 19. Frecuencia de uso de la computadora en la escuela por los alumnos. Nivel de logro: conseguir que los profesores y los alumnos utilicen la computadora en el proceso de enseñanza-aprendizaje de forma habitual para el $2021 .^{13}$

En el tema de biblioteca se propone:

- Meta General 10. Mejorar la dotación de bibliotecas y computadoras en las escuelas.

- Indicador 12. Elevar el porcentaje de escuelas con bibliotecas. Y su correspondiente nivel de logro: conseguir que al menos $40 \%$ de las escuelas dispongan de bibliotecas escolares en 2015 y el $100 \%$ en el año 2021.

Con la finalidad de intercambiar puntos de vista y experiencias en torno al objetivo que hace referencia a la lectura, recientemente se abrió un foro de discusión a nivel latinoamericano en la página web de la OEI y Metas 2021, en donde se destaca lo siguiente:

13 OEI, op. cit. 
- En nuestra región es en el nivel medio de escolaridad donde reside en la actualidad el mayor déficit global, mientras que $90 \%$ de los niños latinoamericanos en esa edad concurren efectivamente a ese nivel; este porcentaje desciende a $68 \%$ en el caso del nivel secundario y se evidencian dificultades para terminar la secundaria. ${ }^{14}$ De lo anterior se desprende que los jóvenes de 15 años o menos abandonan la escuela para insertarse en edad temprana al campo laboral. Para ayudar en esto será necesaria la participación de diferentes instancias, entre ellas la bibliotecaria, en los siguientes rubros:

- Crear condiciones para un uso equitativo de la cultura escrita y fomentar su uso para el desarrollo de las potencialidades y los derechos de las personas, con el fin de darles la oportunidad de participar en su transformación y en la de su entorno.

- Crear programas para propiciar la integración de comunidades excluidas tanto en las áreas urbanas como en las rurales.

- Diseñar estrategias y opciones de desarrollo en áreas rurales y zonas marginadas.

- Implantar estrategias para incorporar a las culturas nativas, así como a los y las jóvenes indígenas a los contextos nacionales e internacionales fundamentales, como la identidad, la ciudadanía, la educación, la salud y el trabajo.

- Generar espacios de participación e interacción para los jóvenes, sobre todo los de sectores menos favorecidos, que les permitan desarrollar actividades de recreación.

- Ampliar el uso de nuevas tecnologías en el sistema educativo, sobre todo en las áreas más rezagadas, tanto urbanas como rurales, y poner especial atención en el acceso de las mujeres jóvenes a estas nuevas tecnologías.

Idem. 
- Educar en un ambiente sano pero acorde con sus intereses y preferencias. Incrementar y mejorar la calidad de los servicios de salud para adolescentes y jóvenes.

- Desplegar esfuerzos importantes para mejorar la calidad y la pertinencia de los contenidos educativos y el acceso equitativo de toda la población joven a éstos, y esforzarse por lograr una mayor calidad y cobertura de los programas de formación profesional, con estrecha vinculación y participación de la empresa privada.

- Promover sistemas de información con acceso a información de mercados, de las nuevas tecnologías, de procesos de comercialización y de capacitación a distancia para jóvenes emprendedores, tanto urbanos como rurales.

- Fomentar entre la población joven la construcción de una ciudadanía proactiva que pueda participar y vincularse con los grandes debates nacionales.

El panorama de la cultura escrita sin duda presenta avances, pero también retos para los gobiernos de América Latina y el Caribe, y deberán cumplir con los compromisos adquiridos en la Cumbre Mundial sobre la Sociedad de la Información (CMSI) para el 2025; entre ellos la erradicación del analfabetismo, la educación básica de 9 años mínimos para la población y la interconexión a la infraestructura digital al alcance de todos los ciudadanos, conforme a las metas 2015 y $2025 .{ }^{15}$ A estos acuerdos se agregan los suscritos desde 1992 en las cumbres y conferencias

15 Lo anterior puede constatarse en acuerdos regionales, entre ellos el de la Sociedad de Información de América Latina y el Caribe de la Comisión Económica para América Latina y el Caribe, que nos asigna la tarea de formación y competencias así como constituirnos en centros de acceso público para la información y la pluralidad cultural, principalmente la contenida en el medio electrónico, con el objetivo de atenuar las exclusiones de las comunidades en riesgo de perpetuarse en la zaga del desarrollo. Comisión Económica para América Latina y el Caribe (CEPAL), http://www.eclac. org/ 
anuales de las naciones iberoamericanas sobre los temas de la alfabetización, la lectura, el libro, las bibliotecas y la tecnología, entre otros, como lo observamos en sus acuerdos y metas (Tabla 2).

Tabla 2. Acuerdos relacionados con la lectura y las bibliotecas presentados en las Cumbres Iberoamericanas de América Latina y el Caribe

\begin{tabular}{|c|c|c|}
\hline 1992 & $\begin{array}{l}\text { II Cumbre Iberoamericana. Declaración } \\
\text { de Madrid }\end{array}$ & Programa de estímulo a la lectura. \\
\hline 1995 & $\begin{array}{l}\text { v Cumbre Iberoamericana. Declaración } \\
\text { de Bariloche }\end{array}$ & $\begin{array}{l}\text { Proyecto iberoamericano de promoción } \\
\text { de la lectura. }\end{array}$ \\
\hline 1999 & $\begin{array}{l}\text { IX Cumbre Iberoamericana. } \\
\text { La Habana, Cuba }\end{array}$ & $\begin{array}{l}\text { Programa de la Asociación de } \\
\text { Bibliotecas Nacionales de los Países } \\
\text { de Iberoamérica (ABINIA). } \\
\text { Promover la libre circulación del libro. } \\
\text { Cooperación en materia de bibliotecas } \\
\text { públicas. }\end{array}$ \\
\hline 2000 & $\begin{array}{l}\text { x Cumbre Iberoamericana. Declaración } \\
\text { de Panamá }\end{array}$ & $\begin{array}{l}\text { Desarrollo de las competencias para el } \\
\text { aprendizaje de lectura-escritura. }\end{array}$ \\
\hline 2001 & $\begin{array}{l}\text { XI Cumbre Iberoamericana. Declaración } \\
\text { de Lima }\end{array}$ & $\begin{array}{l}\text { Plan para conjuntar esfuerzos e impulsar } \\
\text { el libro y la lectura. }\end{array}$ \\
\hline 2002 & $\begin{array}{l}\text { VI Conferencia Iberoamericana de } \\
\text { Cultura. Santo Domingo, República } \\
\text { Dominicana }\end{array}$ & $\begin{array}{l}\text { Acuerdos: } \\
\text { Reconocer esfuerzos por el impulso al } \\
\text { libro y la lectura. } \\
\text { Realizar acciones con vistas al Plan } \\
\text { iberoamericano de promoción y fomento } \\
\text { de la lectura. }\end{array}$ \\
\hline 2003 & $\begin{array}{l}\text { VII Conferencia Iberoamericana de } \\
\text { Cultura. Declaración de Cochabamba }\end{array}$ & Plan Iberoamericano de Lectura. \\
\hline 2003 & $\begin{array}{l}\text { XIII Conferencia Iberoamericana de } \\
\text { Educación. Declaración de Tarija, Bolivia }\end{array}$ & $\begin{array}{l}\text { Declaración para el año 2005, el Año } \\
\text { lberoamericano de la Lectura. }\end{array}$ \\
\hline 2004 & $\begin{array}{l}\text { XIV Cumbre Iberoamericana en San } \\
\text { José, Costa Rica }\end{array}$ & $\begin{array}{l}\text { Apoyo para realizar actividades para el } \\
\text { Año Iberoamericano de la Lectura. }\end{array}$ \\
\hline 2005 & $\begin{array}{l}\text { VIII Conferencia Iberoamericana de } \\
\text { Cultura. Declaración de Córdoba }\end{array}$ & $\begin{array}{l}\text { Resultados positivos de las actividades } \\
\text { del Año Iberoamericano de la Lectura. }\end{array}$ \\
\hline 2006 & $\begin{array}{l}\text { XVI Cumbre Iberoamericana en } \\
\text { Montevideo, Uruguay }\end{array}$ & $\begin{array}{l}\text { Asegurar el derecho de toda la pobla- } \\
\text { ción a la alfabetización y educación } \\
\text { básica. } \\
\text { Fomentar el cultivo de la lectura, el acce- } \\
\text { so al libro y a las bibliotecas públicas. }\end{array}$ \\
\hline
\end{tabular}




\begin{tabular}{|l|l|l|}
\hline 2007 & $\begin{array}{l}\text { XVII Cumbre Iberoamericana en Santia- } \\
\text { go de Chile }\end{array}$ & $\begin{array}{l}\text { Programa de acciones: } \\
\text { Aprobar la incorporación del Plan Ibero- } \\
\text { americano de Alfabetización y educación } \\
\text { básica de jóvenes y adultos (PIA). } \\
\text { Apoyar la Segunda Reunión Ministerial } \\
\text { sobre Sociedad de la Información. }\end{array}$ \\
\hline 2007 & $\begin{array}{l}\text { XVII Conferencia Iberoamericana de } \\
\text { Educación. Declaración de Valparaíso }\end{array}$ & $\begin{array}{l}\text { Reafirmar el apoyo a las iniciativas del } \\
\text { fomento de la lectura y la escritura en } \\
\text { nuestros países, así como el desa- } \\
\text { rollo de programas que garanticen la } \\
\text { apropiación, por parte de las familias, } \\
\text { de material bibliográfico que promueva } \\
\text { los valores de la diversidad cultural y el } \\
\text { pensamiento crítico. }\end{array}$ \\
\hline 2008 & $\begin{array}{l}\text { XVIII Conferencia Iberoamericana de } \\
\text { Educación en Sonsonate, El Salvador }\end{array}$ & $\begin{array}{l}\text { Presentan un documento de trabajo titu- } \\
\text { lado "Calidad de la educación" haciendo } \\
\text { mención de un programa relacionado } \\
\text { con la promoción de la lectura y biblio- } \\
\text { tecas escolares con sus determinadas } \\
\text { estrategias y líneas de acción. }\end{array}$ \\
\hline
\end{tabular}

Se suma a lo anterior lo acordado en la Conferencia Iberoamericana de los Ministros de Educación 2008, en su documento sobre Metas Educativas 2021: la educación que queremos para la generación de los bicentenarios. En la citada conferencia los ministros acordaron que, ante la imposibilidad de abordar todos los componentes de la calidad de la educación, se optaría por cuatro factores de especial relevancia: la prevención del fracaso escolar; el apoyo a la lectura y a las bibliotecas escolares; la implantación de las tecnologías de la información en las escuelas y la evaluación de las escuelas. $^{16}$

Hoy en día la alfabetización ya no significa haber adquirido sólo un primer nivel de destrezas para leer y escribir letras, ahora es considerado un proceso que se prolonga a lo largo de nuestra vida y que es más bien un aprendizaje permanente, en tanto que no se agota en el descifrado de signos, sino que se continúa y se diversifica en diferentes lenguajes, niveles, maneras de lectura

OEI, op. cit. 
y escritura y supone la incorporación de la cultura digital. El desafío que representa la formación de lectores en el ámbito bibliotecario exige revisar cómo se forma personal, de allí la importancia de la EIL, que recoge de la práctica de los bibliotecarios de nuestra región sus propuestas sobre los conocimientos y habilidades con el fin de transformar los problemas en oportunidades para la institución bibliotecaria en la medida en que renueve sus programas y consolide su participación en la formación de sociedades lectoras para el siglo XXI.

\section{LAS REVELACIONES DE LA EIL}

La Encuesta Internacional de Lectura aplicada a una muestra de 523 personas en bibliotecas públicas de 12 países de América Latina y el Caribe (EIL/LAC) se realizó, por un lado, en un momento oportuno dado que la realidad actual de la sociedad de la información y el conocimiento exige que las instituciones bibliotecarias asuman una función de mayor relevancia en la construcción de sociedades lectoras competentes en la gestión, uso y aprovechamiento de la información para generar conocimiento y producir e innovar bienes y servicios, y por el otro, facilita a los ciudadanos la incorporación de modalidades de aprendizaje como un proceso permanente que les proporciona mejores condiciones para acceder a las oportunidades de educación, y con ello a reducir progresivamente las desigualdades sociales y culturales, pero también las ocasionadas por las constantes innovaciones tecnológicas que implican cambios en los procedimientos y en la necesidad de capacitación. A la vez se busca favorecer el intercambio, la comunicación y el beneficio que aportan los saberes de diferentes latitudes, que son fundamentales y deben garantizar su preservación y difusión, como son las culturas de América Latina y el Caribe.

En suma el modelo de la sociedad actual transita sobre cuatro ejes, tres de ellos propuestos por Jorge A. González: ${ }^{17}$ la cultura

17 Jorge A. González (coord.), José A. Amozurrutia y Margarita Maass, Cibercultur@e iniciaciónen la investigación, p. 21. 
de la información, la cultura del conocimiento, la cultura de la comunicación, y se agregaría a éstas la del aprendizaje; estas culturas están inmersas en la función bibliotecaria, la cual construye y ha sostenido hasta ahora el lazo entre el universo de las diversas comunidades y el de los medios bibliográficos y documentales; y también otros dos ámbitos, el de los valores (de naturaleza normativa relativo al orden de lo ideal) y el de los intereses (de naturaleza funcional). Como bien apunta Jesse Shera esa función se ubica entre el ser humano y su registro gráfico, allí se sitúa el punto en que el hombre y el libro se cruzan en una fructífera experiencia intelectual. Es en esa intersección donde se halla la clave de su filosofía bibliotecológica. ${ }^{18}$ En efecto, esa función de lazo se orienta por principios y valores, pero al mismo tiempo por las necesidades sociales que varían en cada época y en cada comunidad. De esta manera existe una tensión entre los intereses del sector económico, que impone sus designios sobre los modelos tanto de producción como de consumo, y es frecuente que esto se contradiga con los valores que defienden ciertos sectores culturales y educativos que buscan el desarrollo y transformación de las facultades humanas con el fin de ejercer sus derechos.

Así el bibliotecólogo debe orientarse por marcos éticos en los procesos involucrados en las actividades relativas a los objetos que contienen la producción del intelecto humano y que implican su selección, preservación y organización para hacerlos accesibles. Lo cual es también cierto en lo relativo al universo de los individuos, por lo que la bibliotecología se debe apoyar en una gama de disciplinas humanas y de las ciencias sociales, pues es indispensable conocer los diversos factores que dan lugar a las circunstancias y peculiaridades de las comunidades, las cuales deben orientar la planeación, diseño y desarrollo de colecciones y servicios, al mismo tiempo que las intervenciones o mediaciones precisamente propician el lazo entre los dos universos antes señalados, para que la lectura sea un potencial con el cual los lectores puedan crear diversas formas de interrelación y apropiación para diferentes 
propósitos y no únicamente los que determinan los intereses económicos.

De este modo las funciones que le son propias a la instancia bibliotecaria en esencia no han cambiado, aunque sí los principios, propósitos y modos, así como sus alcances, ya que cada tiempo histórico produce sus modelos culturales, proyectos sociales y tecnologías. Ahora la biblioteca debe definir los principios que guiarán su participación en cuanto a la formación de lectores y los procedimientos para realizar esto, para lo que habremos de conocer las acciones dirigidas a formar comportamientos lectores, los cuales nos atrevemos a sugerir en tanto que no han sido definidos por las instancias bibliotecológicas, sino que más bien se han guiado tanto por criterios escolares tradicionales como por la industria editorial.

Sabemos que la lectura en la escuela se funda en ideales formativos; sin embargo, el excesivo afán normativo y prescriptivo que busca controlar y al mismo tiempo masificar la educación por añadidura recibe la presión de organismos internacionales, como la OCDE, que pretende imponer la educación de competencias de acuerdo con el proceso productivo bajo las reglas de la tecnología electrónica, además de reducir los tiempos escolares de los ciudadanos; lo que ha terminado por malograr la oportunidad de formar lectores con mejores destrezas y actitudes que favorezcan el ejercicio de la lectura como una actividad para la transformación y el desarrollo personal.

En cuanto al mundo editorial, éste persigue incrementar el consumo de libros con fines económicos y por lo mismo impulsa legislaciones y programas de apoyo al libro y a la lectura. La biblioteca pública lleva a cabo acciones para fomentar la lectura con base en sus fines y trascendencia, aunque carecemos de la fuerza política que tienen los sectores escolar y editorial. A lo anterior se suma que en el área bibliotecológica la lectura no tiene una presencia en el proceso de formación de sus cuadros salvo algunas excepciones, sin embargo la promoción de la lectura en las bibliotecas púbicas es parte de las funciones del personal, como se aprecia en las siguientes gráficas. 


\begin{tabular}{|l|c|c|}
\hline \multicolumn{1}{|c|}{ País } & No & Sí \\
\hline Argentina & 51 & 49 \\
\hline Bolivia & 20 & 80 \\
\hline Chile & 5 & 95 \\
\hline Colombia & 25 & 75 \\
\hline Costa Rica & 6.7 & 93.3 \\
\hline Cuba & - & 100 \\
\hline Ecuador & 4.1 & 95.8 \\
\hline El Salvador & 11 & 89 \\
\hline México & 2 & 90.6 \\
\hline Panamá & 10 & 90 \\
\hline Perú & 10 & 90 \\
\hline West Indies & 44.4 & 55.5 \\
\hline
\end{tabular}

Tabla 3

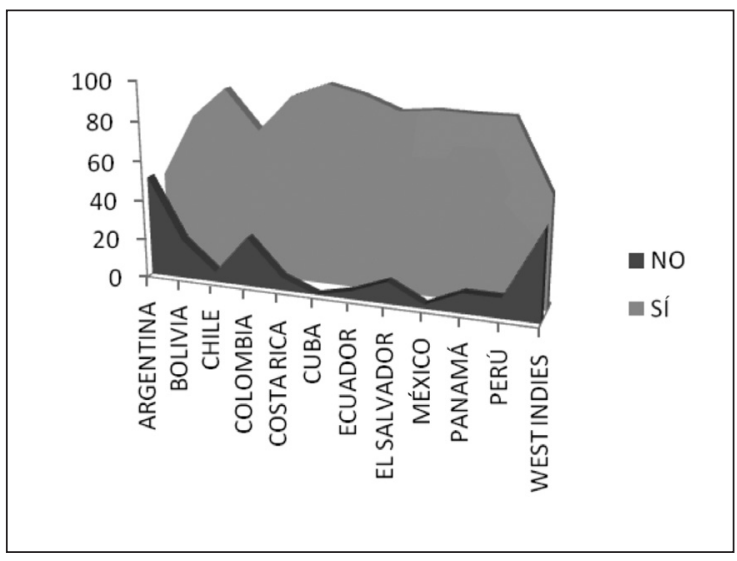

Gráfica 1. La promoción de la lectura forma parte del trabajo del personal

La EIL/IFLA/LAC nos ofrece indicios sobre las actividades de promoción de la lectura en las bibliotecas públicas de acuerdo a procedimientos, alcances e implicaciones para la institución bibliotecaria. Estos datos de las instituciones encuestadas nos aportan elementos no previstos, pero sin duda de enorme valor por los efectos que podrían tener en las reflexiones de las autoridades sobre la necesidad de modificar factores administrativos y sociales orientados a lograr una participación en la solución de los problemas de la lectura y de información coincidentes, actuales e históricos en las comunidades de Latinoamérica y el Caribe.

A continuación examinaremos cada uno de los rubros de la encuesta, tomando como base no sólo los datos estadísticos sino también los análisis que vertieron los coordinadores en sus documentos, los cuales resultan esenciales para entender cada una de las realidades que conforman el versátil ecosistema latinoamericano.

Políticas de lectura

- Funcionamiento de la política en la práctica.

- Eficacia de la política.

- Articulación con otras agencias/organizaciones/instituciones. 
Los gobiernos de América Latina y el Caribe han suscrito acuerdos internacionales y regionales tanto en el ámbito educativo como en el cultural, relativos a la lectura, el libro, la biblioteca y las tecnologías de la información, de los cuales se han derivado planes y programas nacionales de lectura y el libro que podríamos englobar en políticas, algunas de ellas expresadas claramente como tales o incluso vertidas en leyes y dirigidas a elevar la calidad y la frecuencia de lectura de la población y mejorar sus habilidades informativas, así como a expandir las posibilidades de acceder a los libros y medios electrónicos, con el apoyo de la biblioteca. Es decir, ésta se afirma como una de las instituciones indispensables para impulsar dichas acciones. Sin embargo, pese a los avances en el desarrollo de las bibliotecas públicas latinoamericanas y caribeñas de los últimos años, en la realidad persisten debilidades que limitan la participación bibliotecaria para la construcción de sociedades lectoras. ${ }^{19}$

\begin{tabular}{|l|c|c|}
\hline \multicolumn{1}{|c|}{ País } & Sí & No \\
\hline Argentina & 66 & 34 \\
\hline Bolivia & 5 & 95 \\
\hline Chile & 20 & 80 \\
\hline Colombia & 30 & 70 \\
\hline Costa Rica & 46.7 & 53.3 \\
\hline Cuba & 100 & - \\
\hline Ecuador & 62.5 & 37.5 \\
\hline El Salvador & 27 & 73 \\
\hline México & 23.3 & 68 \\
\hline Panamá & 60 & 30 \\
\hline Perú & 40 & 60 \\
\hline West Indies & 11.1 & 88.8 \\
\hline
\end{tabular}

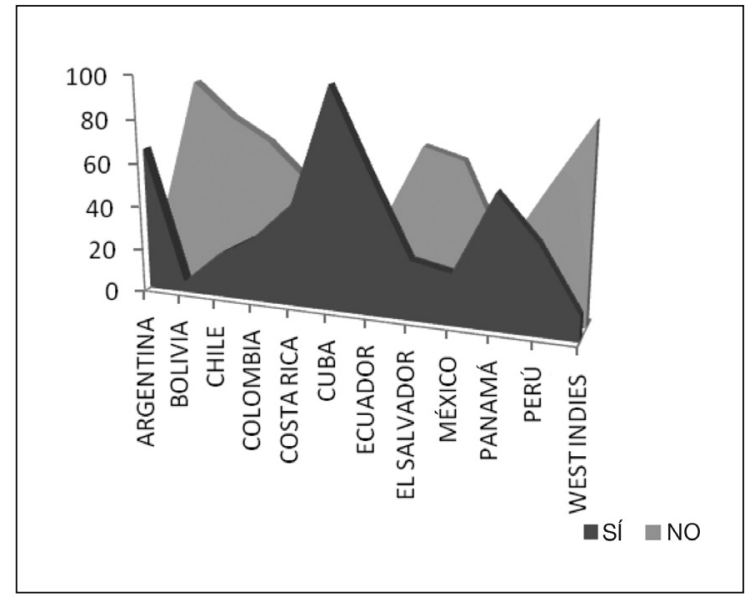

Tabla 4

Gráfica 2. Institución que se rige por alguna política de lectura

19 En la página de CERLALC se puede encontrar información sobre los planes de lectura: http://www.cerlalc.org 
En los resultados que se desprenden de la EIL encontramos como tendencia general una heterogénea consolidación de planes y programas bibliotecarios, tanto en la región como en cada país, debido a factores políticos, económicos, geográficos, tecnológicos y a la falta de instrumentos de evaluación y de prácticas administrativas que incorporen el seguimiento del desarrollo de la concreción de los lineamientos. Existe también una carencia de directrices en cuanto al personal bibliotecario que redunde en su mejor formación, remuneración y autoridad para hacer accionar las políticas. En general, las formas de gobierno de la región son de tipo mixto e involucran tres niveles de autoridades (locales, estatales y federales), de manera que las responsabilidades tienden a ser imprecisas.

En los países donde existe una dirección o coordinación de los sistemas bibliotecarios se establece una normatividad que está regulada por lo que toca a la responsabilidad, de acuerdo con la estructura de los gobiernos locales. El modelo más extendido consiste en acuerdos que estipulan los compromisos y responsabilidades de las instancias federales y las estatales o municipales en cuanto a la selección y compra de materiales, construcción y mantenimiento del local e instalaciones, mobiliario, equipamiento, contratación de personal, capacitación, asesoría, diseño de directrices para el funcionamiento y la colección bibliográfica, así como el diseño, desarrollo e insumos de los programas relacionados con la lectura. En general los recursos federales asignados al desarrollo bibliotecario se rigen por un reparto equitativo que es complementado por los gobiernos estatales, provinciales o municipales cuya asignación no está debidamente regulada, por lo cual los recursos también deben operar con relación a las políticas o programas, por lo que el proceso se realiza de manera desigual. Aparte los apoyos suelen estar sujetos a diversas variables y por lo mismo no tienen una trayectoria estable y sostenida, situación que se refleja en el desarrollo de los acervos y servicios en cuanto a calidad, actualidad y variedad suficiente; lo mismo sucede en las actividades que pretenden extender los servicios y en las acciones para formar lectores. En cuanto a la infraestructura tecnológica, si bien tiende a 
crecer, existen zonas en donde incluso los requerimientos básicos, como son la electricidad y la telefonía, se encuentran en etapas de desarrollo incipiente o son de plano inexistentes, lo que imposibilita no sólo los enlaces que permitan la comunicación y el acceso a recursos digitales sino las posibilidades de que los órganos centrales otorguen asistencia social.

Otro aspecto que se evidenció en la EIL/IFLA/LAC es el desconocimiento, por una parte de los bibliotecarios encuestados, acerca de la participación y las responsabilidades que son competencia de la biblioteca pública como parte de políticas, planes, leyes nacionales de lectura y del libro. Es decir, no han sido debidamente involucrados y esto ha propiciado la desvinculación entre los órganos de gobierno responsables de operar los programas y las entidades que deben desarrollar las acciones, por lo mismo se dificulta el alcance de las metas. También es oportuno aclarar que en varios de los países encuestados, como se aprecia en el cuadro de planes nacionales de lectura, estas metas son de reciente creación, por lo que se encuentran en proceso de consolidación. Para ejemplificar lo anterior, seleccionamos los siguientes casos:

En Cuba se encontró que todos los encuestados conocen y afirman formar parte de las políticas del Estado en materia de lectura. En otros países cada entidad federativa tiene autonomía por que cuenta con sus propios procedimientos para plasmar las políticas nacionales. En los demás países las respuestas fueron variables acerca de la incorporación de la política de Estado en lo referente a la lectura, la información y el libro. Los datos de la EIL/LAC suscitan cuestionamientos sobre la posible confusión o desconocimiento de los planes oficiales, dado que el alcance de las acciones gubernamentales deja fuera a una porción de las bibliotecas públicas.

En Argentina, de las 285 bibliotecas populares (70.3 \%) que participan en alguna política, plan o programa de promoción de la lectura, $22.8 \%$ del total de bibliotecas activas regulares tienen vínculo con el Consejo Nacional Bibliotecas Populares (CONABIP). Aunque esta participación implica poco más de la mitad de las bibliotecas populares adheridas al plan, una parte de ese sector está 
en proceso de integración. Precisamente el CONABIP tiene entre sus objetivos de gestión hasta el 2012 no sólo promover la incorporación al mismo, sino aumentar la base de acuerdos con otros niveles de gobierno y organizaciones, en función de orientar las acciones hacia un verdadero Plan Nacional de Lectura, integral y federal. Sin embargo el Consejo ha tenido una trayectoria complicada por lo que la consolidación de las acciones de coordinación han empezado a fortalecerse en los últimos años.

En Colombia $30 \%$ de las bibliotecas afirmaron que orientan sus acciones al campo de la promoción de la lectura mediante alguna política. Destacan las iniciativas de la Asociación Colombiana de Lectura y Escritura (Asolectura), que desde 2002 ha venido impulsando la discusión de políticas de lectura en los municipios colombianos, asimismo ha presentado algunas propuestas ante el Consejo Nacional del Libro y la Lectura. Vale la pena resaltar los logros en cuanto a la formulación de la política pública de lectura en las ciudades de Cali (2005) y Bogotá (2006). En lo referente al año de procedencia de las políticas y lineamientos institucionales para la promoción de la lectura en las bibliotecas públicas, cabe señalar que más de un tercio de las bibliotecas indican que a partir de 2002 se cuenta con estas pautas. Esta fecha coincide con las primeras consideraciones del Plan Nacional de Lectura y Bibliotecas, lo cual permitiría intuir que, desde sus inicios, el Plan ha podido impactar positivamente a ciertos sectores de las bibliotecas públicas del país. En primer lugar $31 \%$ de las bibliotecas públicas encuestadas declaró tener un manual para orientar y realizar las actividades de promoción de la lectura. Tal hecho estaría señalando un movimiento muy positivo, en tanto que las actividades de promoción de la lectura se realizan de acuerdo con los lineamientos y contenidos generales.

En el caso de Chile, la Política Nacional del Libro y la Lectura procede de 2006. Por su parte, el Consejo Nacional de Fomento del Libro y la Lectura elaboró un documento propio a partir de los lineamientos del año 2007. En su elaboración participó también la Dirección de Bibliotecas, Archivos y Museos, el Ministerio de Educación y sectores de la industria editorial del libro y de la sociedad 
civil. Su primer objetivo era "crear las condiciones para asegurar el más amplio acceso al libro y la lectura, integrando en este esfuerzo a todos los actores relacionados, así como al conjunto de la comunidad". Es posible que debido a la reciente emisión de estos documentos, el $\mathbf{2 2 . 7} \%$ de los bibliotecarios señaló que se rige por alguna política de lectura, en comparación con el $77.3 \%$, cuya respuesta fue negativa. La Subdirección de Bibliotecas Públicas ha impulsado al sector bibliotecario hacia acciones dirigidas a fomentar entre las personas la lectura y el acercamiento a los libros de manera institucional, y a establecer políticas de promoción de la lectura que abarcan el desarrollo de colecciones con acceso a los materiales y servicios bibliotecarios, así como la oferta de lectura en otros formatos.

En cuanto a México, $68 \%$ de los encuestados afirmaron desconocer las políticas del Plan de Lectura, el cual se creó en el año 2000 bajo el lema "Hacia un país de lectores" y en el que las bibliotecas públicas tienen una importante participación. Por su parte, la Dirección General de Bibliotecas, órgano coordinador de la Red Nacional de Bibliotecas Públicas del Consejo Nacional para la Cultura y las Artes (Conaculta), realiza diferentes actividades de capacitación al personal, como conferencias periódicas, además distribuye de manera amplia publicaciones sobre temas diversos, entre ellos la lectura, y también manuales para realizar actividades de promoción de la lectura, entre ellos el programa nacional Mis vacaciones en la biblioteca, que tiene como propósito animar a los niños a acercarse a la lectura de entretenimiento; este programa se realiza cada verano desde 1984 en casi todas las bibliotecas de la red, cuyo número suma hoy 7211 . Además, la Secretaría de Educación Pública es la responsable de los coordinadores estatales del Plan Nacional de Lectura en el ámbito escolar.

En Perú, la Ley de Democratización del Libro y Fomento de la Lectura de 2003 dio lugar al diseño y desarrollo de las políticas para hacer de la lectura un derecho social de los ciudadanos, que se plasmó en el Plan Nacional de Lectura (2005), en el que se propusieron los lineamientos de política y las acciones que debían ser ejecutadas por las diferentes entidades, entre ellas las bibliotecas 
públicas. Por su parte la escuela promueve la lectura regalando un libro por mes, tanto a profesores como a alumnos. En cuanto a la respuesta sobre la relación con las políticas de lectura, $60 \%$ de las bibliotecas respondió que no se rigen por ninguna y $40 \%$ afirmó que sí lo hace. De estas últimas, tres señalaron como políticas a las disposiciones de las municipalidades de las que dependen; una biblioteca mencionó en forma específica las disposiciones contenidas en la propuesta del Plan Nacional. En cuanto a las actividades de promoción de la lectura que se orientan conforme a un manual, $90 \%$ respondió que no cuenta con esta herramienta y sólo una biblioteca refirió que sus actividades se basan en el manual de lectura del programa MundoBus (Programa Binacional España-Perú).

Se sabe bien que la formación de lectores es un proceso muy complicado y difícilmente se logra despertar el gusto por la lectura mediante una serie de prescripciones generales, sin embargo no se puede sustraer que la realidad, en la mayor parte de las bibliotecas de la región, tiene en común que su personal no cuenta con formación profesional. A lo anterior se agrega la poca claridad existente en cuanto a la finalidad que orienta las acciones bibliotecarias relacionadas con la promoción de la lectura. El propósito de que se lea mejor y de manera analítica y crítica es poco considerado. Bajo esas circunstancias de un nutrido número de bibliotecas públicas, los manuales o guías de alguna manera pueden considerarse directrices y cumplen su cometido de establecer líneas de acción y de orientar al personal de las bibliotecas en actividades de formación de lectores. Esos materiales son elaborados por las coordinaciones o direcciones, que igualmente imparten algunos talleres y cursos o promueven programas o campañas de lectura. En cuanto a los resultados de la EIL/IFLA/LAC, éstos revelan que posiblemente las actividades y los documentos distribuidos no se expresan en la vinculación de la biblioteca con las políticas nacionales, ni en las responsabilidades que le corresponde desempeñar en cuanto a las actividades relacionadas con la lectura. En algunos casos la aplicación de las actividades descritas en los manuales no está sujeta a evaluación. Por otro lado persiste 
una falta de homogeneidad con relación a los apoyos que reciben las bibliotecas conforme a lo dispuesto en los planes, por lo que las comunidades resultan perjudicadas en sus derechos, dado que no se cumplen con cabalidad las acciones a las que se encuentran comprometidas en los documentos oficiales.

Los resultados del uso de los manuales o guías los incluimos bajo el rubro "Directrices" y llaman la atención porque en general un alto porcentaje de las respuestas, a excepción de Argentina, Cuba y El Salvador, señaló que se guía por ellos. En tanto, entre los encuestados mexicanos sólo 55 \% declaró que sí usa los manuales a pesar de la distribución tan amplia de ellos. En Colombia y Ecuador el porcentaje de quienes los utilizan no alcanza $50 \%$. Los demás países muestran porcentajes menores, por lo que confirmamos problemas en sus canales de comunicación y atención homogénea, incluyendo los órganos centrales sobre aplicación de las directrices o recomendaciones que emiten, como puede apreciarse en la siguiente gráfica.

\begin{tabular}{|l|c|c|}
\hline \multicolumn{1}{|c|}{ País } & Sí & No \\
\hline Argentina & 90.4 & 9.6 \\
\hline Bolivia & 5 & 95 \\
\hline Chile & 20 & 80 \\
\hline Colombia & 30 & 70 \\
\hline Costa Rica & 26.7 & 66.7 \\
\hline Cuba & 100 & - \\
\hline Ecuador & 45.8 & 50 \\
\hline El Salvador & 81.8 & 18.2 \\
\hline México & 55.3 & 34 \\
\hline Panamá & 10 & 90 \\
\hline Perú & 10 & 90 \\
\hline
\end{tabular}

Tabla 5

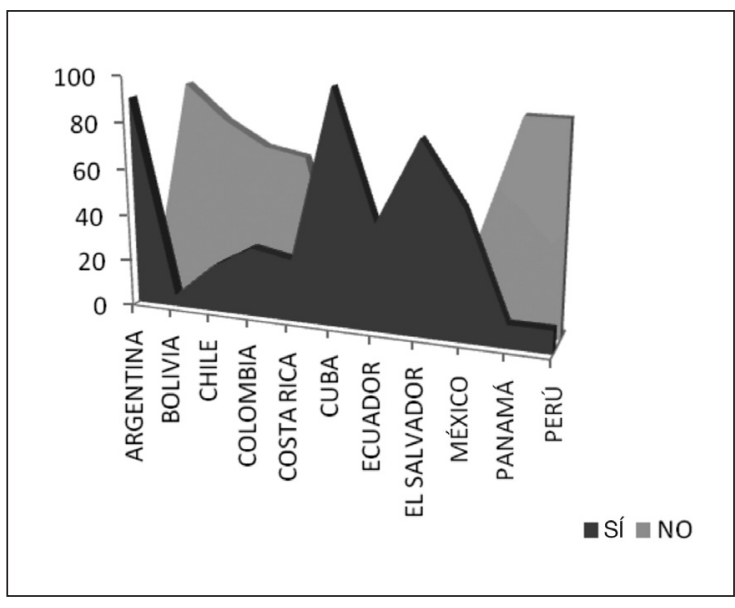

Gráfica 3. Actividades que se realizan con la guía de algún material 
Vinculación de la biblioteca con diferentes actores sociales

La dimensión del problema de la lectura requiere un conjunto de acciones constantes e integrales que involucran a diferentes instituciones, organismos públicos y privados, así como agrupaciones de la sociedad civil. En los países donde se impulsan planes y campañas nacionales de la lectura y el libro aparece la biblioteca, en especial la pública y la escolar, como una de las instituciones estratégicas de este impulso, junto con la familia, la escuela, los organismos culturales, el sector editorial y los medios de comunicación. Por consiguiente, la biblioteca debe crear su articulación con más y diversos sectores de los antes mencionados e involucrarse con diferentes agrupaciones civiles, dado que debe cumplir con el principio, conforme a la recomendaciones del Manifiesto de la Unesco/ IFLA para Bibliotecas Públicas, de ofrecer en igualdad de condiciones acceso a la lectura, al libro y a la información a todas las personas, independientemente de su edad, raza, sexo, religión, nacionalidad, idioma o condición social, además de proporcionar servicios específicos para quienes por una u otra razón no puedan valerse de los servicios y materiales ordinarios, como las minorías lingüísticas y los deficientes físicos y mentales, enfermos o reclusos.

En las últimas décadas, en nuestra región se han creado diferentes organizaciones públicas y privadas, y también instituciones gubernamentales, que realizan actividades de promoción de la lectura, pero las relaciones de colaboración no están suficientemente articuladas con la biblioteca, situación que limita la capacidades de cada sector para potenciar los recursos y experiencias, e incluso alcanzar un cambio estructural dirigido a modificar las representaciones y prácticas de lectura en las comunidades hacia una verdadera integración como parte indispensable para ejercer sus derechos a la educación y a la libertad de información en sus dos vertientes: informar e informarse.

Por lo anterior, en la EIL/IFLA/LAC se buscó conocer los vínculos y alianzas que los bibliotecarios han establecido en relación con sus actividades de promoción de la lectura, lo cual permite configurar el alcance de su intervención en la sociedad. Al mismo 
tiempo se identificaron las posibilidades de la biblioteca pública para ampliar y diversificar los servicios en apoyo a la formación de lectores. Un aspecto de importancia es que la institución bibliotecaria alcance una participación de mayor influencia en el ámbito político y social de cada país. Lo que implica la renovación de los modos de operación de las bibliotecas para integrarse en programas con los diferentes sectores.

\begin{tabular}{|l|c|c|}
\hline \multicolumn{1}{|c|}{ País } & No & Sí \\
\hline Argentina & 4.3 & 95.7 \\
\hline Bolivia & 90 & 10 \\
\hline Chile & 10 & 90 \\
\hline Colombia & 30 & 70 \\
\hline Costa Rica & 20 & 80 \\
\hline Cuba & - & 100 \\
\hline Ecuador & 4.1 & 95.8 \\
\hline El Salvador & - & 100 \\
\hline México & 37.3 & 55.3 \\
\hline Panamá & 30 & 70 \\
\hline Perú & 10 & 90 \\
\hline West Indies & - & 100 \\
\hline
\end{tabular}

Tabla 6

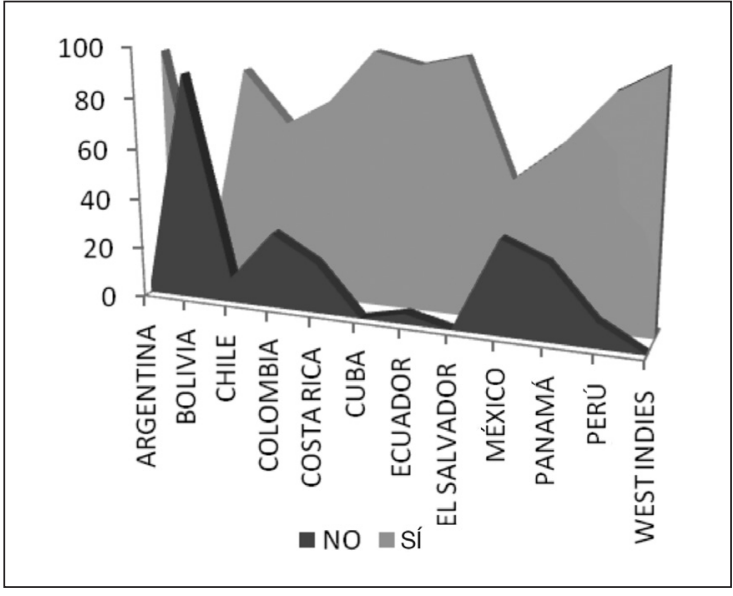

Gráfica 4. La promoción de la lectura se realiza con otras instituciones

De los bibliotecarios encuestados, como puede observarse en las gráficas, casi la totalidad (95.7\%) cuenta con algún tipo de articulación con otras instituciones orientadas al desarrollo de actividades en torno a la lectura, en tanto sólo $4.3 \%$ declara no tener ningún tipo de colaboración. Con relación a la opinión de los bibliotecarios encuestados, todos consideraron que las alianzas son estratégicas para sobrellevar los desafíos implícitos en las actividades de promoción de la lectura. Las actividades de animación a la lectura representan $32.5 \%$ del total de las realizadas cooperativamente. Las respuestas se configuraron en los siguientes ámbitos como los más comunes: 
Por tipo de institución:

- Bibliotecas: públicas y escolares.

- Organizaciones civiles, redes: ONG.

- Sector escolar: jardines de niños, escuelas, colegios de la comunidad, universidades e institutos superiores.

- Comités de deportes.

- Organizaciones sociales en zonas urbanas o rurales.

- Domicilio de lectores impedidos.

- Sector salud: hospitales, centros para la atención integral de personas adultas con discapacidad, casas de retiro y asilos.

- Gobierno: municipios, instancias de educación y cultura, gobiernos provinciales, centros de trabajo, centros penitenciarios.

- Organismos privados: editoriales y librerías, bancos, cajas de compensación familiar, Diners Club.

- Asociaciones de bibliotecarios.

- Juntas parroquiales.

- Medios públicos de comunicación.

- Cámaras del libro.

- Organismos internacionales: Asociación de Academias de la Lengua Española, IFLA, UNICEF.

Las actividades de colaboración son las siguientes:

- Cursos de capacitación en computación, actividades culturales e informativas.

- Actividades cuentacuentos, hora del cuento.

- Jornadas de capacitación a docentes y bibliotecarios, formación y asesoría en promoción de la lectura con docentes y bibliotecarios.

- Programa de pasantías para bibliotecarios públicos.

- Programas de asistencia a domicilio para lectores impedidos.

- Festivales, tertulias y concursos literarios.

- Ferias del libro en conjunto con editoriales y librerías.

- Lanzamiento de novedades editoriales.

- Actividades con escritores. 
- Seminarios y capacitaciones.

- Formación y mantenimiento de clubes de lectura.

- Lectura en espacios abiertos y con públicos especiales.

Los beneficios mencionados son:

- Recursos económicos para subsidiar gastos de los bibliobuses.

- Convocatorias y patrocinio a eventos.

- Difusión y apoyo logístico en actividades.

- Fortalecimiento de redes sociales locales.

- Colaboración de profesionales.

- Actividades que demandan a las bibliotecas esfuerzos logísticos considerables, como los concursos literarios y los de promoción de la lectura.

- Posicionamiento como centro cultural relevante en la comuna; pero lo que es común entre todos es el aumento en la cobertura de atenciones y el incremento en los préstamos de libros.

- Racionalización en el uso de los recursos disponibles, lo que es satisfactorio.

- Divulgación y reconocimiento a la biblioteca por parte de su comunidad por recurrir a la colaboración de otras organizaciones e instituciones.

- Extensión de las actividades y el logro de una mayor vinculación de los lectores con la biblioteca.

- Apertura de espacios de inclusión y colaboración con diversas iniciativas que, desde otros sectores u organizaciones, se desarrollan o difunden en el país.

Tipos de articulaciones más frecuentes:

- Aporte de libros; intercambio de información y conocimientos; mayor espacio físico para actividades; uso compartido de catálogos y colecciones, materiales de difusión, personal especializado y practicantes para mejorar y ampliar actividades y servicios; organización de ferias y creación de una mayor conciencia sobre la lectura, entre otras actividades. 


\section{La formación de lectores en las actividades bibliotecarias}

En los años transcurridos durante este siglo las bibliotecas públicas de los países de América Latina y el Caribe han progresado en cantidad y calidad, desde luego no al mismo ritmo, dado que éste lo determinan las condiciones de cada país y sus situaciones económicas y políticas locales, que repercuten en los ámbitos de la educación, la cultura y la tecnología, en un contexto cada vez más mundializado que es el que establece metas. Entre las acciones a las que las bibliotecas han empezado a prestar mayor atención están las relacionadas con la formación de lectores a través del fomento, la promoción y animación de la lectura y, en algunas, el desarrollo de las habilidades informativas (también denominadas alfabetización informacional).

\begin{tabular}{|l|c|c|}
\hline \multicolumn{1}{|c|}{ País } & No & Sí \\
\hline Argentina & 3.5 & 91.6 \\
\hline Bolivia & 25 & 75 \\
\hline Chile & - & 100 \\
\hline Colombia & - & 100 \\
\hline Costa Rica & - & 100 \\
\hline Cuba & - & 100 \\
\hline Ecuador & - & 100 \\
\hline El Salvador & - & 100 \\
\hline México & 12.7 & 87.3 \\
\hline Panamá & 10 & 90 \\
\hline Perú & 10 & 90 \\
\hline West Indies & - & 100 \\
\hline
\end{tabular}

Tabla 7

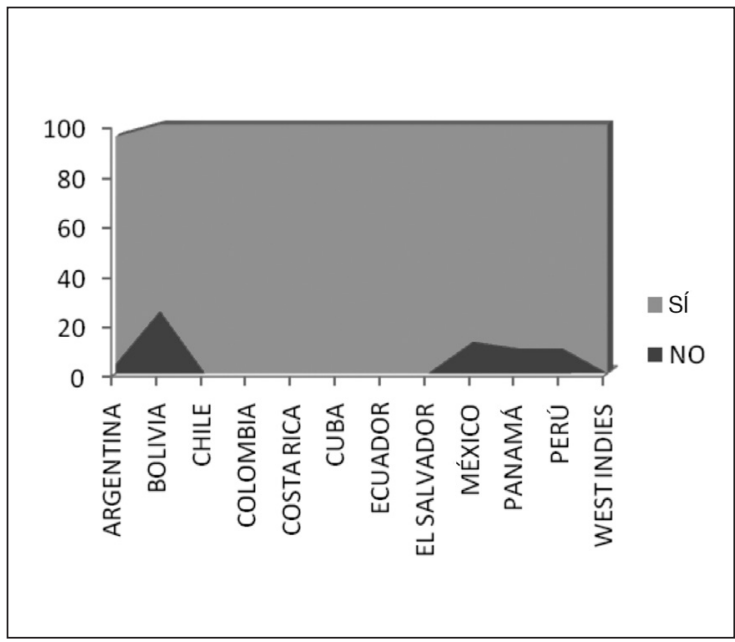

Gráfica 5. Realiza actividades de promoción a la lectura

Además, en algunos países las bibliotecas son apoyadas para extender los servicios bibliotecarios y programas de lectura a diferentes sectores de la población, dado que por varias décadas ha sido el sector infantil al que mayor atención se le ha dispensado 
en cuestiones de promoción de lectura. Ahora los bibliotecarios empiezan a extender programas de lectura y espacios en lugares externos al recinto bibliotecario, donde ofrecen libros y otros materiales con el fin de beneficiar a un mayor número de personas, por lo general jóvenes y adultos quienes no suelen asistir a la biblioteca, y no acceden así a una gama de libros y revistas sin que les implique un costo, y donde tendrían la oportunidad de participar en actividades de lectura; sin embargo no acuden a ella por diferentes motivos, entre ellos, la imagen escolarizada fuertemente arraigada, característica que propicia con frecuencia que un numeroso público se autoexcluya, o considere que su formación ha concluido y ya no requiere o no puede obtener más. En otros casos las distancias dificultan el traslado o lo impiden, y una elevada proporción no considera la lectura como una actividad de entretenimiento. En cuanto a la lectura informativa ésta tiene un arraigo homogéneo en capas extensas de la población; este tipo de lectura se circunscribe a los diarios, la televisión, la radio, y ahora Internet, medios que tienden a ensanchar la oferta informativa, y por lo tanto muchos prescinden de la biblioteca.

Las actividades de lectura en las bibliotecas por lo general se solían considerar programas especiales o de extensión, ya que la lectura todavía no se encuentra debidamente incorporada como uno de los elementos estructurales y naturales de las bibliotecas. Es decir, aparece de manera muy tenue la finalidad de lograr que todos los ciudadanos tengan las mismas oportunidades para ejercer su derecho a leer e informarse, y parecen ignorar que leyendo pueden mejorar y transformar su calidad de vida, no sólo material sino espiritual, y para desarrollar más sus facultades. Esta situación se explica porque durante décadas prevaleció como eje principal el libro, ahora la tendencia es colocar a las colectividades en el centro. En esta nueva perspectiva la lectura también debería estar comprendida entre las tareas cotidianas de los bibliotecarios. Precisamente, esta perspectiva la proponemos como marco de referencia para ubicar las actividades relacionadas con la formación de lectores, entre las que incluimos las actividades relativas a la promoción, animación y fomento de la lectura, el libro y la biblioteca, 
así como a la alfabetización, el fortalecimiento de destrezas y el desarrollo de habilidades informativas, ya sea que se lleven a cabo dentro o fuera del recinto bibliotecario. En los resultados se observa que un porcentaje importante de bibliotecas realiza alguna de estas actividades.

En la EIL/IFLA/LAC se encuentran indicios sobre las actividades de lectura que permiten vislumbrar el alcance de su trascendencia social. A continuación enlistamos los sectores sociales, actividades y espacios externos centrados en los niños, que en su mayoría fueron mencionados por los bibliotecarios encuestados.

Los sectores de la población mencionados a los que van dirigidos los programas de lectura son los siguientes:

- Escolares de todos los niveles incluyendo nivel de párvulos

- Adultos y público en general

- Adultos mayores

- Mujeres

- Niños

- Jóvenes y adolescentes

- Bebés

- Invidentes

Las actividades de lectura mencionadas son las siguientes:

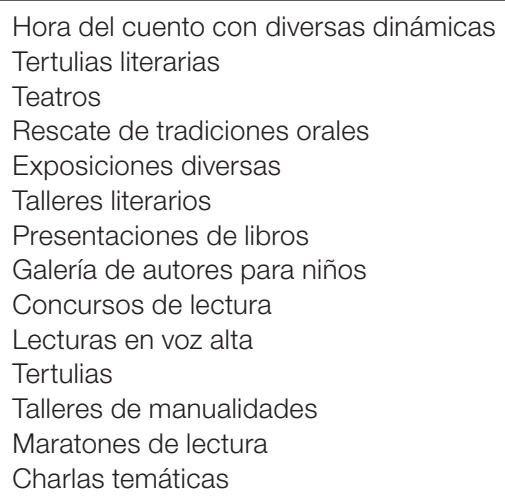

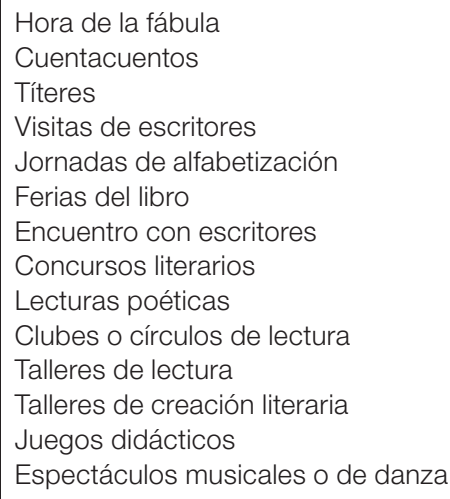


Los abuelos con nosotros Inodoros pensantes

Fomento de ediciones de clásicos nacionales de literatura

Celebraciones de días especiales
Cine clubes

Educación de usuarios

Visitas guiadas

Actividades de lectura en espacios diferentes a las instalaciones de la biblioteca:

\begin{tabular}{|l|c|c|}
\hline \multicolumn{1}{|c|}{ País } & No & Sí \\
\hline Argentina & 3.5 & 83.3 \\
\hline Bolivia & 80 & 20 \\
\hline Chile & 15 & 85 \\
\hline Colombia & 26 & 74 \\
\hline Costa Rica & 33.3 & 66.7 \\
\hline Cuba & - & 100 \\
\hline Ecuador & 25 & 70.8 \\
\hline El Salvador & 65 & 35 \\
\hline México & 49.3 & 41.3 \\
\hline Panamá & 60 & 40 \\
\hline Perú & 30 & 70 \\
\hline
\end{tabular}

Tabla 8

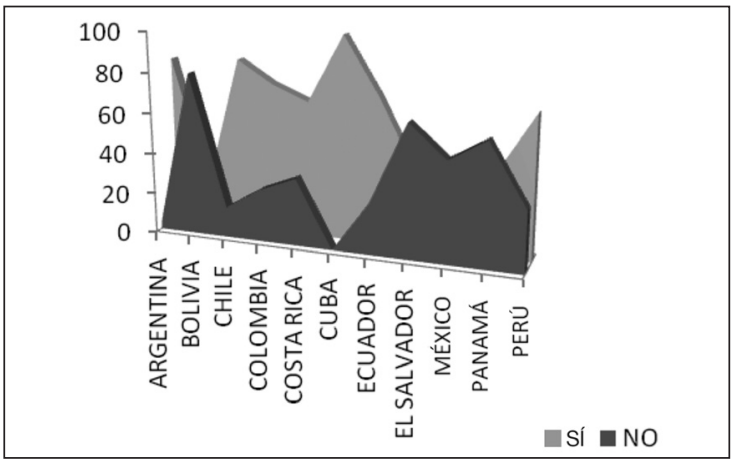

Gráfica 6. La biblioteca ha creado otros espacios o puntos de acceso

Las actividades que se realizan fuera de los recintos de las bibliotecas se exponen en orden de importancia de acuerdo con la frecuencia de las respuestas:

\section{Niños}

2. Escolares de todos los niveles incluyendo nivel de párvulos

3. Jóvenes

4. Adultos y público en general

5. Personas privadas de su libertad

6. Adultos mayores

7. Personas con discapacidad visual

8. Niños hospitalizados

9. Comunidades indígenas

10. Ciegos

11. Investigadores 
Las actividades que se llevan a cabo fuera de la biblioteca son:

Cuentacuentos y lectura poética

Charlas literarias

Cuentacuentos y horas del cuento

Círculos de la lectura

Préstamos de libros

Préstamo de libros y cuentacuentos

Préstamo de libros

Préstamo de libros a sectores rurales

Cajas viajeras

Charlas, conferencias y conversatorios

Encuentro con escritores

Promoción de investigaciones científicas
Promoción de clásicos y contemporáneos de literatura impresa en Braille

Cursos vacacionales, diferentes actividades manuales y académicas: dibujo, piñatería, encuadernación, álgebra y aritmética, floristería, filigrana, etcétera, con apoyo del material bibliográfico existente en la biblioteca Acciones para la lectura en familia Talleres de idiomas

Talleres de Internet y computación

Los espacios donde se realizan son:

- Espacios públicos: parques, plazas, calles

- Colegios y ferias del libro

- Colegios, hogares de menores y jardines infantiles, ferias del libro

- Centros de detención preventiva y reclusorios

- Hospitales infantiles

- Asilos

- Espacios culturales: casas de cultura, teatros

- Hogares infantiles y juveniles

- Reclusorios

- Resguardos

- Establecimientos comerciales

- Bibliotecas

- Internet

- Casas particulares

- Bibliobuses

- Actividades mensuales en diferentes comunidades, bajo un lema cuyo significado se relaciona con celebraciones o efemérides importantes

- Mercados

- Albergues de los damnificados 
- Iglesias

- Clubes

\section{Relación de grupos con actividades:}

\begin{tabular}{|l|l|}
\hline \multicolumn{1}{|c|}{ Grupos } & \multicolumn{1}{c|}{ Lugar y actividades } \\
\hline $\begin{array}{l}\text { Jóvenes, adultos y terce- } \\
\text { ra edad }\end{array}$ & $\begin{array}{l}\text { Escuelas, hospitales, prisiones, asilos, casas de abuelos, nú- } \\
\text { cleos urbanos o rurales carentes de bibliotecas, charlas, confe- } \\
\text { rencias y conversatorios. }\end{array}$ \\
\hline $\begin{array}{l}\text { Jóvenes adultos, } \\
\text { adultos, tercera edad }\end{array}$ & $\begin{array}{l}\text { Prisiones, asilos, casas de abuelos, núcleos urbanos o rurales } \\
\text { carentes de bibliotecas, encuentro con escritores. }\end{array}$ \\
\hline $\begin{array}{l}\text { Ciegos y débiles } \\
\text { visuales }\end{array}$ & $\begin{array}{l}\text { Domicilio. Promoción de clásicos y contemporáneos de literatura } \\
\text { impresa en Braille. }{ }^{20}\end{array}$ \\
\hline Investigadores & Ciberespacio. Promoción de investigaciones científicas. \\
\hline $\begin{array}{l}\text { Niños, jóvenes adultos, } \\
\text { adultos, tercera edad }\end{array}$ & $\begin{array}{l}\text { Área de consejo popular en coordinación con el Centro de In- } \\
\text { formación y Educación Ambiental. Diversos tipos de actividades } \\
\text { de promoción de lectura en función de la educación ambiental. }\end{array}$ \\
\hline Todas las edades & $\begin{array}{l}\text { Comunidades fuera del radio de acción de las bibliotecas. } \\
\text { Los mensajeros del saber. }{ }^{21}\end{array}$ \\
\hline
\end{tabular}

Como ejemplo de la frecuencia de las actividades realizadas en las bibliotecas ubicamos lo siguiente:

\begin{tabular}{|l|l|l|}
\hline \multicolumn{1}{|c|}{ Grupos } & \multicolumn{1}{|c|}{ Frecuencia } & \multicolumn{1}{c|}{ Actividades } \\
\hline Niños & Martes, miércoles & $\begin{array}{l}\text { Hora del cuento, lectura o relato de } \\
\text { cuentos. } \\
\text { Teatro, títeres. }\end{array}$ \\
\hline Niños & Vacaciones de verano & Mis vacaciones en la biblioteca. \\
\hline
\end{tabular}

20 Promoción de clásicos y contemporáneos de literatura impresa en Braille. Actividad personalizada para discapacitados visuales que no tienen la posibilidad de comprar el libro que desean, se les facilita así el disfrute de lecturas de los clásicos y los contemporáneos a través de la ayuda de un lector voluntario facilitado por el Servicio de Extensión Bibliotecaria.

21 Colaboradores de la biblioteca. Alumnos de Sedes Universitarias municipales, entrenados para realizar acciones de promoción de lectura en comunidades con potencialidades lectoras situadas fuera del radio de acción de la institución. 
Encuesta Internacional...

\begin{tabular}{|l|l|l|}
\hline Niños y jóvenes & Periodo vacacional & $\begin{array}{l}\text { Talleres de dibujo, piñatería, encuader- } \\
\text { nación, álgebra y aritmética, floristería } \\
\text { yiligrana, con el material bibliográfico } \\
\text { existente en la biblioteca. }\end{array}$ \\
\hline Grupos de jóvenes & Viernes & $\begin{array}{l}\text { Conversatorios, foros, videos, charlas, } \\
\text { acción social. }\end{array}$ \\
\hline Grupos de mujeres & Días especiales & $\begin{array}{l}\text { Economía del hogar, derechos. } \\
\text { Charlas, conferencias, homenajes. }\end{array}$ \\
\hline $\begin{array}{l}\text { Grupos de niños o } \\
\text { jóvenes }\end{array}$ & Una vez al mes & $\begin{array}{l}\text { Concursos, dibujo, cuento, lectura, es- } \\
\text { critura, versos, poemas. }\end{array}$ \\
\hline Comunidad & Según fechas de aniversario & $\begin{array}{l}\text { Realización de eventos culturales co- } \\
\text { munitarios. }\end{array}$ \\
\hline Mujeres & Una vez al mes & Reuniones comunales. \\
\hline Adultos mayores & Dos veces al mes & $\begin{array}{l}\text { Visitas en los hogares, préstamos de } \\
\text { libros. }\end{array}$ \\
\hline Niños & Según oportunidad & Escuela, jardín, colegio. \\
\hline Padres de familia & Según planificación barrial & Reuniones comunitarias o de barrio. \\
\hline Deportistas & Una vez al mes & Eventos programados. \\
\hline
\end{tabular}

Algunas bibliotecas tienen programas de circulación de libros mediante cajas o bolsas viajeras, bibliobuses, bibliolanchas y bibliomóviles. Las bibliotecas extienden el acceso al libro y promueven la lectura, con ellas se crean espacios que comparten con las escuelas y colegios dada la imposibilidad de crear bibliotecas permanentes a corto plazo en todo el país. Las cajas contienen colecciones de libros que son renovados periódicamente de acuerdo con las edades, gustos, etcétera. El propósito es llegar en especial a los lugares más alejados para apoyar a los niños y jóvenes en proceso escolar que no cuentan con servicios bibliotecarios en sus localidades; a la vez se busca que lean con regularidad y por placer. El maestro a cargo recibe capacitación bibliotecaria en actividades de promoción como la hora de lectura de los niños y jóvenes. También se ofrecen servicios de préstamo a los profesores y alumnos, y todos los materiales pueden ser llevados a los hogares, para ello los libros están adecuados con bolsillos y tarjetas de préstamos, asimismo el profesor-bibliotecario cumple funciones de alfabetizador.

El bibliobús es una biblioteca rodante que incluye actividades de lectura, algunos de ellos cuentan con un área lúdica donde los 
niños pueden recrearse y aprender al mismo tiempo, sin bajar del autobús. Los libros seleccionados son adecuados para la comunidad a la que van a servir: niños, jóvenes, adultos y adultos mayores. El personal a cargo suele estar preparado como promotor de lectura; entre sus actividades identificamos cuentacuentos, círculo de lectura, rincón infantil y otras.

Los servicios como bibliomóviles, bibliolanchas, bibliobuses, mochilas viajeras, etcétera representan una acción que busca facilitar el acceso y el acercamiento a la lectura en zonas geográficas alejadas. Y lo mismo se propone la realización de actividades en plazas, en tanto espacios de intercambio, pues de alguna forma representan la incorporación de las bibliotecas públicas a la creación de sociabilidades en torno a la lectura, actividad que la modernidad fue dejando fuera de los círculos familiares y sociales.

\section{Valoración de actividades de promoción de la lectura por sus lectores y la comunidad}

La valorización de los lectores respecto a las activadades de lectura que ofrece la biblioteca pública han sido efectuadas por algunos bibliotecarios encuestados durante ciertas manifestaciones y expresiones de los diferentes públicos participantes, y de ellas se derivan algunos indicios sobre los efectos y los beneficios de estas actividades. Cabe precisar que la EIL/LAC se propuso conocer las apreciaciones de los encuestados a pesar de que éstas puedan considerarse subjetivas y dado que en la mayoría de los casos no suelen evaluarse los resultados de dichas acciones, lo que dificulta contratarlas y compararlas tanto cuantitativa como cualitativamente. Sin embargo se obtuvo información sobre algunos de los efectos que produjo la intervención bibliotecaria mediante diversas actividades de promoción, fomento, animación y hasta alfabetización; por otra parte, los resultados de dichas acciones pocas veces suelen evaluarse de manera más objetiva. Cabe destacar que estas valoraciones dan cuenta también de las implicaciones que las activadades bibliotecarias tienen para el personal y la propia biblioteca, dado que se crean nuevas necesidades, competencias y expectativas 
que repercuten en demandas e incluso exigencias más elevadas en la medida que los implicados experimentan los beneficios de la lectura y los servicios bibliotecarios.

Entre las respuestas obtenidas encontramos que $89 \%$ de las bibliotecas encuestadas respondieron que las actividades de promoción de la lectura son muy bien valoradas por sus lectores y por la comunidad. El 11 \% restante afirma lo contrario. Además, quienes solicitan las actividades de lectura son quienes participan de manera reiterada en estas actividades. Otras manifestaciones identificadas por los encuestados son:

- El uso de las bibliotecas fomenta la promoción en los lectores que habitualmente no leían.

- La asistencia a las actividades de promoción de lectura es reiterada.

- Las opiniones que emiten los asistentes acerca de las actividades son favorables.

- Las personas que participan en los talleres regresan porque gracias a lo aprendido en ocasiones instalan pequeños negocios que les brindan un beneficio económico, y lo más importante es que siguen haciendo uso del material bibliográfico.

- Hay un incremento de lectores, principalmente jóvenes.

- Hay presencia de padres de familia en la biblioteca.

- Las actividades de la biblioteca crean expectativa en la comunidad.

- Aumenta el interés de los ciudadanos por la lectura.

- Los lectores reclaman cuando la biblioteca está cerrada.

- Los miembros de la comunidad les agradecen a las autoridades de la municipalidad los servicios que les da la biblioteca.

- Es cada vez mayor el número de personas que se ofrecen como voluntarios en la biblioteca, entre otras expresiones.

- Han aumentado la asistencia a la biblioteca y las solicitudes de libros y de préstamos a domicilio. 
- Se aprecia un aumento en la participación de las actividades que se ofrecen en la biblioteca.

- Se solicitan nuevas actividades.

- Mejora el posicionamiento de la biblioteca como centro de cultura comunitaria.

- Hay alegría en la comunidad que asiste a estos lugares para recibir las charlas que les programan, y no sólo los niños disfrutan de estas actividades. Los padres les leen otro tipo de libros a sus hijos como parte de las actividades preparadas por el personal que va en el bibliobús.

- Mejoran las relaciones del bibliobús con las instituciones educativas, lo que ha significado un aumento en los recursos, de por sí escasos, y en la atención a los públicos escolares. La permanencia del bibliobús depende del uso que se haga de los servicios bibliotecarios para justificar su existencia ante las autoridades y la sociedad.

Estas situaciones son consideradas por algunos bibliotecarios como paradojas que se desprenden de su particular relación con la institución escolar, la que no suele contar con infraestructura bibliotecaria propia (bibliotecas escolares); por consiguiente al elevarse la demanda de estudiantes se propicia la desatención de otros públicos, sobre todo, de aquellos que por diferentes condiciones y circunstancias no pueden desplazarse hasta las bibliotecas.

\section{La formación de los bibliotecarios}

En este rubro la EIL/LAC ofrece información de los efectos en las actividades de lectura para el ámbito bibliotecario que se manifiestan en necesidades de entrenamiento y actualización, lo que representa una manera indirecta de autoevaluar sus actitudes y aptitudes y de hacer sugerencias sobre las conductas y habilidades que los ayudan a emprender la tarea de formación de lectores, como se aprecia en la gráfica siguiente. 
Encuesta Internacional...

\begin{tabular}{|l|c|c|}
\hline \multicolumn{1}{|c|}{ País } & No & Sí \\
\hline Argentina & 42.1 & 51.5 \\
\hline Bolivia & 90 & 10 \\
\hline Chile & 40 & 60 \\
\hline Colombia & 46 & 54 \\
\hline Costa Rica & 26.7 & 73.3 \\
\hline Cuba & - & 100 \\
\hline El Salvador & 67 & 32.9 \\
\hline México & 21.4 & 69.2 \\
\hline Panamá & 10 & 90 \\
\hline Perú & - & 100 \\
\hline
\end{tabular}

Tabla 9

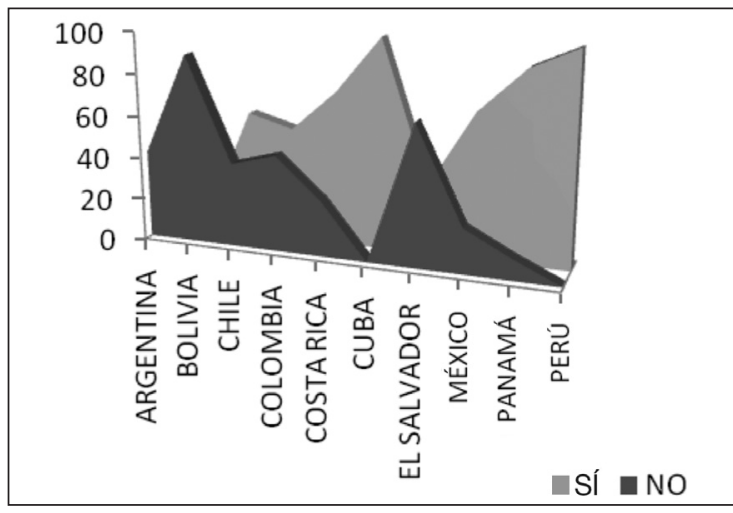

Gráfica 7. Recibe entrenamiento para desarrollar destrezas en las actividades para el fomento a la lectura

\section{Aptitudes y habilidades para promover la lectura entre los lectores y formar nuevos conocimiento aprendizaje}

En las respuestas se propuso lo siguiente:

\begin{tabular}{|l|l|}
\hline \multicolumn{1}{|c|}{ Aptitudes } & \multicolumn{1}{|c|}{ Conocimientos y habilidades } \\
\hline Sensibilidad social & $\begin{array}{l}\text { Conocer la colección e informarse de manera } \\
\text { Vocación }\end{array}$ \\
Entusiasmo & riales y temas de Literatura y cultura. \\
Responsabilidad & Dominar estrategias de animación de la lectura. \\
Destrezas comunicativas & Experimentar técnicas de motivación. \\
Manejo de grupo & Mantenerse informado sobre intereses de \\
Atención a la diversidad & lectura de la población. \\
Ser lector (sólo en dos bibliotecas lo consi- & Actualizarse sobre diferentes estrategias pa- \\
deran como una condición previa para ser & ra acercarse a las personas y familias. \\
promotor de lectura) & Crear ambientes agradables y cómodos en \\
Facilidad para el trabajo en equipo & las áreas de la biblioteca. \\
Habilidad para trabajar en equipo & Mantenerse informado sobre los intereses de \\
Condiciones personales para orientar a los & lectura de la población. \\
usuarios & Innovar sobre actividades de lectura. \\
Vocación de servicio & \\
Creatividad y espíritu innovador & \multicolumn{2}{|l}{ Liderazgo para organizar grupos } \\
Capacidad para motivar la participación co- & \\
lectiva & \\
\hline
\end{tabular}


Sensibilidad para saber el momento adecuado y la manera de introducir actividades de promoción

Habilidad narrativa

Capacidad de convencimiento

\section{Actividades de actualización y formación}

En este rubro se incluyeron todas las propuestas de los encuestados, en varias de ellas encontramos coincidencias:

- Cursos, talleres y diplomados

- Técnicas de animación lectora

- Talleres de narración de cuentos

- Formación de lectores

- Promoción de lecto-escritura

- Técnicas de trabajo grupal y liderazgo

- Diálogo y reflexión sobre las experiencias de fomento a la lectura

- Técnicas de comunicación novedosas, tipos de comunicación, retos de la comunicación, aspectos que la facilitan

- Técnicas dinámicas participativas

- Relaciones intrapersonales

- Técnicas promocionales o marketing

- Técnicas para hablar en público o de expresión oral, de comunicación interpersonal y para perder el miedo escénico

- Métodos de estudios de usuarios

- Literatura del momento

- Cultura general

- Técnicas y métodos de promoción cultural en general

- Psicología social

- Psicología general de la personalidad

Entre las propuestas destacan las necesidades de contar con estudios de posgrado sobre encuentros interbibliotecarios, investigaciones, conferencias de especialistas, así como conocer y actualizarse en las experiencias con otros países, e incluso tener la 
posibilidad de intercambios de experiencias con otros promotores. Algunos se interesan en alguna metodología de la investigación que les permita realizar estudios sobre las tendencias y comportamientos de lectura en la comunidad. Mencionan también la posibilidad de recibir demostraciones de acciones de promoción de la lectura, a fin de estar actualizados sobre este tema.

Uno de los comentarios recibidos sostiene que no todos los buenos bibliotecarios logran desarrollar las habilidades necesarias para hacer las actividades de promoción, entendidas éstas como actividades culturales; es decir, que el entrenamiento debería dársele a aquellos que tengan aptitudes para ello. El entrenamiento debe ir encaminado a desarrollar las habilidades que se necesitan.

\section{BIBLIOGRAFÍA}

González, Jorge A. (coord.), José A. Amozurrutia y Margarita Maass, Cibercultur@e iniciación en la investigación, México, Conaculta/Centro de Investigaciones Multidisciplinarias en Ciencias Sociales/UNAM/Instituto Mexiquense de Cultura, 2007.

Ramírez Leyva, Elsa, "Encuesta Internacional de Lectura para América Latina y el Caribe", en Tercer Seminario Hispano-Mexicano de Investigación en Bibliotecología y Documentación, México, CUIB-UNAM, 2007, pp. 361-380.

—, "La lectura en la región de América Latina y el Caribe", en Bibliotecas y bibliotecología en América Latina y el Caribe: un acercamiento, México, CUIB-UNAM, 2007, pp. 67-80.

Ramírez Leyva, Elsa y M. Ibáñez Marmolejo, "Encuesta Internacional de Lectura para las Bibliotecas Públicas de América Latina y el Caribe (IFLA/LAC/CUIB)", en $E l$ Bibliotecario. Nueva época, México, DGB-Conaculta, 2007, año 7, núm. 71-73, pp. 1-28 (Suplemento: Lecturas de Bibliotecarios). 
Shera, J., Los fundamentos de la educación bibliotecológica, trad. de Surya Peniche de Sánchez McGrégor con colaboración de Francisco González, México, UNAM/ CUIB, 1991.

Train, Briony, "International Reading Survey: presentation of findings", en 68 IFLA Council and General Conference. Libraries for life: democracy, diversity, delivery [en línea], 2002, http://www.ifla.org/IV/ifla68/ papers/177-train.pdf Fecha de consulta: 5 de septiembre de 2009.

—, "Reading: an international focus. The IFLA reading survey", en Reading and reader development: the pleasure of reading, Judith Elkin, Briony Train, Debbie Denham, Londres, Facet Publishing.

Unesco, Los aprendizajes de los estudiantes de América Latina y el Caribe, Santiago de Chile, Unesco, LLECE, 2008.

Unesco, "Panorama regional: América Latina y el Caribe", en Informe de Seguimiento de la EPT en el mundo [en línea], 2008, http://unesdoc.unesco.org/images/ 0014/001489/148957s.pdf Fecha de consulta: 12 de marzo de 2009. 


\title{
Argentina. Participación cultural, formación ciudadana y acceso a la información. Un acercamiento a modalidades de promoción de la lectura en las Bibliotecas Populares
}

\author{
SEBASTIÁN RICARDI ${ }^{1}$ \\ CONABIP, Secretaría de Cultura de la Nación, Argentina
}

\begin{abstract}
7 ste trabajo intenta conocer y sistematizar los elementos que dan cuenta del aporte que las bibliotecas populares (en adelante BP) hacen a los procesos de construcción de la ciudadanía a través de acciones de promoción de la lectura en el marco de la Sociedad de la Información, en Argentina.

Pretende ser un aporte para reflexionar cómo mejorar los sistemas de información y las políticas y planes integrales de lectura, para lograr una mayor comprensión e incidencia sobre los contextos y condiciones en los que se producen las posibilidades de acceso a la lectura. Es parte de un dispositivo de investigación y diagnóstico que realiza la Comisión Nacional Protectora de Bibliotecas Populares (CONABIP) para reforzar su Plan Nacional de Lectura y pretende contribuir al proceso interinstitucional orientado a articular los distintos programas de promoción de la lectura en Argentina y fortalecer así una política nacional e integral.
\end{abstract}

1 Con la colaboración de María del Carmen Bianchi. Equipo de trabajo: Lorena Vega, Valeria Chorny, Joaquín Lacambra e Isabel Fraire. 
LAS BiblioteCAS POPULARES Y LA CONABIP: UNA ALIANZA ESTRATÉGICA PARA LA PROMOCIÓN CULTURAL, DE LA LECTURA Y EL ACCESO A LA INFORMACIÓN

La CONABIP apoya la labor de más de 2000 organizaciones de la sociedad civil que de manera autónoma y desinteresada promueven el acceso al libro y la lectura, el conocimiento de los derechos y la participación cultural de cada una de las comunidades en las que están insertas a lo largo y ancho del territorio argentino. Estas instituciones, articulación entre la experiencia local cotidiana y el proceso nacional y global de producción de la cultura, informan a los ciudadanos, difunden los derechos y el modo de ejercerlos, además de generar otras asociaciones -con organizaciones y personas- para hacer circular, conocer y valorar los bienes culturales.

La Ley 419 del 23 de septiembre de 1870 propuesta por Domingo Faustino Sarmiento dio origen a la CONABIP con el propósito de fomentar la creación y el desarrollo de dichas instituciones. Estos 138 años subrayan su supervivencia y sustentabilidad, pero también multiplican los desafíos de cara a las nuevas manifestaciones de la comunicación, la información y la cultura, que claramente le disputan a la cultura letrada su lugar privilegiado e indiscutido en la transmisión y producción cultural.

\section{Aspectos metodológicos}

Con base en sus objetivos, las BP de Argentina se han definido como una unidad de análisis, actualmente registradas en CONABIP en marzo de 2008. Asimismo, se tomó como unidad de recolección a los dirigentes bibliotecarios y sociales que las integran. La metodología de trabajo utilizada combinó estrategias cualitativas y cuantitativas, que comenzaron por sistematizar la información ya existente acopiada por la CONABIP para aplicarla como instrumento de recolección de datos primarios en la Encuesta de la IFLA. Esta última fue levemente modificada respetando las principales dimensiones -con la intención de que no se pierda el propósito original que es su homologación-, adaptándose a la realidad de 
las BP en Argentina, ya que las primeras encuestas tal como estaban diseñadas no eran comprendidas adecuadamente por los encuestados. En la mayoría de los casos esto se debió al empleo de términos específicos que estaban orientados hacia las bibliotecas públicas. También se incorporó un nuevo ítem para que los miembros de las organizaciones pudieran contarnos libremente sobre los proyectos de promoción de la lectura que han tenido mayor éxito en sus bibliotecas.

La recolección de datos se realizó entre marzo y mayo de 2008. La Encuesta fue enviada electrónicamente a las bibliotecas registradas en la CONABIP, además se entregaron volúmenes impresos de ella durante la Feria Internacional del Libro para reforzar la participación. Su aplicación fue autogestionada, y de la totalidad de las encuestas recibidas se seleccionaron $405^{2}$ de forma aleatoria teniendo en cuenta la proporcionalidad de BP activas por provincia. Los resultados se presentan en el siguiente informe, donde se comparan las variables que mide la encuesta.

\section{Políticas de lectura}

1. ¿Su institución se rige por alguna política de lectura?

Poco más del $70 \%$ de las BP sí se rige por alguna política, plan o programa de promoción en el ámbito estatal o en varios de ellos; mientras que cerca del 29 \% declara no hacerlo. Cabe señalar que del total de bibliotecas que participan en alguna acción pública, un $66 \%$ lo hace a través del Plan Nacional de Lectura diseñado e implementado por la CONABIP.

2. ¿Las actividades de promoción se realizan conforme a algún manual?

Más del 90 \% de las BP que se adhieren al Plan Nacional de Lectura de CONABIP desarrollan sus actividades o proyectos con material teórico y práctico, mientras que menos de una décima parte $(9.6 \%)$ declara no hacerlo. Que casi la totalidad de las BP utilice los saberes teórico prácticos existentes para mejorar

2 Esta muestra representa $32.4 \%$ del total de bibliotecas públicas activas. 
las actividades de promoción puede explicarse en gran medida por la estrategia de gestión de la CONABIP que, a través de su Plan de Lectura, no sólo incentiva la utilización de material de apoyo como una forma de mejorar la autogestión y por lo tanto la autonomía de la BP, sino que lo proporciona mediante la compra y distribución de material bibliográfico afín. En los últimos cuatro años la CONABIP ha adquirido y distribuido a las BP 4828664 libros para el desarrollo de los programas y proyectos, y se han destinado 2011943 libros, en el mismo periodo, para las actividades y proyectos específicos enmarcados en el Plan. ${ }^{3}$

\section{Colaboraciones en actividades de promoción de la lectura}

1. ¿La promoción de la lectura se desarrolla con otras instituciones u organismos?

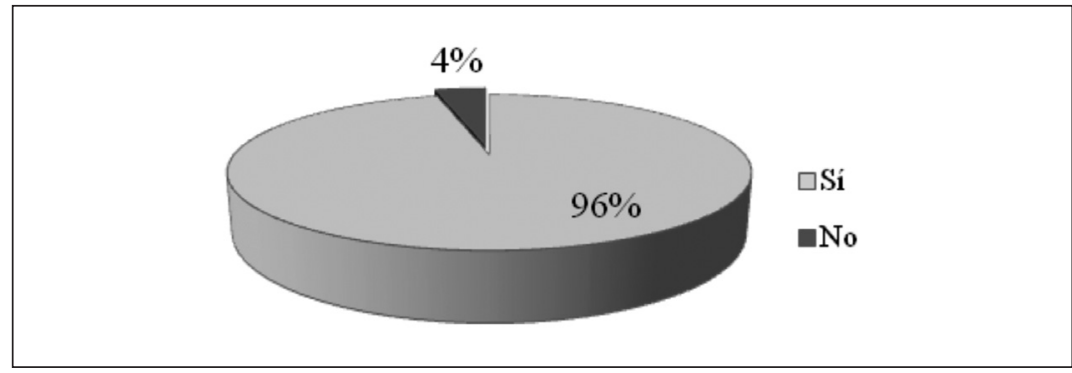

Más allá del tipo de articulación específica que cada BP desarrolla en su ámbito de acción, el cuadro muestra con claridad la importancia capital de establecer lazos y alianzas, que pueden ser estratégicas, para hacer frente a los desafíos implícitos en las actividades de promoción de la lectura.

2. ¿En qué beneficia a la biblioteca la colaboración con instituciones u organismos?

3 Fuente: Unidad del Libro y la Lectura (CONABIP), diciembre de 2007. 
Mejora la calidad de las actividades, amplía el número de usuarios y les proporciona mayor visibilidad y reconocimiento a las BP. Estas tres alternativas consideradas para evaluar los beneficios de la cooperación interinstitucional alcanzaron una alta tasa de respuestas entre los encuestados, superando en todos los casos el $70 \% .{ }^{4}$ En ese sentido la percepción que los encuestados tienen sobre estos beneficios complementa y amplía la información sobre la importancia de llevar a cabo proyectos de promoción basados en procesos articulatorios.

\section{Actividades de promoción de la lectura}

1. ¿Realiza actividades de promoción de la lectura?

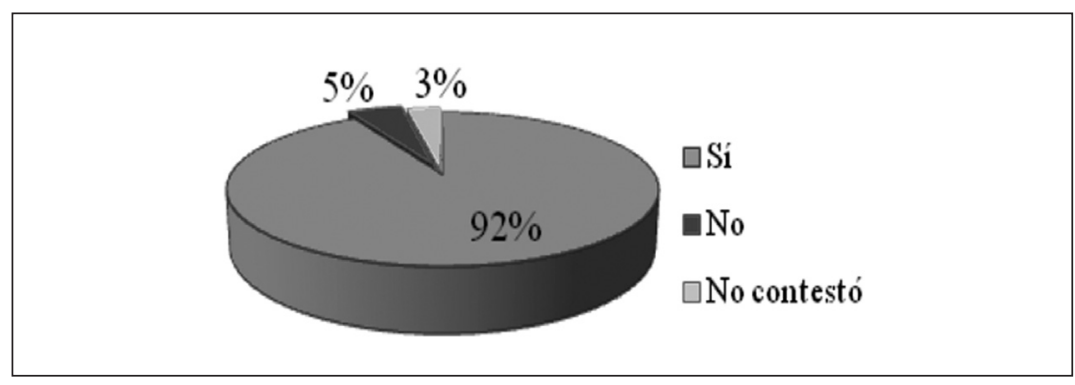

De acuerdo con los objetivos de este trabajo, los tipos de actividades y proyectos que más llevan a cabo las BP son: Talleres de escritura y lectura, Actividades culturales, Encuentros de escritores, Circuitos de lectores, Información ciudadana, difusión en radio $^{5}$ y otras actividades.

4 En el caso del ítem "otros", con un $14.6 \%$ aparecieron múltiples respuestas, dentro de las cuales se mencionan: la integración, el intercambio de experiencias, la mejora de la gestión y el incremento de recursos, entre otras. "Información ciudadana" y "difusión en radio" son las categorías que aparecen con mayor frecuencia en el rubro "otros"; el alto porcentaje de respuestas que representan justifica su inclusión como categorías. 
Las respuestas muestran que entre las actividades y proyectos de promoción de la lectura desarrollados con mayor frecuencia se encuentran las categorías "actividades culturales" y "talleres de escritura y lectura" con 82.2 y $81.4 \%$, respectivamente. Cabe aclarar que por actividades culturales se entienden iniciativas que de forma indirecta contribuyen a la promoción de la lectura. Se trata de obras de teatro y títeres, muestras de arte o exposiciones (pintura, cerámica, fotografía, etcétera), espectáculos musicales o de danza y charlas temáticas, entre otras actividades.

A continuación se ubica la categoría "encuentros con escritores", que alcanza más del $50 \%$ de las respuestas y a la cual le sigue "información ciudadana", con $33.2 \%$, "circuitos de lectores" con 30.5 \% y finalmente "difusión en radio", como última categoría significativa que llega al $15.1 \%$ de las respuestas. ${ }^{6}$

Del mismo modo que con otros ítems, la no exclusividad de las categorías implica que en la mayoría de los casos las respuestas incluyeron más de una alternativa, dándole mayor importancia y diversidad a los proyectos de promoción implementados, lo que fortaleció de ese modo los vínculos con la comunidad. Como datos relevantes en este sentido surge que más del $45 \%$ de las respuestas sostienen haber realizado entre cuatro y cinco de estas actividades simultáneamente, un $44 \%$ entre dos y tres, y casi $11 \%$ sólo realizó una.

2. ¿Dónde realizan las actividades de promoción de la lectura? En las instalaciones y fuera de la biblioteca, se observó la siguiente estadística:

\begin{tabular}{|l|c|}
\hline \multicolumn{1}{|c|}{ Actividad } & Porcentaje \\
\hline Talleres de escritura y lectura & 70.3 y 47.7 \\
Actividades culturales & 65.3 y 52.8
\end{tabular}

6 Dentro del ítem "otros", con un $8.7 \%$, las respuestas que más aparecen son: talleres de manualidades, talleres de idiomas y visitas guiadas, entre otras. 


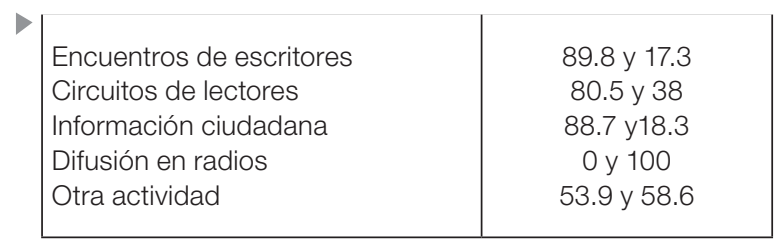

Resulta significativo que las actividades no se realizan sólo dentro de las instalaciones de las BP sino, en la mayoría de los casos, también son desarrolladas fuera de ellas, variando los porcentajes según el tipo de actividad. Ambas modalidades se complementan y son condición necesaria para lograr una mayor articulación e inserción comunitaria.

La frecuencia más habitual en la mayoría de las actividades o proyectos es la opción mensual, con $41.3 \%$ en talleres de escritura y lectura, $52.2 \%$ en actividades culturales (y sus especificidades ya explícitas), $31.6 \%$ en circuitos de lectores y $32.4 \%$ en información ciudadana. En cambio en el ítem "encuentros de escritores" la regularidad en la implementación fue anual, con más del $77 \%$. Finalmente, en "difusión en radio y otros medios" la mayor frecuencia se ubicó en la opción semanal con $45.6 \%$ y $52.6 \%$, respectivamente. Cabe resaltar que las frecuencias mensual y semanal que presentan las actividades y proyectos implementados por las BP dan cuenta de una significativa regularidad que permitiría, a través de la constancia, profundizar la cercanía con las distintas necesidades y requerimientos de la comunidad, de acuerdo con cada contexto específico.

En la categoría "destinatarios" puede señalarse lo siguiente. El ítem "niños y adolescentes" aparece con gran fuerza tanto en las actividades vinculadas a talleres de escritura y lectura como en los circuitos de lectores, con $93.1 \%$ y $78.7 \%$ respectivamente. No obstante, con menos porcentaje, pero no con menor significancia, se ubica en un rango que va desde casi $30 \%$ y hasta $54 \%$ en las demás actividades, excepto en información 
ciudadana en la que sólo llega al $14.1 \%{ }^{7}$ En cuanto al grupo de adultos éste se ubica con un alto porcentaje en la mayoría de las actividades, superando en todos los casos la mitad y alcanzando en una de ellas, "encuentros con escritores", el $86.8 \%$. La excepción a este hecho se produce en los ítem "otros", con 42.1\% y "talleres de escritura y lectura" con el $33.7 \%$.

Aunque el ítem "jubilados y ancianos" no se posiciona en ninguna actividad como el destinatario de mayor frecuencia su importancia no es menor. Excepto en las actividades "talleres de escritura y lectura" y "encuentros con escritores" donde ronda casi el $15 \%$, su importancia relativa se instala entre $21.9 \%$ y $45.1 \%$. Estos datos no sólo dan cuenta de una perspectiva integral que poseen las BP cuando realizan los distintos proyectos en la comunidad, sino que señalan, dentro de esta diversidad, la importancia estratégica que tiene para ellas la promoción de la lectura orientada a grupos de niños y adolescentes.

3. ¿La biblioteca ha creado otros espacios o puntos de acceso a libros y otros materiales?

7 La menor frecuencia de la opción niños y adolescentes que presenta el ítem "información ciudadana" puede explicarse porque la principal característica de esta actividad es la de brindar un servicio de consulta sobre derechos, programas, servicios, guías de trámite, mecanismos de participación ciudadana y reclamo, y los datos de contacto con las instituciones responsables. Este tipo de consultas las realizan en mayor medida los adultos. El $14 \%$ correspondiente a niños y adolescentes se refiere a la realización de actividades de formación y concientización que tienen como destinataria a esta población, a través de charlas dadas por especialistas sobre derechos de niños y niñas, consumo responsable, educación tributaria, medio ambiente, etcétera; obras teatrales con la temática de los derechos, concursos para la realización de trabajos de difusión y concientización de temáticas de interés ciudadano y campañas de difusión de los derechos de niños y niñas desarrolladas en espacios escolares, comedores comunitarios o clubes deportivos frecuentados por niños, niñas y adolescentes. 


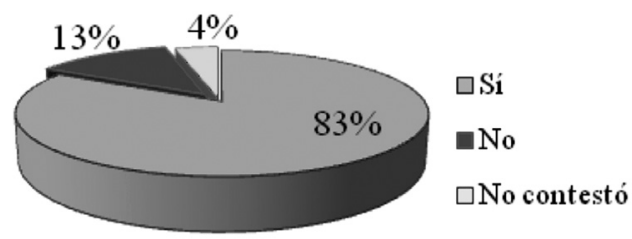

Como ya se mencionó, las actividades y proyectos de promoción de la lectura se llevan a cabo dentro de las instalaciones de las BP; así como en otros ámbitos e instituciones del espacio público estatal y privado. En este sentido se plantearon opciones no excluyentes que engloban la mayor parte de estas iniciativas y actividades en espacios públicos. El mayor porcentaje de las respuestas a esta pregunta se ubica en el ítem "escuelas", con un $74 \%$ en consonancia con la importancia de los niños y adolescentes como destinatarios de la mayor parte de las actividades de promoción. La creación de puntos de acceso al libro y la lectura también se produce en otros espacios públicos. En este sentido al ámbito escolar le siguen los servicios móviles con un $45 \%$ de las respuestas, las plazas con $41.4 \%$, las ferias con $22.7 \%$, hospitales con el $14.9 \%$, los comedores con el $9.7 \%$ y finalmente los clubes con un $6.8 \%$.

De estos datos, que expresan la importancia que tiene para las BP acercar el libro y la lectura desde una diversidad de espacios no tradicionales, resultan significativas tanto las actividades desarrolladas a través de servicios móviles como los efectuados en las plazas. La primera modalidad, que abarca una variedad de servicios como bibliomóviles, bibliolanchas, bibliobuses, mochilas viajeras, etcétera, representa una acción verdaderamente novedosa, tanto que facilita el acceso y el acercamiento a la lectura en zonas geográficamente alejadas. Asimismo, la realización de actividades en plazas representa de alguna forma la incorporación de las BP en la reconstrucción del ámbito público no estatal, tan deteriorado en Argentina. 
Por último, en el ítem "otros", con $14 \%$ de las respuestas, aparecen una variedad de puntos de acceso al libro y la lectura que, si bien no entran en la categorización propuesta, subrayan aún más la diversidad mencionada. Los más recurrentes son hogares infantiles y de ancianos, centros culturales, cárceles, iglesias y comercios.

4. ¿Considera que las actividades de promoción de la lectura son valoradas por sus lectores y la comunidad?

El $93 \%$ de las BP considera que son valoradas positivamente por sus destinatarios y el $1.3 \%$ afirma lo contrario; mientras que el $5.7 \%$ no respondió. Asimismo, el $91.4 \%$ considera que la comunidad en general valora positivamente el desarrollo de las actividades de promoción; $2.6 \%$ que no y el $6 \%$ no contestó.

De lo anterior se desprende la fundamental importancia que tiene para las BP que tanto los destinatarios como la comunidad en general den su aceptación y valoren el desarrollo de las actividades de promoción, con lo cual favorecen su continuidad y sostenimiento.

\section{Habilidades del personal y necesidades de entrenamiento}

1. ¿La biblioteca tiene personal destinado exclusivamente a realizar actividades de promoción de la lectura?

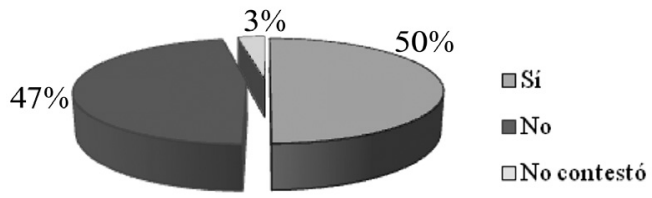

De los dirigentes bibliotecarios y sociales encuestados casi el $50 \%$ afirma que sus BP tienen personal exclusivamente dedicado a realizar actividades de promoción de la lectura, lo que demuestra la gran importancia que tienen en la labor regular y, que trascendiendo el rol más acotado que muchas de ellas 
históricamente han tenido, está vinculado básicamente a la conservación y préstamo de material bibliográfico. ${ }^{8}$ En este sentido cabe señalar que casi la mitad (49 \%) de las BP que cuentan con personal dedicado exclusivamente a la promoción de la lectura cuenta con dos o más personas para tal fin.

2. Actualmente, ¿qué habilidades son necesarias para promover la lectura?

Para sistematizar las respuestas a esta interrogante de carácter abierto se realizó un tipo de análisis de contenido simple a través del cual se determinaron las apariciones más frecuentes de los términos y expresiones utilizados para definir los tipos de habilidades. Con base en ellos, se estableció lo siguiente:

- Habilidades sociales

- Buena llegada al público.

- Sensibilidad social.

- Vocación.

- Entusiasmo.

- Responsabilidad.

- Destrezas comunicativas.

- Manejo de grupo.

- Atención a la diversidad.

- Habilidades para el desarrollo de las tareas

- Conocimiento sobre materiales.

- Capacidad para realizar estrategias.

- Capacidad de planificación.

- Capacidad para generar participación.

- Sensibilidad para la promoción.

- Habilidad narrativa.

Puede agregarse que los términos o expresiones referidos dan cuenta de la necesidad planteada en las encuestas, y que ambos tipos de habilidades son requeridas de manera más o

8 Más aún teniendo en cuenta la diversidad de tareas que suelen llevar a cabo estas organizaciones. Entre otras se encuentran, por ejemplo, la de atención bibliotecaria, gestión institucional, mantenimiento de las instalaciones, etcétera. 
menos complementaria. En este sentido debe destacarse que el significativo número de personal voluntario, que es de 30000 personas en las BP -las cuales desinteresadamente cumplen con su labor de promoción a la lectura-, refleja la necesidad y los beneficios que reportan para estas organizaciones contar con personal que tenga ambos tipos de habilidades.

3. ¿Reciben entrenamiento para desarrollar destrezas?

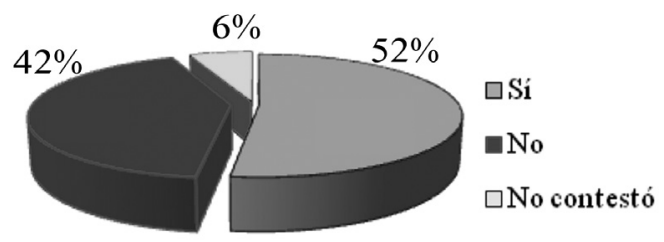

Más del $50 \%$ de las BP encuestadas afirman que el personal que se desempeña en ellas recibe algún tipo de capacitación para realizar actividades y proyectos de promoción a la lectura, mientras que $42.1 \%$ sostiene que no.?

Dentro de las temáticas de capacitación más habituales, los encuestados mencionaron la promoción de la lectura como tal, así como otras temáticas y modalidades vinculadas que, según ya fue señalado, contribuyen a la promoción de la lectura. Entre ellas las más relevantes son: narración oral, bibliotecología, gestión social y participativa, NTIC (Nuevas Tecnologías de la Información y Comunicación) y participación ciudadana.

En cuanto a la capacitación que se imparte, sin ser excluyentes, el $96 \%$ la recibe en forma presencial, en tanto que $20 \%$ se capacita con la modalidad virtual. En relación con la frecuencia, el $88 \%$ de los encuestados manifestó recibir capacitación

9 En este sentido se debe destacar que durante 2006 y 2007, CONABIP ha realizado 39 cursos de capacitación, presenciales y virtuales, en los que han participado 2383 voluntarios y dirigentes sociales pertenecientes a más de 1700 BP (Fuente: Informe de Gestión y Resultados 2003-2007, CONABIP). 
de manera discontinua; esto es, no más de dos cursos anuales sobre la temática específica. El $12 \%$ restante declara participar en capacitaciones con una frecuencia mensual o semanal.

4. ¿Qué tipo de entrenamiento consideran necesario recibir? Las principales temáticas de capacitación que los encuestados declaran como necesarias son NTIC y promoción de la lectura, lo que da cuenta no sólo de las debilidades que en materia de formación tienen las BP, sino de la importancia que les asignan a estas temáticas como formas de afrontar los desafíos que plantean las nuevas redes de información.

\section{CONCLUSIONES}

Fortalezas y debilidades

El objetivo de este trabajo fue conocer y sistematizar aquellos elementos que dan cuenta del aporte que las bibliotecas populares hacen a los procesos de construcción de ciudadanía, a través de acciones de promoción de la lectura en el marco de la denominada Sociedad de la Información y en el contexto social y cultural específico de Argentina. Para ello se mostró información sobre distintas modalidades de promoción de la lectura, participación cultural e información ciudadana, llevadas a cabo por las BP con miras a avanzar hacia diagnósticos más específicos que permitan conocer sus fortalezas y debilidades.

Gran parte de las bibliotecas encuestadas participan en alguna política, plan o programa de promoción de la lectura en el ámbito estatal y casi la totalidad se articula con otras instituciones para desarrollar estas actividades y proyectos. Esta situación refleja lo imprescindible que es para ellas establecer alianzas que favorezcan su sostenimiento y continuidad en el actual contexto.

Específicamente, para la mayoría de las bibliotecas tiene gran relevancia la articulación en el ámbito o contexto local donde la interacción es más horizontal, tal es el caso de las organizaciones sociales, respecto a la relación con una estructura de gobierno más cercana como la municipal que permitiría desarrollar varios 
de los aspectos que necesitan un dispositivo estratégicamente disenado, que impacte en las distintas necesidades y realidades locales.

Se dieron a conocer varios tipos de actividades y proyectos de promoción de la lectura. Esta multiplicidad amplía el vínculo con la comunidad local y contribuye a fortalecer el lazo entre ésta y las BP. También resalta la incorporación de las nuevas tecnologías y soportes audiovisuales como modos de llegar al libro por otras vías, algunos ejemplos: cine debate, concursos de guiones y documentales, espectáculos musicales acompañados de trabajos con cancioneros y biografías de grupos y músicos, entre otras.

En cuanto a esta diversidad un dato a destacar es la relevancia de proyectos vinculados con la información, que propician el mejoramiento de la calidad del ciudadano y otras actividades de promoción de sus derechos, importancia que adquiere su significado en tanto que las modalidades que proponen el acceso igualitario a la información son otras formas y posibilidades de promoción de la lectura.

Igualmente, la frecuencia en las actividades (siendo más habitual la opción mensual) señala constancia y regularidad en su implementación, profundizando la cercanía con la comunidad y articulando e incorporando las principales necesidades y demandas del barrio. En cuanto a los destinatarios, el rasgo de mayor importancia es el protagonismo que adquieren para la mayoría de las actividades los niños y adolescentes, principalmente en las actividades vinculadas a talleres de escritura y lectura y a circuitos de lectores, teniendo en cuenta que en estos grupos se encuentra la población de mayor vulnerabilidad en Argentina.

Una gran mayoría de las BP encuestadas han creado y desarrollado, a través de diversas actividades, puntos de acceso al libro y la lectura en espacios públicos estatales y no estatales. La creación de éstos, como uno de los contextos en los que se desarrollan las oportunidades de acceso a la lectura, es un aspecto central en la labor de las BP. Esta lógica de promoción contribuye al fortalecimiento de los procesos de creación y transmisión del saber como un bien cultural público.

Tanto la escuela, las plazas y el desarrollo de servicios móviles presentaron las frecuencias más altas de este ítem. Esto demuestra 
cierta intencionalidad de la dirigencia de las BP para salir y trascender sus antiguas prácticas limitadas a la conservación y préstamo de libros, con la intención de reconquistar parte del espacio público, sorteando su fragmentación a través de la creación e implementación de distintas modalidades, algunas muy novedosas como bibliomóviles, bibliobicis, lanchas viajeras, etcétera.

Con respecto al eje del diagnóstico, planificación y evaluación de resultados se ha encontrado una gran mayoría de entidades que desarrollan las tres instancias. No obstante, a partir de la experiencia recabada en las actividades que desarrolla CONABIP con su Plan Nacional de Capacitación, se podría arriesgar que detrás de esa respuesta mayoritaria existe en muchos casos una concepción no rigurosamente técnica de lo que implican las etapas del proceso. Podría buscarse un entendimiento más cercano al sentido común. De hecho, en gran medida resultan novedosos los contenidos de los cursos en gestión social, planificación estratégica y formulación de proyectos.

En cuanto a la disponibilidad de personal exclusivo para el desarrollo de actividades de promoción de la lectura, formación cultural y promoción de derechos, se registra que la mitad de los encuestados cuentan con dicha disponibilidad. Esto da cuenta de una presencia destacable de voluntariado en estas organizaciones sociales, que puede asumir estos roles, pero también de la dificultad que muchas veces enfrentan al momento de planificar actividades a mediano y largo plazo con personal transitorio y que puede no contar con capacitación adecuada.

Precisamente en el punto en que se indagó sobre la capacitación que reciben las $\mathrm{BP}$, poco menos de la mitad respondió negativamente. A su vez, las temáticas detectadas como prioritarias fueron promoción de la lectura y Nuevas Tecnologías de la Información y la Comunicación. De alguna manera, aparece aquí plasmada la necesidad de reconfigurar las prácticas por medio de las cuales se atraen lectores, y al mismo tiempo incorporar las $\mathrm{BP}$ a los desafíos de las nuevas redes de información proveyéndo a los usuarios de servicios integrales.

Para finalizar sólo resta reafirmar que las BP desempeñan en la Argentina un rol estratégico y fundamental en las acciones que 
pretenden potenciar y fortalecer la lectura, traducida ésta en prácticas sociales y culturales de las que se apropian las diversas comunidades en su vida cotidiana. De este modo colaboran en el proceso de construcción de ciudadanía; es decir, en la profundización de la democracia mediante la participación popular y el ejercicio ciudadano de los derechos.

En este sentido es indudable la importancia que también tiene para estas organizaciones desarrollar su autonomía y fortalecer sus identidades a través de articulaciones con otras organizaciones de la sociedad civil. Asimismo se reconoce en ellas una vocación de coordinarse con el Estado, pero en espacios de gestión mixtos que respeten las particularidades de cada actor; ya que en la mayoría de los países de esta región es difícil pensar en el desarrollo sin la participación activa del sector público asociado a la gestión no gubernamental. 


\title{
Biblioteca pública y lectura en Bolivia
}

\author{
Doris Samanez Alzamora \\ Red de Estación del Conocimiento, Perú
}

\section{INTRODUCCIÓN}

$\mathrm{E}$

n 1970 mediante decreto supremo 09177 se crea el Banco del Libro, dependiente del Viceministerio de Cultura del Ministerio de Educación, teniendo como misión fomentar el establecimiento y la conducción de las bibliotecas públicas, populares y escolares, y siendo sus usuarios los estudiantes de todos los ciclos: prebásico, primaria y secundaria, además de los trabajadores y amas de casa. Este decreto es resultado del "Primer Congreso Pedagógico Nacional" realizado en la ciudad de La Paz, donde se ratifica la importancia de la biblioteca y se funda el Banco del Libro. Tres décadas después, el 21 de febrero del 2006, con la Ley LOPE No. 3351 y el decreto Supremo Reglamentario del 9 de marzo se crea la Unidad Nacional de Bibliotecas y Repositorio, como fusión del Repositorio Nacional al Banco del Libro, y se constituye la nueva estructura del Viceministerio de Desarrollo de las Culturas. Esta Unidad tiene a su cargo ahora la Red Nacional de Bibliotecas Público-escolares con un total de 350 (entre públicas, escolares y universitarias), de las cuales las principales están en La Paz, Cochabamba y Santa Cruz.

El último censo en Bolivia reportó un total de 361 bibliotecas y unidades de información similares. El desarrollo alcanzado a nivel nacional es notablemente desigual, pues las ciudades antes mencionadas poseen el $71 \%$ del total de unidades de información, mientras que 
las restantes ciudades capitales de los seis departamentos reportan el $29 \%$ de ellos. Se ha establecido que Pando cuenta con apenas cuatro bibliotecas, lo cual muestra una abismal diferencia con La Paz, que tiene 144. El resto tiene las siguientes cifras que son reveladoras: Trinidad, 7; Sucre, 31; Cochabamba, 39; Oruro, 24; Potosí, 16; Santa Cruz, 74, y Tarija, 22. ${ }^{1}$ A la fecha, Bolivia no cuenta con una legislación bibliotecaria ni con un sistema nacional de bibliotecas públicas. La promulgación de legislaciones de aplicación local propicia la falta de políticas y planes estatales de desarrollo bibliotecario. A fin de generar propuestas para la organización del sistema bibliotecario boliviano, en marzo de 2008 el Archivo y Biblioteca Nacionales de Bolivia (ABNB) convocó a una reunión nacional de bibliotecarios para revisar el "Anteproyecto de Ley del Sistema de Bibliotecas y Fomento del Libro y la Lectura", en el cual participaron los directores y bibliotecarios de las bibliotecas municipales, escolares, universitarias, especializadas, centros de documentación y los editores.

Las bibliotecas, por iniciativa propia, se han asociado en redes integradas por instituciones privadas y públicas, tales como la Red Boliviana de Información en Ciencias de la Salud (REBICS), la Red de Información Etnológica Boliviana (REDETBO), la Red de Centros de Documentación de Cochabamba (REDOC), la Red Local de Información Socio-Económica (RELISE) y la Red de Centros Documentales y Bibliotecas Cruceñas (CDBC), entre otras.

\section{UNIDAD NACIONAL DE BIBLIOTECAS Y REPOSITORIO NACIONAL}

La Unidad Nacional de Bibliotecas tiene a su cargo ahora la Red Nacional de Bibliotecas Públicas y Escolares con 215 bibliotecas. La visión que persigue la entidad consolidada es contribuir al desarrollo técnico y científico de las bibliotecas públicas y escolares, que preservan el

1 Luis Oporto, Nota informativa. Existe otro dato en el Directorio Nacional de Bibliotecas del 2003, elaborado por la Academia Nacional de Ciencias de Bolivia, donde se menciona que entre bibliotecas públicas, escolares y universitarias existen 361, para un país con más de 9 millones de habitantes. 
patrimonio intelectual bibliográfico y documental del país. Su objetivo general es promover el desarrollo e implementación de la Red Nacional de Bibliotecas Públicas y escolares mediante las prefecturas y municipios de todo el país, elaborando planes de desarrollo y fortalecimiento, así como preservando y conservando la producción intelectual boliviana, que es el patrimonio documental de la nación. Las tareas operativas que desarrolla la Red se encuentran divididas en:

a) Apertura y Reapertura de Bibliotecas Filiales. Con el objeto de ampliar la cobertura de la Red, la Unidad Nacional de Bibliotecas, de acuerdo con los requerimientos de prefecturas, municipios, parroquias y colegios, programa la apertura de nuevas bibliotecas filiales, la reapertura de otras existentes, y también incrementa sus fondos bibliográficos con materiales nuevos, a través de programas de apoyo y fortalecimiento de la Red de Bibliotecas.

b) Promoción y Animación a la Lectura. Se realiza a través de actividades como la de cuentacuentos; concursos de lectura; elaboración de periódicos murales y de afiches; teatro de títeres y la proyección de videos y películas infantiles, educativas y de entretenimiento; además del establecimiento de los rincones de lectura en las bibliotecas.

c) Capacitación Técnica en Bibliotecología. Con el propósito de mejorar los servicios de atención al público lector en las bibliotecas filiales de la Red, la Unidad Nacional de Bibliotecas ofrece cursos presenciales de capacitación técnica y administrativa al personal de las bibliotecas filiales, previa solicitud de la autoridad competente de la prefectura, municipio, parroquia o colegio al que pertenecen.

d) Semanas del Libro y de la Cultura. Son espacios abiertos dedicados a un país o invitado, en los que se muestra parte de su arte y cultura, a través de la exposición de libros, revistas, fotografías, cuadros, pinturas, artesanía y videos, entre otras actividades. Con esta exposición -que dura una semana- se interactúa con diferentes colectivos sociales, que aprecian la muestra cultural. Una vez concluida, gran 
parte de los libros, revistas y otros materiales expuestos pasan al pabellón internacional de la Unidad Nacional de Bibliotecas y Repositorio para su consulta e investigación.

e) Valijas Bibliográficas en Hospitales y Penitenciarías. Con el fin de incentivar el hábito de la lectura entre los internos de hospitales y cárceles, la Unidad cuenta con el programa de apoyo y asistencia a la población por medio de las "valijas bibliográficas", que se renuevan mensualmente para ofrecer libros y revistas de interés general y de entretenimiento, así como la proyección de videos, con participación de los internos, quienes se encargan del préstamo del material bibliográfico, su circulación y su cuidado.

f) Apoyo al Programa Nacional de Alfabetización. La Unidad Nacional de Bibliotecas, al formar parte del Programa Nacional de Alfabetización, realiza actividades de capacitación, promoción y difusión de la campaña nacional y del proceso de postalfabetización, a través del Sistema de Bibliotecas Públicas y Escolares en provincias del interior del país, pero también les proporciona publicaciones adecuadas a los neolectores y sectores alfabetizados.

g) Préstamo de Material Bibliográfico en Sala. Tiene por objeto brindar el servicio de préstamo de material bibliográfico y hemerográfico en sala, por medio de libros y periódicos existentes en sus diferentes colecciones especializadas.

h) Coordinación Bibliotecaria. Celebra la firma de convenios interinstitucionales de cooperación técnica con organizaciones e instituciones, así como la realización de actividades en el campo bibliotecológico y eventos relacionados con el libro, la lectura y las bibliotecas.

i) Registro del Depósito Legal. Realiza el registro de toda la producción bibliográfica e impresa en nuestro país por medio del registro del Depósito Legal, mismo que es gratuito. Consiste en la entrega de un código que debe ser colocado en un lugar visible dentro de la publicación, debiendo el solicitante entregar cinco ejemplares de ésta al Repositorio Nacional, el que se encargará de distribuir los ejemplares de acuerdo con 
el reglamento, así como de su preservación como parte del acervo bibliográfico nacional.

\section{BIBLIOTECAS PÚBLICAS MUNICIPALES}

En el caso de las bibliotecas públicas de La Paz, Cochabamba y Santa Cruz, se ha creado una red de bibliotecas zonales que cumplen un rol de bibliotecas escolares.

\section{Departamento La Paz}

La primera biblioteca pública de Bolivia fue creada mediante decreto el 30 de junio de 1838 y fue también una especie de biblioteca de depósito, lo que le otorgó un gran prestigio y la gran cantidad de volúmenes con los que cuenta actualmente, cerca de 156000 ejemplares. El 17 de julio de 1944 se inauguró el edificio que hoy ocupa la biblioteca, declarado patrimonio arquitectónico. Además, cuenta con 17 zonales y dos especializadas (en arte e historia), lo que hacen un total de 20 que brindan consultas en sala, servicio de préstamo y actividades de extensión cultural.

\section{Departamento Santa Cruz de la Sierra}

La Biblioteca Central abrió sus puertas en 1983, teniendo como colección base el material bibliográfico de la que fuera la "Biblioteca República Argentina", a la que se añadieron los donativos de particulares e instituciones. La compra de libros se realizó con un fondo especial de la entonces Corporación Regional de Desarrollo, y en noviembre de 1984 se puso en servicio la biblioteca infantil y juvenil, siendo en su momento el único espacio dedicado exclusivamente para este segmento de la población. Con el crecimiento de ésta aumentó paralelamente la demanda de actividades y ofertas de tipo cultural en la ciudad.

En 1980 surgieron también agrupaciones de tipo juvenil que realizaron y generaron un interesante movimiento de acciones socioculturales, 
mismas que provocarían la creación de la denominada Unión de Grupos Culturales. En ese momento la Casa de la Cultura asume el reto de crear bibliotecas en los barrios con la directa participación de las organizaciones de base, en las zonas donde éstas funcionarían (en la actualidad ha llegado a tener 14). En los barrios de mayor población existen más de una.

En 2006, el Consejo Municipal de Santa Cruz de la Sierra firma un convenio institucional con la Fundación Universitaria Simón Patiño con el objeto de impulsar el hábito de la lectura e incentivar la escritura creativa en la niñez, para mejorar su capacidad de comprensión. Además, se comprometió a activar, con recursos propios, mejoras en la salas de lectura de seis de las 14 bibliotecas populares.

\section{Departamento Cochabamba}

Además de la biblioteca pública municipal cuenta con el Centro Pedagógico y Cultural Simón Patiño, cuyas líneas de estudio están vinculadas con los diferentes problemas nacionales, relacionados con la pedagogía, la cultura y la ciencia.

Una prioridad dentro de sus actividades es la relacionada con el libro y la promoción de la lectura. Han organizado una red completa de bibliotecas populares distribuidas por todo el departamento y cuentan con una sección especializada en promoción de la lectura, destinada especialmente a los sectores más pobres. Sus locales son muy originales con la intención de captar el interés de la juventud; por ejemplo, un antiguo avión, un vagón de ferrocarril, etcétera, todos ellos acondicionados para dicha función.

\section{Departamento Potosí}

Existen 15 bibliotecas con las que el Centro de Promoción Minera de Bolivia (CEPROMIN) trabaja desde hace 22 años. Asisten los niños y jóvenes de las poblaciones de Tatasi, Atocha, Ánimas y Siete Suyos. Por la altura en que se encuentran estas poblaciones (3000 $\mathrm{msnm}$ ) reciben escasa atención. 


\section{RESULTADOS DE LA ENCUESTA}

Con la finalidad de cumplir con los objetivos generales de la Encuesta Internacional de Lectura se consideraron exclusivamente las bibliotecas públicas en las que se aplicaron 20 cuestionarios de acuerdo al total de bibliotecas que actualmente suman 63. Del análisis e interpretación de los resultados se desprenden los siguientes datos que conforman las categorías determinadas.

Políticas de lectura

1. ¿Su institución se rige por alguna política de lectura?

Respecto a esta pregunta, del total de las 19 bibliotecas encuestadas, que representan el $95 \%$, respondieron que no se rigen por una política de lectura; es decir, solamente una respondió afirmativamente.

2. ¿Las actividades de promoción se realizan conforme a algún manual?

Igualmente aquí, el 95 \% no utiliza ningún manual, únicamente una biblioteca manifestó tenerlo.

Colaboraciones en actividades de promoción de la lectura

1. ¿La promoción de la lectura la desarrolla con otras instituciones u organismos?

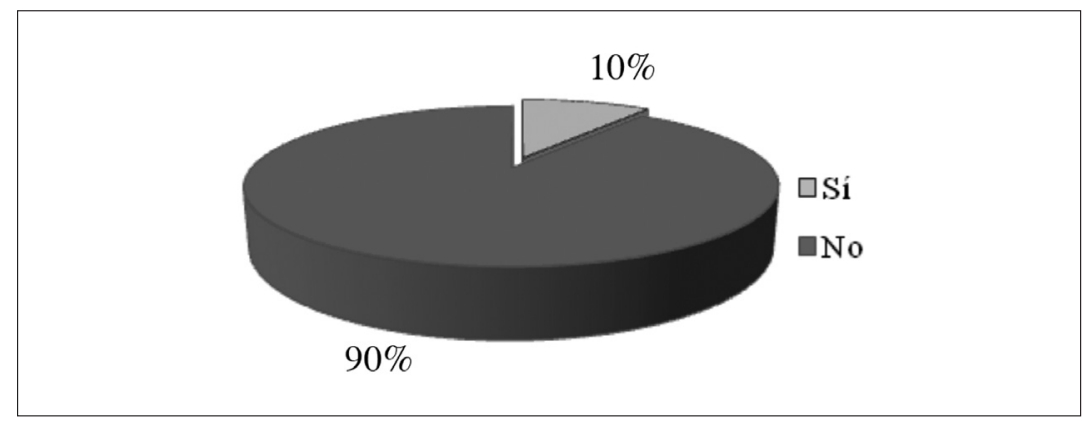


Con base en las respuestas, las bibliotecas públicas reportaron que son dos instituciones u organismos aquellos con los que realizan actividades en colaboración: la Fundación Simón Patiño y el Centro Boliviano Americano.

2. ¿En qué beneficia a la biblioteca la colaboración con instituciones u organismos?

En el sentido de desarrollar novedades con relación a la promoción de la lectura y diseñar talleres que permitan el acercamiento a la comunidad.

\section{Actividades de promoción}

1. ¿Realiza actividades de promoción a la lectura?

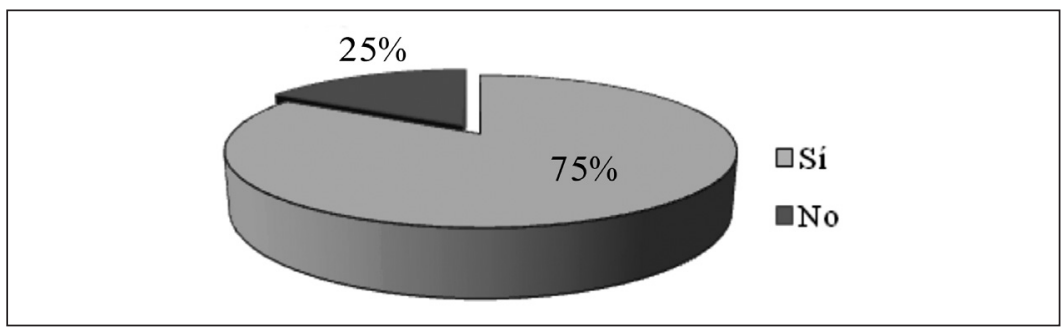

El $25 \%$ negativo que reflejan las respuestas de las bibliotecas públicas se debe a la falta de personal y presupuesto por parte del gobierno, como sucede con la capacitación del personal sobre las técnicas para desarrollar habilidades de lectura en la comunidad. Los programas más exitosos de lectura son los que impulsan los sistemas de bibliotecas municipales en Santa Cruz, La Paz y Cochabamba.

Los clubes del libro que existen en las capitales de los nueve departamentos de la República desempeñan un papel importante y están organizados en comités departamentales y éstos a su vez en la Unión Boliviana del Club del Libro.

2. ¿Dónde realizan las actividades de promoción de la lectura? En las instalaciones de la biblioteca. Todas las actividades se realizan en sus instalaciones una vez al mes, están dirigidas 
a niños y jóvenes y consisten en cuentacuentos y títeres. Solamente seis actividades se realizaron fuera de sus instalaciones, están dirigidas a la comunidad en general. Se llevan a cabo cada dos meses con actividades de lectura dirigida, cuentacuentos y tertulias literarias.

3. ¿La biblioteca ha creado otros espacios o puntos de acceso a libros y demás materiales?

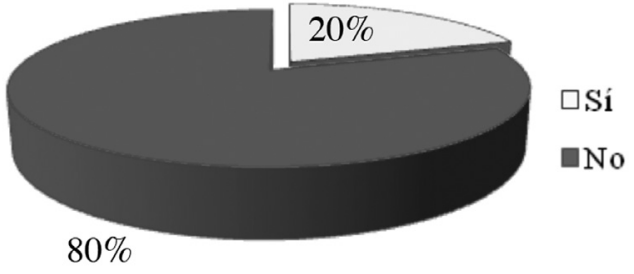

Ver los incisos d), e) y f) en el apartado de la Unidad Nacional de Bibliotecas y Repositorio Nacional.

4. ¿Considera que las actividades de promoción de la lectura son valoradas por sus lectores y la comunidad?

La evaluación se realiza de acuerdo con las solicitudes de talleres, de actividades como cuentacuentos y por sus sugerencias en relación con la adquisición de libros nuevos.

Habilidades del personal y necesidades de entrenamiento

1. ¿La promoción de la lectura forma parte del trabajo del personal de la biblioteca?

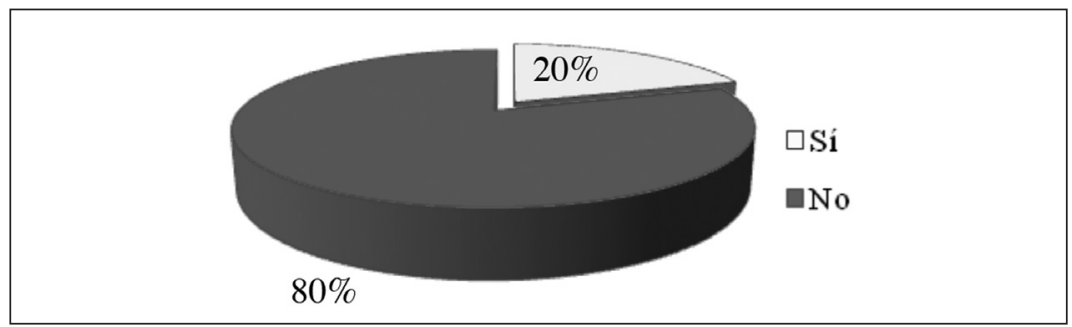


2. ¿La biblioteca tiene personal destinado exclusivamente a realizar actividades de promoción de la lectura?

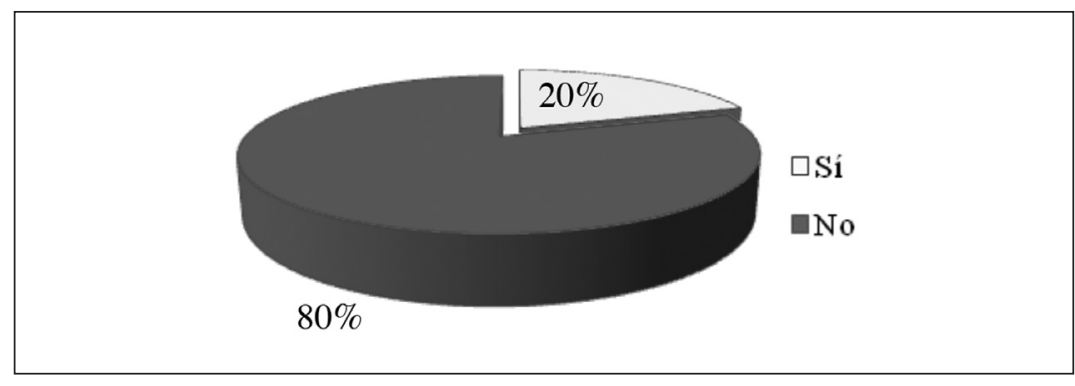

De acuerdo con los resultados sólo el $20 \%$ de las bibliotecas públicas cuenta con la presencia de personal exclusivo para desempeñar actividades de promoción de la lectura, y tal personal tiene las siguientes características:

- Edad: de 25 a 35 años.

- Sexo: 80 \% son mujeres y el resto hombres.

- Profesión: maestros.

3. Actualmente, ¿qué habilidades son necesarias para promover la lectura?

- Es importante ser buen lector.

- Sólo un lector forma a otro lector.

- Comunicación fluida y adecuada para llegar a los demás.

4. ¿Qué habilidades ayudarían a transformar a los no lectores en lectores que encuentren placer en la lectura y en los libros?

La Encuesta resalta la importancia de capacitarse constantemente para poder desarrollar la creatividad con el fin de despertar el interés de los lectores.

5. ¿El personal de la biblioteca tiene la preparación y habilidades para diseñar y desarrollar acciones que transformen a los no lectores en lectores, aficionados a la lectura y al libro? 


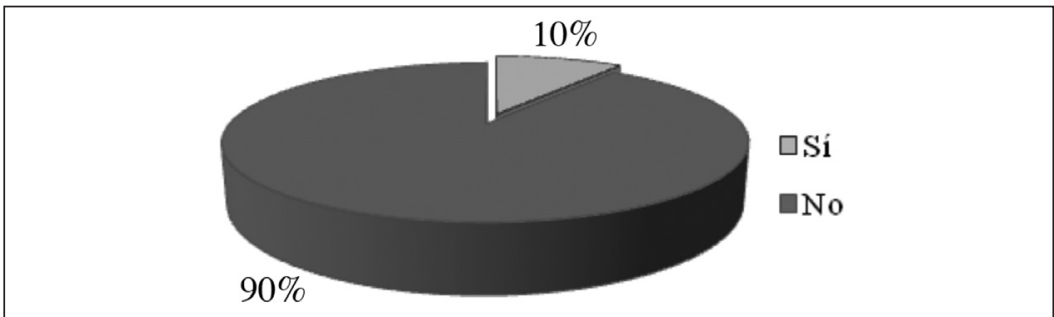

6. ¿Recibe el personal el entrenamiento para desarrollar destrezas?

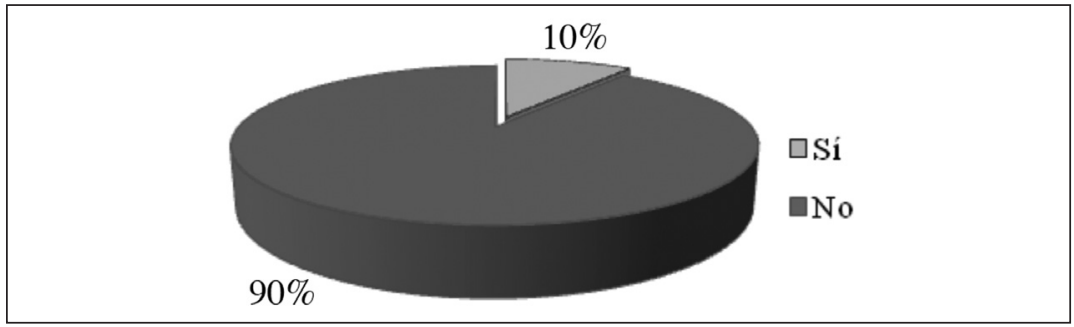

En el caso de las bibliotecas de la Fundación Simón Patiño el tipo de entrenamiento que se imparte es mediante talleres.

7. ¿Qué tipo de entrenamiento consideran importante recibir? Lo que más solicitan es la capacitación sobre técnicas y dinámicas de animación a la lectura.

\section{CONCLUSIONES}

La Encuesta Internacional de Lectura ha sido la primera que se ha aplicado en las bibliotecas públicas de Bolivia y ha arrojado información valiosa y oportuna, en tanto que nos ha revelado el gran potencial cultural y social que representan; a eso hay que apostar en el momento de proponer políticas públicas de lectura que permitan tener recursos, equipamiento, normativas de organización y capacitación de los recursos humanos. 
- Fortalezas

- Las tasas de población alfabetizada han crecido notablemente y el analfabetismo tiende a retroceder sostenidamente.

- La tasa de nivel de instrucción mantiene una expectativa creciente.

- En 1994 el parlamento aprobó las Reformas a la Constitución de 1967 que reconocieron a Bolivia como un país intercultural y plurilingüe.

- Existe una biblioteca pública por cada 11317 habitantes potencialmente lectores.

- El último censo realizado en Bolivia ha reportado un total de 359 bibliotecas y unidades de información similares.

- Si sumamos a éstas las 215 bibliotecas dependientes del Banco del Libro, tendríamos un total de 574 unidades de información bibliotecaria, en el territorio nacional.

- Debilidades

- Falta de una política nacional sobre bibliotecas y de una Red de Bibliotecas Públicas.

- Escaso presupuesto para mejorar los servicios requeridos por las comunidades.

- No dar seguimiento a la capacitación del personal que se encuentra al frente de las bibliotecas.

- Oportunidades

- Las misiones extranjeras en Bolivia sostienen varias bibliotecas de servicio público. Los casos más representativos son el Goethe Institute (Alemania), el Centro Boliviano Brasilero (Brasil), el Centro Boliviano Americano y el Centro de Recursos de Información (Estados Unidos).

- En marzo de 2008 se reunieron todos ellos en la ciudad de Sucre, por convocatoria del Archivo y Biblioteca Nacional de Bolivia (ABNA), para discutir la propuesta de Ley del Sistema Nacional de Bibliotecas. 


\title{
Bibliotecas sin muros. \\ Acercando la lectura a las familias de Chile
}

\author{
GONZALO OYARZÚN ${ }^{1}$ \\ Biblioteca Pública de Santiago de Chile, \\ Dirección de Bibliotecas, Archivos y Museos (Dibam), Chile
}

\section{INTRODUCCIÓN}

L

a Dirección de Bibliotecas, Archivos y Museos (Dibam), fundada en 1929, creó la Subdirección de Bibliotecas Públicas en 1978 con el objeto de desarrollar un Sistema Nacional de Bibliotecas Públicas, mismo que funciona a través de 15 Coordinaciones Regionales instaladas en la ciudad cabecera de la región. La Coordinación de Bibliotecas Públicas es el organismo regional responsable de la existencia y el fortalecimiento de un eficiente Sistema de Bibliotecas Públicas que responde a los lineamientos estratégicos de la Dibam y que promueve el cambio social contribuyendo al desarrollo integral de la región.

La Red está conformada por 415 bibliotecas públicas, de las cuales 362 son municipales de carácter comunal, que funcionan mediante un convenio o contrato con la Dibam y de las que dependen 31 filiales. Seis están ubicadas en la capital de la región: Copiapó, Valparaíso, Santiago, Talca, Puerto Montt y Aysén. Éstas son administradas directamente por la Dibam a excepción de Talca, que tiene un convenio con la municipalidad. De otro tipo son las 16 bibliotecas que se encuentran dentro de recintos penitenciarios y

1 Con la colaboración de Virginia González. 
que funcionan en convenio con la Gendarmería de Chile y últimamente con las nuevas cárceles que han hecho convenios con instituciones privadas, las que actúan como sostenedores.

En los últimos años la Dibam ha impulsado la idea de las bibliotecas sin muros, lo que ha significado el desarrollo de diversas modalidades de acceso a los libros y a la lectura, a través de servicios móviles asociados por distintas vías con las bibliotecas comunales. Estos servicios varían según su conformación y van desde los bibliobuses (45), de los cuales cinco son administrados directamente por la Dibam, hasta otras modalidades de transporte más liviano o servicios móviles especiales, como las bibliomotos, la bibliocarretela, el triciclo amarillo y la bibliolancha, en los que se transportan los libros.

Al mismo tiempo se cuenta con 52 puntos de préstamo, que incluyen servicios tan relevantes como los 11 módulos de bibliometro en Santiago, ubicados en las principales estaciones del metro, así como quioscos en los cerros de Valparaíso, Puchuncaví y Quintay, y en Centros de Salud. Están también los caseros del libro, ubicados en las ferias libres. Estos servicios se complementan con las cajas viajeras, modalidad que ha servido para brindar servicios a las comunidades rurales y de sectores específicos, como los centros para el adulto mayor, los jardines infantiles y algunos colegios de zonas apartadas.

Existen 378 bibliotecas que cuentan con tecnología de punta, tienen acceso gratuito a Internet a través del Programa BiblioRedes, financiado en sus inicios por la Fundación Bill y Melinda Gates y que actualmente cuenta con recursos del Estado para mantener la calidad y permanencia del servicio. Gracias a él se ha capacitado a 320784 personas en el uso de las nuevas tecnologías.

\section{FACILITANDO EL ACCESO A LAS BIBLIOTECAS}

Una de las principales políticas de promoción de la lectura desarrolladas por la Subdirección es el acercamiento de los libros a las personas, que inició abriendo las estanterías de las bibliotecas para 
permitirle al lector ver, tocar y seleccionar su lectura. También se han creado servicios móviles que llegan a los lugares aislados geográficamente o a las zonas urbanas, como el bibliometro, ubicado en las estaciones del metro y que posibilita el acceso al libro en el trayecto al trabajo, el colegio o la casa; el casero del libro se instaló en las ferias libres, que es un lugar de todos, donde el libro se ha hecho tan necesario como la cebolla y la zanahoria. Para muchos usuarios ésta ha sido la primera vez que llevan un libro en préstamo a sus hogares, lo han disfrutado y se han acercado por primera vez a la biblioteca de su comunidad.

Un nuevo proyecto es el maletín literario iniciado este año, y que lleva un conjunto de libros a los hogares de escasos recursos. Las expectativas creadas en las familias han sorprendido hasta a los más optimistas. El 23 de abril se entregaron los primeros libros y las familias beneficiadas se han alegrado de tener en sus casas una buena enciclopedia, libros de poesía, novelas, cuentos infantiles y comics.

El acceso a un catálogo público automatizado es otro de los elementos que acercan los libros a la gente. Mediante el Online Public Automatized Catalog, OPAC por sus siglas en inglés, es posible localizar los títulos y, desde otra perspectiva, la circulación automatizada nos permitirá contar con estadísticas cuya finalidad será mejorar el desarrollo de las colecciones.

\section{PROGRAMAS NACIONALES DE LECTURA}

Durante 2007 se formuló el Diagnóstico Nacional sobre Promoción de la Lectura, que sirvió de base en la formulación de los planes regionales de lectura que impulsa el Consejo Nacional para la Cultura y las Artes. Este primer diagnóstico estableció los puntos críticos que deberán considerarse en cada plan. El trabajo interinstitucional es un requerimiento para lograr objetivos en el fomento de la lectura. Esto abarca dos aspectos fundamentales: la capacitación del personal de bibliotecas públicas y la alianza para llegar a diversos sectores de la comunidad. 


\section{Capacitación}

Con el programa Quijotes de la Lectura organizado por el Consejo Nacional del Libro y la Lectura (2005), se capacitaron 2000 animadores de lectura, entre voluntarios y funcionarios de las bibliotecas. También participaron en esto 200 funcionarios de la Red de Bibliotecas; se incluyó un manual Animación a la lectura como regalo para los participantes.

BiblioCRA (Centro de Recursos para el Aprendizaje) es un programa a distancia que ofrece el Ministerio de Educación y la Universidad Católica de Chile para capacitar a personas que trabajan principalmente en bibliotecas escolares. En los últimos tres años han participado en él alrededor de 120 trabajadores de bibliotecas públicas. Es un curso que integra la modalidad e-learning (aprendizaje virtual a distancia) y presencial. Los especialistas de la propia Coordinación Regional ofrecen además la capacitación y si bien ésta no es sistemática, se brinda en forma de charlas o talleres de corta duración.

Un importante aporte para la capacitación cada año se logra a través de los recursos que se someten al concurso del Fondo Nacional de Fomento del Libro y la Lectura, así como las becas y las pasantías.

\section{Alianzas interinstitucionales}

Nos permiten llegar a sectores que atiende el Estado y a instituciones privadas. Se trata de aquellas instituciones que atienden a los jardines infantiles, los hospitales públicos, los pensionados, entre otros. Recientemente se ha realizado una labor conjunta con el Instituto de Normalización Previsional que trabaja con los adultos mayores: en 16 comunas de nuestro país, las bibliotecas llevaron cajas viajeras a las casas de encuentro con el objeto de contribuir a estimular el lenguaje, la comunicación y la participación de los adultos mayores. La metodología empleada está expuesta en el manual $E l$ viaje de los libros.

A raíz del impulso dado por nuestro país al tema de las nuevas tecnologías y la alfabetización digital en estos últimos años, hemos 
incorporado muchas organizaciones comunitarias a los servicios de las bibliotecas; quienes llegan en principio para tomar cursos de capacitación en computación terminan a veces integrándose posteriormente a las actividades culturales e informativas que les ofrece la biblioteca.

\section{EvAluACIÓN DE LOS RESULTADOS DE LA ENCUESTA}

Los resultados obtenidos nos permiten observar que no hay grandes diferencias en el funcionamiento, puesto que la Dibam se ha preocupado de entregar lineamientos generales a todas las bibliotecas, buscando la equidad y la igualdad de oportunidades para todos los chilenos sin importar el lugar donde se encuentren. De ese modo los resultados apuntan más bien a una diferencia numérica en términos de cobertura y no de calidad, ya que los servicios que ofrecen son similares.

El hecho de formar parte de una red que tiene una planificación estratégica común y compromisos de desempeño establecidos a nivel nacional implica un trabajo bastante normalizado en términos de los resultados esperados. Su línea de base para el trabajo son los lineamientos estratégicos de la Dibam.

Políticas de lectura

1. ¿Su institución se rige por alguna política de lectura?

El $77 \%$, es decir 17 de las bibliotecas consultadas, manifestaron no contar con una política de lectura.

2. ¿Las actividades de promoción las realizan de acuerdo a algún manual?

Si bien el $77 \%$ de las bibliotecas dicen no contar con un manual, reconocen tener elementos comunes gracias a la capacitación recibida y al material de apoyo que utilizan en sus actividades. 
Colaboraciones en actividades de promoción de la lectura

1. ¿La promoción de la lectura la desarrolla con otras instituciones u organismos?

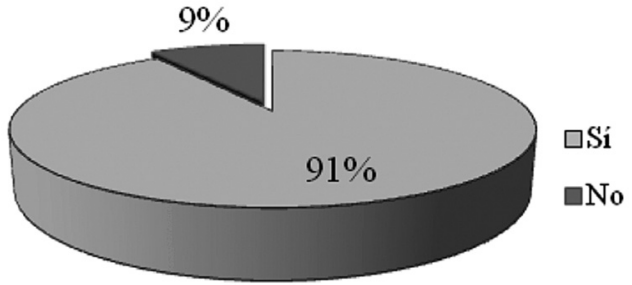

Las instituciones que generalmente nombran las bibliotecas como colaboradores son los municipios, las casas de la cultura, los Departamentos de Educación Municipal, el Instituto de Normalización Previsional y las instituciones educativas y sociales como Integra y Agrupaciones Comunitarias. En el caso de la Biblioteca de Santiago el espectro de estas instituciones y organizaciones es mucho más amplio. Las actividades que realizan son variadas, por ejemplo: cuentacuentos, hora del cuento, jornadas de capacitación, tertulias y concursos literarios, bolsas literarias, ferias del libro (en conjunto con editoriales y librerías), visitas de escritores, baúles literarios, bibliobuses, lanzamientos de libros, seminarios y capacitaciones.

2. ¿En qué beneficia a la biblioteca la colaboración con instituciones u organismos?

Los beneficios son diversos, por un lado están los recursos económicos para subsidiar los gastos de los bibliobuses, las convocatorias y los patrocinios a eventos; y por otra parte, la difusión y el apoyo logístico en actividades; el fortalecimiento de redes sociales locales y la colaboración de profesionales. Obtendremos un mejor posicionamiento como centro cultural relevante en la comunidad, lo que redunda en beneficios en cuanto a la atención y los préstamos de libros. 


\section{Actividades de promoción}

1. ¿Realiza actividades de promoción a la lectura?

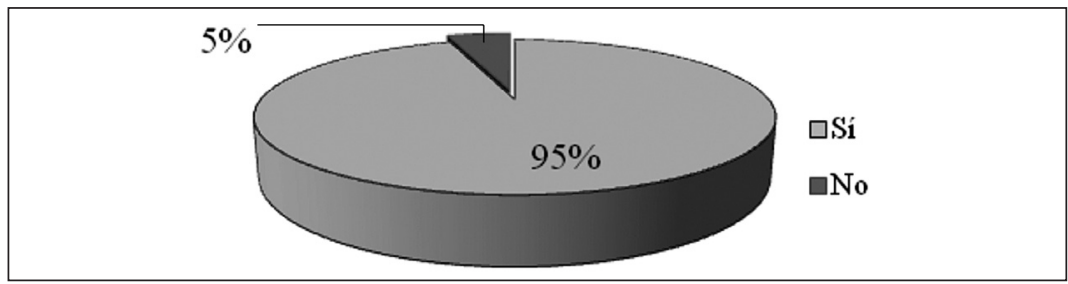

2. ¿Dónde realizan las actividades de promoción a la lectura?

En las instalaciones de la biblioteca y en los grupos de escolares de todos los niveles, incluyendo el jardín de niños, adultos, adultos mayores y público en general.

Sólo la biblioteca de Santiago ha segmentado al público joven y a los bebés, para los cuales tiene algunos programas específicos. Las actividades pueden incluir horas del cuento con diversas dinámicas, talleres literarios, tertulias literarias, jornadas de capacitación, cuentacuentos, ferias del libro, rescate de tradiciones orales, lanzamiento de libros, visitas de escritores, concursos literarios, celebración del Día del Libro, lecturas poéticas y exposiciones diversas.

La mayoría de las bibliotecas que realizan jornadas de capacitación lo hacen una vez al año, ya que dependen de un concurso del Fondo Nacional de Fomento del Libro y la Lectura. Así sucede con las ferias del libro y los concursos literarios. En cuanto a las actividades de cuentacuentos y hora del cuento a los niños, se dan por lo general en forma semanal y en las bibliotecas más pequeñas quincenalmente. Las dirigidas a los adultos mayores y a las madres, como son talleres de cuentacuentos y tertulias, se dan por lo general una vez al mes. La Biblioteca de Santiago tiene una oferta de actividades diaria y semanal, de modo que el público pregunta y espera la cartelera cultural.

Fuera de las instalaciones de la biblioteca, pueden beneficiar a los siguientes grupos: 
- Escolares de todos los niveles incluyendo jardín de niños.

- Adultos y público en general.

- Personas privadas de su libertad.

- Adultos mayores.

- Personas con discapacidad visual.

- Niños hospitalizados.

Con las actividades y en los lugares siguientes:

- Cuentacuentos y lecturas poéticas en parques, plazas y calles.

- Charlas literarias en colegios y ferias del libro.

- Cuentacuentos y horas del cuento en colegios, hogares de menores, jardines infantiles y ferias del libro.

- Préstamos de libros en los centros de detención preventiva de San Miguel, Puente Alto y Santiago Sur.

- Préstamo de libros y cuentacuentos en los hospitales de niños Roberto del Río y San Juan de Dios, y en el CIDEVI.

- Préstamo de libros a sectores rurales mediante la caja viajera y/o el bibliobús.

Las actividades en plazas y parques son ocasionales, por lo general con motivo del Día del Libro u otro evento importante. Se realizan una vez al año. Para los niños se privilegia la visita a la biblioteca, por ello no son más de dos visitas anuales a los colegios. Lo mismo sucede con los adultos mayores, las actividades se realizan en la biblioteca, por ello su frecuencia también es dos veces al año, sin embargo donde funciona un punto de préstamo se visita el lugar semanalmente. También los bibliobuses hacen recorridos semanales por los puntos establecidos.

3. ¿La biblioteca ha creado otros espacios o puntos de acceso a libros y demás materiales?

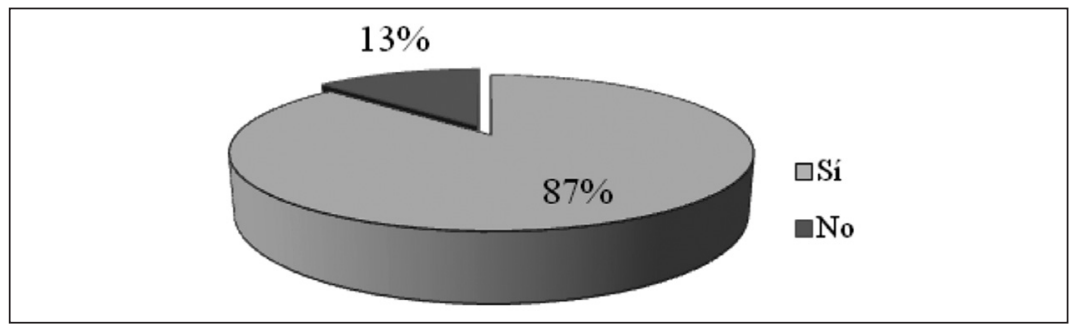


La mayoría de las bibliotecas encuestadas manejan cajas viajeras, algunas las llevan a sectores rurales, a agrupaciones comunitarias o colegios. De las encuestas, dos corresponden a un Dibamóvil: vehículo de la Dibam que recorre diversos sectores de la región a la cual están adscritos. La Biblioteca de Santiago propone dentro de la biblioteca otros puntos de acceso a los libros y a la lectura a través de paneles, circuitos de televisión de plasma e inodoros pensantes.

4. ¿Considera que las actividades de promoción de la lectura son valoradas por sus lectores y la comunidad?

La respuesta fue positiva en todos los casos. La valorización de los lectores se manifiesta en el aumento de la asistencia a la biblioteca, el aumento de las solicitudes de libros y de préstamos a domicilio. En el caso de la comunidad se aprecia que aumenta la participación activa y la solicitud de actividades al igual que el posicionamiento de la biblioteca como centro de cultura para la comunidad y por ende abundan las felicitaciones.

Habilidades del personal y necesidades de entrenamiento

1. ¿La promoción de la lectura forma parte del trabajo del personal de la biblioteca?

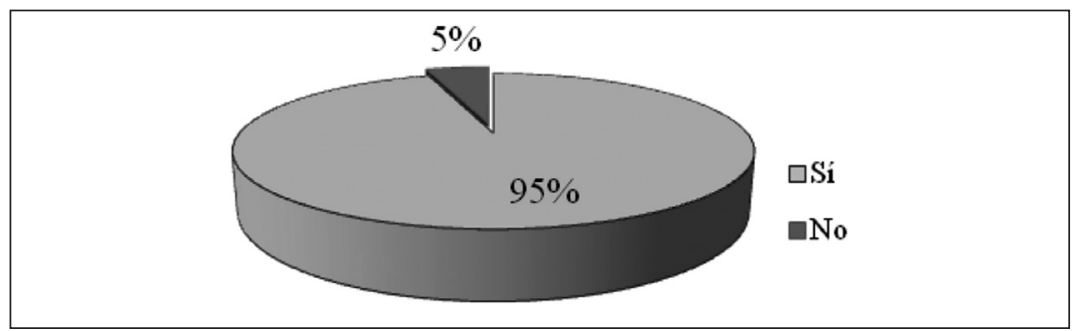

2. ¿La biblioteca tiene personal destinado exclusivamente a realizar actividades de promoción de lectura?

Las bibliotecas que contestaron afirmativamente indican que sólo tienen una persona. 


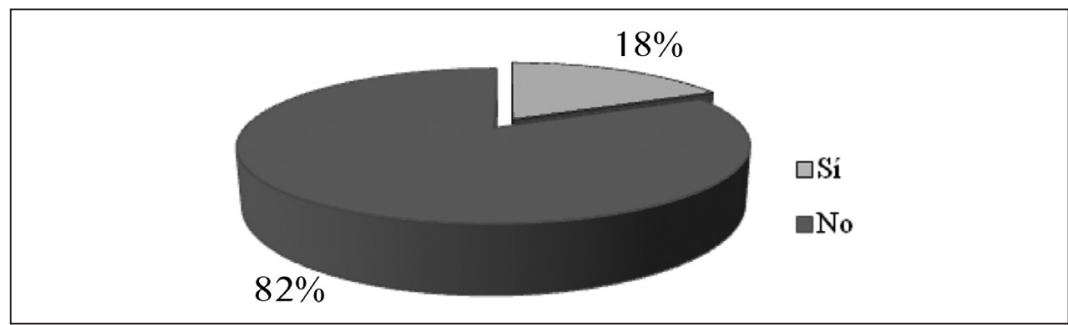

Sin embargo, en los lugares donde trabajan varias personas hay conformación de un equipo, de modo que hay colaboración para las actividades.

3. Actualmente, ¿qué habilidades son necesarias para promover la lectura?

Es importante ser un buen lector, contar con un buen manejo de la colección, tener conocimientos de literatura; ser capaz de conocer e identificar las necesidades de lectura de los usuarios, ofrecer un trato amable, tener el deseo de enseñarles (a los niños). Buen manejo de la comunicación, conocimientos de psicología, mercadotecnia y diseño de estrategias.

4. ¿Qué habilidades ayudarían a transformar a los no lectores en lectores que encuentren placer en la lectura y en los libros?

La mayoría opina que es importante el conocimiento de los libros de la colección y las lecturas adecuadas en la atención al público. También tener conocimiento sobre los gustos y necesidades del no lector para adecuarse a la oferta. Ayuda la lectura constante en los colegios y ofrecer actividades de animación a lecturas lúdicas. También se menciona la participación ciudadana.

Un aporte importante lo proporciona la biblioteca de Santiago que sale en busca de los lectores a través de diversos métodos, algunos muy creativos, para poner la lectura en el camino de las personas. Y también para llegar a la lectura a través de las nueva tecnologías.

5. ¿El personal de la biblioteca tiene la preparación y las habilidades para diseñar y desarrollar acciones que transformen a los no lectores en lectores aficionados a la lectura y el libro? 


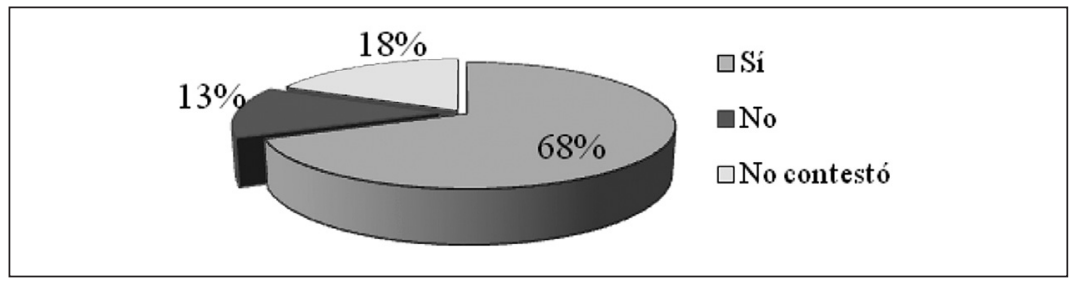

6. ¿Reciben entrenamiento para desarrollar destrezas?

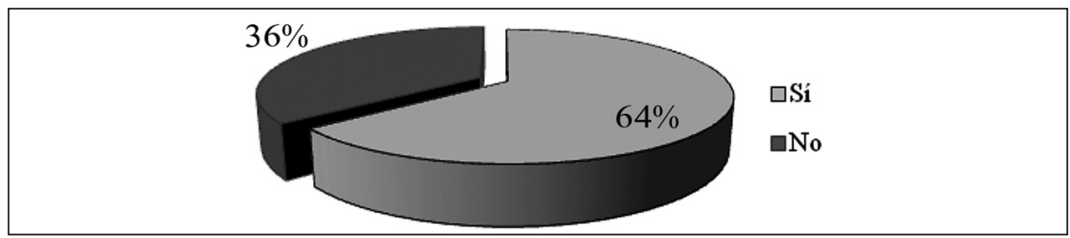

Casi $80 \%$ de la capacitación recibida es anual, si bien no responde a un programa sistemático sino al interés personal, ya que deben buscar la forma de acceder a algún curso. La mayoría participa de cursos que no tienen costo para ellos. Las instituciones que entregan capacitación son la Dibam, el Consejo del Libro a través de proyectos concursables, CRA y organismos internacionales. Los cursos otorgados en general han sido presenciales y en el caso del CRA tienen un componente virtual.

7. ¿Qué tipo de entrenamiento consideran importante recibir? Cursos solicitados: talleres de técnicas de animación lectora, de formación de lectores, de promoción de lecto-escritura, de técnicas de trabajo grupal y liderazgo, y de diálogo y reflexión sobre las experiencias de fomento lector.

\section{CONCLUSIONES}

- Fortalezas

- Metodología de trabajo participativo instalado en las bibliotecas públicas a partir de 1996, que fortaleció el trabajo con las redes locales. 
- Becas y pasantías del Consejo de la Cultura y las Artes que permiten anualmente acceder a instancias de capacitación nacional e internacional.

- Implementación de la Política Nacional del Libro y la Lectura (2006), elaborada por el Consejo Nacional del Libro y la Lectura.

- Formulación del Diagnóstico para la elaboración del Plan Nacional de Fomento Lector, a partir del Consejo Nacional de la Cultura y las Artes (2007), que sirve de base para formular el Plan de la Dibam.

- Política nacional de protección a la infancia.

- Participación en una Red Nacional de Bibliotecas que establece estándares mínimos de funcionamiento.

- Tecnología de punta para acceso a Internet desde la biblioteca.

- Capacitación sistemática en el uso y aplicación de las nuevas tecnologías.

- Fortalecimiento de alianzas interinstitucionales desde el nivel central, a través de convenios.

- Debilidades

- Falta de estructura legal en las municipalidades para implementar y mantener servicios de calidad.

- Falta de recursos presupuestarios en los municipios para mejorar las dotaciones de personal para las bibliotecas en cantidad y calidad.

- Falta de un programa de capacitación sistemática.

- Falta de un estudio de usuarios para detectar necesidades de lectura.

- Insuficiente colección de libros y otros materiales para los niveles prelectores infantiles y juveniles, no escolares, etcétera.

- Oportunidades

- Vincular la biblioteca pública con familias beneficiarias del maletín literario.

- Desarrollar servicios virtuales que favorezcan la promoción lectora. 
- Interesar al Estado en desarrollar un Plan Nacional de Fomento lector.

- Establecer convenios con las municipalidades y mantener los compromisos.

\section{EXPERIENCIAS EXITOSAS}

La Biblioteca de Santiago es para la Red de Bibliotecas Públicas de Chile un modelo de gestión en todos los sentidos, tanto en servicios como en infraestructura y equipamiento. En cuanto a lo que nos convoca el programa de fomento lector, en esta biblioteca se ha desarrollado un modelo muy creativo que busca atraer nuevos lectores y mantener activos a los que ya están interesados.

Podemos destacar los aspectos innovadores siguientes:

- Lugar de encuentro, que acoge e impone mínimas reglas de comportamiento, ello hace que las personas se sientan a gusto porque están como en casa.

- Estímulos al acto de leer salen al paso en cada lugar, no invitando a leer, sino leyendo. Para ello se ha hecho una selección de extractos de obras, que contienen título, breve biografía del autor y del lugar de ubicación del libro en la biblioteca, en hojas que se instalan en lugares estratégicos como los baños públicos.

- Planificación de las actividades con un cronograma, lo que permite difundir las actividades con suficiente anticipación, a través de la cartelera cultural de la Dibam y las páginas web de la biblioteca.

- Trabajo participativo con la comunidad que permite estar permanentemente vinculado con sus necesidades e inquietudes.

- Programa de actividades mensuales que permite una dinámica hacia los distintos grupos de la población.

- La segmentación de los usuarios ha permitido desarrollar servicios adecuados a los grupos objetivos. 


\title{
La promoción de la lectura en la biblioteca pública de Colombia ${ }^{1}$
}

\author{
Didier ÁlVAREz Zapata \\ YiCEL NAYROBIS GiRALDO GiRALDO \\ Escuela Interamericana de Bibliotecología, \\ Universidad de Antioquia, Colombia
}

$\mathrm{E}$

ste texto informa sintéticamente sobre los resultados de la aplicación de la Encuesta Internacional de Lectura (EIL) en Colombia, con la que se intentó hacer una lectura sistemática y articulada de la presencia de la biblioteca en la dimensión social y cultural de la lectura, y del papel que cumplen las iniciativas de promoción de la lectura en esa relación. Para ello se asumió la hipótesis de que la biblioteca pública en Colombia ha venido transitando de un modelo tradicional que la representaba como una institución entronizada en templo de la modernidad, a otro más dinámico que pretende llevarla al ciudadano mediante la promoción social de la lectura, en conjunción

1 Texto derivado de la investigación "Aplicación de la Encuesta Internacional de Lectura en Colombia", realizada en el marco del convenio entre la Universidad de Antioquia y la Universidad Nacional Autónoma de México. Esta investigación desarrollada en América Latina y el Caribe contó, además, con el financiamiento de IFLA-LAC dentro del Programa ALP. Una versión extensa de este trabajo se publicó con el título "Acercamiento al estado actual de la promoción de la lectura en la biblioteca pública en Colombia”, en Revista Interamericana de Bibliotecología, vol. 31, núm. 2, julio-diciembre, 2008, pp. 13-43. Con la colaboración de Gloria María Rodríguez Santamaría (asesora temática) y Maricela Gómez Vargas (auxiliar de investigación). 
con estrategias como los servicios de información a la comunidad y el acceso a tecnologías de la información. En este escenario de transición parece ser que la lectura representa algo muy distinto para la biblioteca pública; es decir, ya no una simple mediadora para obtener información, sino una rica dimensión para el actuar social y cultural.

\section{LA BIBLIOTECA PÚBLICA EN COLOMBIA}

El territorio colombiano está desigualmente habitado y lleno de enormes diferencias entre la vida urbana y la rural. Tal vez su tendencia a ser un país de urbes andinas se corresponda con la propensión insular que ha hecho que, a pesar de tener costas sobre el Océano Pacífico y el mar Caribe, Colombia siga exhibiendo una vocación de montaña y una cierta prevención con las costas y con la inmigración. En este contexto, puede decirse que es un país que se mira a sí mismo y que ha estado marcado por una larga historia de violencia y conflictos políticos que se expresan contemporáneamente en los habitantes desplazados, que ascienden al $10 \%$ de su población total.

En lo concerniente a la distribución y el desarrollo de la biblioteca pública en el territorio colombiano puede decirse que ambas cuestiones han estado determinadas por los mismos factores culturales, políticos y económicos que han hecho que la población, las fuentes de producción y control de riqueza y el poder político se concentren principalmente en las ciudades de la llamada zona Andina. ${ }^{2}$

Por último, la biblioteca pública en Colombia tiene una tipología prácticamente única en el contexto de América Latina, tal cual lo proponen Orlanda Jaramillo y Mónica Montoya: ${ }^{3}$ la biblioteca

2 Colombia está divida en seis zonas cuyas características geográficas y climáticas son similares: Andina, Amazonía, Orinoquía, Pacífica, Caribe e Insular.

3 Orlanda Jaramillo y Mónica Montoya Ríos, "Revisión conceptual de la biblioteca pública”, p. 20. 
pública estatal, que es la que tiene origen y apoyo en el Estado; la biblioteca pública privada, que es creada y mantenida por el sector privado, y la biblioteca popular, que surge por iniciativa civil en los sectores populares.

La promoción de la lectura y las transformaciones de la biblioteca pública en Colombia. Hallazgos e interpretaciones

Esta parte presenta un conjunto de hipótesis referidas a los resultados de la aplicación de la Encuesta Internacional de Lectura en Colombia, específicamente en lo concerniente a las relaciones de la biblioteca con la sociedad y el papel que la promoción de la lectura tiene en ello.

\section{Los propósitos de las iniciativas de la promoción de la lectura}

En este tema sobresale la alusión de las bibliotecas a la promoción de la lectura como una tarea fundamental para cumplir con sus funciones sociales. En efecto, algunas de las respuestas de las bibliotecas públicas encuestadas apuntan al reconocimiento de la promoción de la lectura como elemento central integrado a la planeación estratégica que se ha trazado la institución bibliotecaria, lo que se materializa en su misión y su visión.

En esto se hacen evidentes los desiguales niveles de comprensión de la promoción de la lectura que tienen las bibliotecas públicas. Sin duda, mejorar el comportamiento lector e incrementar los niveles de lectura de la población son objetivos loables que requieren de una base comprensiva social, política y ética amplia, que pueda dar soporte a lo que hace la biblioteca pública en el ámbito de la lectura y no sólo en el espacio incierto de las estadísticas de lectura.

\section{El personal de la biblioteca pública}

Es importante resaltar que la burocracia bibliotecaria pública en Colombia puede estar creciendo en funcionalidad. El hecho de 
que se describan cargos de coordinación (50.2\%) y de administradores, gerentes y directores (47.3\%) muestra una tendencia a la cualificación administrativa de la labor bibliotecaria. Llama también la atención la presencia de voluntarios, asunto que puede estar vinculado a la tradición solidaria de las bibliotecas populares de las zonas urbanas y a la presencia postergada de estudiantes de último grado de bachillerato, que prestan el servicio social del estudiantado y que se quedan luego de terminado su periodo, apoyando las labores de la biblioteca.

Por otra parte, aunque no resulta extraña la presencia de maestros en la biblioteca pública debido a que es claramente conocida la oleada escolarizante que ha matizado la labor de la biblioteca pública en Colombia, sí llama la atención la vinculación laboral a la biblioteca de maestros con el cargo de docentes y no de bibliotecarios (11.2\%). Tal vez ésta sea otra evidencia de esa equivocada representación de la biblioteca pública como suministradora de servicios de consulta para la escuela.

\section{Formación del personal}

Hay un alto porcentaje de personas que trabajan en las bibliotecas públicas cuya formación académica es baja (el 97.4\% de las personas referidas en la Encuesta sólo tienen estudios de secundaria). La realidad muestra que son las bibliotecas públicas de las grandes áreas urbanas las que tiene más personal profesional. Las del sector rural, por su parte, siguen estando a cargo de personas con formación secundaria y, en algunos casos, con apenas educación primaria. Aunado a ello la oferta formativa en el campo de la promoción de la lectura es escasa: en efecto, aunque no puede restársele importancia al lugar que ocupan los eventos académicos en ello, siguen siendo insuficientes en la tarea de ofrecer formación estructurada, sistemática y permanente, pues sólo el $54 \%$ de los talleres y las capacitaciones son espacios claramente intencionados para la formación del personal; las demás son actividades de carácter divulgativo y general en torno a las prácticas de animación a la lectura. 
En lo que respecta a las instituciones que están formando al promotor de la lectura en la biblioteca pública de Colombia, se observa una tendencia endógena; es decir, que la biblioteca está formándose a sí misma en el campo de la promoción de la lectura (casi una cuarta parte de las actividades son ofrecidas por el personal de la misma biblioteca).

\section{Personal dedicado exclusivamente a las actividades de promoción de la lectura}

El $75 \%$ de las bibliotecas encuestadas dice tener personal dedicado exclusivamente a las actividades de promoción de la lectura, pero dada su amplia difusión en las bibliotecas públicas de Colombia, es muy posible que muchos bibliotecarios se dediquen a ellas sin tener un cargo exclusivamente nombrado para esa tarea.

Por otra parte debe decirse que la acción de los promotores jóvenes está marcando nuevos matices en la intervención lectora de la biblioteca pública: el $47 \%$ del personal dedicado exclusivamente a las actividades de promoción de la lectura en las bibliotecas se encuentra en el rango de los 18 a los 27 años. Sin embargo, esto no se hace lo suficientemente visible y público porque tal vez las prácticas de esos jóvenes promotores se incrustan con frecuencia en estructuras bibliotecarias a veces muy formalizadas (tradicionales), o porque ellos no tienen una actitud constituida de narración, de sistematización y de comunicación de sus prácticas para promover la lectura.

No sorprende, tampoco, que haya un alto porcentaje de personal femenino dedicado exclusivamente a las actividades de promoción de la lectura (61 \% mujeres y sólo 26 \% hombres). Es tradicionalmente aceptado que las mujeres sean las que acompañen los procesos de formación de los lectores (en la familia como madres y en la escuela como maestras); sin duda, la biblioteca pública no escapa a este imperativo cultural, lo que, además, está refrendado por la fuerte presencia femenina en la profesión bibliotecológica. 


\section{El acceso alternativo a los materiales de lectura}

En lo que se refiere al acceso a los materiales de lectura es importante considerar el alto porcentaje ( $89 \%$ ) de bibliotecas que dicen ofrecer a los lectores modalidades no tradicionales de acceso a los materiales de lectura: cajas viajeras, bibliobuses, bibliojeeps, bibliochalupas, biblioburros, bibliotaxi, bibliocorreo, etcétera. Esta diversidad creciente en la oferta de colecciones alternativas podría ser explicada como una tentativa para romper los esquemas tradicionales en la prestación de los servicios a los lectores, "estar más allá de las cuatro paredes", o como una forma de separar los servicios tradicionales asociados a la consulta escolar, al tedioso uso de la biblioteca por ejemplo, de los "servicios divertidos"; esto es, dinámicos y alegres, propios de tales modalidades alternativas.

Los procesos administrativos de la promoción de la lectura en la biblioteca pública

\section{La planeación de la promoción de la lectura: políticas y lineamientos institucionales}

Resulta significativo que un porcentaje importante, casi un tercio de las bibliotecas integradas a la muestra (23.64\%), diga orientar sus acciones al campo de la promoción de la lectura debido a alguna política, entendida ésta por las bibliotecas como lineamiento institucional para la promoción de la lectura, de la forma en que lo asume el equipo de investigación. Queda la duda metodológica sobre lo que se considera política y lineamiento institucional en la Encuesta Internacional de Lectura y lo que entendieron las bibliotecas por ello.

Capítulo aparte merecen las ya viejas tentativas para formular una política de bibliotecas públicas y lectura para el país. En ello hay que destacar las iniciativas de la Asociación Colombiana de Lectura y Escritura -ASOLECTURA-, que desde el año 2002 ha impulsado la discusión de políticas de lectura en los municipios colombianos. Vale la pena resaltar los logros obtenidos en cuanto 
a la formulación de la política pública de lectura en las ciudades de Cali (2005) y Bogotá (2006). ${ }^{4}$

\section{La realización de las actividades de promoción de la lectura: actividades, públicos lectores y lugares}

En cuanto a la realización de las actividades de promoción de la lectura en la biblioteca pública, debe considerarse en primer lugar que $31 \%$ de las bibliotecas públicas diga tener un manual para orientar y realizar las actividades de promoción de la lectura. Esto resulta significativo, pues estaría señalando que las actividades de promoción de la lectura se realizan de acuerdo con los lineamientos contenidos en un manual. Sin embargo, no resulta creíble (a la luz de las evidencias empíricas) que ese porcentaje esté mostrando la realidad; puede pasar que la idea de manual, para muchos bibliotecarios, se reduzca a documentos muy básicos en los que se señalan horarios, periodicidad de las actividades y responsables, o un conjunto de planillas de programación de actividades o, quizás, los tradicionales recetarios sobre horas del cuento u otras actividades de animación a la lectura.

En segundo lugar, debe decirse que, de lejos, las actividades de animación a la lectura constituyen la realización central de las iniciativas de promoción de la lectura que despliega la biblioteca pública en Colombia: las horas del cuento con $63.9 \%$, la lectura en voz alta con $44.4 \%$, los clubes de lectura con $33.3 \%$, los juegos didácticos y de lectura con $30.6 \%$, los talleres de lectura con $30.6 \%$, los cineclubes y la proyección de películas con $27.8 \%$.

Parece ser que la promoción de la lectura no logra entenderse más allá de la posible y necesaria puesta en relación de los lectores con los materiales de lectura (que es el propósito de la animación a la lectura). Este enfoque es absolutamente reduccionista de las

4 Decreto 133 del 21 de abril de 2006, por medio del cual se adoptan los lineamientos de la Política Pública de Fomento a la Lectura para el periodo 2006-2016, disponible en: http://www.asolectura.org/archivos/Fomen to_a_la_Lectura_distrito.pdf (Fecha de consulta: 28 de mayo de 2008). 
potencialidades que la promoción de la lectura tiene en la transformación de la biblioteca pública como institución social.

Con respecto a los públicos lectores a los que están dirigidas las actividades de promoción de la lectura es evidente la alta oferta de servicios de lectura dirigida a la población infantil (100 \% de las bibliotecas públicas ofrece actividades de promoción de la lectura a los niños). Seguidamente, aparece la atención de grupos de escolares $(80 \%)$ y por último está la atención de los jóvenes (50 \%).

En esto no queda claro si todos los niños que van a la biblioteca pública lo hacen en su condición de escolares, pero es de sospechar que en el conjunto de actividades de promoción de la lectura que se les ofrece haya algunas a las que pueden asistir en el tiempo en el que no están integrados a la escuela, lo que les resulta, por cierto, cada vez más difícil dada la jornada escolar en Colombia ( 25 horas semanales para primaria y 30 para secundaria). Todo ello, a su vez, puede señalar una actitud temerosa y paternalista del mundo adulto que cree que los niños no saben usar su tiempo libre y que, por lo tanto, se les debe programar, y qué mejor institución que la escuela para cumplir esa tarea de control social.

En cuarto lugar, en lo concerniente a la frecuencia de realización de las actividades de promoción de la lectura, el más alto porcentaje es para las actividades realizadas semanalmente con el $38 \%$, las diarias con $19 \%$, y las mensuales con $16 \%$. Frente a ello podría decirse que la frecuencia determina un elemento esencial para poder cumplir con los propósitos de la promoción de la lectura y realizar actividades, determinadas directamente por la disponibilidad de personal para atenderlas.

En cuanto a las actividades de promoción de la lectura fuera de sus instalaciones bibliotecarias, debe decirse que de las 109 actividades, el 37 \% están dirigidas a los niños y el $25 \%$ a los niños y jóvenes; pero desde la perspectiva de su frecuencia es alta la concentración de actividades dirigidas a los grupos escolares, el $63.9 \%$, lo que corrobora la tendencia a la escolarización de la biblioteca pública que anteriormente se comentaba.

Sin embargo, llama la atención el hecho de que sean foco de atención algunos grupos sociales tradicionalmente olvidados como 
son los reclusos (38.9\%), los adultos mayores (19.4\%), las comunidades indígenas y minorías étnicas (5.6\%), las personas discapacitadas (5.6\%), y las personas hospitalizadas (2.8\%). Dos grupos sociales que, dada la dinámica social y política del conflicto en Colombia, deberían estar siendo atendidos prioritariamente por la biblioteca pública, como son los desplazados y los reinsertados (desmovilizados por grupos armados fuera de la ley), tienen porcentajes prácticamente marginales en las actividades de promoción de la lectura. ${ }^{5}$

Llama la atención que en lo referente a los espacios extrabibliotecarios, el sector rural siga siendo precariamente atendido, pues sólo el $8 \%$ de las actividades se dirigen a este sector; otra prueba más de que la biblioteca pública en Colombia es un fenómeno urbano.

Un último porcentaje muy limitado de actividades de promoción de la lectura ( $1 \%$ ) se realiza en espacios virtuales, esto es, en Internet. No obstante, la biblioteca se mantiene como una institución fuertemente determinada por sus instalaciones y edificios.

\section{La evaluación de las actividades de promoción de la lectura: valoración y evidencias}

En cuanto a la valoración de las actividades, un asunto vinculado al proceso general de evaluación de la promoción de la lectura en la biblioteca pública, la Encuesta Internacional de Lectura sólo indagó por su recepción, centrada en la aceptación que dan las comunidades a la oferta bibliotecaria en este campo. Al respecto, el

5 La única experiencia documentada con reinsertados -pero no bibliotecaria-conocida por el equipo de investigación es la que lleva por nombre una bella y muy diciente frase: "Retomo la Palabra". Esta iniciativa es desarrollada por el CERLALC "[...] en asocio con la Alta Consejería para la Reintegración Social y Económica de Personas y Grupos Alzados en Armas de la Presidencia de la República de Colombia [...]" Boletín Sri. CERLALC, Bogotá, julio-septiembre, 2007, disponible en http://www.cerlalc.org/secciones/ publicaciones/boletin_sri_26/noticia_18.htm (Fecha de consulta: 3 de junio de 2008). 
$89 \%$ responde que las actividades de promoción de la lectura son valoradas por sus lectores y por la comunidad. El $11 \%$ restante respondió que no lo son. Lo que medianamente queda claro en este asunto es que las bibliotecas no realizan una adecuada sistematización de sus iniciativas de promoción de la lectura.

\section{La cooperación bibliotecaria: de las prácticas insulares a las prácticas vinculantes}

A pesar de que en general no hay una actitud evidente por parte de las bibliotecas para integrar verdaderas redes y sistemas bibliotecarios, pues persiste en el país lo que Gloria María Rodríguez llama las "redes de papel", 6 aparentemente sí tienen una mejor disposición a integrarse en el campo de la promoción de la lectura. En efecto, es variado el conjunto de actividades que realizan las bibliotecas junto con otras instituciones en este campo. La mayoría son las estrategias tradicionales de animación a la lectura como horas del cuento (30.6\%), talleres de lectura (27.8\%), tertulias literarias (19.6\%), clubes de lectura (11.2\%), festivales literarios (8.4\%), lectura en espacios públicos (14\%) y lectura con públicos especiales (33.4\%). Estas actividades de animación a la lectura representan el $32.5 \%$ del total. Le siguen las destinadas a la formación y asesoría en promoción de la lectura con docentes y bibliotecarios (11.2\%). Respecto de la cooperación internacional en el campo de la promoción de la lectura no hay mayores datos, salvo el programa de pasantías para bibliotecarios públicos colombianos y extranjeros organizado en años recientes por el Departamento de Cultura y Bibliotecas de Comfenalco Antioquia con el apoyo de la IFLA. ${ }^{7}$

6 Gloria María Rodríguez Santamaría, "La biblioteca pública en Colombia: miradas a una realidad", p. 5.

7 Correo de las Bibliotecas Públicas Iberoamericanas, Boletín informativo núm. 17, disponible en http://www.cerlalc.org/picbip/secciones/eventos_ realizados17.htm\#item02 (Fecha de consulta: 29 de mayo de 2008). 


\section{Las experiencias exitosas de la promoción de la lectura: el tránsito de lo tradicional a la innovación bibliotecaria}

La condición exitosa de una experiencia de promoción de la lectura está esencialmente ligada a la idea de que cumple con los propósitos que se le han trazado. Sin embargo, tal calificación conlleva a grandes confusiones, porque lo exitoso se puede confundir, en primer lugar, con lo visible o con lo publicitado. En efecto: que una experiencia sea conocida y difundida ya expresa parte de su éxito, pues la presencia en lo público exige de la "publicidad" entendida, desde la dimensión política, como la acción de dar a conocer lo que de suyo incumbe a todos, y en segundo lugar con el hecho de que está documentada y registrada, lo que también muestra una actitud aplicada y responsable de quien la ejecuta. En Colombia se pueden resaltar las siguientes experiencias de promoción de la lectura en la biblioteca pública: ${ }^{8}$

- La bibliocarreta de la Biblioteca Municipal de Sabaneta. La iniciativa consiste en llevar materiales de lectura, en un vehículo liviano, a diferentes sectores del municipio de Sabaneta. Entre los objetivos están rescatar el gusto por la lectura, descentralizar los servicios de la biblioteca, ofrecer alternativas para el acceso a los materiales de lectura y mejorar la calidad de vida de los habitantes del municipio. Los beneficiarios son niños, jóvenes, adultos, adultos mayores, personas hospitalizadas, reclusos, amas de casa, obreros, comerciantes y desempleados, entre otros.

- El biblioburro del Municipio de Granada (Magdalena). A lomo de burro, un profesor de español transporta libros, entre enciclopedias, cuentos, diccionarios y libros informativos,

8 Algunas de las experiencias fueron tomadas del Portal de la Red de Bibliotecas Públicas de Colombia-Senderos. Colombia, Ministerio de Cultura, Biblioteca Nacional, Experiencias exitosas, disponible en: http://www.sen deros.gov.co/experiencias/default.aspx (Fecha de consulta: 29 de mayo de 2008). 
para los niños y niñas de los resguardos indígenas Nabusimake y La Caja, ubicados en la Sierra Nevada de Santa Marta.

- La Casa del Pueblo (Guanacas, Inzá, Cauca). Es una iniciativa que refleja el interés de una comunidad por impulsar la construcción de una biblioteca pública en su municipio. Un grupo de estudiantes oriundos de la comunidad, asesorados por la Facultad de Arquitectura de la Pontificia Universidad Javeriana, solicitaron apoyo a la Embajada Japonesa para emprender la construcción de la biblioteca, usando materiales propios de esta zona geográfica del país. Dicha construcción recibió en el año 2004 el Premio Nacional de Arquitectura.

- Minga por las bibliotecas públicas del Valle del Cauca. Retomando una tradición de origen prehispánico, la minga, en 2006 los vecinos de los diferentes municipios del departamento del Valle del Cauca hicieron de la creación de las bibliotecas una verdadera reunión de amigos, sin otro propósito que el de mejorar las condiciones de vida de la comunidad.

- La carreta de leer de la Biblioteca Pública Jesús Antonio Arango Gallo del Municipio del Carmen de Viboral (Antioquia). Programa que tiene por objetivo ofrecer acceso a diversos y variados materiales de lectura a los habitantes del Municipio en espacios públicos como parques, escuelas, calles, cárceles, hospitales y centros comunitarios. Los libros son transportados a diferentes lugares en una carreta de dos ruedas.

- La casa de lectura infantil del Departamento de Cultura y Bibliotecas de Comfenalco Antioquia.? Es un espacio creado en el centro de la ciudad de Medellín para promover la lectura, que fue entregado por la Alcaldía Municipal a la Caja de Compensación Comfenalco Antioquia para que lo administrara.

9 Véase información adicional en http://www.comfenalcoantioquia.com/bi bliotecas/InicioBibliotecas/Ni\%C3\%B1os/CasadelaLecturaInfantilCasaBarrien tos/tabid/4679/Default.aspx (Fecha de consulta: 30 de mayo de 2008). 
Allí se desarrollan diferentes actividades de promoción de la lectura, tales como horas del cuento, matinales, clubes de lectura, leer en familia, talleres y cine-foros, entre otras.

- El Centro de Lectura de la Fundación Ratón de Biblioteca, Medellín. Es una modalidad de servicio bibliotecario público dirigido exclusivamente a la lectura y su promoción. Desde el centro de Lectura, la Fundación Ratón de Biblioteca ha manifestado un interés sostenido en el desarrollo de proyectos de evaluación y de sistematización.

- El cuento viajero de la Biblioteca Pública "José María Velaz Fe" y "Alegría Regional Bello" (Antioquia). Es una iniciativa de promoción de la lectura en la que se distribuyen historias y cuentos cortos, mes a mes, entre los habitantes; inicialmente, los del barrio Niquía del Municipio de Bello. Sin embargo, su acogida ha sido tal que llega a otros lugares no sólo de Bello, sino también de la ciudad de Medellín y su área metropolitana.

- "Préstame tus ojos" de la Biblioteca Pública Municipal "Gabriel Turbay" (Bucaramanga, Santander). Se trata de una iniciativa dirigida a las personas con discapacidad visual y auditiva, la cual nació de un convenio entre el Instituto Nacional para Ciegos, INCI, y el Instituto Distrital de Cultura. Actualmente el programa cuenta con el personal de base y apoyo de los estudiantes que prestan el servicio social, conocidos como alfabetizadores, para atender a los lectores.

- Lectura sin barreras de la Red Distrital de Bibliotecas Públicas (Bogotá). Es un programa que se desarrolla en el centro de reclusión para mujeres de Bogotá, llamada cárcel El Buen Pastor, desde 2003. El programa se plantea como objetivo generar interacciones renovadas entre los lectores y la lectura, permitiéndoles encontrarse con otros al calor de la palabra escrita. 


\section{CONCLUSIONES}

Estudiar las iniciativas de promoción de la lectura que realiza la biblioteca pública en Colombia no sólo implica preguntarse por los efectos que genera en la sociedad, sino también por las transformaciones que este campo de trabajo ha traído a la biblioteca. Al respecto debe decirse que, como expresión de la actividad bibliotecaria, la promoción de la lectura no ha sido, por lo común, una tarea asumida desde perspectivas administrativas integrales sino que sigue siendo una actividad apreciada con entusiamo, pero precariamente planeada y evaluada. Como contraste, aparece la tendencia a estructurar áreas o unidades especializadas dentro de las bibliotecas públicas, principalmente en los grandes sistemas bibliotecarios que tienen el reto de impulsar el campo de la promoción de la lectura como elemento esencial en la vida de la biblioteca pública moderna, con lo cual enfrentan el riesgo de escindir del perfil básico del bibliotecario la labor de promoción para entregársela a una cierta élite conocedora y experta.

En el tema de los materiales de lectura merece especial atención el problema de la literatura infantil y juvenil en los intereses de la promoción de la lectura en Colombia. Éste parece ser el dominio predilecto alrededor del cual han girado las temáticas de formación y actualización de los promotores. De hecho, buena parte de las propuestas formativas en este campo desarrollan grandes componentes sobre autores y títulos de la literatura infantil y juvenil. Esto tiende a dejar, o al menos a generar, una gran distancia entre las actividades posicionadas que algunas bibliotecas en el país realizaban con gran éxito, desde décadas tan lejanas como la de 1960, con públicos adultos (de las que son ejemplo los talleres de escritores y los concursos de cuento y poesía de la Biblioteca Pública Piloto de Medellín para América Latina) y las nuevas actividades de animación a la lectura orientadas preferentemente a los niños.

En el asunto de los públicos lectores llama la atención la persistente asociación de la práctica de promoción de la lectura de la biblioteca pública colombiana, principalmente la de animación, con los niños y los jóvenes. Se dejan de lado con esto a grupos lectores 
que requieren con urgencia que se les promueva y garantice el derecho a la lectura, lo que denotaría plenamente a la biblioteca como institución comprometida con la promoción de la cultura escrita, capaz de diferenciar con claridad sus tareas en un mundo en el que se entrelazan tantas posibilidades que no necesariamente están disponibles para los lectores, ni contribuyen a fortalecer por igual la capacidad simbólica de las personas.

A esto se vincula la tendencia a acompañar la lectura y la escritura con alguna actividad, de tal manera que las prácticas de animación a la lectura siguen estando confusamente relacionadas con áreas como las manualidades, el teatro o la pintura, por ejemplo. Parece ser que no bastará con la lectura. Para hacerla atractiva habría que acompañarla de algo, lo que hace que en muchos casos los asistentes a las actividades de animación, principalmente los niños, vayan a ellas tras la recompensa de la caricatura, el moldeado de plastilina y de la figura de origami.

Otra cuestión importante por considerar es la relación que sostiene la biblioteca con la escuela y sus propuestas de formación de lectores. En efecto, parece mantenerse la lejanía de discursos y pretensiones entre el bibliotecario y el maestro; el primero ve en los niños escolarizados un público que llena las bibliotecas fácilmente y que, tras la atención de las consultas escolares, puede ser inducido al universo de la lectura con las actividades de animación. Por su parte, el maestro no logra separar a la biblioteca de la idea de extensión del aula. Todo este panorama constituye el contenido del grave proceso de escolarización que la biblioteca pública ha sufrido y frente al cual ve peligrar sus ideales con la lectura como dimensión mejor vinculada a la vida ciudadana.

Una consideración renovada de la promoción de la lectura debería abrir una puerta de cuestionamiento a la idea tradicional de la biblioteca como templo en el que se oficia la doctrina de la modernidad (representar, signar y controlar), que propone al bibliotecario como el oficiante de un ritual superior que indica cómo juzgar, cómo decidir, cómo componer, cómo ubicar, cómo ordenar; en la que el lector, por su parte, es señalado como la representación de la ambigüedad, la indecisión, la duda, la ruta errática, la 
carencia, que habría también que normalizar por la vía del canon y la dietética lectora; es decir, la recomendación de lo que se puede y debe leer y lo que no. En este sentido no es descabellado considerar que la promoción de la lectura ha empezado a contribuir al proceso de institucionalización de la biblioteca pública en Colombia, al permitirle relacionarse con los actores sociales en dimensiones que no habían sido concurridas en las tradicionales prácticas públicas bibliotecarias. Dicho proceso se ha dado, no obstante, mediante un lento, poco sistemático, tímido y hasta tardío proceso de reconocimiento, integración y valoración de lo que la biblioteca pública les permite a las personas y a los grupos sociales.

Es evidente que la promoción de la lectura, entendida como un campo de intervención social dinámico y práctico, ha hecho que las bibliotecas públicas en Colombia empiecen a tener una presencia distinta en las comunidades, pues les ayuda a mostrarse como instituciones vivas en las que las personas realizan cosas con los libros y la lectura, y en las cuales pueden construir relaciones con otros; de hecho, los bibliotecarios que promueven la lectura encarnan una figura renovada en comparación con los viejos imaginarios y representaciones del bibliotecario tradicional que atendía a los fieles que asistían al templo del saber. Sin embargo, de la mano de esta dinámica introducida por la promoción de la lectura en la biblioteca pública, todavía marcha el activismo lector como consolidación de un ejercicio mecánico que no reflexiona; es decir, la imagen de una biblioteca que hace mucho con la lectura pero que tiene dificultades para explicarse y explicarle a la sociedad lo que hace en esa compleja dimensión simbólica.

Por último, es prácticamente imposible que la intervención lectora que la biblioteca pública realiza en la sociedad sea realmente una cuestión que ayude a construir un espacio social de la lectura mucho más humanizado y a transformar a la misma biblioteca, si no se emprende esto desde perspectivas de cooperación que la vinculen en redes y sistemas de trabajo bibliotecario y de acción social; vincularla no sólo con otras bibliotecas, sino también con otras instituciones de corte social, educativo, cultural y político. No puede olvidarse que la promoción de la lectura es una práctica de 
intervención social y que, como tal, debe considerar que sus efectos tocan las dimensiones estéticas de los lectores (aspecto que puede ser el asiento de la predilección de las prácticas de animación a la lectura por la literatura), así como las esferas de lo ético y lo político.

\section{BIBLIOGRAFÍA}

Giraldo Giraldo, Yicel Nayrobis y Gloria Elena Román Betancur, Representaciones de los niños y las niñas sobre la biblioteca pública como ambiente educativo para el encuentro ciudadano: un estudio en la comuna uno de la ciudad de Medellín, Medellin, CINDE, 2008, tesis para el título de Magister en Educación y Desarrollo Humano.

Jaramillo, Orlanda y Mónica Montoya Ríos, "Revisión conceptual de la biblioteca pública", en Revista Interamericana de Bibliotecología, Medellín, vol. 23, núm. 1-2, enero-diciembre, 2000, pp. 13-56.

Marín Pérez, Consuelo, "Los programas bibliotecarios para jóvenes en el contexto de la guerra urbana”, en Nuevas Hojas de Lectura, Bogotá, núm. 6, octubre 2004-abril 2005, pp. 35-41.

Martínez, Elsa y Gloria Rodríguez, Social/Cultural/Information and Communication Technology for Development. Public Libraries and other service models. Phase 1 report, documento para Global Libraries, febrero, 2007.

Plan Nacional de Lectura y Bibliotecas, Bogotá, Consejo de Política Económica y Social, 2003.

Rodríguez Santamaría, Gloria María, "La biblioteca pública en Colombia: miradas a una realidad", Congreso Internacional La biblioteca pública: un continente entre los continentes, Medellín, noviembre de 2007. 
Encuesta Internacional...

Soto, Arley, "Apuntes sobre las bibliotecas públicas municipales en Colombia”, en Códice, vol. 3, núm. 1, enerojunio, 2007, pp. 49-59. 


\title{
Promoción de la lectura en las bibliotecas públicas costarricenses: grandes esfuerzos, resultados insuficientes
}

\author{
SARAY CÓRDOBA GONZÁLEZ \\ Universidad de Costa Rica
}

\section{INTRODUCCIÓN}

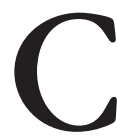

osta Rica tiene una extensión de 50000 kilómetros cuadrados y 4486756 habitantes. Es el segundo país más pequeño de América Central y con un curso histórico diferente al de los demás, con lo cual se ha ganado la imagen de país desarrollado o más desarrollado que los otros. En realidad, las posibilidades de impulsar políticas sociales en diferentes periodos de su historia le han permitido contar con un fuerte aparato en educación y salud, que han hecho de éste un país con índices propios del primer mundo, a pesar de que en muchos campos muestra condiciones deficientes en su desarrollo.

Dentro de este panorama el desarrollo bibliotecario se observa también contradictorio. Desde hace muchos años las bibliotecas públicas cumplen de hecho funciones de bibliotecas escolares, tanto así que en el periodo de vacaciones el $91 \%$ de los usuarios no consideró necesario acercarse a las bibliotecas públicas (Rodríguez y Méndez, 2006). Por otro lado, Costa Rica tiene al día de hoy una biblioteca pública por cada 81577 habitantes, lo cual indica una disminución importante, si tomamos en cuenta que en 1978 
era de una biblioteca por cada 61761 habitantes (Córdoba, 1980). Esta situación muestra parcialmente la problemática de las bibliotecas públicas nacionales pero los detalles de estas condiciones se ampliarán más adelante.

\section{SITUACIÓN ACTUAL}

Existen 55 bibliotecas en todo el país, de ellas, el 64.28 \% se concentra en el área metropolitana, que abarca las capitales de las cuatro provincias del centro del país: San José (12), Alajuela (11), Heredia (5) y Cartago (8). Las 19 restantes se encuentran distribuidas en cinco regiones periféricas del país. Cada capital de las siete provincias tiene la suya, que a su vez se caracteriza por ser la mejor dotada de recursos humanos y materiales.

Por su parte, la capital no cuenta con una biblioteca pública, pues equivocada y tradicionalmente se ha asumido que esa función la cumple la Biblioteca Nacional. Además, existe un bibliobús desde 2004, cuya misión principal es visitar las localidades para fomentar el hábito de la lectura. En su sitio ${ }^{1}$ nos informa que ha visitado 38 comunidades diferentes con 5000 usuarios infantiles beneficiados con este servicio. El bibliobús fue donado por la Unesco y es la segunda vez que se hace este tipo de donación, pues en 1985 este organismo había realizando una acción similar.

Oficialmente las bibliotecas públicas dependen del Ministerio de Cultura y Juventud y son definidas como "centros de información bibliográfica y de extensión cultural, que ponen a disposición de los ciudadanos las obras más representativas del conocimiento universal, desarrollan una labor de fomento al hábito de la lectura y difunden la información de carácter recreativo, informativo y educativo".

En su conjunto son dirigidas por un órgano rector denominado Dirección General de Bibliotecas (DGB), cuya cabeza depende directamente del Ministro correspondiente. El total de bibliotecas

1 Véase en http://www.mcjdcr.go.cr/sistema_bibliotecas/Bibliobus.html 
públicas, junto con la Biblioteca Nacional "Miguel Obregón Lizano", conforman el Sistema Nacional de Bibliotecas (SINABI) creado en el 2000. En su mayoría estas bibliotecas cuentan con edificios propios $^{2}$ y en muchos casos son atendidas por profesionales. En las ciudades más pobladas se cuenta con uno o más asistentes para el profesional que está a cargo. Además, algunas tienen el apoyo de un conserje y un guardia. En consecuencia, la cantidad de recursos humanos que se le destinan varía según el volumen de población que atiendan, y de la persona encargada de dirigir la biblioteca. Por ejemplo, en las zonas periféricas del país existe menos personal calificado atendiéndolas que en el centro.

En el Directorio de Bibliotecas Públicas ${ }^{3}$ aparece la cantidad y tipo de servicios que ofrece cada una de ellas, los cuales van desde el préstamo en sala hasta las búsquedas por Internet. La mayoría utiliza la terminología tradicional para denominar estos servicios, lo cual refleja cómo se mantiene esa visión añeja de la biblioteca en muchas de éstas. Por ejemplo, la Biblioteca de Esparza -según se puede leer en su sitio web- ofrece servicios de referencia, préstamo a sala y domicilio, archivo documental, sala infantil y actividades culturales y de extensión bibliotecaria. ${ }^{4}$

\section{Políticas de lectura}

1. ¿Su institución se rige por alguna política de lectura?

Desde la perspectiva oficial es interesante notar que casi la mitad de los encuestados afirma que no existen políticas respecto al fomento de la lectura. Por otra parte, se aduce que "los directores se reúnen periódicamente durante el año para discutir, determinar políticas y estrategias y darles seguimiento para

2 Pueden verse las fotografías en http://www.mcjdcr.go.cr/sistema_bibliote cas/directorio_bibliot_publicas.html

3 Véase en http://www.mcjdcr.go.cr/sistema_bibliotecas/directorio_bibliot_ publicas.html

4 Véase en http://www.mcjdcr.go.cr/sistema_bibliotecas/biblioteca_esparza. html 
el cumplimiento de las misiones y alcanzar la visión, acordes con el contexto sociocultural costarricense y el presupuesto asignado". En efecto, existe una comisión que periódicamente "planea las actividades para todas las bibliotecas; cada una de las cuales aplica lo que sea viable, de acuerdo con sus recursos, pero también pone en práctica su creatividad". Pareciera que más bien la diferencia de criterio estriba en reconocer qué es una política, y no en determinar si ésta existe o no.

2. ¿Las actividades de promoción se realizan conforme a algún manual?

Solamente el $27 \%$ de las bibliotecas afirma que cuenta con un manual que las oriente en el trabajo, el resto dice que ha obtenido ideas a partir de los talleres que ha recibido o las ha extraído de libros o textos relacionados con el tema.

Colaboraciones en actividades de promoción de la lectura

1. ¿La promoción de la lectura la desarrolla con otras instituciones u organismos?

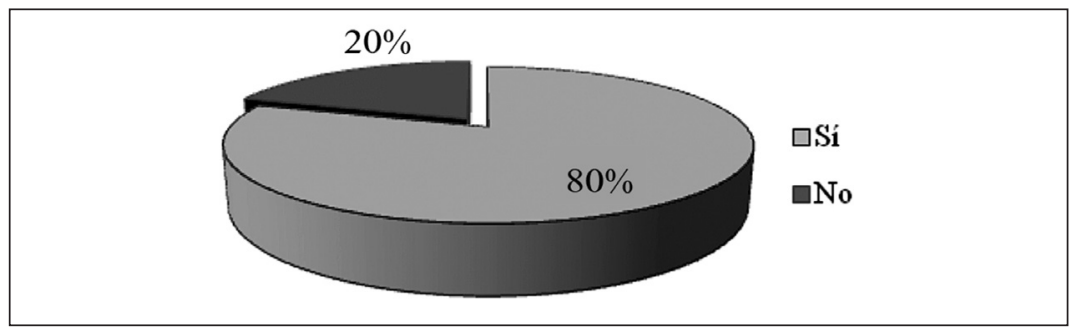

Entre las instituciones y organizaciones mencionadas se encuentran asociaciones culturales, centros educativos de las provincias, escuelas y colegios de la comunidad, un comité de deportes, el centro para la atención integral de personas adultas con discapacidad, el Ministerio de Salud, empresas privadas y los gobiernos locales.

2. ¿En qué beneficia a la biblioteca la colaboración con instituciones u organismos? 
Esto muestra la racionalización en el uso de los recursos disponibles, lo cual es satisfactorio tomando en cuenta que en los países en vías de desarrollo, como Costa Rica, los recursos son limitados. Sin embargo, también es una circunstancia producto del impulso del Estado, el cual tiende a trasladar cada vez más su responsabilidad hacia otras entidades. Los encuestados aducen razones principalmente de divulgación y reconocimiento de la biblioteca por parte de su comunidad para recurrir a la colaboración de otras organizaciones e instituciones.

\section{Actividades de promoción de la lectura}

1. ¿Realiza actividades de promoción a la lectura?

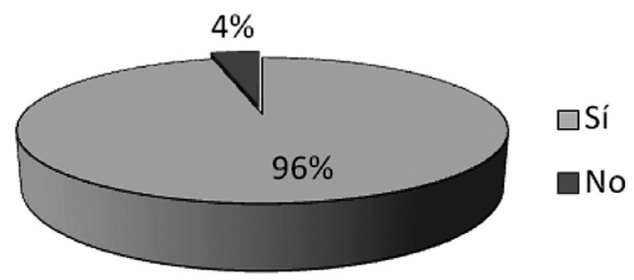

Las bibliotecas públicas costarricenses realizan diversas actividades de promoción de la lectura a partir del impulso que brinda su órgano rector, la Coordinación del SINABI. Éste se encarga de lanzar las directrices para estimular a los y las encargadas de las bibliotecas públicas a realizar esfuerzos en apoyo al fomento de la lectura.

La mayoría de las bibliotecas aluden a las actividades de fomento de la lectura como acciones extraordinarias que llevan a cabo cada cierto tiempo, sin considerarlas parte de su rutina. Dentro de los servicios enlistados por las bibliotecas públicas se encuentran tres tipos relacionados con la promoción de la lectura: actividades de fomento en el hábito de la lectura, educación a usuarios o actividades de extensión, según cada biblioteca. Sin embargo, las actividades de extensión tienden a perseguir 
otros objetivos y no específicamente el fomento a la lectura. En la investigación de Retana y Salas (2006) se muestra que este tipo de actividades son las más comunes, pero que unas veces están conformadas por cursos, charlas, exposiciones, divulgación, y otras con diversos fines.

Sin embargo, podríamos considerar que cualquiera de las actividades de estos tres tipos de servicios puede representar acciones de fomento a la lectura.

2. ¿Dónde realizan las actividades de promoción a la lectura?

En las instalaciones de la biblioteca

Éstas atienden a niños de preescolar, estudiantes de educación primaria y secundaria, adultos mayores y adultos discapacitados (sic). Se desarrollan actividades como cuentacuentos, talleres de literatura infantil, hora del cuento, leyendo en casa, presentaciones de libros o cine foros.

Fuera de las instalaciones de la biblioteca

Los bibliotecarios se desplazan a escuelas primarias, parques, hogares de ancianos y cárceles de mujeres.

3. ¿La biblioteca ha creado otros espacios o puntos de acceso a libros y demás materiales?

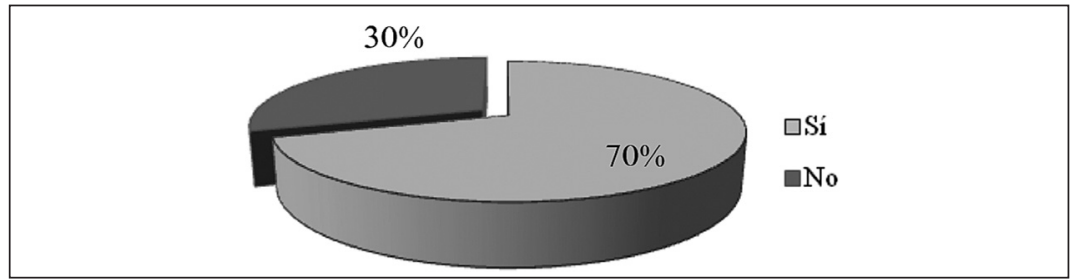

4. ¿Considera que las actividades de promoción de la lectura son valoradas por sus lectores y la comunidad?

Las personas encuestadas aseguran que los espacios, actividades y materiales que se ofrecen para promover la lectura son valorados por ambos sectores, lo que se hace evidente por las manifestaciones positivas de los participantes y el interés que demuestran. También por la continuidad de la asistencia a la biblioteca pública. 
Habilidades del personal y necesidades de entrenamiento

1. ¿La biblioteca tiene personal destinado exclusivamente a realizar actividades de promoción de lectura?

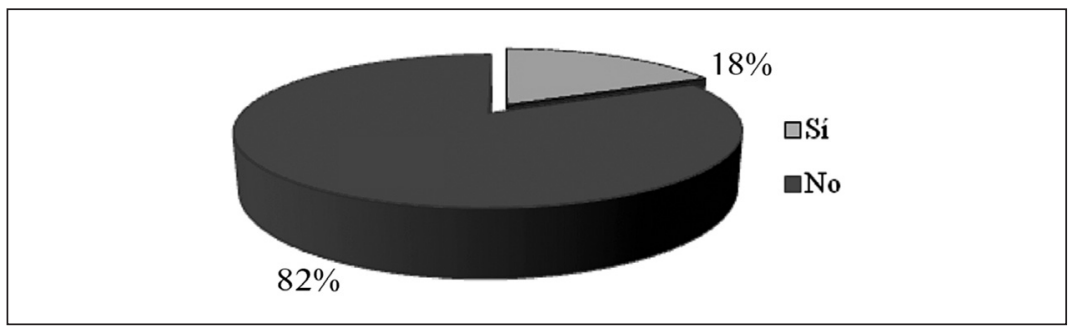

2. Actualmente, ¿qué habilidades son necesarias para promover la lectura?

- Convencimiento sobre la actividad.

- Sensibilización para trabajar con niños.

- Habilidad de expresión oral y mímica.

- Habilidad para trabajar en grupos.

- Sensibilidad por la literatura.

- Facilidad y disponibilidad para la animación a la lectura.

- Ser lector.

- Mostrar liderazgo, creatividad.

- Manejo de la expresión corporal.

- Actualización sobre las técnicas.

- Manejo de medios audiovisuales.

- Conocimiento de las teorías sobre los procesos de lectura y sus técnicas.

3. ¿Qué habilidades ayudarían a transformar a los no lectores en lectores que encuentren placer en la lectura y en los libros?

- Conocer la colección.

- Involucrarse en el proceso de lectura y darle seguimiento para darse cuenta de que otros también han descubierto que la lectura es un proceso socializador y placentero.

- Involucrar al usuario para colaborar en los procesos de promoción de lectura. 
- Combinar las actividades de promoción de lectura con las recreativas y creativas.

- Habilidad y creatividad.

4. ¿El personal de la biblioteca tiene la preparación y las habilidades para diseñar y desarrollar acciones para transformar a los no lectores en lectores aficionados a la lectura y el libro?

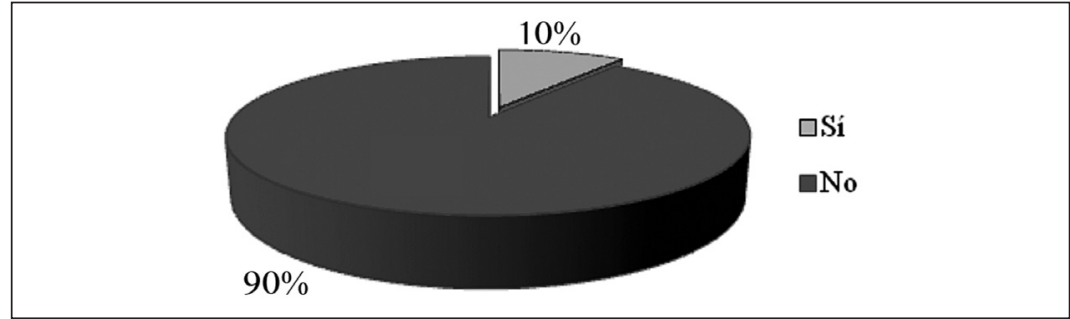

5. ¿Qué tipo de entrenamiento consideran importante recibir?

- Talleres de narraciones.

- Además de los cursos de entrenamiento, también se solicitan recursos y más personal para realizar las actividades que conlleva el fomento a la lectura.

- Un diagnóstico de las comunidades y del personal que labora en las bibliotecas.

- Técnicas de lectura y fomento para apoyar las que ya se han desarrollado.

- Teoría y práctica sobre la promoción de la lectura.

- Técnicas actualizadas de animación lectora para aquellos usuarios con limitaciones físicas.

\section{LA BIBLIOTECA PÚBLICA DE DESAMPARADOS: \\ UN CASO DESTACABLE}

Está en uno de los cantones de la provincia de San José, ubicado dentro de la gran área metropolitana, a unos $5 \mathrm{~km}$ del centro de la capital. Desamparados es uno de los cantones más poblados, con 193478 habitantes, según el censo de 2004; es el tercer cantón más 
popular del país y tiene una densidad poblacional de 1636.04 habitantes por kilómetro cuadrado. La Biblioteca Pública "Joaquín García Monge" lleva el nombre de uno de los escritores costarricenses más importantes, quien nació en esa localidad.

En el campo de la promoción de la lectura he destacado este caso por dos razones: la primera, porque ofrece actividades más variadas que las restantes 14 bibliotecas, y la segunda, porque muchas de éstas se enfocan hacia la literatura y otras producciones culturales como el cine, el teatro o la música, lo cual hace la diferencia entre la calidad de las actividades que se desarrollan en las bibliotecas. Con ello deseo destacar que en algunos casos las bibliotecas desarrollan actividades sin contenido, quizás partiendo de la presunción de que sólo por el hecho de ofrecer una charla, el objetivo de promover la lectura estará logrado plenamente.

Las actividades que se realizan son planeadas anualmente. La directora de esta biblioteca participa en la comisión que tiene el SINABI para tales fines, pero además ella incluye otras actividades, según la oportunidad y recursos con que cuente. ${ }^{5}$ Las personas que asisten a las actividades posteriormente llegan a la biblioteca, aunque esto se convierte en un reto, pues hay que medir la demanda, para responder con los recursos que se tienen disponibles. En este sentido su directora considera que uno de los problemas que enfrentan es que no tienen suficiente personal para cubrir la demanda de los usuarios, pero sí cuentan con una buena colección que contiene música, revistas y videos (C. Monge, comunicación personal, 5 de junio de 2008). Esta información es excepcional porque se celebra el año de las Bibliotecas Públicas de Centroamérica y por ello se han reforzado las actividades que comúnmente se realizan. Por ejemplo, cada mes tuvo un lema: en

5 Cuenta C. Monge que en sus inicios, cuando empezó a trabajar en esta biblioteca, le proponía ideas a su jefa y ella la desmotivaba porque consideraba que no era posible desarrollar tantas cosas, así que continuó sola y posteriormente, ya como directora de la Biblioteca de Desamparados, se empeñó en desarrollar un programa completo con el fin de fomentar la lectura (C. Monge, comunicación personal, 5 de junio de 2008). 
enero fue "La biblioteca pública para el parque"; en julio "Vacaciones en mi biblioteca"; en octubre "Leyendo con las y los abuelos: los niños les leen a los adultos mayores”. En este caso, además de la lectura se realizaron tertulias en las que los adultos conversaron con los niños y les contaron sus anécdotas y costumbres de antaño. Otro tipo de actividad consiste en invitar a profesionales de distintas áreas para que les hablen a los niños sobre su quehacer.

En estos casos se aprovechan las diferentes efemérides u otras ocasiones importantes para celebrar actividades relacionadas. Un ejemplo destacado es el mes de la música (cuyo día es el 21 de noviembre), en el que se realizan diversas actividades sobre ese tema. También están iniciando con la organización de "Tanda de 4", 6 que consiste en la proyección de una película costarricense a las 4 de la tarde una vez a la semana. Luego hay un comentario o cineforo, y la invitación a conocer más detalladamente la biblioteca.

Las actividades se realizan tanto dentro como fuera de la biblioteca, pero requieren especial mención las visitas a la cárcel de mujeres y al hogar de ancianos, o el proyecto "Lectura a enfermos en su casa”, con el que se está empezando. En estos casos se trabaja con personal voluntario (estudiantes de bibliotecología y preescolar); muchachos colegiales y cuatro personas de la Asociación Gerontológica Costarricense (AGECO). Todos ellos aportan su esfuerzo y en muchos casos también recursos materiales con el fin de lograr las metas previstas.

Después de estas actividades se organiza una tertulia para comentar sobre la lectura, la película o la pieza musical y se aprovecha para ofrecerles los servicios de la biblioteca o pasarlos al exhibidor que contiene lecturas afines. La afluencia de personas es variable; desde 18 niños y adultos a las actividades de rutina -como la Hora del Cuento, por ejemplo- y hasta 175 o 265 personas en actividades especiales, como la celebración del Día del Niño. También a veces

6 La Tanda de 4 o de 2 constituye una costumbre costarricense que ha perdido vigencia. Consistía en asistir al cine a esa hora como una forma de recreación, con la seguridad de que las películas eran para todo el público por la hora en que se proyectaban. 
se invita a un grupo de una escuela para garantizar un auditorio fijo, pero son personas que luego continúan visitando la biblioteca.

Estas gestiones se han realizado desde hace 5 años, a partir del Festival del Libro que organizó la DGB en su oportunidad y que consistió en que todas las bibliotecas realizaban actividades durante una semana de acuerdo con sus posibilidades. Ello ha reforzado las acciones conducentes al fomento de la lectura a nivel nacional. Se aprovecha también la iniciativa anual que realiza la Alianza Francesa denominada "Leer es una fiesta" para realizar sus propios eventos y aprovechar la infraestructura propagandística que tiene este programa. En estos casos se obtiene el apoyo de otras instituciones, como la Municipalidad, que aporta recursos para tales efectos.

Las actividades de esta biblioteca, en resumen, son:

a) Todo público: "La biblioteca para el parque" (tres veces al año), "Tanda de 4" (semanal), "Festival del libro" (una vez al año), "Leer es una fiesta" (una vez al año).

b) Niños (actividades que se llevan a cabo cuatro veces al año): la Biblioteca en la Feria de la Salud, La Biblioteca con Usted, y otras actividades. Visitas específicas a diferentes centros educativos, participación en promoción de lectura de acuerdo con las invitaciones recibidas. Invitación que hacen algunas comunidades para que les lleven el bibliobús de la DGB.

c) Jóvenes (según demanda y oportunidad): talleres de prevención de VIH/SIDA, en las Instituciones por invitación y en ciertas actividades en conjunto con la Oficina de Gestión Cultural de la Municipalidad.

d) Adultos (según demanda y oportunidad): en la cárcel de mujeres, en el hogar de ancianos y en actividades llevadas a cabo fuera de la biblioteca, en coordinación con otras instituciones: tertulias, talleres, narración oral. Teatro para adultos. 


\section{CONCLUSIONES}

Fortalezas y debilidades

- Se puede afirmar que las bibliotecas públicas costarricenses realizan múltiples esfuerzos para promover la lectura. Sin embargo, los resultados son insuficientes, no porque en esta ocasión nos ocupáramos de medirlos, sino por las diferencias tan marcadas que se observan entre las distintas bibliotecas. Esas diferencias se presentan de acuerdo a la ubicación geográfica de la biblioteca, la dotación de personal (capacitado o no), la disposición del personal responsable de desarrollar esas actividades y del apoyo que reciban de otras instituciones colaboradoras. Sin embargo, se mantiene la limitación que genera la escasa dotación de recursos, tanto humanos como materiales, detectada no sólo en este estudio sino en otros realizados sobre el tópico (Córdoba, 1980; Córdoba, 1992; Freiband, 2004).

- Es importante destacar que en los últimos años se han redoblado los esfuerzos por fomentar la lectura. Las acciones que se realizan son más coordinadas y planificadas; sin embargo, tuvimos dificultades para llegar a las bibliotecas de las zonas periféricas del país. Sabemos por experiencia que éstas difieren en cantidad y calidad de recursos de las que están ubicadas en el centro del país, por ello no podríamos generalizar que lo que se presenta en esta muestra de $27.27 \%$ se aplica a todo el territorio.

- El ejemplo de la Biblioteca Pública de Desamparados muestra una faceta destacada al presentar un conglomerado de actividades que se realizan permanentemente para promover la lectura entre usuarios de todas las edades y priorizando a aquellos que no asisten a los centros educativos. Es un caso excepcional, producido por una directora con muchos años de experiencia, que tiene creatividad y voluntad $y$, por otro lado cierta disponibilidad de recursos 
que aunque limitados son suficientes para desarrollar un programa que rinde jugosos frutos.

- Definitivamente el fomento a la lectura en las bibliotecas públicas exige mucho esfuerzo y creatividad. Los resultados dependerán del empeño de los y las profesionales que las atienden.

\section{BIBLIOGRAFÍA}

Córdoba, E. (2008), "Libros dejan estantes y isalen a la calle!”, La Nación, San José, C. R., enero. Disponible en: http://www.nacion.com/ln_ee/2008/enero/31/aldea14 05068.html (Consultado el 13 de mayo de 2008).

Córdoba, S. (1980), El Sistema de bibliotecas públicas de Costa Rica: Diagnóstico general de su funcionamiento y sugerencias para su mejoramiento, tesis para optar por el grado de licenciada en Bibliotecología. San José, C. R., Universidad de Costa Rica, Escuela de Administración Educativa, Sección de Bibliotecología.

Córdoba, S. (1992), "La participación del estado en el desarrollo de las bibliotecas públicas en Costa Rica: 1948-1988", en Estela Morales C. y Elsa Ramírez L. (comp.), Edición conmemorativa del $X$ aniversario del Centro Universitario de Investigaciones Bibliotecológicas, México, DGB/Consejo Nacional para la Cultura y las Artes y UNAM/Centro Universitario de Investigaciones Bibliotecológicas.

Freiband, S. (2004), "Los servicios para adultos en las bibliotecas públicas de Costa Rica, Nicaragua y Panamá", en Líber: Revista de Bibliotecología, 6 (1), pp. 4-16. Disponible en: http://eprints.rclis.org/archive/00 003536/01/costa.pdf (Consultado el 5 junio de 2008).

Gill, P. (2003), Directrices IFLA/UNESCO para el desarrollo del servicio de bibliotecas públicas, México, Conaculta. 
Retana, M. y Salas, M. E. (2006). Proyección cultural de las bibliotecas públicas a la comunidad: Casos de las bibliotecas públicas de Goicoechea y Santa Ana, tesis para optar por el grado de licenciadas en Bibliotecología. San José, C. R., Universidad de Costa Rica, Escuela de Bibliotecología y Ciencias de la Información.

Rodríguez, O. y Méndez, X. (2006), "La Escolarización de la biblioteca pública, con una propuesta para extender la cobertura de las bibliotecas públicas oficiales de Costa Rica a la comunidad", en Bibliotecas: Boletín de la Escuela de Bibliotecología, Documentación e Información, 24 (1 y 2), pp. 107-113. 


\title{
La promoción de la lectura en las bibliotecas públicas cubanas
}

\author{
Emilio Setín Quesada \\ Asociación Cubana de Bibliotecarios, Cuba
}

\section{INTRODUCCIÓN}

T a información que se ofrece se obtuvo en la Biblioteca Nacional José Martí, como órgano rector del sistema de bibliotecas públicas; las escuelas formadoras, los eventos de promoción de la lectura de la Asociación Cubana de Bibliotecarios y -para las preguntas de opinión- encuestados procedentes de 30 bibliotecas que representan el occidente, centro y oriente del país, cuya información fue recogida por las filiales de la Asociación en esos territorios y que puede aceptarse con un $95 \%$ de confianza, de acuerdo con la cantidad de entrevistados y el método de Ávila Acosta. ${ }^{1}$

Al momento de aplicarse la Encuesta Internacional de Lectura IFLA para América Latina y el Caribe, el país contaba con 413 recintos en el sistema de bibliotecas adscrito al Ministerio de Cultura: 13 provinciales; 156 de categoría I, situadas por lo general en las cabeceras de los municipios; 232 de categoría II, que son

1 Véase R. B. Ávila Acosta, Metodología de la investigación, Lima, Estudios y Ediciones RA, 2001. 
sucursales por lo común, aunque pueden serlo también algunas municipales que no hayan alcanzado todo el desarrollo que les corresponde, y 12 bibliotecas populares creadas inicialmente por la Unión de Jóvenes Comunistas en barrios y zonas de su interés. ${ }^{2}$

\section{El Programa Nacional de Lectura}

El país cuenta con el Programa Nacional por la Lectura que contempla un conjunto de acciones de carácter estratégico, proyectadas para un desarrollo a largo plazo y con participación y efectos tan amplios como la totalidad de la sociedad cubana. Al mismo tiempo, se propone la coordinación de los esfuerzos de todos los organismos, instituciones, grupos y personas del país interesados en promover el libro y la lectura. ${ }^{3}$

Fuentes de información con que cuenta el bibliotecario para orientar el trabajo de promoción

Las actividades de promoción en Cuba no se realizan conforme a manual alguno. Los bibliotecarios reciben formación como promotores de la lectura en asignaturas de ese nombre, tanto en la carrera universitaria como en las escuelas de técnicos medios. Cuentan, además, con diversas fuentes de consulta al respecto, publicados en Bibliotecas, año 29, núm. 1-2, 1991, y con el libro de Víctor Fowler, La lectura: ese poliedro, publicado por la Biblioteca Nacional José Martí, cuyo texto completo puede consultarse en línea en la Web de la Biblioteca Nacional.

2 Al momento de redactarse esta síntesis, las bibliotecas populares son ya parte integral del sistema atendido por el Ministerio de Cultura.

$3 \mathrm{Al}$ cierre de esta información se ha conocido que el programa se encuentra en fase de revisión y actualización. 
Colaboraciones en actividades de promoción de la lectura y sus beneficios

Las actividades que se desarrollan en colaboración con otras instituciones y organismos responden a la tipología que aparece descrita en Bibliotecas, citada anteriormente, y se realizan en círculos infantiles, escuelas, hospitales, asilos, casas de abuelos, clubes de jóvenes, centros de trabajo -de horarios continuos fundamentalmente-, centros penitenciarios, organizaciones sociales en zonas urbanas o rurales poco pobladas donde no existen bibliotecas y en el domicilio de lectores impedidos.

El mayor beneficio que se deriva de esas coordinaciones es la extensión de las actividades y el logro de una mayor vinculación de lectores con la biblioteca.

\section{Opiniones de bibliotecarios entrevistados}

sobre el porqué de las actividades de promoción

de la lectura en la biblioteca

Las opiniones sobre el porqué se efectúan actividades de promoción de la lectura en las bibliotecas se pueden sintetizar en cuatro razones principales, que ordenadas de mayor a menor peso en las respuestas recibidas expresan:

- Contribuyen a desarrollar la cultura de los lectores.

- Dan a conocer las colecciones de las bibliotecas.

- Contribuyen a crear hábitos de lectura y a formar y transformar conductas lectoras.

- Constituyen la función fundamental de toda biblioteca.

Esto evidencia que el bibliotecario se ve como un trabajador de la cultura que cumple como tal formando lectores, factor que constituye uno de los productos principales de su actividad creadora. 
Caracterización de las actividades de promoción a la lectura que se realizan

- El libro del mes: generalmente se efectúan lecturas comentadas o presentaciones de libros que tienen como objetivo fundamental resaltar, a través de lecturas, los valores de las obras seleccionadas con el fin de despertar el interés por las mismas, así como contribuir al desarrollo de la imaginación y de la lectura a partir de la expresión oral.

- Presentaciones de libros nuevos adquiridos: como su nombre lo indica se realizan presentaciones o charlas sobre libros de nueva adquisición. Esto puede realizarse de diferentes formas y referirse a un solo libro o a varios. En este último caso pueden ser obras de un mismo autor o temática, y establecerse entre ellos relaciones que permitan presentarlos como una unidad. En dicha actividad se exponen además todos los libros nuevos.

- Charlas, conferencias y conversatorios: actividad que se realiza con la participación de un conferencista invitado quien puede abordar diferentes temas de acuerdo con su especialidad, actividad que se acompaña de una exposición de libros acordes al tema tratado.

- Encuentro con escritores: se organizan con la participación de autores de obras literarias, científicas, técnicas, históricas, sociales, etcétera. En estas actividades se pide a los autores que comenten una o varias de sus obras y que realcen los contenidos más interesantes en forma sugerente para despertar el interés de la lectura o la narración, o hablen de la forma en que creó la obra o las obras que presenta, haciendo hincapié en las condiciones que lo condujeron a la creación de ésta -problemas, vivencias, lecturas, etcétera-. Esto último puede contribuir a incidir en el carácter de la lectura al darle a conocer al lector cómo se originó el proceso de creación. En la organización de los Encuentros con escritores, el bibliotecario debe jugar un papel activo dando a conocer las obras de dicho escritor que posee la biblioteca 
- Los abuelos con nosotros: esta actividad de promoción de lectura se realiza teniendo en cuenta las características de este grupo etario, sus intereses y gustos. Inicia con un juego de participación acorde con la tercera edad, vinculado a la promoción de la lectura, y a continuación se realizan presentaciones de libros, lecturas, charlas sobre temas actuales, lectura de poemas y artículos de prensa, curiosidades, recetas de cocina, consejos de belleza, etcétera.

- Leer a Martí concurso anual convocado por los lectores de bibliotecas públicas y escolares, los participantes presentan composiciones basadas en las obras del Apóstol leídas durante el año previo a la convocatoria.

- Concurso anual de las bibliotecas escolares: los alumnos hacen demostraciones de conocimientos tomando como base los libros leídos durante el año precedente a la convocatoria.

- En nuestro jardín: se comenta sobre un hecho trascendente de carácter histórico, social, cultural, etcétera, ocurrido en la localidad, y el bibliotecario interactúa con el público presente y le ayuda a conocer las fuentes de información que posee la biblioteca.

- Purofeeling: actividad cultural que se realiza con la participación de amantes del género. Se ofrecen recitales en vivo o con música grabada sobre feeling. Conjuntamente se promueve la obra poética de diferentes autores.

- Juegos didácticos: son creados, diseñados y manejados mayormente por los bibliotecarios públicos y escolares:

- De mesa: generalmente emplean barajas literarias o preguntas y respuestas, pero también tableros y dados para introducir esa variante del azar; estos materiales incrementan los conocimientos en general y divierten. Los rompecabezas para diferentes edades están incluidos en este grupo. Se intenta incrementar la presencia del Scrabble ya que este juego despierta el interés por las palabras y puede lograrse un rápido desarrollo de la lengua a través de él. 
- De salón: juegos de palabras con o sin gestualidad corpórea, dramatización de sentimientos, agilidad mental o empleo de los sentidos. Su función es primordialmente ayudar al desarrollo de la comunicación social. Los títeres figuran en este grupo.

- Electrónicos: multimedia e interactivos. Para el entretenimiento y como vehículo para la alfabetización funcional, visual, digital y multimedia. Programas creativos para el tiempo de ocio de los niños y adolescentes, pero buscando su desarrollo cultural, lector y el aprendizaje permanente. Su selección ha de ser rigurosa pues sólo un pequeño porcentaje de lo que se ofrece en el mercado internacional supera la mediocridad. Los materiales de producción cubana son confiables por los patrones de conducta social que diseminan.

- La Galería de autores para niños: es una muestra permanente de retratos que reúne a personalidades de la literatura cubana para niños, desde los fundadores de ésta al triunfo revolucionario y hasta el día de hoy. Ingresan a ella aquellos que poseen los premios Magistral o Especial "La Rosa Blanca", mayor galardón que otorga la UNEAC a los creadores de la literatura infantil y juvenil cubana. Alrededor de la galeria se organiza un conjunto de actividades.

- Charlas sobre libros relacionados al Programa Maternidad y Paternidad responsables.

- Promoción de clásicos y contemporáneos de literatura impresa en Braille: actividad personalizada para discapacitados visuales que no tienen la posibilidad de comprar el libro que desean en las librerías; se les facilita el disfrute de lecturas de los clásicos de la literatura y de los contemporáneos a través de la ayuda de un lector voluntario del Servicio de Extensión Bibliotecaria. 
Valoración de las actividades de promoción

Según la opinión de los encuestados la aceptación de las actividades de promoción por parte de los lectores se manifiesta fundamentalmente en:

- El uso que hacen de las bibliotecas en busca de los libros promovidos.

- La asistencia reiterada a las actividades de promoción.

- Las opiniones favorables que emiten los asistentes a las actividades.

En la década de los años ochenta se hicieron experimentos sociales en las bibliotecas públicas para medir la efectividad de las actividades de promoción y la consulta de los títulos promovidos durante el mes siguiente a la actividad en los que fueron incluidos.

El personal de las bibliotecas en la promoción de la lectura. Formación y habilidades necesarias

Aunque generalmente la coordinación de las actividades de promoción de la lectura está a cargo de algún bibliotecario específico, en ellas participan otros que se relacionan con el tipo de lector a que se destine la actividad o de la temática que se incluya en ella. Pueden ser bibliotecarios universitarios o técnicos medios, sin distinción de edades o género, aunque es el sexo femenino el que predomina en las bibliotecas públicas del país.

Como se apuntó anteriormente los bibliotecarios reciben formación como promotores de la lectura en asignaturas de ese nombre, tanto en la carrera universitaria como en las escuelas de técnicos medios, así como en la extensión de esos estudios adquiridos en cursos a distancia o mediante la municipalización de la enseñanza especializada de nivel medio y superior. Participan además cada dos años en eventos dedicados especialmente al intercambio 
de las experiencias más novedosas de la promoción con el patrocinio de la Asociación Cubana de Bibliotecarios.

A nivel universitario los bibliotecarios estudian los contenidos siguientes:

- Concepto de Lectura. Lectura, multilectura y niveles de lectura. Concepto de promoción. Por qué, para qué y a quiénes se promueve la lectura.

- Lectura y comunicación. Principios teóricos. La radio, la televisión, Internet y los medios en general y las influencias tanto negativas o positivas que ejercen éstos sobre el hábito de la lectura.

- Breve mención teórica. La anotación como forma de apropiación del conocimiento. La lectura como recreación o entretenimiento. La afirmación y creación de valores y códigos éticos a través de la lectura.

- Características específicas por grupos etarios y profesionales. Propaganda visual de murales, volantes impresos, utilización de los medios de información masivos y otros. ¿Cómo hacer un proyecto? Clubes y talleres de lectura oral.

- Necesidad de los países de contar con programas nacionales de lectura. Características. Principales exponentes. Programas internacionales de lectura. Programa Nacional de la Lectura (Cuba). Características y participantes. Programa Leer a Martí.

Los técnicos medios se preparan en los contenidos siguientes:

- Conceptos básicos sobre los perfiles del animador (promotor de lectura: sus características). Conceptos de comunicación, relaciones públicas y propaganda.

- La promoción cultural y de la lectura. Principios. La promoción en las diferentes manifestaciones de la cultura. La promoción de la lectura, sus métodos de trabajo.

- La animación sociocultural. Definición y características. Problemas operativos de la animación (de personas, de lugar, de tiempo, de actividades, de métodos y de medios). 
- Las técnicas participativas como herramientas para el trabajo de animación y promoción en las bibliotecas.

- El trabajo comunitario. Objetivos, principios y métodos del trabajo comunitario. El diseño y los objetivos de los programas y proyectos comunitarios.

Los encuestados opinan, además, que los promotores deben ser buenos lectores para dominar las colecciones que va a promover; saber cómo conocer al público lector en su radio de acción; tener habilidades de comunicador y expresarse correctamente, y dominar las técnicas de promoción.

Es necesario que el especialista reciba ante todo conocimientos teóricos sobre la lectura y su promoción, la animación y las estrategias a utilizar, para que pueda después poner en práctica los conocimientos recibidos.

Deben los promotores realizar investigaciones para conocer al público, asistir a cursos de comunicación social y a talleres de promoción de la lectura que sirvan para perfeccionar su trabajo.

Deben también recibir:

- Entrenamiento metodológico acerca de cómo realizar la actividad, qué tipo de actividad se dará, qué libros puede utilizar de acuerdo a la edad e intereses de los usuarios.

- Talleres sobre narración oral, cursos o seminarios sobre promoción de la lectura y sus diferentes técnicas.

- Cursos sobre técnicas narrativas, comunicación social, psicología entre otras, que puedan ayudar a su desenvolvimiento en estas actividades. 


\title{
SINAB: de bibliotecas comunitarias a compromiso estatal. El caso del Ecuador
}

\author{
JULIO CÉSAR DE LA ROCHE MARTÍNEZ \\ Sistema Nacional de Bibliotecas del Ministerio \\ de Educación del Ecuador
}

\section{El Sistema Nacional de Bibliotecas}

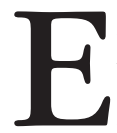

1 Sistema Nacional de Bibliotecas (SINAB) fue creado por una idea original del entonces Ministro de Educación Camilo Gallegos Domínguez, que fue continuada por el ministro Iván Gallegos. Se designó dentro del Ministerio una comisión que procedió a realizar un diagnóstico del proyecto. Ese trabajo se llevó a cabo intensamente y contó con el respaldo de la OEA, el MEC y las direcciones provinciales de educación. El proyecto se desarrolló pensando en integrar las bibliotecas escolares de todo el país y abrirlas a la comunidad. El diagnóstico determinó qué libros existían en las bibliotecas escolares, las preferencias de consulta y las falencias bibliográficas que existían.

El 3 de junio de 1987 se publicó el reglamento de las Bibliotecas Escolares Abiertas (BEA) en el registro oficial núm. 699, y el 17 de julio se nombró a Francisco Delgado como primer director ejecutivo nacional. El proyecto nació financiado con un crédito reembolsable del BID, y es una entidad descentralizada y adscrita al Ministerio de Educación que busca generar procesos de participación comunitaria en el área cultural en torno a las bibliotecas. Es parte 
de una nueva concepción de política cultural democratizadora, que tiene como meta satisfacer, en parte, la carencia de servicios bibliotecarios y centros culturales comunitarios en las áreas rurales y urbanas marginales del país.

El 21 de mayo de 1991 se creó el Sistema Nacional de Bibliotecas con el registro oficial núm. 688. Al momento en el país cubrimos el $82 \%$ de los territorios municipales en todas las provincias de la república.

Unidades de información del SINAB del Ministerio de Educación del Ecuador

\begin{tabular}{|l|c|c|c|c|c|c|c|c|c|c|c|c|}
\hline \multicolumn{1}{|c|}{ Provincias } & \multicolumn{2}{c|}{ Bibliotecas } & \multicolumn{2}{c|}{ CCC } & \multicolumn{2}{c|}{ CFIC } & \multicolumn{2}{c|}{ CPL } & \multicolumn{3}{c|}{ Totales } \\
\hline & $\mathrm{A}$ & $\mathrm{C}$ & $\mathrm{A}$ & $\mathrm{C}$ & $\mathrm{A}$ & $\mathrm{C}$ & $\mathrm{A}$ & $\mathrm{C}$ & $\mathrm{A}$ & $\mathrm{C}$ & $T$ \\
\hline Azuay & 21 & 0 & 4 & 1 & - & - & 0 & 0 & 25 & 1 & 26 \\
\hline Bolívar & 11 & 0 & 3 & 0 & - & - & 9 & 0 & 23 & 0 & 23 \\
\hline Cañar & 13 & 0 & 4 & 0 & - & - & 4 & 0 & 21 & 0 & 21 \\
\hline Carchi & 6 & 1 & - & - & 8 & 0 & 5 & 1 & 19 & 2 & 21 \\
\hline Chimborazo & 27 & 0 & 3 & 0 & - & - & 6 & 0 & 36 & 0 & 36 \\
\hline Cotopaxi & 16 & 0 & 3 & 0 & - & - & 1 & 0 & 20 & 0 & 20 \\
\hline El Oro & 41 & 1 & - & - & 10 & 0 & 2 & 0 & 53 & 1 & 54 \\
\hline Esmeraldas & 8 & 1 & - & - & 5 & 0 & 3 & 0 & 16 & 1 & 17 \\
\hline Galápagos & 2 & 0 & 2 & 0 & - & - & & 1 & 4 & 1 & 5 \\
\hline Guayas & 20 & 9 & 5 & 1 & - & - & 11 & 1 & 36 & 11 & 47 \\
\hline Imbabura & 9 & 1 & 5 & 0 & - & - & 4 & 0 & 18 & 1 & 19 \\
\hline Loja & 29 & 3 & - & - & 6 & 0 & 0 & 0 & 35 & 3 & 38 \\
\hline Los Ríos & 16 & 4 & 4 & 0 & - & - & 4 & 0 & 24 & 4 & 28 \\
\hline Manabí & 29 & 1 & 5 & 0 & - & - & 11 & 2 & 45 & 3 & 48 \\
\hline Morona Santiago & 10 & 1 & - & - & 4 & 0 & 5 & 0 & 19 & 1 & 20 \\
\hline Napo & 10 & 0 & 2 & 0 & - & - & 4 & 0 & 16 & 0 & 16 \\
\hline Orellana & 4 & 0 & 0 & 0 & - & - & 0 & 0 & 4 & 0 & 4 \\
\hline Pastaza & 8 & 2 & 3 & 0 & - & - & 4 & 0 & 15 & 2 & 17 \\
\hline Pichincha & 31 & 0 & 7 & 0 & - & - & 3 & 0 & 41 & 0 & 41 \\
\hline Sucumbíos & 12 & 0 & - & - & 10 & 0 & 0 & 0 & 22 & 0 & 22 \\
\hline Tungurahua & 19 & 0 & 2 & 0 & - & - & 5 & 0 & 26 & 0 & 26 \\
\hline Zamora Chinchipe & 15 & 0 & - & - & 4 & 0 & 1 & 0 & 20 & 0 & 20 \\
\hline Totales & 357 & 24 & 52 & 2 & 47 & 0 & 82 & 5 & 538 & 31 & 569 \\
\hline
\end{tabular}

Simbología: $\mathrm{A}=$ Abiertas, $\mathrm{C}=$ Cerradas, CCC = Centros Culturales Comunitarios, CFIC = Centros Fronterizos de Integración Cultural, $\mathrm{CPL}=$ Centros Populares de Lectura y $\mathrm{T}=$ Total 


\section{LAS CAMPAÑAS DE LECTURA}

En Ecuador han nacido diversas iniciativas para promoción de la lectura, una de las más recientes es la "Campaña Nacional Eugenio Espejo". Desde 2001 y con el aval del Ministerio de Educación y Cultura, la Casa de la Cultura y el BID, esta experiencia no gubernamental en medio de un proyecto innovador y con financiamiento internacional fomentó ediciones de clásicos nacionales de literatura para jóvenes y adultos, creó clubes de lectura y realizó congresos internacionales sobre el tema. La Campaña Nacional de Lectura fue una iniciativa de la Casa de la Cultura Ecuatoriana "Benjamín Carrión" y del Ministerio de Educación y Cultura teniendo en cuenta los siguientes elementos: el principio de responsabilidad compartida, la concurrencia de actores sociales y el mantenimiento de la memoria colectiva.

Entre sus objetivos contaba con elevar a un primer plano el tema de la lectura; formar integralmente a los y las ciudadanas; promover acciones por la lectura en familia y en otros espacios de convivencia; poner en manos de los lectores productos adecuados y accesibles y contribuir a desarrollar los diferentes sectores que promueven la lectura del libro.

Cabe resaltar que el mayor logro fue llegar a los lectores más diversos, con materiales de literatura, historia y sociología, de fuerte acento nacional y a costos para el público de tan sólo un dólar americano por ejemplar. Sin embargo, nos falta realizar algunos sueños y propósitos, tales como la instalación del sistema informático en la Biblioteca Nacional; la integración de la red ecuatoriana de bibliotecas; la distribución de la colección "El arco y el iris" en Costa, Sierra y Oriente y la inserción de la misma en la Biblioteca Mundial Virtual; la edición de una colección de literatura infantil, la producción de videos documentales sobre autores ecuatorianos, la edición de la colección "Generación del 30" y la organización de eventos en favor de la lectura (concursos, conciertos, teatro, lanzamiento de libros, conferencias, exposiciones); edición de discos compactos y la continuación de actividades permanentes. 
Esta campaña se encuentra en proceso de acercamiento hacia gobiernos locales y con este objetivo se firmó un convenio con el Municipio de Cuenca, entre otros, con lo cual los usuarios de agua potable, energía eléctrica y demás servicios recibirán los libros de las colecciones masivas junto con su comprobante de pago a precios muy bajos. También se desarrollan talleres para bibliotecarios relacionados con la promoción de la lectura en la biblioteca y el manejo del maletín del bibliotecario.

\section{EL RETO DEL SINAB}

El SINAB lleva ya 21 años de vida institucional y su cobertura y el elevado número de unidades de información le dan una gran perspectiva a la labor que puede considerarse en sí un significativo avance al acercar el libro y la lectura a las comunidades más necesitadas. No es del todo así. Si bien la igualdad está consagrada en la mayoría de las leyes, en la práctica y los hechos ésta no se da, así que uno de los mayores retos de los dirigentes serios y con propósitos sociales es darle el vuelco al statu quo, de tal forma que podamos avanzar hacia un modelo asentado en las particularidades locales, y positiva y determinadamente hacia el fortalecimiento del proceso educativo-social y el acceso a los libros, la lectura y los beneficios de los bienes culturales de la población, mayoritariamente marginada, de nuestros países.

\section{Planes y políticas de lectura}

Desde hace dos años el país se dirige bajo en un Plan Decenal de Educación, aprobado en consulta popular en noviembre de 2006 por abrumadora mayoría. El SINAB está trabajando dentro del marco de este Plan, desarrollado por el Ministerio de Educación. Dentro de estos términos, la Política 4 aborda la erradicación del analfabetismo y el fortalecimiento de la educación continua para adultos, mientras que la Política 6 se enfoca al mejoramiento de la calidad y la equidad de la educación y la implementación de un sistema nacional de evaluación y rendición social de cuentas. 
También desarrollamos un Plan de creación e impulso a Centros Culturales Comunitarios (CCC) en todo el país, destacando como prioritarias las regiones de frontera, por lo que fortalecimos en algunos casos, y creamos en otros, Centros Fronterizos de Integración Cultural en regiones limítrofes con Colombia y Perú. Sobre ellos destacamos lo siguiente:

- Al momento tenemos 168 CCC ubicados en todas las provincias del país, en las zonas rurales y urbanas marginales.

- Para el 2008 se prevé crear al menos 58 centros más.

- Muchos de estos centros funcionan en zonas de frontera.

- Los CCC brindan apoyo al sistema educativo formal y refuerzan el conocimiento de niños y jóvenes.

Se trabaja permanentemente con las comunidades a través de los comités de apoyo.

El SINAB tiene un convenio con la Dirección Nacional de Rehabilitación Social y de manera prioritaria y urgente contribuye con la declaratoria de emergencia carcelaria nacional, brindando apoyo a las 23 bibliotecas que se encuentran trabajando en diferentes centros de rehabilitación, los que procuramos dotar de materiales adecuados teniendo en cuenta los particulares pedidos de cada uno de ellos.

Tenemos un amplio plan de capacitación para más de 600 personas involucradas con el SINAB que va en su tercera etapa, es ésta una de las prioridades que manejamos. El diagnóstico previo para esta fase determinó que: "Actualmente las bibliotecas del SINAB tienen una debilidad y es que algunas están trabajando en forma individual al realizar el procesamiento técnico de sus colecciones, lo que ocasiona duplicación de los esfuerzos al procesar los mismos libros de las otras bibliotecas [...]"

Generalmente no contamos con personal técnico o profesional en bibliotecología para registrar su material documental en un catálogo automatizado, que permita la recuperación de los registros. Tampoco se cuenta con el catálogo bibliográfico y documental nacional de cada una de las bibliotecas públicas del Sistema Nacional de Bibliotecas, lo que permitiría reducir el tiempo en el procesamiento técnico 
de sus colecciones. Y muchas bibliotecas carecen del equipo necesario para alcanzar su automatización, no tienen una computadora, ni un software de gestión de la biblioteca y tampoco cuentan con el conocimiento para manejarlo.

Sin embargo, hemos resuelto darle forma a una Red de Bibliotecas. Pero hablar de una red es perseguir metas específicas que vayan de acuerdo con ideologías, intereses comunes, demandas y culturas comunitarias. Se necesita que todas las bibliotecas en el ámbito nacional presenten datos estadísticos que reflejen el trabajo que realizan, pero esto tiene que ser validado por alguna autoridad. Cabe destacar que la fortaleza de las bibliotecas del SINAB se asienta en tres factores clave:

- Las bibliotecas tienen un local adecuado para su funcionamiento, mediante convenios con diferentes organismos.

- Todas las bibliotecas cuentan con un fondo bibliográfico inicial.

- Las bibliotecas cuentan con promotores culturales bibliotecarios.

La adecuada coordinación de estos elementos, más la infraestructura física y los materiales y equipos necesarios, nos permitirá dar respuesta a las demandas y necesidades de información, y nos ayudarán a desarrollar una labor de impacto para darles a nuestras bibliotecas el lugar que les corresponde dentro de la sociedad.

\section{Resultados de la Encuesta en el EcuAdor}

La encuesta se efectuó en 24 bibliotecas y la respuesta fue muy positiva. A continuación se presentan los resultados obtenidos de las 24 bibliotecas encuestadas en Ecuador.

Políticas de lectura

1. ¿Su institución se rige por alguna política de lectura? 
Respecto a esta pregunta, del total de las bibliotecas encuestadas (15), que representan el $62.5 \%$ de las bibliotecas, respondieron que sí se rigen por una política de lectura, y nueve, el $37.5 \%$, señalaron que no la consideran o que la desconocen.

2. ¿Las actividades de promoción las realizan de acuerdo a algún manual?

En cuanto a la aplicación del manual que proporciona el Sistema Nacional de Bibliotecas para realizar las actividades de promoción de la lectura, la mitad de las bibliotecas respondió que sí lo utilizan, en tanto que el otro 50 \% no lo hacen.

Colaboraciones en actividades de promoción de la lectura

1. ¿La promoción de la lectura la desarrolla con otras instituciones u organismos?

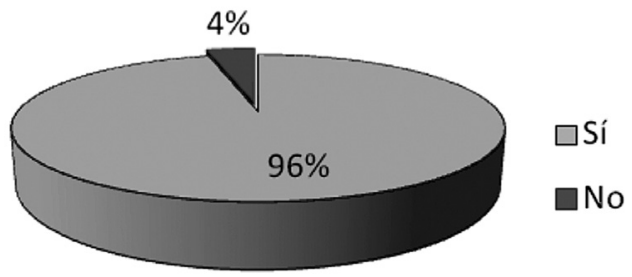

Se mencionó que las bibliotecas públicas establecen actividades de colaboración principalmente con escuelas, colegios, el gobierno municipal, la coordinación provincial del SINAB, la junta parroquial, el INNFA, el sector médico, etcétera. Las principales actividades que se desarrollan son de extensión educativa y cultural, como lectura en voz alta y meditación, formación de clubes de lectura en coordinación con la campaña de lectura "Eugenio Espejo", iniciación a la lectura con el Jardín Gabriela Mistral, mochila viajera, charlas y periódicos murales.

2. ¿En qué beneficia a la biblioteca la colaboración con instituciones u organismos? 
El beneficio que brinda esta cooperación institucional es optimizar recursos, así como establecer un mayor acercamiento entre la escuela y la biblioteca y la comunidad y la biblioteca.

Actividades de promoción de la lectura

1. ¿Realiza actividades de promoción a la lectura?

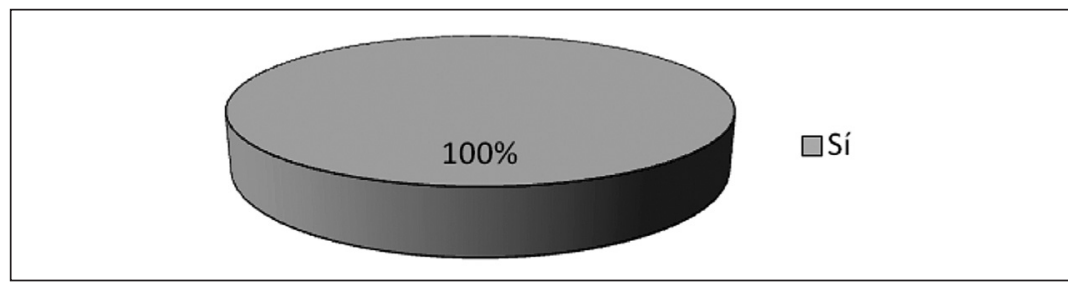

Todas las bibliotecas manifestaron que sí porque no se trata solamente de prestar libros, sino de hacer promoción sociocultural que ayude a la comunidad a la que sirven a través de la lectura. Además se considera a la biblioteca como un espacio idóneo donde existe el material necesario para transformar los procesos cognitivos y formativos del individuo, ¿qué mejor manera de hacer esto que planeando actividades para incentivar el acercamiento a los materiales y despertando el interés por la lectura?

2. ¿Dónde realizan las actividades de promoción a la lectura?

Se llevan a cabo tanto en las instalaciones como fuera de ellas. Las actividades que se ofrecen en las instalaciones de la biblioteca se destinan a los siguientes grupos:

- Niños y jóvenes, una vez al mes, mediante la animación a la lectura, concursos literarios, charlas y proyecciones de videos, lectura compartida, títeres, caja mágica, hora del cuento y periódico mural.

- Entidades educativas, dos veces por semana, a través de exposiciones de libros nuevos, periódico mural y talleres.

- Ancianos, una vez por semana, mediante el relato de anécdotas. 
- Brigadas estudiantiles, cada semana, con las lecturas reflexivas y el libro leído.

Fuera de las instalaciones de la biblioteca, las actividades están dirigidas a:

- Niños, jóvenes y adultos durante el periodo vacacional desarrollando animación a la lectura, manualidades y refuerzos pedagógicos. También se hacen estas actividades en las instalaciones del coliseo parroquial.

- Catequistas y animadores, una vez al mes, en la Casa Campesina.

- Señoras de la población, cada fin de semana en el hotel Ingañán donde se les leen textos escogidos y se les cuentan cuentos.

- Niños de 4 y 5 años, un día a la semana, en el Jardín Gabriela Mistral, con lectura de cuentos, audiciones y escenificaciones.

3. ¿La biblioteca ha creado otros espacios o puntos de acceso a libros y otros materiales?

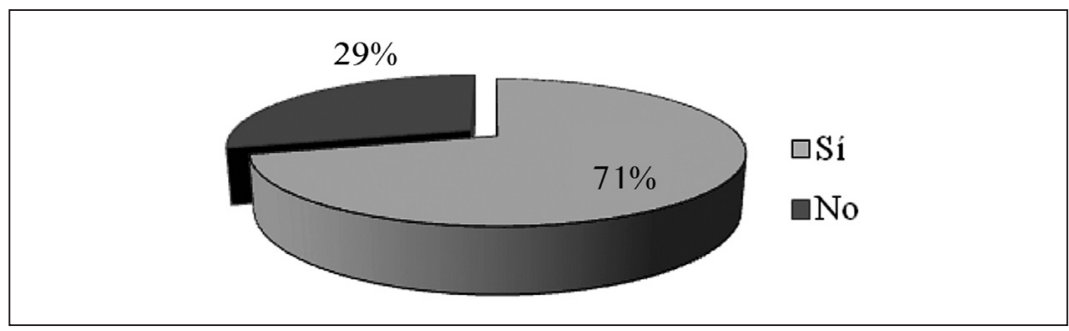

4. ¿Considera que las actividades de promoción de la lectura son valoradas por sus lectores y la comunidad?

Las actividades son valoradas por los dos sectores, porque los usuarios manifiestan la importancia de desarrollar estas actividades al asistir, a través de sus actitudes y su participación. Además consideran a la biblioteca como un punto de encuentro, donde toda la comunidad tiene acceso a una diversidad de servicios, con la finalidad de cubrir sus diferentes necesidades de información; ello representa un gran apoyo tanto académico como cultural. 
Habilidades del personal y necesidades de entrenamiento

1. ¿La promoción de la lectura forma parte del trabajo del personal de la biblioteca?

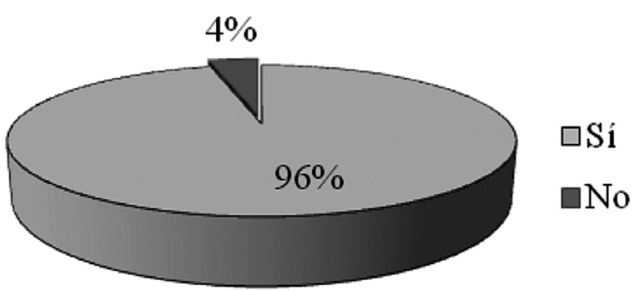

Solamente en una biblioteca no se reconoció que la promoción de la lectura fuera parte de las obligaciones del personal.

2. ¿La biblioteca tiene personal destinado exclusivamente a realizar actividades de promoción de la lectura?

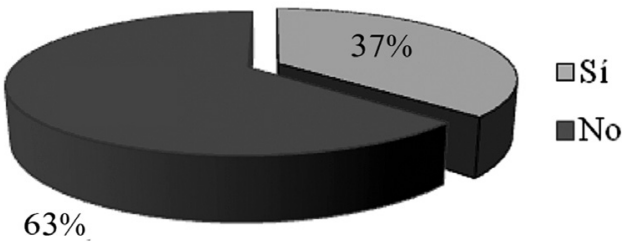

Los resultados reflejan que 15 de las 24 bibliotecas públicas carecen de personal destinado exclusivamente al desempeño de las actividades de promoción de la lectura, y habría que agregar que por lo regular en las diversas comunidades donde se aplicó el cuestionario se contestó que hay una sola persona encargada de desempeñar todas las actividades y labores que demanda la biblioteca.

3. Actualmente, ¿qué habilidades son necesarias para promover la lectura? 
- Brindarle confianza al lector.

- Facilidad para imitar personajes.

- Tener conocimientos de técnicas de lectura.

- Tener una buena expresión corporal.

- Tener capacidad de análisis.

- Cordialidad.

- Gusto por la lectura.

- Conocimientos sobre el lenguaje y la comunicación.

4. ¿Qué habilidades ayudarían a transformar a los no lectores en lectores que encuentren placer en la lectura y en los libros? Adoptar la lectura como una actividad principal no sólo en la escuela y la biblioteca sino también en la casa, y practicar continuamente a través de criterios y responsabilidades para despertar el deseo en quienes nos miran leer. Otra opción sería valerse de juegos y saber leer cuentos con una dramatización para atraer su atención; también habría que desarrollar la capacidad de narración. Habría que ofrecer discursos al usuario para que reconociera la importancia del libro y los beneficios que nos ofrece al transportarnos a mundos lejanos que nos llenan de alegrías e ilusiones.

5. ¿El personal de la biblioteca tiene la preparación y las habilidades para diseñar y desarrollar acciones para transformar a los no lectores en lectores aficionados a la lectura y al libro?

Lamentablemente la mayoría manifiesta no tener la preparación necesaria y que la asistencia a cursos, talleres y seminarios de capacitación les ha permitido desarrollar iniciativas propias de acuerdo al medio y la realidad.

6. ¿Reciben entrenamiento para desarrollar destrezas?

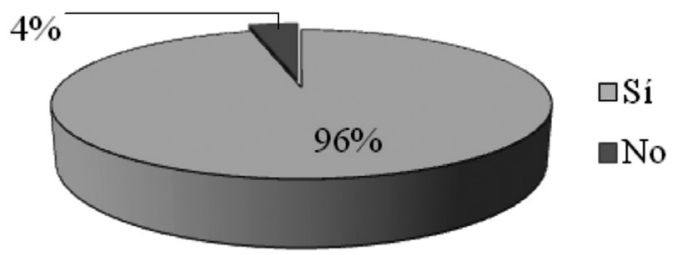


El tipo de entrenamiento que se imparte lo otorga el Sistema Nacional de Bibliotecas aproximadamente dos veces por año. Consiste en cursos de promoción y animación a la lectura, cursos de títeres, cursos de manualidades y cursos de mediación a la lectura, entre otros.

7. ¿Qué tipo de entrenamiento consideran importante recibir? Que les sea proporcionada capacitación más frecuentemente con la finalidad de convertirse en animadores de la lectura: cursos relacionados con la mediación de la lectura, de alfabetización en información, de relaciones humanas, talleres de dramatización, etcétera.

\section{Conclusiones}

Fortalezas y debilidades

El SINAB anhela que las bibliotecas cumplan una función dinamizadora del proceso cultural rico y variado de cada comunidad. Éstas deben ser centros de información, de lectura, de recreo y creación para los sectores populares, y aprovechar siempre el elemento organizativo de la comunidad cultural, dinamizando su funcionamiento, sin que por ello se asuma una actitud paternalista y filantrópica. El propósito es responder a la necesidad cultural de cada recinto, para generar cultura popular, respetarla, enriquecerla con otros aportes y generarla también, en la medida en que se realicen investigaciones para conservar la memoria colectiva.

No es fácil atender a los usuarios en sus demandas de información y conocimiento, ni formarlos en el manejo de los servicios y uso de la información virtual que les permita el trabajo intelectual con los soportes bibliográficos y documentales requeridos, lo que los ayudaría a lograr un real desarrollo de la investigación en los sectores científico y tecnológico.

Habría que poder motivar efectivamente hábitos lectores en los miembros de las comunidades atendidas e impulsar el desarrollo cultural del grupo a través del fortalecimiento de centros culturales comunitarios, que fueran ejes del desarrollo sociocultural y 
dinamizaran la participación comunitaria en la creación, producción, difusión, uso y disfrute de los bienes y servicios culturales. También sería necesario ampliar la red de bibliotecas fronterizas en las comunidades binacionales, para hacer de ellas hitos de integración y desarrollo cultural en el marco de la paz. Sería también bueno continuar con la producción editorial de los encuentros y mesas redondas convocadas en todo el país sobre temas de interés cultural con el patrocinio del SINAB.

Por otra parte, con la finalidad de colaborar con la rehabilitación de los ciudadanos privados de la libertad, el Sistema Nacional de Bibliotecas ascendió a las bibliotecas de los Centros de Rehabilitación Social de la provincia a la categoría de Centros Culturales de Rehabilitación Social, para lo cual se entregaron equipos de computación y audiovisuales en las cárceles 1, 2 y 3 ubicadas en el Ex Penal García Moreno y en la biblioteca del Centro de Rehabilitación de Mujeres, ubicada en El Inca. Se impartió el Taller de Capacitación Sobre Planificación Estratégica Institucional -2008, con el objetivo de desarrollar habilidades gerenciales mediante la participación activa del personal bibliotecario para una acertada gestión y evaluación institucional administrativa y de desempeño con calidad y transparencia. También se fortalece el proceso de regionalización con coordinadores y coordinadoras del SINAB.

Una de las debilidades que enfrentan las bibliotecas es la necesidad de formar bibliotecarios. Para ello se ha emprendido un proyecto trinacional "Leer sin fronteras" en el que participan la Biblioteca Nacional de Perú, la Biblioteca Nacional de Colombia y el Sistema Nacional de Bibliotecas del Ecuador que cuenta con el financiamiento de la Organización de Estados Americanos (OEA). Como parte del proyecto se realizó el Seminario-taller "Leer sin fronteras”, organizado por la OEA. Se ha previsto organizar éste periódicamente. Además una especialista en bibliotecología impartió el curso para todos los promotores de Ecuador e invitados de Colombia. Se realizaron 10 cursos regionales y asistieron promotores de 22 provincias del país. 


\title{
La biblioteca pública viajera en la formación de lectores a distancia en El Salvador
}

\author{
Olinda Estela Gómez Morán \\ Biblioteca "Dr. José Gustavo Guerrero", \\ Ministerio de Relaciones Exteriores, El Salvador
}

\section{HiSTORIA DE LAS BIBLIOTECAS PÚBLICAS}

T a Red Nacional de Bibliotecas en El Salvador fue creada por Decreto Ejecutivo Núm. 891, del 12 de febrero de 1992, publicado en el Diario Oficial, tomo 314, núm. 62, en el que se estableció la creación de la Unidad Coordinadora con la responsabilidad de supervisar todas las actividades del proyecto Red Nacional de Bibliotecas Públicas, que inicialmente debería funcionar en las cabeceras de los 14 Departamentos y 262 municipios que reúnen un total de 6875000 habitantes.

La Unidad Coordinadora es la responsable de instalar y asistir a la red. La primera biblioteca fue instalada en la ciudad de San Miguel, el 12 junio de 1992. La segunda en la de Santa Ana, el 17 de diciembre 1992, la tercera en la ciudad de Sonsonate, el 18 de mayo de 1993 y la cuarta se instaló en la ciudad de San Salvador el 14 de julio de 1993, contando con la presencia del presidente de México, Carlos Salinas de Gortari, quien la inauguró con el nombre de Biblioteca Pública "Chapultepec", en honor a la firma de los acuerdos de paz en El Salvador, que se realizaron en el Castillo de 
Chapultepec, en la ciudad de México, el 16 de enero de $1992 .{ }^{1} \mathrm{Ca}-$ be mencionar que la Biblioteca Pública "Chapultepec" es la biblioteca modelo, responsable de elaborar los programas que se desarrollan en las 14 bibliotecas instaladas a nivel nacional.

La normatividad de la Red Nacional de Bibliotecas de El Salvador se estableció el 16 de febrero de 1994 mediante el Decreto núm. 808, que promulga la Ley del Libro, cuyo Capítulo 1, artículos 7 y 8 , propone:

7. Defender el patrimonio literario, bibliográfico y documental de la nación por medio de la conservación y el desarrollo de un sistema nacional de bibliotecas y archivos;

8. Desarrollar una estrategia nacional de fomento de la lectura, del acceso al libro, la información, del fortalecimiento de la red de bibliotecas, archivos y centros de documentación, librerías y otros puntos de venta.

En febrero de 2008, como parte de la celebración del primer año de la biblioteca pública del departamento de Zacatecoluca, se puso en marcha el bibliobús, unidad acondicionada como biblioteca, dedicada a estimular la lectura en los jóvenes y que pretende visitar durante el año todas las bibliotecas públicas de El Salvador. Cuenta también con un área lúdica, donde los niños pueden recrearse y aprender al mismo tiempo.

Las 15 bibliotecas públicas que están sirviendo a la comunidad se han modificado gracias a la Agencia Sueca de Cooperación Internacional (ASDI), la Unidad Coordinadora y la Biblioteca Nacional, que han tenido un papel protagónico junto con la ayuda sueca. También han sido dotadas con estantería nueva, equipo de cómputo y mobiliario, libros, material lúdico y material de apoyo al Programa Fomento al Hábito de Lectura.

1 El gobierno mexicano aportó el mobiliario y las colecciones de las primeras 13 bibliotecas que conformaron dicha red. Los gobiernos centrales y municipales salvadoreños se encargaron de proveer las instalaciones, el personal, el mantenimiento y otros recursos necesarios. Concultura, organismo dependiente del Ministerio de Educación de El Salvador fue nombrado gestor del proyecto. 


\section{LA Red de Bibliotecas Públicas}

La Red de Bibliotecas Públicas depende de la Dirección Nacional de Espacios de Desarrollo Cultural del Consejo Nacional para la Cultura y el Arte, Concultura. Su misión es impulsar el desarrollo cultural en un marco integral propio de la razón de ser de la biblioteca pública, y su labor es garantizar el libre acceso a la información de los servicios, por ello las misiones y objetivos de la biblioteca pública, expuestos por la Unesco en 1994, son acordes con los principios fundamentales de la Dirección Nacional a la que pertenece la Red de Bibliotecas Públicas.

Objetivos generales

- Fortalecer la biblioteca pública mediante el trabajo organizado tomando en cuenta la planeación y ejecución en toda actividad a emprender, para la mejor obtención de resultados en términos de calidad y cantidad.

- Conocer, dominar y practicar tareas técnicas en el campo de la bibliotecología, servicios de información y difusión de actividades para el fomento de la lectura en la comunidad.

- Promocionar y gestionar recursos para la biblioteca a través de diversas estrategias de trabajo que conlleven a tener presencia institucional en la comunidad.

Objetivos específicos

- Organizar, elaborar y ejecutar toda clase de planificación estratégica pertinente para el accionar de la biblioteca pública como tal (programaciones semanales, mensuales, evaluaciones, estadísticas, guías didácticas, etcétera).

- Difundir eficientemente la información a través de los libros y promover la lectura creativa en la comunidad por medio del Programa del Fomento a la Lectura (PFL).

- Contribuir al desarrollo cultural y educativo de la comunidad demandante de los servicios.

- Promocionar ampliamente la biblioteca pública y realizar gestiones para obtener recursos por medio de diversas acciones y estrategias de trabajo orientadas hacia la comunidad en general. 


\section{Resultados DE LA ENCUESTA DE LeCTURA}

Políticas de lectura

1. ¿Su institución se rige por alguna política de lectura?

Del total de las bibliotecas encuestadas, ocho (que representan el $73 \%$ ) respondieron que no se rigen por ninguna política de lectura, y solamente dos de ellas, es decir, el $27 \%$, contestaron afirmativamente.

2. ¿Las actividades de promoción las realizan conforme a algún manual?

En cuanto a la aplicación de algún manual para realizar las actividades de promoción de la lectura, solamente dos (el $18 \%$ ) de las bibliotecas respondieron que sí, en tanto que las otras nueve (el $82 \%$ ) manifestaron no utilizar ningún manual.

Colaboraciones en actividades de promoción de la lectura

1. ¿La promoción de la lectura se desarrolla con otras instituciones u organismos?

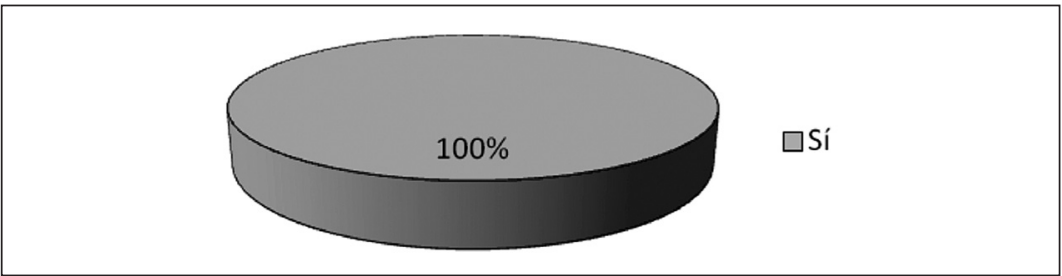

2. ¿En qué beneficia a la biblioteca la colaboración con instituciones u organismos?

La mayoría realiza la promoción con instituciones escolares tanto públicas como privadas.

Actividades de promoción de la lectura

1. ¿Realiza actividades de promoción a la lectura? 


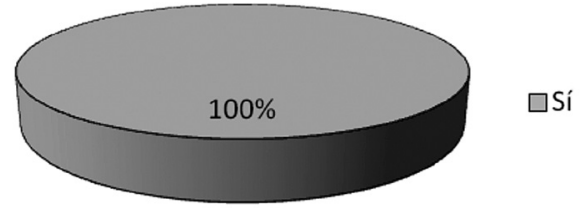

Se cuenta con el Programa de Fomento del Hábito de la Lectura, que es desarrollado entre febrero y diciembre de cada año, a nivel de las bibliotecas públicas distribuidas en todo el territorio nacional, responsables de que se realice el programa y se cumplan sus objetivos. Con éste se pretende fomentar el hábito de la lectura en niños, jóvenes, adultos y adultos mayores, incorporando elementos novedosos que propicien el acercamiento a la lectura y la formación de lectores asiduos a la biblioteca. Entre sus objetivos están:

- Difundir el Programa de Fomento del Hábito a la Lectura en los diferentes sectores de la comunidad a los cuales atiende.

- Dar a conocer la gama de bibliografía que posee la biblioteca en las diferentes áreas.

- Fomentar el gusto por la lectura en la comunidad.

- Contribuir al desarrollo cultural y educativo de los participantes en el programa.

- Promocionar la información a través de los libros y promover la lectura recreativa en los participantes por medio del programa.

- Crear en los participantes el uso de la biblioteca como herramienta necesaria para su desarrollo cultural y social.

Las actividades que se realizan son: círculo de lectura, visita guiada, maratones de lectura, hora de la fábula y la poesía, tertulia, juegos de investigación, charla cultural, hora del cuento, conversatorios, taller de creación literaria, semana cívica, programa de talleres "Mis vacaciones" y la celebración del libro infantil, del día del niño, del adulto mayor, de la amistad, de la cruz, de las madres, internacional de la poesía y del libro infantil y juvenil, del libro y derecho de autor (Semana Nacional de la Lectura). 
2. ¿Dónde realizan las actividades de promoción a la lectura? En las instalaciones de la biblioteca:

- A niños y niñas (semanal). Horas del cuento, la fábula, la poesía, así como juego de investigación y teatro en atril.

- Adolescentes y jóvenes (semanal). Visitas guiadas, charlas culturales, tertulias, teatro, entre otros.

Fuera de las instalaciones de la biblioteca:

- Niños y niñas (dos veces por año). En el parque de San Miguel (celebración del día del niño), hora del cuento.

- Niños y niñas (una vez al mes). En escuelas públicas (hora del cuento).

- Adultos mayores (dos veces por año). Promoción de los servicios con los pensionados, tertulias.

- Señoras (dos veces al mes). Charlas culturales en el mercado municipal apoyadas por Concultura.

Asimismo, en las 15 bibliotecas públicas del país, se llevan a cabo talleres y cursos vacacionales donde se les enseña a niños, niñas, jóvenes y adultos diferentes actividades manuales y académicas que redundan en su propio beneficio, tales como dibujo, piñatería, encuadernación, álgebra y aritmética, floristería, filigrana, etcétera. Éstos se imparten con el material bibliográfico existente en la biblioteca, durante los meses de febrero a diciembre, según el nivel. Las personas que han participado en los talleres continúan llegando, porque gracias a lo aprendido instalan sus pequeños negocios que les reditúan un beneficio económico. Y lo más importante es que siguen haciendo uso del material bibliográfico.

3. ¿La biblioteca ha creado otros espacios o puntos de acceso a libros y otros materiales?

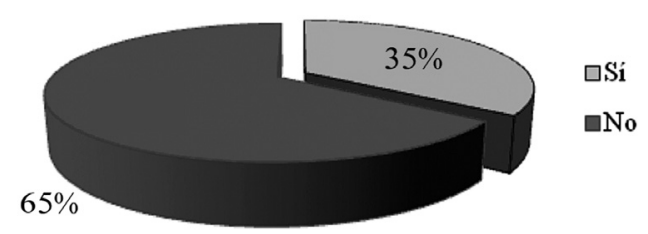


Independientemente del resultado de la Encuesta se pueden considerar otros espacios o puntos de acceso a libros y demás materiales, como las cajas viajeras y el bibliobús.

Cajas viajeras. Por medio de esta modalidad la Biblioteca Nacional y la Biblioteca Pública ofrecen el servicio de biblioteca sin muros. Ante la imposibilidad de crear bibliotecas permanentes en todo el país se ha implementado el servicio de las cajas viajeras, que con colecciones mínimas, renovables periódicamente, circulan a través del territorio nacional con material adecuado para los distintos centros escolares y las diferentes comunidades. Las cajas viajeras tienen una misión permanente de gran trascendencia, puesto que contribuyen de manera eficaz al desarrollo de la cultura en zonas rurales y urbanas. Además realizan actividades como la hora del cuento y los círculos de lectura. Este servicio se lleva a cabo desde 2007.

Las cajas viajeras son delegadas al maestro, el cual es capacitado para encargarse del cuidado de los libros, así como de la hora de la lectura de los niños y jóvenes y el préstamo de libros. Éstos son uno de los componentes del proyecto de formación en promoción de la lectura que posee la Red de Bibliotecas Públicas de El Salvador. Tomando en cuenta el diagnóstico sobre la situación de las bibliotecas escolares, la distribución de las cajas viajeras está programada para las comunidades donde hay escuelas que no cuentan con una colección de libros, ni mucho menos con una biblioteca escolar, y que están geográficamente muy alejadas. Las cajas viajeras abastecen esas poblaciones de lectura de manera periódica y más o menos permanente.

La selección de libros es el aspecto más difícil y el de mayor responsabilidad dentro de las múltiples tareas del bibliotecario. Y si se puede afirmar que esta labor es difícil para cualquier tipo de biblioteca, lo es aún más cuando se trata de seleccionar libros para cajas viajeras, dadas las condiciones físicas, climatológicas, etnográficas, económicas y sociales de cada zona. El proyecto toma en cuenta las necesidades que afrontan los estudiantes y los adultos, pero incluye obras infantiles y juveniles, así como otras sobre materias diversas que sirvan 
a los programas de estudio e intereses de la comunidad, tales como manuales de artes y oficios, divulgación agrícola, ganadería, actividades industriales, de salud, boletines, etcétera, además de obras sobre literatura, geografía, viajes, biografías y política.

Las cajas viajeras son una de las iniciativas que junto a los servicios del bibliobús convierten en realidad la idea de la biblioteca sin muros (o sin paredes) abierta y cercana a la comunidad.

Bibliobús, actividad exitosa. El bibliobús es otro servicio de extensión que fue donado por la Organización de las Naciones Unidas para la Educación, la Ciencia y la Cultura, Unesco, al Consejo Nacional para la Cultura y el Arte, Concultura (2006). El bibliobús depende de la Biblioteca Nacional y de la Red de Bibliotecas Públicas y es una unidad de transporte modificada y acondicionada como biblioteca, dedicada a estimular la lectura en los jóvenes. Cuenta también con un área lúdica donde los niños pueden recrearse y aprender al mismo tiempo, sin bajarse del autobús.

El bibliobús lleva libros pensando en toda la comunidad que va a servir y en todos los niveles: niños, jóvenes, adultos y adultos mayores; y también en el tipo de literatura, ya que el personal ha sido preparado para dichas actividades, entre las que podemos mencionar cuentacuentos, círculo de lectura, rincón infantil y otras, en las que se puede apreciar la alegría con la que la comunidad asiste para escuchar las charlas que les programan, y no solamente los niños disfrutan sino también los padres leen libros mientras sus hijos participan en las actividades.

4. ¿Considera que las actividades de promoción de la lectura son valoradas por los lectores y la comunidad?

Definitivamente por ambos, porque su participación es constante y se han convertido en usuarios potenciales con su presencia en la biblioteca. 
Habilidades del personal y necesidades de entrenamiento

1. ¿La promoción de la lectura forma parte del trabajo del personal de la biblioteca?

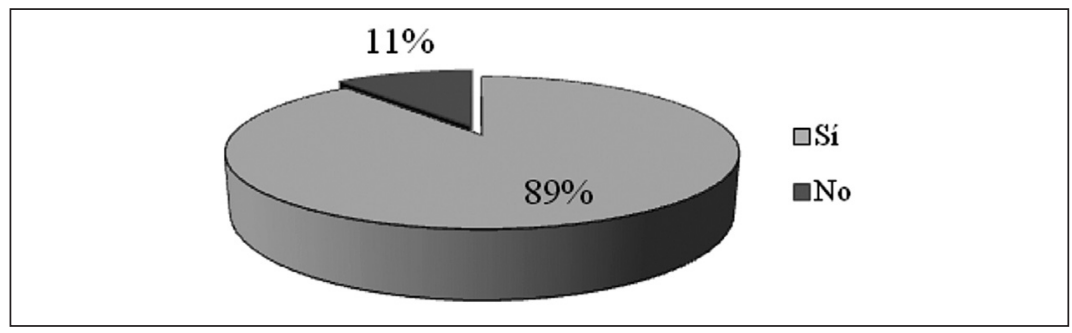

2. ¿La biblioteca tiene personal destinado exclusivamente a realizar actividades de promoción de la lectura?

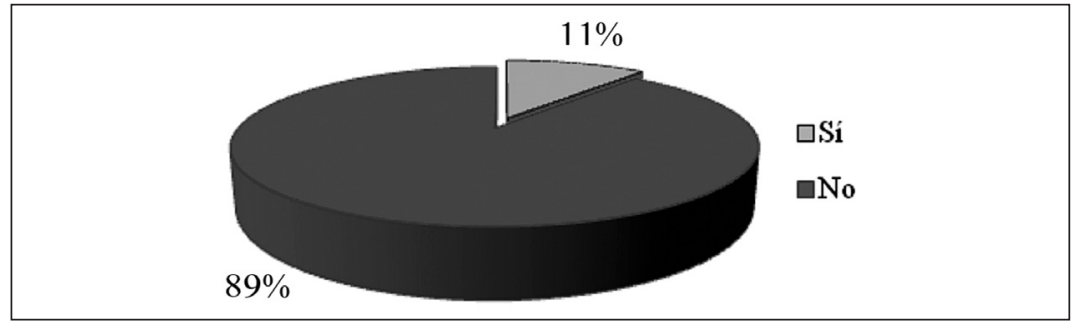

3. Actualmente, ¿qué habilidades son necesarias para promover la lectura?

- Ser interactivo.

- Tener imaginación.

- Desarrollar habilidades y destrezas para activar la participación grupal.

- Tener creatividad.

- Ser dinámico.

- Tener espíritu de servicio.

- Gustar de la lectura.

4. ¿Qué habilidades ayudarían a transformar a los no lectores en lectores que encuentren placer en la lectura y en los libros? 
Crear actividades nuevas que propicien el acercamiento a la lectura e incorporar elementos novedosos en el programa de fomento a la lectura. Leer con sabor, es decir, haciendo la lectura de una manera animada tomando en cuenta una preparación previa para el desenvolvimiento del tema ante el lector. Desarrollar actividades de lectura a través de presentaciones de libros que despierten el interés del nuevo lector.

5. ¿El personal de la biblioteca tiene la preparación y las habilidades para diseñar y desarrollar acciones para transformar a los no lectores en lectores aficionados a la lectura y al libro?

Cuentan con preparación, sin embargo sería importante contar con libros que les proporcionen los elementos necesarios para desarrollar una animación a la lectura. Como también importaría que la Red de Bibliotecas Públicas desarrollara más y mejores programas de capacitación que ayuden a desempeñar las actividades necesarias para transformar a los no lectores en lectores.

6. ¿Reciben entrenamiento para desarrollar destrezas para las actividades de fomento?

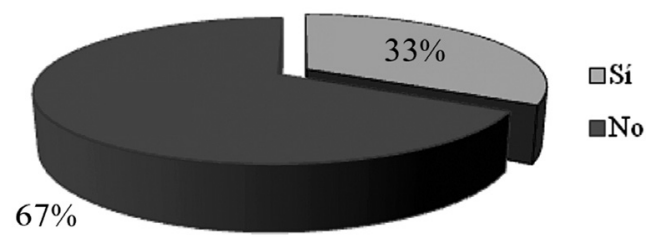

La coordinación de la Red de Bibliotecas Públicas es la encargada de realizar las capacitaciones de manera frecuente.

7. ¿Qué tipo de entrenamiento consideran necesario recibir?

- Invitar a otros colegas a presentar sus experiencias en la demostración de animaciones para la lectura.

- Desarrollar talleres creativos de promoción de la lectura en forma práctica. 


\section{CONCLUSIONES}

Fortalezas

Entre las fortalezas de las bibliotecas públicas tenemos:

a) Programa Fomento al Hábito de Lectura.

b) Personal calificado con el perfil para las actividades del Fomento del Hábito de la Lectura (profesionales).

c) Personal dispuesto a realizar las actividades que el FHL le encomiende.

d) Material bibliográfico actualizado.

e) Disposición de los usuarios en el mercado y en las instituciones escolares.

f) Participación en la Feria Internacional del Libro, con bibliotecas en pequeño con 300 libros variados.

g) Préstamo bibliotecario.

Debilidades

a) No se cuenta con un presupuesto exclusivo para las bibliotecas.

b) Se realizan las actividades con niños y no hay presupuesto para comprar el material ni para ofrecerles un pequeño refrigerio.

c) No se cuenta con fotocopiadora porque se dañó y no se reparó.

d) Se carece de transporte para el traslado del personal a las actividades de Fomento del Hábito de la Lectura y para llevar el material bibliográfico donde se realizará la actividad.

e) Falta de bolsones adaptables y apropiados para llevar el material fuera de la propia biblioteca.

f) En las bibliotecas públicas no se cuenta con aire acondicionado. 


\title{
La Red Nacional de Bibliotecas Públicas de México. La lectura y los servicios bibliotecarios
}

\author{
LOURDES LÓPEZ LÓPEZ \\ Dirección General de Bibliotecas, \\ Conaculta, México
}

\section{INTRODUCCIÓN}

$\tau$

a Red Nacional de Bibliotecas Públicas (RNBP) de México actualmente cuenta con 7261 recintos bibliotecarios, cada uno de los cuales constituye un espacio dedicado a la formación, información y recreación de los usuarios, a través de los libros y la lectura y un centro de convivencia social en los que se realizan diversas actividades de extensión cultural y educativa tales como talleres, cursos, exposiciones, visitas guiadas y presentaciones de libros.

Existen bibliotecas públicas en 2266 municipios de la República. De los 179 municipios que aún carecen del servicio, 176 se localizan en Oaxaca, dos en Guerrero y uno en el estado de México. Del total de bibliotecas en México, 31 son centrales estatales que son las de mayor tamaño en cuanto a infraestructura, cantidad de servicios proporcionados y número de empleados; 16 son centrales delegacionales, 218 regionales y 538 institucionales.

La instalación de Módulos de Servicios Digitales (MSD) ha constituido un importante apoyo no sólo para fortalecer el acceso a la información, sino para ampliar el acervo a través de las obras existentes en otras bibliotecas, cuyos portales están abiertos al 
público en general. Se cuenta con 2729 módulos en igual número de bibliotecas.

En la educación formal el fomento a la lectura no constituye un tema prioritario del nivel escolar; no obstante, en los últimos años se han realizado importantes esfuerzos por parte de los gobiernos locales para incrementar el número de lectores, prueba de ello es el impulso que se ha dado a la creación y consolidación de bibliotecas públicas, escolares, de aula y especializadas. Ante este panorama, la promoción del libro y la lectura constituye todo un reto para los bibliotecarios ya que en la mayoría de los casos, los no usuarios no cuentan con hábitos de lectura arraigados.

De este modo, a través de la aplicación de las encuestas de lectura se ha redescubierto que los mejores lugares para crear lectores eficientes y constantes son el hogar, la escuela y la biblioteca, pues a la fecha no se ha sabido de ningún país cuyos lectores se hayan formado por decreto.

Así, la capacitación en cuanto al fomento de la lectura del personal que labora en las bibliotecas es una tarea que la DGB asume con responsabilidad. La meta es que cada vez sean más los bibliotecarios los verdaderos promotores de la cultura, interesados en compartir con el público en general sus conocimientos en torno a los libros.

Con la aplicación de la Encuesta Internacional de Lectura entre el personal bibliotecario, se permitió constatar que, aun cuando los trabajadores están conscientes de la importancia que tiene la lectura para el desarrollo de su trabajo, no siempre cuentan con los elementos teórico-prácticos necesarios para poder promover la palabra escrita entre los usuarios. También se detectaron áreas de oportunidad para la mejor planeación de las actividades vinculadas con el fomento de la lectura, que es un tema de interés nacional.

Además, al ser complementada la información con los resultados de la Encuesta Nacional de Lectura del Conaculta y los del Instituto de Investigaciones Jurídicas de la UNAM (2006), pudieron conocerse los principales aspectos de la lectura en México y la interpretación crítica de las dos investigaciones apoya a los responsables de la toma de decisiones, para que las actividades y acciones 
a favor de la promoción de la lectura se fundamenten con base en datos tomados de la realidad nacional actual y que sean acordes con el Programa Nacional de Cultura 2007-2012, para que incidan verdaderamente en la formación de lectores autónomos, críticos y responsables.

\section{REFLEXIONES EN TORNO A LOS RESULTADOS DE LA ENCUESTA INTERNACIONAL DE LECTURA EN MÉXICO}

Para el gobierno mexicano la promoción de la lectura desde las bibliotecas públicas constituye una actividad primordial, ya que éstas cuentan con acervos de carácter general cuyos contenidos interesan prácticamente a cualquier tipo de persona. Entre las distintas instituciones públicas, la biblioteca es una de las más democráticas, pues para acceder a la mayoría de sus servicios no se pide ningún requisito; no obstante, posicionarse entre los lugares de mayor recurrencia es un reto constante para las bibliotecas.

Para lograr lo anterior es necesario que el personal conozca la normatividad vigente, las políticas de lectura y que utilice a su favor los conocimientos adquiridos a través de la capacitación. En relación con esto, durante la aplicación de la Encuesta 60 \% de los bibliotecarios mencionó que la biblioteca no se rige por políticas de lectura.

Cabe señalar que todas las actividades de las bibliotecas públicas se enmarcan en la Ley General de Bibliotecas (con carácter federal y de observancia general), y en un Reglamento General de los Servicios Bibliotecarios (donde se da conocer al personal encargado de otorgar los servicios cuál es el marco normativo que los rige), además de que existe una serie de manuales e instructivos editados por la DGB que desarrollan y especifican las estrategias y técnicas para la correcta aplicación de las actividades intrínsecas y de la promoción de la bibliotecas; se subraya su compromiso de difundir la cultura, así como el fomento a la lectura, sin olvidar que todo está en función del proyecto establecido en el Programa Nacional de Cultura (PNC). Gracias a la Encuesta se supo que $55 \%$ del personal conoce los manuales y los utiliza. 
En cuanto al impacto de las actividades de fomento para la lectura, la DGB únicamente cuenta con factores numéricos obtenidos a través de la estadística mensual, que cada una de las bibliotecas envía a sus coordinaciones estatales para ser integradas en el informe que cada estado le envía mensualmente a la DGB. Como tarea pendiente falta todavía la elaboración de indicadores cualitativos que permitan conocer el impacto de las actividades con respecto a los usuarios atendidos.

En lo relacionado a los foros utilizados por el personal bibliotecario para promover al libro, la Encuesta muestra que aunque la biblioteca es el lugar en que se realiza la mayoría de las actividades, también se utilizan espacios externos como parques, centros comerciales y escuelas, por mencionar sólo algunos.

Entre las características que el personal bibliotecario considera importantes para realizar actividades de fomento de la lectura destacan: iniciativa, dinamismo, creatividad, conocimiento del material de lectura, motivación, organización, disposición y un profundo conocimiento del público usuario. Con respecto a las habilidades que deben desarrollar los bibliotecarios, el personal mencionó que es necesario aprender nuevas y variadas estrategias de motivación lectora, desarrollar la creatividad, ser sociable y procurar un trato amable, conocer las características del lector, además de manejar apropiadamente las dinámicas de integración, animación y análisis literario.

Un aspecto que se debe desarrollar dentro de los cursos de capacitación, señalado por el personal bibliotecario, se refiere a las técnicas para la conquista de nuevos usuarios, analizar el perfil de la comunidad para planificar la oferta de servicios culturales y elevar la calidad de los de fomento a la lectura.

Ante ello la DGB proporciona cursos y talleres de capacitación vinculados con el fomento a la lectura, entre los que destacan: Curso Básico de Fomento de la Lectura; Taller de Lectura en Voz Alta y Narración Oral Escénica; Ambientación de Bibliotecas para la Promoción del Libro y la Lectura; Lectura, Arte y Cultura para jóvenes; TIC y Bibliotecas, La Lectura y las Nuevas Tecnologías de la Información y la Comunicación. Un lugar privilegiado lo ocupa el Programa Nacional "Mis vacaciones en la biblioteca". 
Sin embargo, quizá sea necesario que el propio bibliotecario sea quien esté convencido de que la lectura puede sostenerse por sí misma para atrapar al lector potencial, y que la manualidad, a la que tanto se ha recurrido para mantener interesado al usuario, no sea un elemento sustantivo sino el producto de una actividad por demás interesante que es la lectura: creativa, recreativa y crítica.

En conclusión, los resultados de la Encuesta Internacional de Lectura constituyen una importante aportación para la toma de decisiones de quienes tienen la responsabilidad de promover la palabra escrita, sin olvidar al bibliotecario que es el intermediario entre los libros y los lectores.

\section{Resultados de la Encuesta en MéXico}

\section{Políticas de lectura}

1. ¿Su institución se rige por alguna política de lectura?

La respuesta del $68 \%$ de entrevistados fue negativa; menos de la tercera parte, el $23.3 \%$, dijo contar con alguna política, y el $8.7 \%$ se abstuvo de responder.

2. ¿Las actividades de promoción se realizan conforme a algún manual?

De acuerdo con las respuestas se hace necesario enfatizarles a los bibliotecarios que existe una variedad de manuales en los que se desarrollan ampliamente las estrategias de promoción de fomento a la lectura, ya que el 55 \% de los encuestados menciona que estas actividades se llevan a cabo con el apoyo de manuales y el $34 \%$, parece desconocerlos o no recurrir a ellos (no contestó a la pregunta el restante $10.7 \%$ ).

Por su parte, algunos coordinadores estatales establecen lineamientos específicos para sus redes de bibliotecas, con base en los programas culturales que son difundidos por medio de la Secretaría de Cultura del Estado o sus institutos de cultura. Por ejemplo, en Quintana Roo cada mes se establecen temas para promover el libro y la palabra escrita, y se propone una calendarización de actividades. De este modo, aunque los manuales 
son un referente importante para poder desarrollar las técnicas de impartición de las actividades de promoción a la lectura, los bibliotecarios pueden desarrollar otras, si aplican su creatividad y conocen a su público.

Colaboraciones en actividades de promoción de la lectura

1. ¿La promoción de la lectura la desarrolla con otras instituciones u organismos?

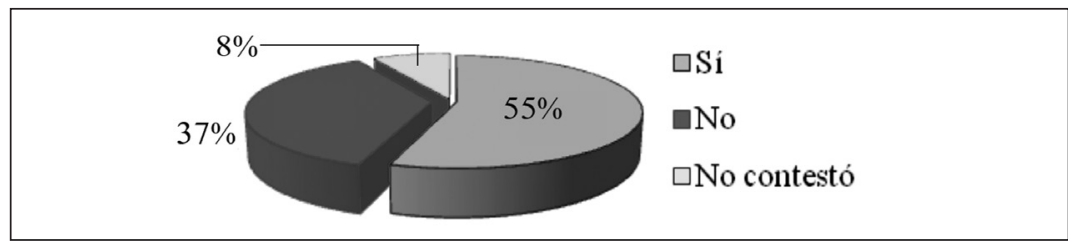

A pesar de que diversas instituciones llevan a cabo actividades y talleres de fomento, únicamente $55.3 \%$ de los bibliotecarios trabaja en forma coordinada con otras instituciones. El resto desconoce quiénes las realizan por lo que en varias entidades duplican los esfuerzos. Debido a ello, sería conveniente que los diversos gestores culturales procuraran trabajar en forma coordinada y con objetivos y proyectos claros y específicos, para que los esfuerzos de todos se vean reflejados en mayores beneficios para los usuarios.

Actualmente la DGB colabora con diferentes áreas del Conaculta, escuelas de educación básica y media, centros de desarrollo, DIF, Secretaría de Salud, asociaciones civiles y centros culturales, entre otras institutciones. Pero aún falta establecer acuerdos específicos y calendarizados con los institutos, las secretarías de cultura estatales y las escuelas de nivel medio y superior, para poder abarcar un público más amplio. Otras acciones que se podrían coordinar son las presentaciones de libros, las charlas con autores y las coediciones.

La DGB tiene como prioridad la promoción de la biblioteca pública y con ello el fomento a la lectura a través de la formación de una red de promotores. Entre ellos destaca la participación de 
fideicomisarios de las bibliotecas (quienes tienen generalmente conexiones políticas con influencias para abogar sobre los intereses de la biblioteca y de su comunidad); amigos de la biblioteca (que fungen como embajadores para que los legisladores tomen en cuenta los asuntos de las bibliotecas); líderes institucionales de la comunidad (como directores de escuelas, rectores de las universidades y directivos de empresas, quienes ayudan a que el mensaje se escuche en los niveles más altos de la comunidad), y especialmente a muchos usuarios de las bibliotecas y a los bibliotecarios.

2. ¿En qué beneficia a la biblioteca la colaboración con instituciones u organismos?

Se acrecienta la afluencia de usuarios, se capacita mejor al personal, se crean nuevos programas y diferentes actividades, se beneficia la relación con sus programas de lectura, se consolida el uso de la biblioteca, se promueve a la biblioteca y se motiva al lector a vincularse con el fomento del hábito de la lectura, a ampliar el margen de acción de los programas culturales, educativos y de fomento a la lectura, a coordinar proyectos a favor de la recaudación de fondos para mejorar la biblioteca y programar acciones en beneficio de las comunidades y desarrollar eventos conjuntos para ampliar los foros de fomento a la lectura. Cuando la biblioteca tiene algún impedimento para poder impartir los talleres de fomento a la lectura o desarrollar actividades dentro de la misma, se promueven los servicios de extensión.

Actividades de promoción a la lectura

1. ¿Realiza actividades de promoción a la lectura?

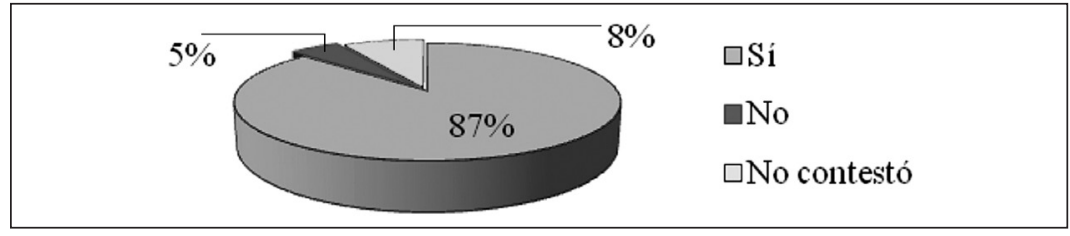


Es evidente que el número de bibliotecarios que desarrollan programas y talleres de fomento a la lectura es muy alto (87.3\%), pero aún quedan muchos aspectos por perfeccionar. Sería interesante conocer el impacto real en las comunidades, ya que se ha observado que no todos los asistentes a los talleres o actividades de la biblioteca son usuarios permanentes de ellas.

Para conocer el impacto de los talleres y acciones de promoción del libro y la lectura, la DGB les solicita a las bibliotecas públicas un informe estadístico mensual sobre cuáles han sido sus actividades de fomento a la lectura y cuántos fueron sus asistentes, pero dichos datos son únicamente cuantitativos, queda como reto establecer indicadores cualitativos que podrían reflejar con mayor precisión el impacto de dichas acciones.

2. ¿En dónde realizan las actividades de promoción a la lectura? Dentro de la biblioteca:

- Dirigidas a los niños, a través de círculos de lectura y la hora del cuento. A jóvenes y adultos, por medio de visitas guiadas, bibliomanualidades, "Mis vacaciones en la biblioteca", rescate de la tradición oral, charla literaria, actividades culturales, tertulias, escritura creativa, actividades lúdicas, talleres infantiles, teatro en atril, actividades de presentación y actividades de integración.

Fuera de la biblioteca:

- Las actividades se organizan para niños, jóvenes y adultos y se llevan a cabo en escuelas primarias, parques, plazas comerciales y centros culturales, en donde se nos permita realizar los servicios de extensión.

3. ¿La biblioteca ha creado espacios o puntos de acceso a libros y otros materiales?

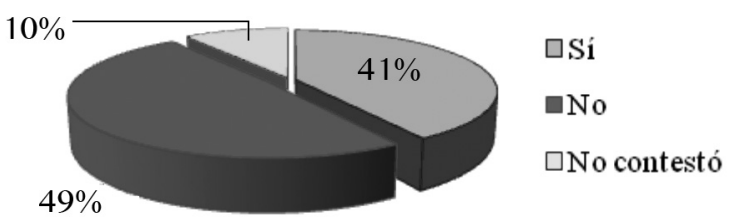


4. ¿Considera que las actividades de promoción de la lectura son valoradas por sus lectores y la comunidad?

Las actividades de promoción son ciertamente reconocidas por la comunidad, a juzgar por su asistencia y participación. También es común que se invite a los bibliotecarios a participar en ferias del libro y otros eventos culturales. No obstante, aun cuando a los talleres programados de fomento a la lectura asisten muchos usuarios, esta tendencia no se ve reflejada en la asistencia cotidiana a la biblioteca, lo que significa que no se ha logrado consolidar el hábito de la lectura entre la población. Esto implica un reto, no sólo para la biblioteca pública sino también para las instituciones educativas en general.

Habilidades del personal y necesidades de entrenamiento

1. ¿La promoción de la lectura forma parte del trabajo del personal de la biblioteca?

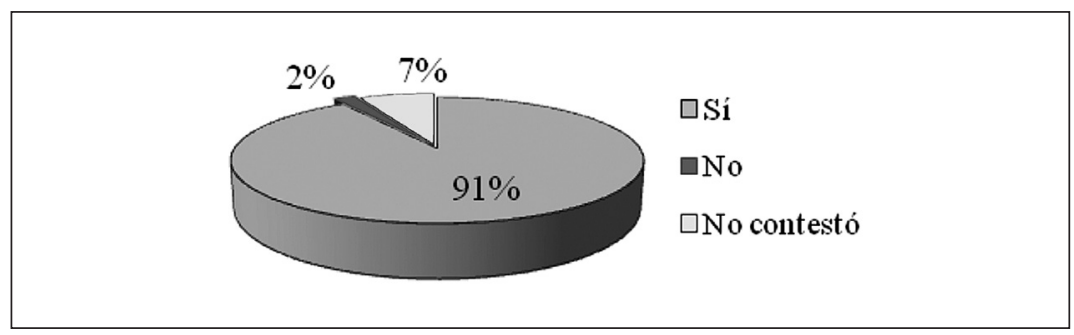

Evidentemente, existe una clara conciencia por parte del personal de las bibliotecas públicas de que una de sus características como trabajadores de la educación está vinculada con la promoción del libro y la lectura, que son sus instrumentos de trabajo por excelencia.

2. ¿La biblioteca tiene personal destinado exclusivamente a realizar actividades de promoción de la lectura? 


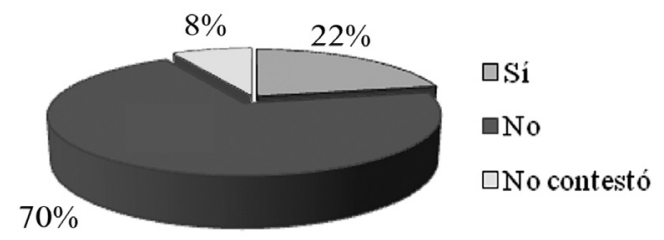

Es preciso señalar que las bibliotecas públicas en general cuentan con un mínimo de recursos humanos para desarrollar las actividades inherentes a su ámbito laboral; por lo anterior, la DGB ha hecho el esfuerzo de diseñar actividades de fomento a la lectura teniendo en cuenta la movilidad y carencia de capacitación de muchos bibliotecarios. De las bibliotecas que operan en el país, sólo 22 \% cuenta con personal dedicado exclusivamente a realizar actividades de fomento a la lectura. Entre las habilidades que los bibliotecarios distinguen como necesarias para transformar a los no lectores en lectores habituales se encuentran: la creatividad, la sociabilidad, el trato amable, el gusto por la lectura y el conocimiento del material de lectura, entre las más importantes.

3. Actualmente, ¿qué habilidades son necesarias para promover la lectura?

Iniciativa, dinamismo, creatividad, conocimiento del material de lectura, motivación, organización, buena presentación, disposición y un profundo conocimiento de su público usuario. En el trabajo bibliotecario no debe tener importancia el ofrecer "todo a todos" de forma experimental y tanteando el acercamiento, lo que se debe tener perfectamente claro es la "oferta bibliotecaria”. Hay que reconocer que la gestión efectiva para los programas de fomento a la lectura puede definirse simplemente como "servicio por uso". El usuario recibe lo que necesita (a través de los talleres de fomento a la lectura) a cambio del uso de la biblioteca, un servicio. Para ello es necesario saber: ¿cuál es nuestra labor? ¿Quiénes son nuestros usuarios? ¿Quiénes nuestros no usuarios? ¿Quién de los pertenecientes al grupo de los no usuarios puede pertenecer al de usuarios potenciales? 
4. ¿Qué habilidades ayudarían a transformar a los no lectores en lectores que encuentren placer en la lectura y en los libros?

Estrategias de motivación lectora, creatividad, sociabilidad y trato amable, así como fomentar el gusto por la lectura, desarrollar talleres de acuerdo a etapas lectoras (los que empiezan a leer, los que leen bien y los lectores asiduos), establecer dinámicas de integración que permitan crear unión de grupo a través de experiencias vivenciales que permitan un ambiente relajado y armónico; tanto así que el o la lectora se adapten a una reunión social que alcance el estatus de un club de lectores. Específicamente que sea un medio donde el usuario encuentre la posibilidad de alcanzar su desarrollo personal de forma agradable.

5. ¿El personal de la biblioteca tiene la preparación y las habilidades para diseñar y desarrollar acciones para transformar a los no lectores en lectores aficionados a la lectura y al libro?

Contestaron afirmativamente, pero necesitan aplicar más acciones para transformar a los no lectores. En general el personal bibliotecario valora la capacitación que ha recibido y es capaz de desarrollar programas de promoción del libro y la lectura, además de conocer diversas técnicas y actividades de animación. La idea principal es incursionar sobre los principios y la práctica de la mercadotecnia para las instituciones sin fines de lucro, es decir, la mercadotecnia como actitud mental, en donde lo importante es la planificación, la evaluación y el rediseño. Asimismo es necesario conocer y analizar el perfil de la comunidad para planificar la oferta cultural y anteponer la calidad frente a la cantidad.

6. ¿Reciben entrenamiento para desarrollar destrezas?

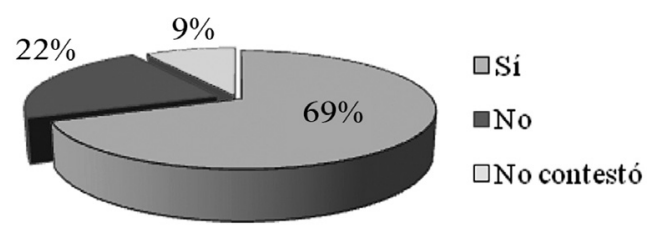


La DGB proporciona talleres de capacitación vinculados con el fomento de la lectura, entre los que destacan los siguientes: Curso Básico de Fomento de la Lectura; Taller de Lectura en Voz Alta y Narración Oral Escénica; Ambientación de Bibliotecas para la Promoción del Libro y la Lectura; Lectura, Arte y Cultura para jóvenes; La Lectura y las Tecnologías de la Información y la Comunicación, Voces Jóvenes en tu Biblioteca; Talleres de Lectura "Para no olvidar", destacando el Programa Nacional "Mis vacaciones en la biblioteca" en el que participan usuarios principalmente del sector infantil y juvenil.

7. ¿Qué tipo de entrenamiento consideran necesario recibir? Entrenamiento sobre fomento a la lectura, cursos de relaciones humanas, entrenamiento en mercadotecnia, cursos en motivación, creatividad, oratoria, narrativa y manualidades, así como talleres dedicados a la familia y adultos mayores.

También sería necesario que el propio bibliotecario esté convencido de que la lectura puede sostenerse por sí misma para atrapar al lector potencial, y de que la manualidad no es un elemento sustantivo sino el producto de la lectura, una actividad por demás interesante, creativa, recreativa y crítica.

\section{CONCLUSIONES}

Fortalezas y debilidades

Lograr la satisfacción de las necesidades de información, formación y recreación de los usuarios debería ser el principal objetivo de las actividades y talleres de fomento de la lectura, y como común denominador tendría que buscar más la calidad que la cantidad de las actividades. Si logramos que por lo menos el $80 \%$ de nuestros bibliotecarios sean lectores activos, críticos y propositivos, seguramente el panorama de la lectura podría ser más halagüeño. 


\title{
Los avances de las bibliotecas públicas y la lectura en Panamá
}

\author{
Octavio Castillo SÁnchez \\ Universidad de Panamá (SIBIUP)
}

\section{ANTECEDENTES}

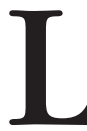

a Biblioteca Nacional "Ernesto J. Castillero R." tiene el objetivo de propiciar el desarrollo y fortalecimiento de las bibliotecas públicas para que cumplan su misión de brindar acceso a toda la población. Su función es la coordinación nacional ante la Red Nacional de Bibliotecas Públicas como unidad responsable de gestionar permanentemente las acciones relacionadas a su integración y fortalecimiento. Sus acciones están encaminadas a ofrecer el funcionamiento permanente de la Red como un ente normativo, orientador, promotor, capacitador y evaluador dentro del marco de las políticas definidas y los recursos provistos por la Fundación Pro Biblioteca Nacional y las diferentes coordinaciones especializadas en materia de servicios bibliotecarios. En 1996 fue creada la Fundación Biblioteca Nacional y dos años más tarde se firmó un convenio con el Ministerio de Educación para la Administración de la Biblioteca Nacional y la Red de Bibliotecas Públicas adscritas a ésta.

La Biblioteca Nacional posee una estructura organizativa integrada por una Junta Directiva, el cuerpo de asesores, la Dirección Técnica, la Dirección Administrativa y una serie de coordinaciones, 
secciones y unidades para su desarrollo y funcionamiento. Dentro de la Dirección Técnica está la Coordinación de la Red de Bibliotecas Públicas, las bibliotecas públicas ubicadas en las cabeceras de provincia que fungen como enlace con la Coordinación Nacional de Bibliotecas Públicas y el resto de las que están en distritos y corregimientos del país.

La Red Nacional de Bibliotecas Públicas adscrita a la Biblioteca Nacional de Panamá está conformada por 60 bibliotecas públicas distribuidas en las provincias de Bocas del Toro, Chiriquí, Coclé, Colón, Darién, Herrera, Los Santos, Panamá, Veraguas y Comarca Kunayala.

\section{Servicios culturales}

Se organizan una serie de acciones en las bibliotecas encaminadas a:

- Actividades de fomento a la lectura entre niños y jóvenes como la hora del cuento, cuentacuentos, talleres de expresión y de creatividad, encuentro con escritores, etcétera, así como para el público adulto.

- Exposiciones bibliográficas, de arte y científicas; conferencias, mesas redondas, recitales y veladas literarias; presentaciones teatrales, cursos y talleres sobre temas de interés local.

- Actividades de fomento e impulso para la narración oral.

- Otras actividades que impulsen las manifestaciones culturales de la comunidad

\section{Recursos económicos}

La biblioteca pública debe contar con una fuente de financiación estable que asegure su creación, funcionamiento y desarrollo eficaz, así como su calidad. Por ello elabora un presupuesto de inversiones y funcionamiento para el desarrollo del plan de trabajo, ambos anuales, el cual es presentado a la Coordinación Nacional de la Red de Bibliotecas Públicas y a su vez a la Dirección Técnica 
de la Biblioteca Nacional, para ser llevado a la Junta Directiva de la Fundación Biblioteca Nacional. Estas financiaciones pueden ser:

- Instancias del Gobierno Central-Ministerio de Educación.

- Fundación Biblioteca Nacional.

- Subvenciones del Gobierno Local.

- Organismos públicos y privados.

- Donaciones de Organismos Nacionales e Internacionales.

- Actividades de autogestión.

Recursos de infraestructura, mobiliario y equipo

Dentro de la Red, 16 bibliotecas públicas tienen comités de amigos que funcionan como apoyo. La mayoría recibe poco o mínimo apoyo a nivel municipal y nacional por parte del Ministerio de Educación, el cual en ocasiones resulta escaso. Para las bibliotecas públicas de la Red el apoyo de la Fundación Biblioteca Nacional es bastante adecuado.

\section{Actividades de fomento a la lectura}

La Biblioteca Nacional de Panamá ofrece una serie de actividades incluyendo la presentación de libros en talleres y seminarios sobre lectura, literatura y cuentos. Un ejemplo es el programa orientado a adultos "Cuentos sobre Cuentos", donde escritores leen sus libros y conversan con el público adulto. Como parte del personal de la biblioteca, un promotor de lectura ofrece entrenamiento para grupos (como maestros, bibliotecarios y padres) en el fomento o la promoción de la lectura. Este personal promueve los servicios por medio de su página en el boletín mensual, anuncios y artículos en la prensa y el radio, y además mantiene un mural informativo en la biblioteca.

También se desarrollarán una serie de iniciativas para fortalecer el fomento de la lectura, como Siembra de Lectores; Cafés docentes de APALEC; Círculo de Lectura de la Universidad Latina; Embajadoras de la Lectura; El Abuelo de Mi Abuela; Salas Infantiles en 
Bibliotecas Públicas; Bibliobús del Parque; Asociación de Voluntarios Promotores de Lectura; Para Darle Cuerda al Sol; Talleres de Piali y Bibliobús de Chiriquí, que es una biblioteca móvil instalada en un vehículo rodante que pertenece a la Red de Bibliotecas Públicas y funciona como una pequeña biblioteca pública en diferentes localidades y está a disposición del público de todas las edades. El bibliobús es considerado uno de los proyectos con más éxito. Cuenta con una colección que incluye documentos de consulta como enciclopedias, atlas, diccionarios, libros de contenido general y obras para niños y jóvenes. Su objetivo general es garantizar el derecho a la información, cultura, educación y recreación a las poblaciones de las comunidades desfavorecidas, distantes o que no poseen servicios bibliotecarios permanentes. En su recorrido brinda servicio en ruta fija a los siguientes sitios:

- Barriada Guaymí, corregimiento de Las Lomas, distrito de David.

- Comunidad El Flor y comunidad de Balita, corregimiento de Tinajas, distrito de Dolega.

- Granja de Menores, comunidad de Potrerillos, distrito de Dolega.

- Comunidad de Bijagual, distrito de David.

- Comunidad de San Pablo Arriba, distrito de David durante los meses de verano.

Adicionalmente se efectúan giras mensuales programadas a diferentes escuelas en toda la provincia de Chiriquí, las provincias centrales y Azuero. Los servicios que se ofrecen de manera gratuita son:

- Información sobre temas de interés general para niños y adultos y materiales especiales de las comunidades.

- Consulta y préstamo de documentos.

- Préstamo interbibliotecario.

- Formación de usuarios.

- Actividades de fomento a la lectura especialmente dirigidas al público infantil y juvenil como la hora del cuento, talleres 
de creatividad literaria, caja viajera, clubes de lectura, concursos de dibujo y pintura infantil, cuentacuentos, proyección de vídeos educativos, entre otras.

- Charlas de orientación en temas de interés para la comunidad.

\section{Acciones a favor de la lectura}

En 2007 se realizó un Foro Nacional del Libro y la Lectura cuyo resultado fue el surgimiento del Plan Nacional de Lectura (PNL) ${ }^{1}$ gracias a la participación de un grupo interinstitucional y de la sociedad civil. Las líneas de acción fueron diseñadas con base en seis ejes temáticos: posicionamiento de la lectura como política de Estado; estímulo a la creación de materiales de lectura; creación, desarrollo y fortalecimiento de la biblioteca pública; acciones para la formación de actores en promoción de lectura; acciones para fortalecer la lectura en la escuela, y los medios de comunicación y la lectura.

La organización estructural parte de la Secretaría del Plan Nacional de Lectura adscrita a la presidencia de la República, a su vez este ente posee un vínculo con el Foro Nacional de Lectura que tiene funciones de asesoría permanente y es una instancia compuesta por representantes de todas las instituciones participantes en el plan. El PNL atiende sin distingo social o de cualquier otra índole a todos los panameños o residentes en el país, y sus acciones están dirigidas a infantes, niños y jóvenes, el sector familiar, docente, bibliotecario y de los mediadores de lectura. Sus objetivos generales son:

- Establecer el tema de la lectura como un asunto de interés público para el país.

- Promover de forma permanente y gradual el interés por la lectura en todos los sectores del país, a partir de proyectos institucionales de educación y de cultura.

- Proporcionar la publicación del trabajo intelectual de los autores nacionales en los diferentes formatos de lectura.

1 La información que presentamos en este apartado fue extraída de la siguiente dirección electrónica: http://www.binal.ac.pa/PNL/ 
- Ofrecerle a la población espacios de lectura modernos y dinámicos que coadyuven a la construcción de nuevos conocimientos y fortalezcan su identidad cultural.

- Lograr que el sistema educativo utilice la lectura como una herramienta para el desarrollo integral del ciudadano, que potencie la capacidad de reflexionar, construir juicios e ideas y mejore su calidad de vida.

- Incorporar y comprometer a los medios de comunicación y a las diversas instancias educativas a realizar proyectos para el fomento y la promoción de la lectura.

El PNL tiene como una de sus metas desarrollar un sistema nacional de bibliotecas que acompañe y despierte el hábito de lectura y el comportamiento lector de la población. También deberá articular estrategias en las escuelas urbanas y rurales, los institutos de enseñanza que imparten formación cultural bilingüe y los centros penitenciarios. Habrá de formar también a quienes asuman la responsabilidad de abrir los espacios que permitan el accionar del PNL.

\section{RESUlTAdOS DE LA ENCUESTA DE LECTURA}

Políticas de lectura

1. ¿Su institución se rige por alguna política de lectura?

Respecto a esta pregunta, del total de las bibliotecas encuestadas $67 \%$ manifestó que sí se rigen por una política de lectura, el $33 \%$ restante respondió negativamente.

2. ¿Las actividades de promoción las realizan conforme a algún manual?

Solamente $10 \%$ respondió que sí utilizan manual, 50 \% manifestó que no y el 40 \% restante se abstuvo de contestar la pregunta.

Colaboraciones en actividades de promoción de la lectura

1. ¿La promoción de la lectura la desarrolla con otras instituciones u organismos? 


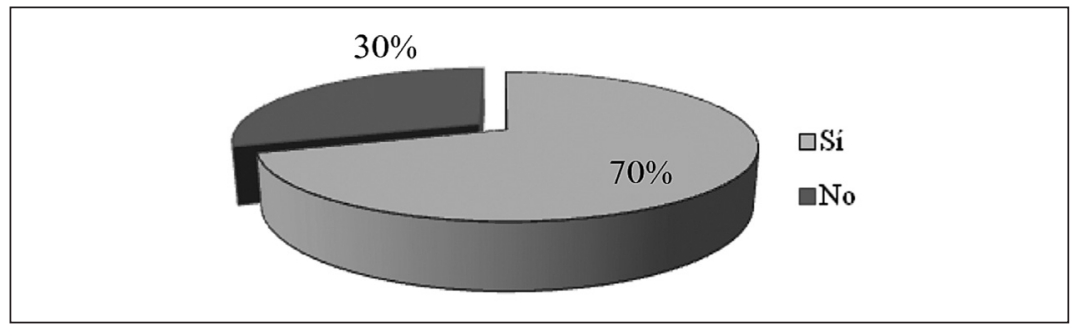

Las instituciones con quienes se realizan estas actividades son: MEDUC, MIDES, BINAL, INAC, Club de Leones, Gobernación, Universidades, FNR.

Actividades de promoción a la lectura

1. ¿Realiza actividades de promoción a la lectura?

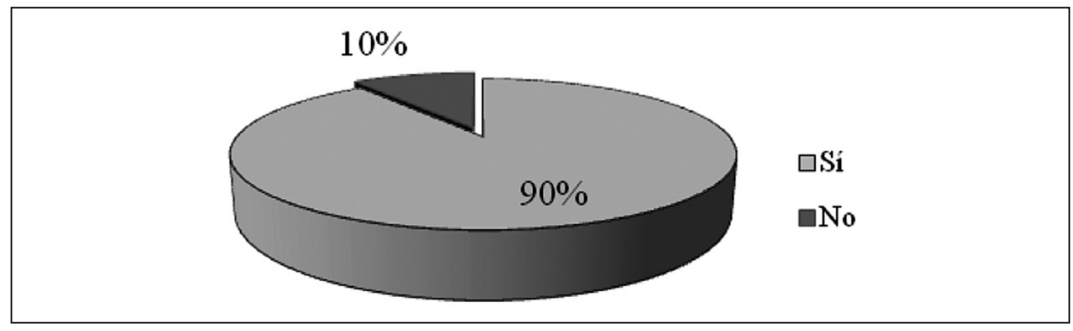

Véase el apartado "Actividades de fomento a la lectura", en Antecedentes.

2. ¿Dónde realizan las actividades de promoción a la lectura?

En las instalaciones de la biblioteca:

- Para escuelas, semanalmente: Hora del cuento, Adivinanzas dinámicas y talleres de dibujo.

- A niños de la comunidad, una vez al mes: Festival de la poesía.

- A adultos de la comunidad, una vez al mes: Círculos de lectura.

- A funcionarios del municipio, dos veces por semana: Círculos de lectura. 
Fuera de las instalaciones de la biblioteca:

- En las casas-hogar, una vez al mes: Hora del cuento.

- En escuelas, una vez al mes: Bolsas viajeras.

- Con los indígenas, una vez por semana: Juegos y rondas.

- Con la comunidad rural, semanalmente: Talleres de dibujo.

- Para los niños de los funcionarios del municipio, una vez por mes: Guías ecológicas.

3. ¿La biblioteca ha creado otros espacios o puntos de acceso a libros y demás materiales?

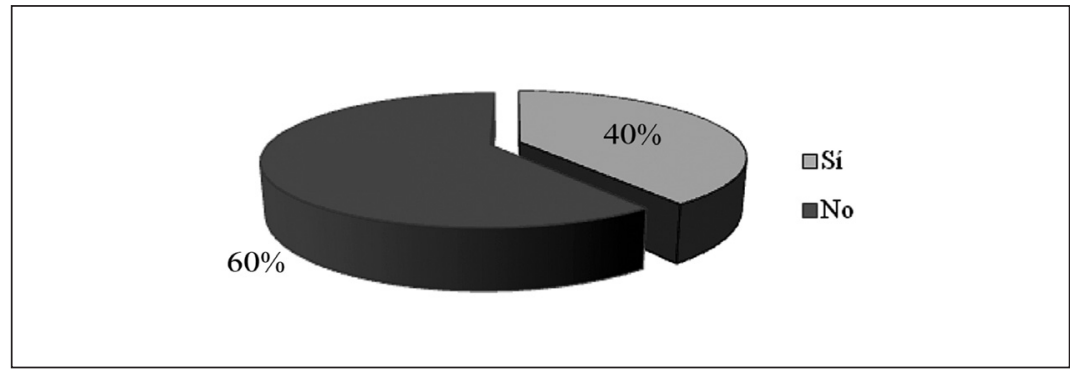

Se trata de videotecas y materiales para diabéticos (véase lo relativo al Bibliobús de Chiriquí en Antecedentes).

4. ¿Considera que las actividades de promoción de la lectura son valoradas por sus lectores y la comunidad?

Sí lo son por ambos, y se manifiesta a través de sus participaciones en las diferentes actividades que se organizan en las bibliotecas. Sin embargo, los niños siguen siendo un sector activo e interesado en integrarse en dichas actividades. En algunas bibliotecas se aplican encuestas o entrevistas donde expresan sus comentarios de manera positiva de acuerdo con la satisfacción lectora que les ha proporcionado la biblioteca.

Habilidades del personal y necesidades de entrenamiento

1. ¿La promoción de la lectura forma parte del trabajo del personal de la biblioteca? 


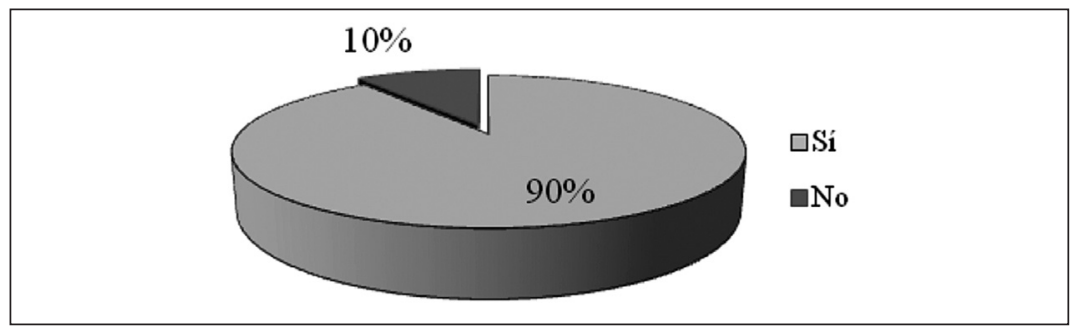

2. ¿La biblioteca tiene personal destinado exclusivamente a realizar actividades de promoción de la lectura?

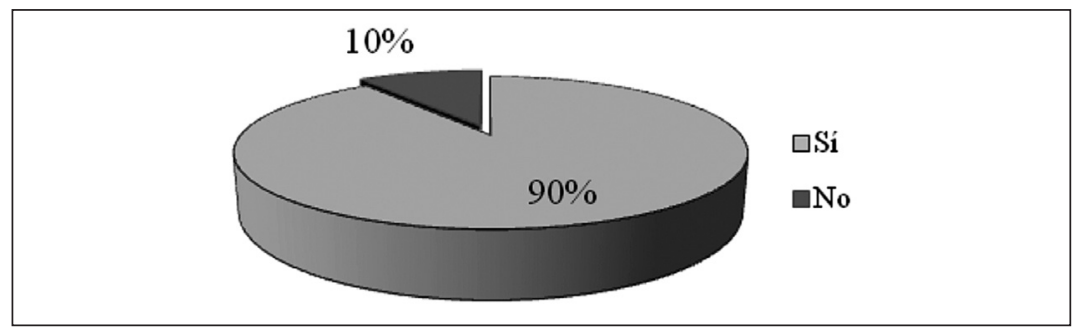

La mayoría cuenta con personal destinado a realizar la promoción de la lectura, el cual posee estudios en educación, diplomados en bibliotecología, así como entrenamientos en la promoción.

3. Actualmente, ¿qué habilidades son necesarias para promover la lectura?

Entre otras:

- Habilidad para motivar al lector.

- Tener el hábito de la lectura.

- Capacidad para dinamizar la animación.

- Creatividad.

- Disposición.

4. ¿Qué habilidades ayudarían a transformar a los no lectores en lectores que encuentren placer en la lectura y en los libros? Impulsar una reacción de adaptación por medio de la lectura, a través de actividades que tengan que ver con los intereses y necesidades diarias de los no lectores. Darnos a conocer con mayor promoción y con la aplicación de estrategias de animación. 
Habría que considerar la infraestructura de las bibliotecas públicas para atraer al lector en condiciones adecuadas y confortables donde realizar la promoción de la lectura.

5. ¿El personal de la biblioteca tiene la preparación y las habilidades para diseñar y desarrollar acciones para transformar a los no lectores en lectores aficionados a la lectura y al libro?

Sí, pero es necesario seguir buscando constantemente estrategias para atraer más lectores, de acuerdo con las necesidades de la población; por lo tanto el personal solicita una mayor capacitación para el desempeño de estas actividades.

6. ¿Reciben entrenamiento para desarrollar destrezas para las actividades de fomento?

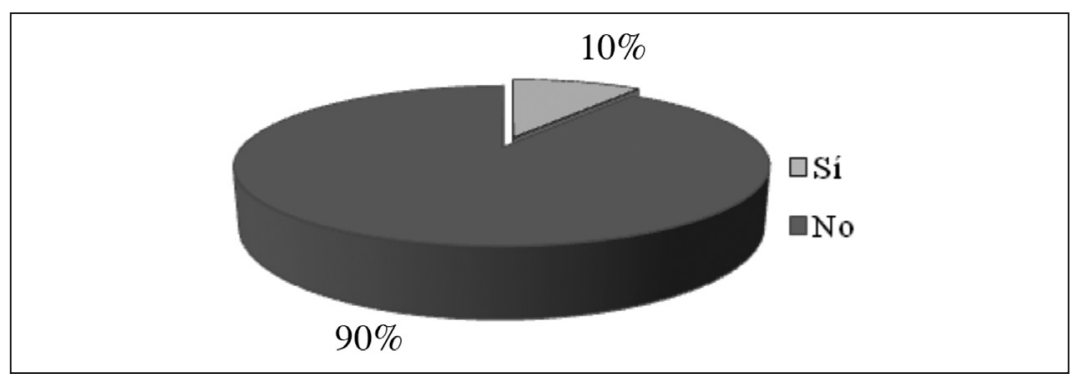

7. ¿Qué tipo de entrenamiento consideran necesario recibir?

- Talleres para elaborar material didáctico de apoyo para las actividades de promoción de la lectura.

- Estrategias para atraer a los usuarios y lectores.

- Capacitación para realizar talleres.

\section{CONCLUSIÓN}

Fortalezas y debilidades

1. Se carece de políticas de Estado a favor del desarrollo de los servicios bibliotecarios y de información.

2. Existen antecedentes y experiencias de integración y de trabajo conjunto en bibliotecas escolares, públicas y universitarias y 
entre las escuelas de bibliotecología, pero esta realidad necesita ser contextualizada en la perspectiva de la sociedad de la información y del conocimiento.

3. A pesar de los esfuerzos realizados, los diferentes tipos de bibliotecas mantienen una serie de carencias y deficiencias que demandan medidas a nivel de políticas de Estado y acciones institucionales agresivas destinadas a fortalecer los servicios bibliotecarios y de información, como componentes del desarrollo educativo, social, cultural y económico de los países.

De acuerdo con los resultados obtenidos en la aplicación de la encuesta se interpreta que necesitamos seguir manteniendo lazos de cooperación con las diversas instituciones y sectores de la sociedad, con el fin de fortalecer la Red de Bibliotecas Públicas e impulsar en mayor medida las actividades para el fomento a la lectura. Entre las acciones que se han emprendido están:

- Impulsar la aprobación de políticas de Estado que favorezcan la promoción y el desarrollo de bibliotecas públicas y la formación de una cultura bibliotecaria en la comunidad.

- Impulsar la actualización y adecuación del marco legal y normativo de los sistemas nacionales de bibliotecas de la región centroamericana, que permitan el funcionamiento y desarrollo sostenible de las bibliotecas públicas.

- Mejorar el perfil del bibliotecario teniendo en cuenta los desafíos de los tiempos presentes, especialmente en lo que atañe a gestión de recursos de información, TIC, promoción y animación de lectura, servicios bibliotecarios adecuados al contexto social, cultural y lingüístico de la comunidad; investigación y formulación de proyectos de desarrollo, valores éticos y disposición al cambio y la innovación.

- Afianzar el trabajo de colaboración entre las bibliotecas públicas de la región y de éstas con las bibliotecas escolares, universitarias y otras unidades de información, escuelas de bibliotecología y asociaciones de bibliotecarios. 
- Impulsar la creación de la Red Centroamericana de Bibliotecas Públicas para el fortalecimiento institucional y para facilitar el trabajo en equipo regional e interinstitucional con el fin de articular estas acciones con los diferentes sectores que tienen incidencia en este tipo de bibliotecas. Se ha creado la Comisión de Integración y Desarrollo Bibliotecario Centroamericano (CIDBIC).

- En el nivel de bibliotecas escolares y públicas existen importantes antecedentes, como el proyecto Multinacional Centroamericano de Bibliotecas Escolares, desarrollado en la década de los ochenta por la OEA y el reciente Proyecto Regional de Bibliotecas de Centroamérica auspiciado por la Agencia Sueca de Cooperación; además, está también el Programa Iberoamericano de Cooperación en materia de Bibliotecas Públicas, entre otros. 


\title{
Biblioteca pública y lectura: situación panorámica del Perú
}

\author{
Cesar Augusto Castro Aliaga \\ IFLA/LAC
}

\section{MARCO GENERAL}

ctualmente existe en el Perú una mayor conciencia sobre la
lectura y su importancia en el desarrollo del ser humano.
Uno de los factores que ha propiciado esta situación es el informe PISA 2000 -que midió el índice de comprensión de lectura por países- en el cual se ubicó al Perú en el último lugar, hecho que generó primero una severa crítica al sistema educativo y a las instituciones vinculadas a la lectura, y posteriormente una serie de medidas, desde diferentes frentes, a favor del fomento a la lectura.

Es así como desde el ámbito del Estado, por ejemplo, se logra la Ley de Democratización del Libro y Fomento de la Lectura (2003) y la creación del Consejo Nacional de Democratización del libro y Fomento de la Lectura, PROMOLIBRO (2004), institución responsable del diseño y desarrollo de las políticas y la que buscará hacer de la lectura un derecho social de los ciudadanos.

Es precisamente PROMOLIBRO, en el marco de las atribuciones que señala la Ley, la entidad que le ha propuesto al país un proyecto de Plan Nacional de Lectura (2005) en el que se expone una serie de lineamientos de política y acciones que deben ser ejecutadas por las diferentes entidades públicas y privadas involucradas, entre ellas las bibliotecas públicas. Simultáneamente otras instituciones, 
principalmente educativas, han puesto en marcha proyectos y actividades de fomento de la lectura. Entre las actividades de mayor alcance está el Plan Lector, promovido por el Ministerio de Educación, en el cual tanto los profesores como los alumnos de escuelas y colegios del país deben leer cuando menos un libro por mes.

Estas medidas reflejan de alguna manera una tendencia favorable a la promoción de la lectura en el Perú, pero sus resultados son todavía incipientes, incluso en las zonas urbanas, donde se concentra por ahora la mayoría de las actividades en favor de la lectura.

\section{Escenario sociogeográfico}

El Perú está ubicado en la parte central de Sudamérica y cuenta con más de 27 millones de habitantes, de los cuales aproximadamente $50 \%$ se encuentra en los rangos de pobreza y extrema pobreza. El idioma predominante es el español; sin embargo, cerca de $40 \%$ de la población es indígena hablante del quechua, el aimara y una variedad de dialectos amazónicos. El índice de analfabetismo es de $11 \%$, porcentaje que aumenta en las zonas rurales e indígenas.

\section{Aplicación de la EnCUESTA}

Este es el marco general en el que se aplica la Encuesta Internacional de Lectura IFLA, con la colaboración de la Biblioteca Nacional del Perú, a través de la Dirección Ejecutiva de Bibliotecas Públicas, y cuyos resultados preliminares se presentan a continuación. Este informe, sin ser definitivo, delinea una tendencia sobre el papel que juega la biblioteca pública en la promoción de la lectura, especialmente en las zonas urbanas del país.

Tamaño de la muestra

- Número de encuestas: 60 (100\%).

- Número de encuestas procesadas: 10 (16.16\%). 
- Distribución geográfica: 7 en Lima y 3 en provincias.

- Las bibliotecas encuestadas están tipificadas por el Sistema Nacional de Bibliotecas como Bibliotecas Públicas Municipales (provincial y distrital).

Resultados preliminares

Política de lectura

1. ¿Su institución se rige por alguna política de lectura?

Seis $(60 \%)$ respondieron que no se rigen por ninguna política de lectura y cuatro (40 \%) que sí lo hacen. De estas últimas, tres señalan como políticas las disposiciones de sus municipalidades y una menciona en forma específica a las contenidas en la propuesta del Plan Nacional de PROMOLIBRO.

2. ¿Las actividades de promoción las realiza conforme a un manual?

Nueve (90\%) respondieron no contar con esta herramienta y sólo una (10\%) refiere que sus actividades se basan en el manual de lectura del programa MundoBus (Programa binacional España-Perú).

\section{Colaboraciones en actividades de promoción de la lectura}

1. ¿La promoción de la lectura la desarrolla con otras instituciones u organismos?

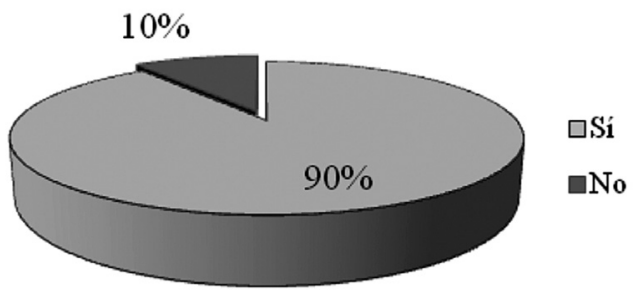


Entre las instituciones con las cuales se mantiene colaboración o apoyo, se mencionan: PromoLibro, Programa MundoBus, editoriales, Cámara Peruana del Libro, Biblioteca Nacional, IFLA, Club del libro, Club Amigos de la Biblioteca, universidades, Mesa de concertación sobre lectura y otras organizaciones de base.

2. ¿En qué beneficia a la biblioteca la colaboración con instituciones u organismos?

Entre los principales beneficios que se obtienen de esta colaboración se encuentran: el aporte de libros; el intercambio de información y conocimientos; un mayor espacio físico para las actividades; un uso compartido de catálogos y colecciones, materiales de difusión, personal especializado y practicantes para mejorar y ampliar actividades y servicios; la organización de ferias y la creación de una mayor conciencia sobre la lectura, entre otras actividades.

\section{Actividades de promoción de la lectura}

1. ¿Realiza actividades de promoción de la lectura?

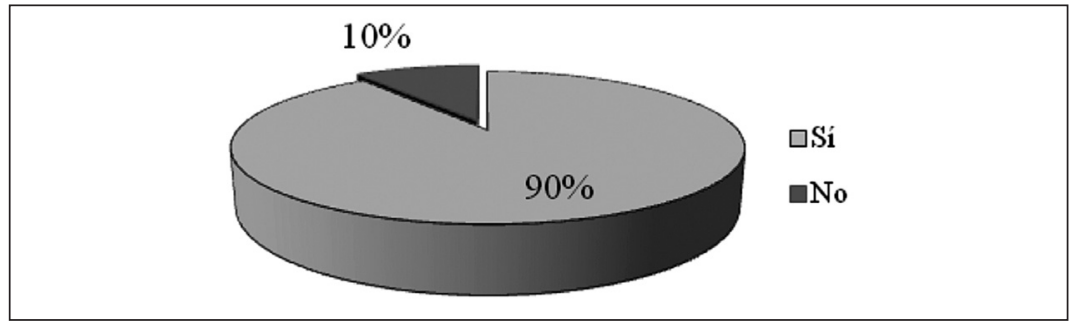

La biblioteca que respondió negativamente, ubicada en una provincia del interior del país, aduce que no realiza actividades de promoción de la lectura por falta de personal y recursos económicos.

Las bibliotecas que realizan promoción de la lectura manifiestan lo siguiente: 
- Es la principal función de la biblioteca.

- Tiene que incrementarse el número de lectores en la comunidad.

- Son pocos los que van a la biblioteca a leer, la mayoría acude para hacer tareas escolares.

- Necesitamos construir una comunidad de lectores.

2. ¿Dónde realizan las actividades de promoción de la lectura?

Nueve de las 10 bibliotecas realizan las actividades en forma interna, es decir, en sus propias instalaciones, y ocho bibliotecas las realizan también fuera de sus instalaciones.

Actividades en las instalaciones de la biblioteca:

- En la mayoría de los casos, están dirigidas a tres grupos: niños, jóvenes y adultos, y se realizan en la salas de lectura o en ambientes especiales. En cuanto a su frecuencia, ésta es diaria, semanal y mensualmente. Entre las actividades más frecuentes se mencionan: Cuentacuentos, hora de la lectura, talleres de lectura, conferencias y cursos de capacitación.

Actividades fuera de las instalaciones de la biblioteca:

- Los grupos destinatarios son niños, jóvenes, adultos, personas con capacidades especiales (invidentes). Entre los lugares donde se realizan estas actividades se mencionan parques, plazas y plazuelas, mercados, paraderos de transporte terrestre, centros educativos, bibliobús. Entre las actividades se mencionan festivales de lectura, ferias de libros, talleres de capacitación para docentes y campañas de lectura, entre otras.

3. ¿La biblioteca ha creado otros espacios o puntos de acceso a libros y demás materiales?

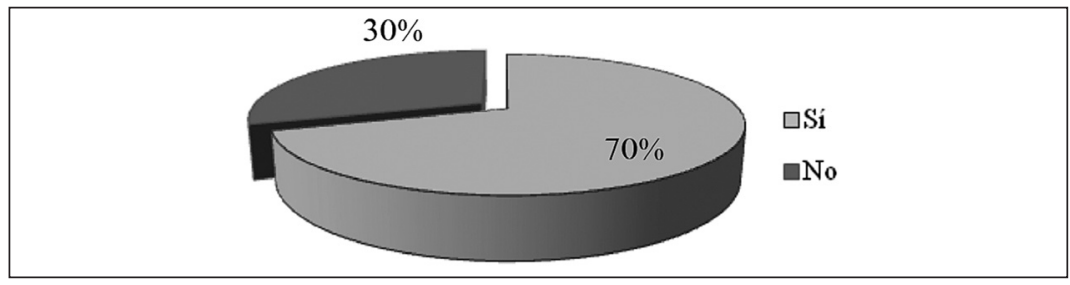


Como nuevos puntos de acceso se mencionan, entre otros, parques, plazuelas, centros educativos, paraderos y mercados.

Entre las razones para crear otros puntos de acceso se mencionaron:

- Que la biblioteca no generaba mucho interés.

- Que la biblioteca sirve solamente para hacer tareas escolares.

4. ¿Considera que las actividades de promoción de la lectura son valoradas por los lectores y la comunidad?

Sí, las nueve bibliotecas que realizan actividades de promoción de la lectura manifiestan que tanto los lectores, en forma individual, como la comunidad en general, valoran dichas actividades, lo que se manifiesta de la siguiente forma:

- Incremento de lectores, principalmente jóvenes.

- Presencia de padres de familia en la biblioteca.

- Expectativa de la comunidad por las actividades de la biblioteca.

- Mayor interés de los ciudadanos por la lectura.

- Reclamo de lectores cuando la biblioteca está cerrada.

- Agradecimiento de los miembros de la comunidad a las autoridades de la municipalidad por los servicios que les presta la biblioteca.

- Más personas que se ofrecen de voluntarios en la biblioteca

\section{Habilidades del personal y necesidades de entrenamiento}

1. ¿La promoción de la lectura forma parte del trabajo del personal de la biblioteca?

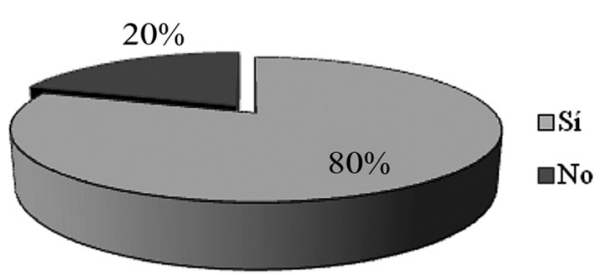


2. ¿La biblioteca tiene personal destinado exclusivamente a realizar actividades de promoción de la lectura?

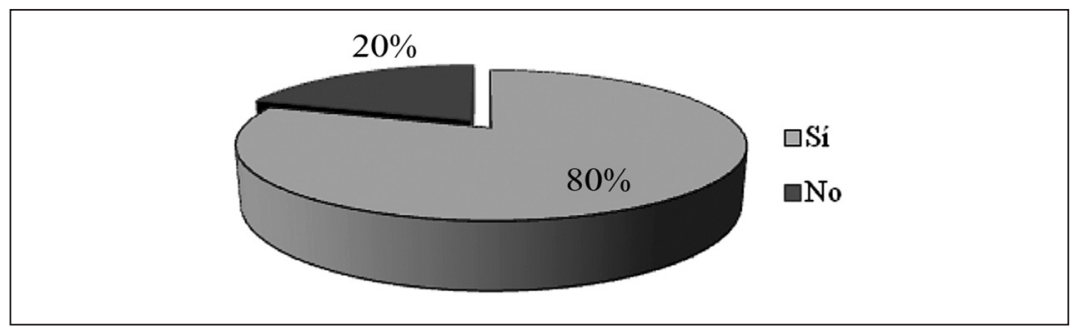

En las ocho bibliotecas que sí hacen promoción de la lectura, el número de personal destinado a estas actividades va de dos a cuatro trabajadores, cuyas edades se ubican en el rango de 30 a 60 años, con algún predominio del sexo femenino. De estas ocho bibliotecas dos han dado detalles sobre el perfil del personal responsable de la promoción de la lectura y han indicado entre los integrantes del equipo a bibliotecólogos, psicólogos, educadores, trabajadores sociales y técnicos.

3. ¿Qué habilidades son necesarias para promover la lectura entre los lectores actuales?

Se mencionaron las siguientes:

- Ser lector, incluso, en dos bibliotecas la consideran como una condición previa para ser promotor de lectura.

- Tener espíritu de trabajo.

- Ser hábiles para trabajar en equipo.

- Reunir condiciones personales para orientar.

- Estar bien informados.

- Tener vocación de servicio.

- Tener capacidad para organizar actividades innovadoras.

4. ¿Qué habilidades ayudarían a transformar a los no lectores en lectores que encuentren placer en la lectura y en los libros?

Las respuestas fueron:

- Capacidad de convencimiento.

- Conocer estrategias de animación de la lectura y los intereses de lectura de la población. 
- Hacer de la biblioteca un ambiente agradable y cómodo.

- Organizar nuevas actividades.

- Conocer estrategias para acercarse a las personas y familias.

5. ¿El personal de la biblioteca tiene la preparación y las habilidades para diseñar y desarrollar acciones que transformen a los no lectores en aficionados a la lectura y el libro?

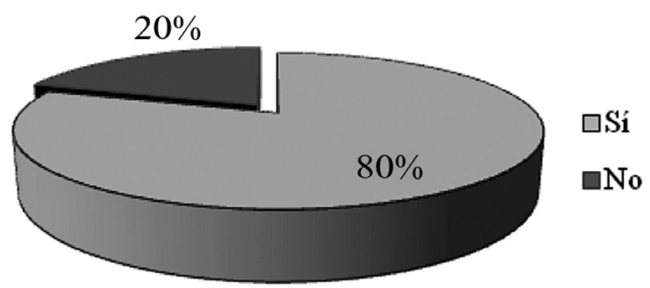

En ocho casos indican que sí; sin embargo, manifiestan que requieren una mayor capacitación. Una de las responsables de biblioteca señala que necesitan conocer experiencias de otros países sobre promoción de la lectura.

6. ¿Reciben entrenamiento para desarrollar destrezas?

Sí: cursos, asistencia a congresos, seminarios de intercambio de experiencias y conocimientos, cuya frecuencia varió de semanal a mensual.

7. ¿Qué tipo de entrenamiento considera necesario recibir?

Las principales respuestas, fueron:

- Cursos especializados sobre el tema.

- Pasantías, para conocer la experiencia de otros países.

- Avances de investigaciones.

- Dinámicas de grupo.

- Autoformación por Internet.

- Estudio de casos.

- Estrategias de animación de la lectura. 


\section{CONCLUSIONES}

Fortalezas y debilidades

Si bien existe en el país una propuesta de política nacional de fomento a la lectura, la mayoría de las bibliotecas públicas la desconocen y sus actividades en este campo las realizan como parte de las actividades cotidianas, orientadas en gran medida sólo por disposiciones o normas locales a nivel de municipalidades, de las que dependen las bibliotecas públicas. El Plan Nacional de Lectura promovido por PROMOLIBRO todavía no alcanza la difusión necesaria.

a) La mayoría de las bibliotecas realizan promoción de la lectura sin un manual específico, utilizando documentos diversos como folletos, separatas de cursos, etcétera. El único manual que fue señalado por una de las bibliotecas encuestadas es el que pertenece al programa español MundoBus.

b) La mayoría de las bibliotecas públicas realizan actividades de promoción de la lectura en colaboración y apoyo con otras instituciones, entre las que sobresalen las empresas editoriales, PROMOLIBRO, Biblioteca Nacional, universidades, IFLA y organizaciones de la sociedad civil. Esto se traduce en más libros y materiales, información y conocimientos, apoyo de personal y nuevos espacios para la lectura, como parques y plazas, entre otros beneficios.

c) Las bibliotecas públicas realizan promoción de la lectura por la necesidad de contar con más usuarios y atraer a nuevos lectores, entre ellos a los adultos, incluyendo a las personas con discapacidad visual, con lo cual se evita que la biblioteca sea sólo un lugar para hacer tareas escolares.

d) La mayoría de las bibliotecas realizan promoción de la lectura para favorecer a niños, jóvenes y adultos. Sólo en un caso la biblioteca incluye a personas con discapacidades.

e) Entre los nuevos puntos de acceso a la lectura creados por las bibliotecas municipales se encuentran, entre otros, parques y plazas, paraderos, centros educativos y mercados. 
Una de las bibliotecas en Lima afirma ser la pionera en llevar la lectura a los parques de su distrito.

f) En la mayoría de los casos las actividades de promoción de la lectura que realizan las bibliotecas públicas cuentan con el reconocimiento de los lectores y de la comunidad, lo que se traduce en un incremento de lectores y diversas expresiones de apoyo, como protestas cuando la biblioteca cierra sus servicios, cartas de agradecimiento y difusión de las actividades en los medios de comunicación.

g) Las bibliotecas que cuentan con equipos multidisciplinarios (bibliotecólogos, educadores, trabajadores sociales), son las que han logrado resultados más significativos y de mayor impacto en la comunidad.

h) Una de las habilidades fundamentales que debe tener el personal responsable de la promoción de la lectura es ser lector, una condición previa a cualquier otra, manifestaron las personas encuestadas.

i) El personal de las bibliotecas públicas demanda una mayor capacitación teórico-práctica, sobre todo en estrategias de animación a la lectura, el estudio de casos, el conocimiento de experiencias de otros países en el tema y avances alcanzados por las investigaciones. 


\title{
Análisis global de los resultados y conclusiones
}

\author{
ElSA M. RAMÍREZ LEYVA \\ Centro Universitario de Investigaciones \\ Bibliotecológicas, UNAM, México
}

\begin{abstract}
T a Encuesta Internacional de Lectura de la IFLA aplicada a una muestra integrada por 523 bibliotecas públicas de 12 países $\checkmark$ de América Latina y el Caribe, ofrece información del panorama general que presenta la región sobre las acciones bibliotecarias destinadas a la formación de lectores, y también acerca de las especificidades locales respecto a las características, alcances y tendencias, en un contexto social marcado por cambios que inciden en el desarrollo de mayores exigencias y en las habilidades de lectura, tanto en los medios tradicionales como en los electrónicos, en especial para los alumnos que egresan de educación media. Es decir, las nuevas generaciones se encuentran en un proceso de transformación en cuanto a las formas de aprendizaje, de informarse y de comunicarse, propiciado tanto por las innovaciones en los modelos pedagógicos como por las derivadas de las características de la tecnología electrónica. Dichas prácticas corresponden a núcleos de lectores y prácticas de lectura que están dejando de ser sólo locales, organizadas y formadas conforme a espacios fijos -bibliotecas, casa, escuelas, museos, cines, etcétera- y que han generado necesidades y condiciones inéditas en cuanto a modalidades de lectura, acceso y uso de la información.
\end{abstract}


Al mismo tiempo se han hecho evidentes importantes deficiencias en las destrezas de lectura y escritura en una proporción de las sociedades de nuestra región que se extiende a casi la mitad de tales poblaciones, incluidas aquellas que han superado la educación básica. Al mismo tiempo la lectura de libros no parece incrementarse a pesar de que en los últimos año la oferta editorial y la creación de bibliotecas ha crecido de manera considerable en todos los países latinoamericanos y del Caribe.

Por lo mismo es importante examinar a las instancias involucradas en la formación de lectores, entre ellas la institución bibliotecaria, a fin de conocer la pertinencia, eficiencia, trascendencia y oportunidad de sus acciones a este respecto. En esta coyuntura la institución bibliotecaria de nuestra región, en particular la pública, está comprometida en defender, garantizar y promover el derecho de todos los ciudadanos por igual a desarrollar competencias de lectura y acceder a los servicios y recursos suficientes de buena calidad de diversos medios, con el fin de lograr que la participación de esa institución sea contundente en la solución de los problemas comunes e históricos de Latinoamérica y el Caribe, los que podemos resumir en lo que se indica a continuación:

- Deficiencias en las destrezas de lectura y escritura en el $50 \%$ de la población, lo que propicia una muy precaria extensión de la lectura.

- Una inadecuada incorporación de la práctica de la lectura por gusto.

- Fallas de los responsables de la promoción de la lectura, en general por falta de una adecuada formación.

- Una promoción de la lectura dirigida principalmente a niños y en menor medida a adultos y jóvenes.

- Programas de fomento a la lectura que no son sostenidos (interrupciones, falta de apoyo, cambios de orientación).

- La desigual distribución y actualización de recursos bibliográficos, tecnológicos, de servicios y de espacio.

- Colecciones que no se corresponden ni en calidad ni en cantidad con las diferentes necesidades y tipos de público. 
- Insuficientes servicios bibliotecarios e informativos acordes con las poblaciones rurales e indígenas de tradición oral que a veces tienen diferentes lenguas y un conocimiento básico de la oficial (el español).

- Personal bibliotecario con preparación desigual, en general poco profesionalizado.

- Bibliotecarios que tienen escasa participación social y política.

- Salarios y estímulos magros para el personal de bibliotecas.

- Políticas que no logran consolidarse por falta de apoyo sostenido, además de una difusión desigual entre las propias bibliotecas.

- Falta de articulación entre las dependencias, y de ellas con otros organismos sociales, para favorecer la cooperación.

- El insuficiente y desigual gasto en servicios bibliotecarios.

- La falta de instrumentos de medición, evaluación y observación del comportamiento de las prácticas de lectura, del libro y del uso de las tecnologías.

La Encuesta revela que los alcances de las bibliotecas públicas han tenido avances importantes, pero también que hace falta fortalecerlas para estar realmente a la altura de los problemas de lectura y acceso a la cultura escrita de nuestra región.

- Se observa una desigual vinculación de las bibliotecas con los planes nacionales de lectura, y en consecuencia su concreción avanza más rápido en algunas regiones que en otras, tanto al interior de los propios países como en el ámbito regional. Esta circunstancia favorece la exclusión de aquellas poblaciones que por lo general cuentan con menos recursos para acceder a la educación, los servicios bibliotecarios y las posibilidades de lectura y acceso a la cultura escrita.

- La articulación de la biblioteca con otras instituciones y organizaciones vinculadas con las actividades de lectura no 
siempre se considera entre las políticas y estrategias en las instancias locales de gobierno, lo cual es indispensable para propiciar una colaboración e interacción armónica que se proponga alcanzar las mismas metas.

- Los espacios bibliotecarios y de lectura que están fuera del recinto son todavía limitados debido a que la colaboración con otras instancias se encuentra en etapas iniciales.

- La fuerte tradición del fomento de la lectura en la población de niños, aunada a la falta de bibliotecas escolares, exige a la biblioteca pública una mayor atención e inversión en recursos para este sector. Puesto que los medios se reducen aún más en las bibliotecas de zonas marginadas y pobres, disminuyen las posibilidades de atender con mayor contundencia a los sectores que se encuentran fuera del ámbito escolar.

- La formación de lectores que han procurado las bibliotecas públicas a través de programas de promoción se ha orientado principalmente a despertar el gusto por la lectura entre los niños; sin embargo, se observa también la incorporación de actividades destinadas a sectores de jóvenes y adultos mediante actividades lúdicas. En las respuestas se aprecian iniciativas muy variadas y creativas, algunas de las cuales se realizan semanalmente y cuyos resultados tienen efectos en los comportamientos de los lectores, como se ha identificado en las apreciaciones que los bibliotecarios reciben de su público.

- Los resultados de las acciones de los programas de promoción de la lectura incrementan la demanda y mayores exigencias a los servicios bibliotecarios. Sin embargo, es frecuente que las autoridades no consideren otorgar mayores apoyos para la mejora de infraestructura y recursos que permitan cumplir con las expectativas y necesidades creadas por los efectos de las acciones bibliotecarias en cuanto a despertar el interés por la lectura.

- De igual manera los programas de promoción y extensión de la lectura a grupos variados elevan las exigencias de la 
preparación en el personal bibliotecario. Además, los planes nacionales de lectura ciertamente tienen implicaciones en cuanto a las responsabilidades de los bibliotecarios.

- Los bibliotecarios involucrados en actividades de lectura se percatan de la necesidad de mejorar sus competencias y conocimientos, los cuales rebasan con mucho las técnicas de animación de la lectura, como puede apreciarse en las respuestas respecto a las áreas que, a juicio de los propios encuestados, deben cubrir los programas de capacitación.

Durante el seminario se convocó a los coordinadores de las encuestas a una reunión con el fin de conocer sus apreciaciones sobre el estudio. Cabe destacar las aportaciones complementarias que se obtuvieron además de los datos recabados. La mayoría coincidió y abrió perspectivas diferentes sobre la participación y los alcances de las actividades bibliotecarias realizadas en la promoción de la lectura. Esto nos permitió percatarnos de la complejidad que representa esa labor para el personal bibliotecario y la necesidad de mejorar las competencias de los responsables de esas actividades, así como la importancia de rectificar los programas de capacitación. Otro aspecto mencionado es el de las relaciones entre las instancias coordinadoras de las bibliotecas y entre la comunicación y la transmisión de políticas o pautas emanadas de éstas, sin considerar que las particularidades de las bibliotecas difieren según las características de las comunidades, por lo que se deberán tomar medidas para buscar la uniformidad y la adecuación a las diferentes circunstancias. En general se advirtió un consenso en cuanto a que la encuesta permitió conocer logros, fortalezas y debilidades de las bibliotecas públicas en torno a los alcances de sus acciones para la formación de lectores. Este ejercicio también nos permitió ver la realidad de las propias bibliotecas.

Entre las recomendaciones planteadas en la reunión se encuentran las siguientes:

- Hacer una aplicación periódica de la encuesta a fin de darles seguimiento a los cambios que se introduzcan en las 
formas de operar los planes de lectura y las directrices de las coordinaciones de las bibliotecas.

- Refinar y perfeccionar el cuestionario.

- Recoger el panorama general que propicia el instrumento para recabar de manera más confiable la información.

- Realizar una segunda etapa de aplicación de la encuesta para incorporar a los países faltantes.

- Mejorar el instrumento para profundizarlo con un enfoque cualitativo.

- Perfilar el instrumento hacia el bibliotecario (sus necesidades, creencias y capacitación).

- Perfilar el instrumento más claramente hacia la promoción de la lectura.

- Incorporar en el instrumento preguntas sobre los efectos que producen los sistemas bibliotecarios en Latinoamérica.

- Analizar los resultados de acuerdo con las visiones de cada país.

- Se sugiere trabajar en las tipologías sobre la lectura y en la conceptualización de ésta, tomando en cuenta el trabajo relacionado con ese tema, presentado por Didier Álvarez en el seminario.

- Determinar con mayor precisión la metodología, en especial, la muestra aplicada en la encuesta.

- Realizar estudios exploratorios.

La Encuesta Internacional de Lectura aplicada en las bibliotecas públicas de Latinoamérica y el Caribe se realizó en un momento oportuno, dado que nuestra región tiene compromisos y metas que cumplir para hacer su transición a la Sociedad de la Información y el Conocimiento. Cabe recordar que las innovaciones crean oportunidades, pero con ellas riesgos y crisis. Al estabilizar los sistemas nuevos se desestabilizan los tradicionales que se producen en un periodo durante el cual se reorganizan y reacomodan los elementos de los entornos culturales, materiales y organizativos, en particular uno del sistema fundamental como es la comunicación, que por cierto siempre ha estado mediado por técnicas 
y herramientas generadas para la producción, transmisión, intercambio, uso y apropiación de la información, como señala Pierre Lévy. ${ }^{1}$

En efecto, hoy vivimos circunstancias inéditas derivadas de las transfiguraciones demandadas por niveles más elevados de competitividad que repercuten en los cambios de las exigencias en las destrezas de lectura y escritura, el acceso y el uso de nuevas formas de informar e informarse. En consecuencia, la alfabetización básica ya no es suficiente para ningún ciudadano. En cuanto a los soportes, las textualidades representan referentes distintos que producen una diversificación de modos de acceso y consumo, y también prácticas de lectura particulares que están dejando de ceñirse a las condiciones tradicionales de los espacios físicos y de las formalidades exclusivamente impresas o grabadas, debido tanto a su desmaterialización como a la incorporación de nuevas herramientas que aumentan su interactividad y favorecen formas inéditas de convivencia y sociabilidad con la cultura escrita. Mucho de lo cual sucede fuera de los ámbitos tradicionales como es el bibliotecario, situación que lo pone en riesgo dentro de una sociedad en la que la institución bibliotecaria está débilmente arraigada en el tejido social.

La realidad actual les exige a las naciones procesos de cambio orientados a evolucionar y participar en el concierto mundial bajo nuevas reglas y circunstancias que involucran a las instituciones bibliotecarias, pues resulta indispensable formar comunidades interdependientes y responsables no sólo de su entorno inmediato, sino también preservar y garantizar las mejores condiciones de desarrollo para todas las formas de vida de nuestro planeta. Y en tanto la interdependencia es una de las condiciones de esta sociedad, resulta indispensable que todos los integrantes de América Latina y el Caribe tengan la formación necesaria para corresponsabilizarse de la producción, el intercambio y el uso adecuado de

1 Véase Cibercultura. Informe al Consejo de Europa, pról. de Manuel Medina, España, Anthropos/UAM, 2001, 126 pp. Disponible en es.scribd.com/ doc/19977800/Levy-Pierre-Cibercultura 
los recursos informativos desde cualquier lugar del planeta para el aprovechamiento y el beneficio de todos. Al mismo tiempo, y no menos importante, es alentar mediante la lectura el desarrollo de las capacidades humanas: pensar, reflexionar, conmoverse, admirar, conversar, gozar, pero también son indispensables la solidaridad, la libertad y la justicia. 


\section{Anexo}

\section{Encuesta Internacional de Lectura para América Latina y el Caribe (IFLA)}

\section{CUESTIONARIO}

El interés de la Encuesta es reunir información sobre las actividades de promoción de la lectura que realiza la biblioteca pública, tanto en las instalaciones de la propia biblioteca como fuera de ellas. Además, se propone conocer con detalle ejemplos que hayan sido exitosos en la formación de prácticas de lectura, o en la formación de no lectores en lectores. Y también quiere averiguar si existen apoyos en programas de alfabetización. Estas experiencias, aunque puedan parecer sencillas, o bien, bajo ciertas circunstancias, consideradas como imprevistas y fuera de lo común, pueden ser muy efectivas, por lo que las consideramos de utilidad para compartir con colegas de otros países, por tal motivo necesitaremos algunos datos para facilitar la comunicación entre todos.

Por lo anterior las respuestas se organizarán en un reporte y se difundirán en la Web de las Secciones de Lectura y de América Latina, en la página de la Federación Internacional de Asociaciones de Bibliotecarios (IFLA), que auspicia esta encuesta con el apoyo del Programa para el Desarrollo Bibliotecario ALP.

El nombre de las personas que incluyan información en los comentarios será resguardado en el anonimato para que tengan la confianza de expresarse con toda libertad y sinceridad.

\section{Nombre:}

Cargo:

Nombre de la institución y datos de su Web, si tiene:

Correo electrónico:

Dirección postal:

Número de fax:

Incluir los siguientes datos:

- Número y tipo de bibliotecas públicas y/o populares en su país* y nombre de organismos o instituciones públicas o privadas de las que dependen.* 
- Si existe Legislación, plan o programa nacional de bibliotecas, libros lectura o programas.*

- Censo sobre lectura.*

- Información sobre estudios nacionales acerca de consumo cultural en el que se incluyan lectura, libros y otros.*

* Datos y dirección electrónica donde se puede acceder a esta información.

Describir de manera breve los programas o proyectos de promoción de la lectura y alfabetización que realiza la biblioteca.

\section{Preguntas}

Puede responder en formato impreso o en forma electrónica.

Describir en una página las características de la comunidad a la que atiende su biblioteca.

Describir brevemente la composición de la plantilla de su personal: número, estudios, etcétera.

\section{Políticas de lectura}

1. ¿Su institución se rige por alguna política de lectura?

\begin{tabular}{|l|l|}
\hline Sí & \\
\hline No & \\
\hline
\end{tabular}

¿De qué año es?

Incluir una copia impresa o dirección electrónica, texto electrónico.

2. ¿Las actividades de promoción se realizan conforme a algún manual?

\section{Colaboraciones en actividades de promoción de la lectura}

1. ¿La promoción de la lectura la desarrolla con otras instituciones u organismos?

\begin{tabular}{|l|l|}
\hline Sí & \\
\hline No & \\
\hline
\end{tabular}


Especificar actividades y nombres de las instituciones y organismos con los cuales se tienen actividades en colaboración.

2. ¿En qué beneficia a la biblioteca la colaboración con otras instituciones u organismos?

III. Actividades de promoción a la lectura

1. ¿Realiza actividades de promoción a la lectura?

\begin{tabular}{|l|l|}
\hline Sí & \\
\hline No & \\
\hline
\end{tabular}

¿Por qué?

2. Las actividades de promoción a la lectura las realizan:

En las instalaciones de la biblioteca:

\begin{tabular}{|c|c|c|}
\hline A qué grupos & Frecuencia & Actividades \\
\hline & & \\
\hline & & \\
\hline & & \\
\hline & & \\
\hline & & \\
\hline & & \\
\hline
\end{tabular}

Fuera de las instalaciones de la biblioteca:

\begin{tabular}{|l|l|l|}
\hline A qué grupos & Lugar y actividades & Frecuencia \\
\hline & & \\
\hline & & \\
\hline & & \\
\hline & & \\
\hline & & \\
\hline & & \\
\hline
\end{tabular}


3. La biblioteca ha creado otros espacios o puntos de acceso:

\begin{tabular}{|l|l|}
\hline Sí & \\
\hline No & \\
\hline
\end{tabular}

¿Por qué?

4. Anote si considera que las actividades de promoción de la lectura son valoradas por:

- Sus lectores

- La comunidad

Explicar brevemente la manera en que esto se hace evidente.

\section{Habilidades del personal y necesidades de entrenamiento}

1. ¿La promoción de la lectura forma parte del trabajo del personal de la biblioteca?

\begin{tabular}{|l|l|}
\hline Sí & \\
\hline No & \\
\hline
\end{tabular}

2. ¿La biblioteca tiene personal destinado exclusivamente a realizar actividades de promoción de la lectura?

\begin{tabular}{|l|l|}
\hline Sí & Cuántos \\
\hline No & \\
\hline
\end{tabular}

Describir características: edad, género, estudios.

3. Actualmente, ¿qué habilidades son necesarias para promover la lectura?

4. ¿Qué habilidades ayudarían a transformar a los no lectores en lectores que encuentren placer en la lectura y en los libros?

5. ¿El personal de la biblioteca tiene la preparación y las habilidades para diseñar y desarrollar acciones para transformar a los no lectores en lectores aficionados a la lectura y al libro? 
6. ¿Reciben entrenamiento para desarrollar destrezas para las actividades de fomento?

$$
\text { Sí }
$$

¿Qué tipo de entrenamiento?

¿Con qué frecuencia?

¿Quién imparte el entrenamiento?

No

7. ¿Qué tipo de entrenamiento consideran necesario recibir?

V. Describir los programas de fomento de la lectura considerados exitosos, es decir, que hayan logrado cambios en las prácticas de lectura entre los miembros de las comunidades a las que están destinados dichos programas.

- Describir programas de lectura considerados exitosos.

- Nombre del programa.

- A quién va dirigido.

- Antigüedad del programa.

- Periodicidad con la que se lleva a cabo.

- Descripción.

- Efectos en la sociedad. 
Encuesta Internacional de Lectura IFLA para las bibliotecas de América Latina y el Caribe. Instituto de Investigaciones Bibliotecológicas y de la Información/UNAM. Coordinación editorial: Carlos Ceballos Sosa; formación editorial y revisión de pruebas: Arte Gráfico y Sonoro, Retorno de Amores no. 14-102, Colonia del Valle, Delegación Benito Juárez, C.P. 03100, México, D.F. Se terminó de producir en el mes de agosto de 2013. 